\title{
Demographic response of American ginseng (Panax quinquefolius L.) to climate change
}

\author{
Sara Souther \\ West Virginia University
}

Follow this and additional works at: https://researchrepository.wvu.edu/etd

\section{Recommended Citation}

Souther, Sara, "Demographic response of American ginseng (Panax quinquefolius L.) to climate change" (2011). Graduate Theses, Dissertations, and Problem Reports. 4793.

https://researchrepository.wvu.edu/etd/4793

This Dissertation is protected by copyright and/or related rights. It has been brought to you by the The Research Repository @ WVU with permission from the rights-holder(s). You are free to use this Dissertation in any way that is permitted by the copyright and related rights legislation that applies to your use. For other uses you must obtain permission from the rights-holder(s) directly, unless additional rights are indicated by a Creative Commons license in the record and/ or on the work itself. This Dissertation has been accepted for inclusion in WVU Graduate Theses, Dissertations, and Problem Reports collection by an authorized administrator of The Research Repository @ WVU.

For more information, please contact researchrepository@mail.wvu.edu. 


\title{
Demographic response of American ginseng (Panax quinquefolius L.) to climate change
}

\author{
Sara Souther \\ Dissertation submitted to the \\ Eberly College of Arts and Sciences \\ at West Virginia University \\ in partial fulfillment of the requirements \\ for the degree of
}
Doctor of Philosophy in Biology

James B. McGraw, Ph.D. Chair Stephen DiFazio, Ph.D. Andrew Liebhold, Ph.D. William Peterjohn, Ph.D. Richard Thomas, Ph.D.

Department of Biology

\author{
Morgantown, West Virginia \\ 2011
}

Keywords: Climate change; demography; Panax; local adaptation Copyright 2011 Sara Souther 


\section{AbSTRACT \\ Demographic response of American ginseng (Panax quinquefolius L.) to climate change}

\section{Sara Souther}

Ecological response to recent climate change has been documented for a multitude of species worldwide. Climate models predict further increases in temperature, as much as 8 times the degree of warming that has already occurred. Given observations of species response to contemporary climate change and the unprecedented degree of warming expected over the next century, climate change will no doubt determine future ecosystem composition and affect global species diversity. In order to prevent loss of biodiversity, it is necessary to understand and accurately project species' response to climate, and to identify species that are vulnerable to climate change driven extinctions. In this thesis, I asked the question "How will climate change affect American ginseng (Panax quinquefolius L.) demography?". In addition to mean temperature increase, climate models predict an increase in anomalous weather events, such as late spring frost. In Chapter 2, I examined the effects of the 2007 spring frost on ginseng demography. Frost negatively impacted ginseng survival, growth, and reproduction, and could depress longterm population growth rates. In Chapter 3, I took advantage of a long-term, spatially extensive dataset to examine range-wide variation in demographic response to climate. Results indicated that populations of ginseng are adapted to local temperature regimes, and form population-specific thermal optima. In Chapter 4, I modeled the effect of climate change on ginseng extinction risk using Population Viability Analysis (PVA). Climatic warming increased extinction risk and decreased viability of ginseng populations. Because ginseng populations are adapted to local temperature regimes, a relatively small degree of warming $\left(1^{\circ} \mathrm{C}\right.$ over a 70 year period) significantly increased extinction risk for all populations throughout ginseng's range. In order to experimentally test for adaptive differentiation of populations with respect to climate, I conducted two reciprocal transplant experiments; one in a controlled growth chamber environment (Chapter 5) and one in a natural setting along an elevational gradient (Chapter 6). Results from Chapter 4 indicated that populations were adaptively differentiated with respect to temperature. However, the expected 'home-site' advantage response of fitness-related traits was rarely observed, indicating that environmental covariates of temperature, such as soil moisture and disease, may be critical to understanding adaptation to temperature. In Chapter 6, confounding environmental factors that varied among transplant gardens precluded accepting or rejecting the hypothesis of local climatic adaptation. In both transplant experiments, warmer climatic conditions negatively affected ginseng reproduction. This research provides compelling evidence that climate change will negatively impact long-term persistence of ginseng and other ecologically similar species. 


\section{ACKNOWLEDGMENTS}

I would like to sincerely thank my advisor, Dr. James McGraw. During this academic journey, I have benefited from the training and support that my advisor has consistently provided - and provided with seemingly limitless enthusiasm for science, nature, and learning. He trained me to be a competent and curious researcher, introduced me to new regions of the world and new people, and encouraged me to work hard, work smart, and take risks. I will never forget the commitment he demonstrated towards this research and my training. I would also like to thank my committee members, Dr. Stephen DiFazio, Dr. Andrew Liebhold, Dr. William Peterjohn, and Dr. Richard Thomas for their guidance and helpful reviews of proposals, papers, and this dissertation. Their comments have strengthened this research.

Sincere thanks to my fellow graduates students, in particular: Zachary Bradford, Zachariah Fowler, Alyssa Hanna, Anne Perez, Stephanie Young, Scott Spal, and Kerry Wixted for their selfless help in the field, as well as their support out of the field. I would like to extend a special thank you to Christine Picard, who assisted me frequently in the field and who has served as a role model for academic integrity and work ethic. Thank you to the many undergraduates who have aided in demographic data collection: Allison Kenyon, Clare Maloy, Mark Guido, Jacque Boyczek, Diana Black, Alixandra Wagner, Caitlyn McGraw, Stevia Morawski, Daniel Doll, and Lorraine Carter-Lovejoy. Thank you to the numerous graduate students involved with the ginseng project whose research has laid the foundation for my own work: Martha Van der Voort, Mary Ann Furedi, Emily Mooney, Erin Hackney, and Kerry Wixted. As an undergraduate, I worked as an intern in the McGraw lab. My supervisors, Dr. Mary Ann Furedi and Dr. Suzanne Sanders, initiated me into the world of ecological research and inspired me to continue my education. I will fondly remember that first research season - dining on gourmet food, trudging around West Virginia under all field conditions, and learning about ecology.

I would like to thank the landowners and land managers that have granted access to their ginseng populations. Thank you to Dr. Mary Beth Adams and the Fernow Experimental Forest for providing technical support and accommodations. Also, I would like to thank Dr. Martin Lechowicz, Mark Romer, and Claire Cooney, who truly made the research I conducted at McGill University possible, and enriched my visits to Montreal. A special thanks to Dr. Anne Lubbers, for graciously providing us with shelter, showers, and air conditioning during the Kentucky census, and for long conversations regarding ecology and conservation, which took place over coffee and other libations.

Thank you to my family and friends, whose love and support have made me who I am today, and who always compel me, through their actions and talent, to be a better person. Finally, I would like to thank my husband, John Souther. During my graduate studies, John went above and beyond spousal duty. He devoted his spare time to fieldwork and provided me with unwavering support. Words cannot express how grateful I am to John for sharing his life with me and for enriching every day with his presence.

This research was funded by NSF-LTREB grant DEB-0613611, and NSF-DDIG grant DEB-0909862. Additional research and travel funding provided by the Earl Core Memorial Fellowship and the Office of the Dean of Eberly Arts and Sciences. 


\section{TABLE OF CONTENTS}

DEMOGRAPHIC RESPONSE OF AMERICAN GINSENG (PANAX QUINQUEFOLIUS L.) TO

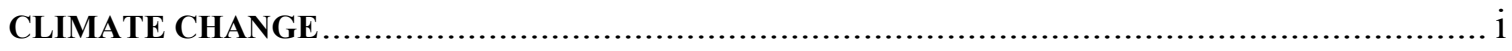

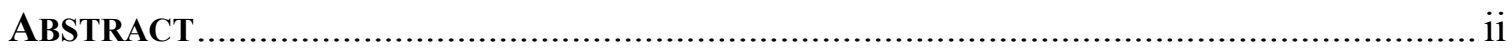

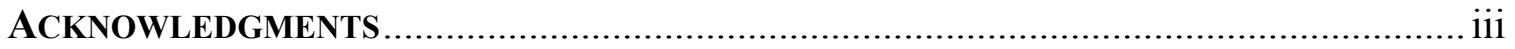

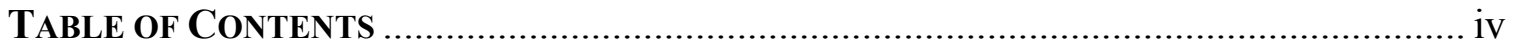

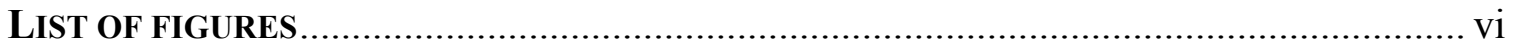

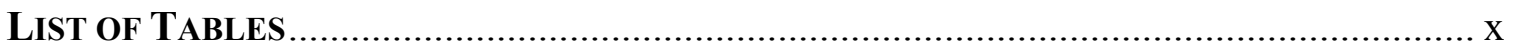

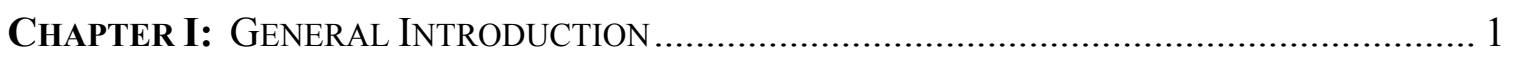

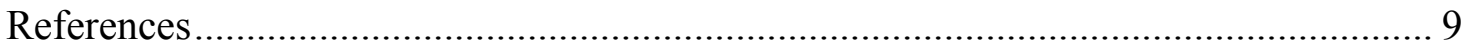

CHAPTER II: VULNERABILITY OF WILD AMERICAN GINSENG TO AN EXTREME EARLY

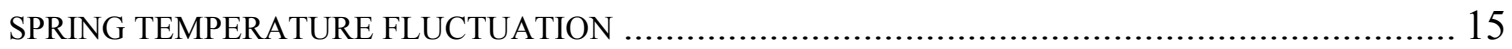

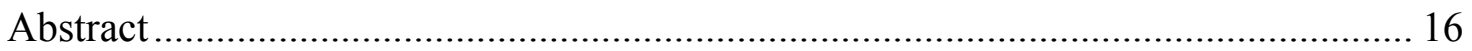

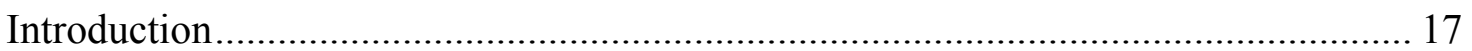

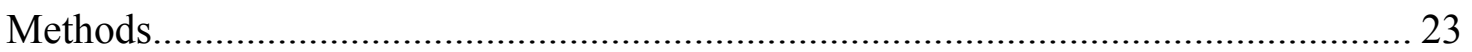

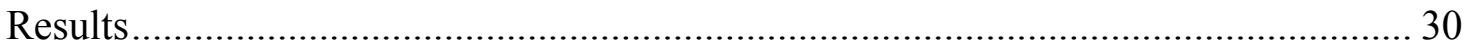

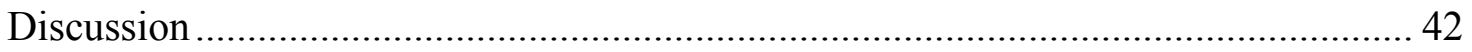

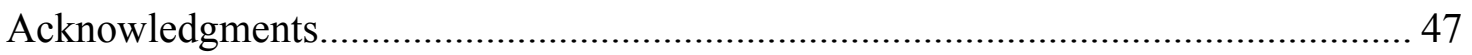

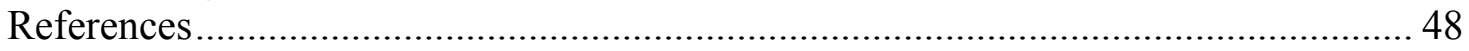

CHAPTER III: EVIDENCE OF LOCAL ADAPTATION IN THE DEMOGRAPHIC RESPONSE OF AMERICAN GINSENG TO INTER-ANNUAL TEMPERATURE VARIATION .............................. 57

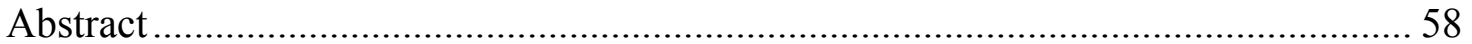

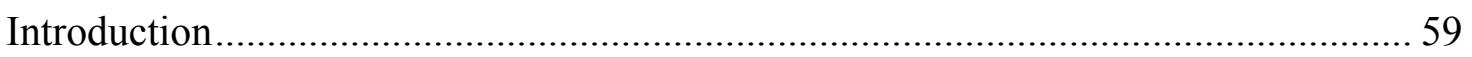

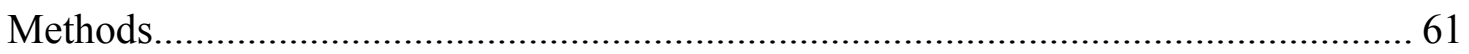

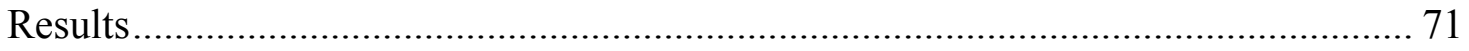

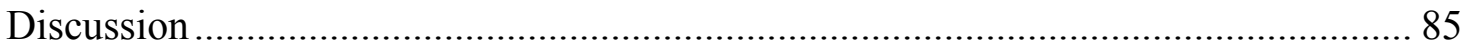

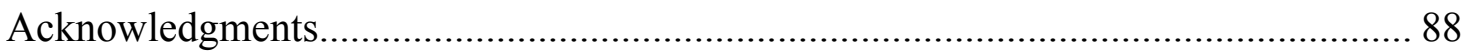

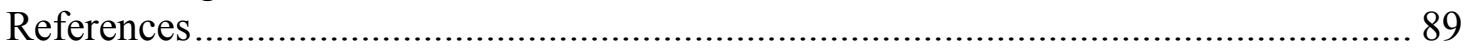

ChAPTER IV: ClimATE CHANGE INCREASES EXTINCTION RISK FOR LOCALLY ADAPTED

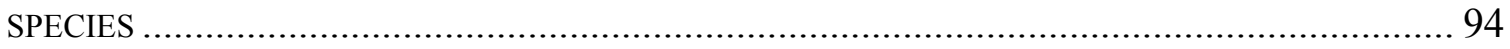

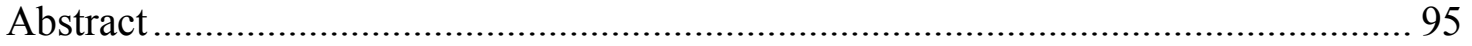

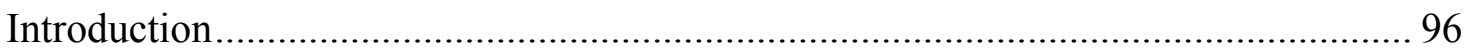

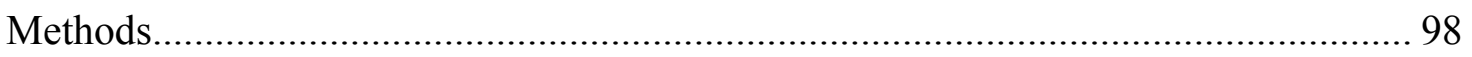

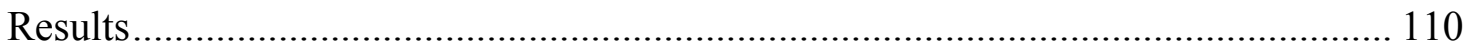

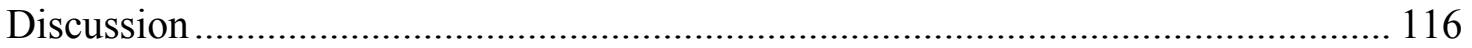

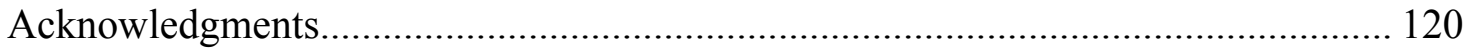

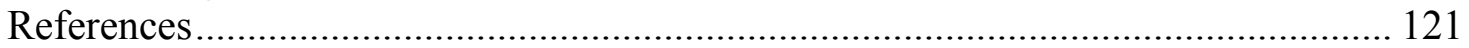


CHAPTER V: EXPERIMENTAL TEST FOR ADAPTIVE DIFFERENTIATION OF GINSENG

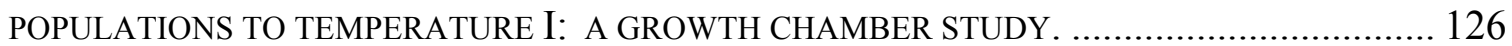

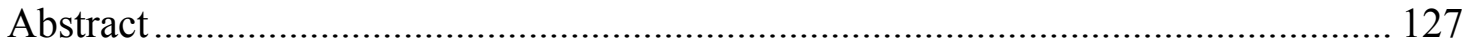

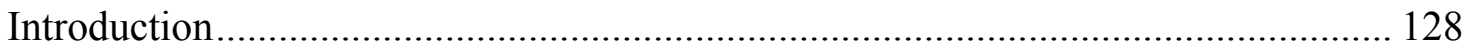

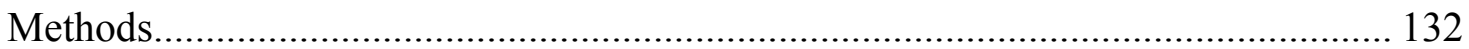

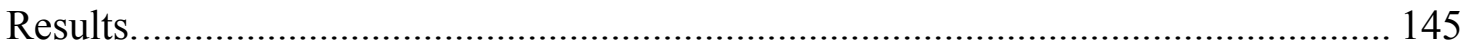

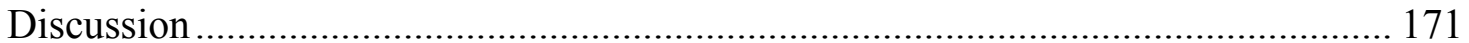

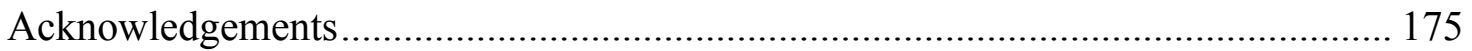

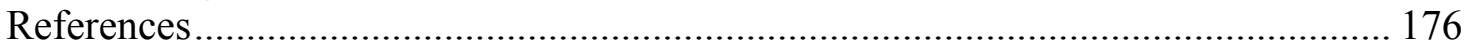

CHAPTER VI: EXPERIMENTAL TEST FOR ADAPTIVE DIFFERENTIATION OF GINSENG

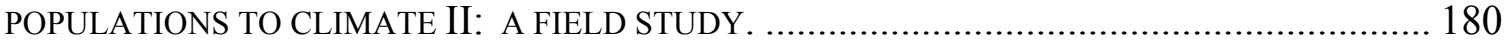

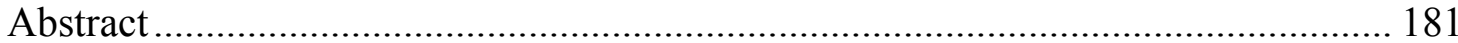

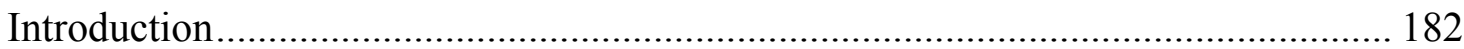

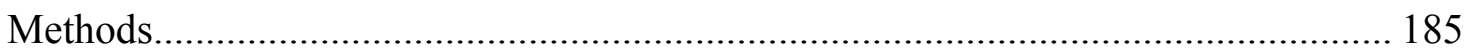

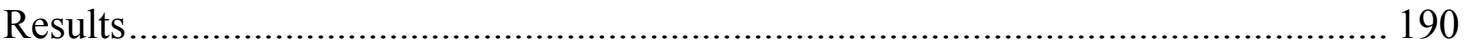

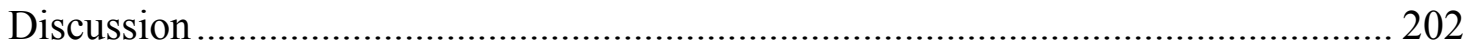

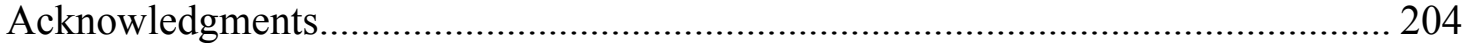

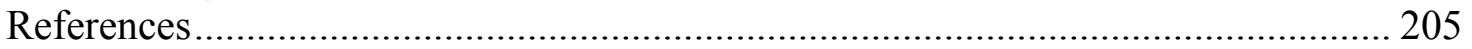

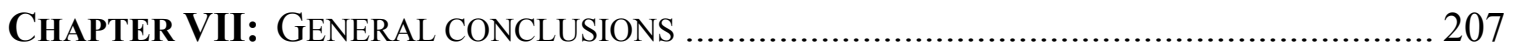

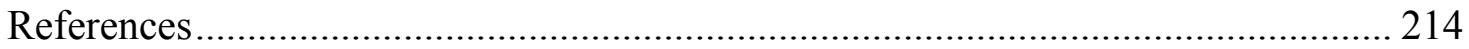

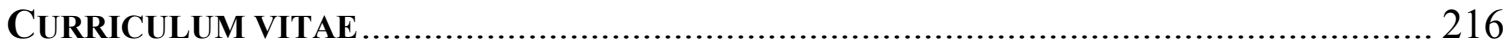




\section{LIST OF FIGURES}

Figure 2.1. The probability of a population being frost-damaged as a function of mean minimum temperature $\left({ }^{\circ} \mathrm{C}\right)$ for the 15 -day period prior to the frost event. Closed-circles indicate data points

Figure 2.2. Regression of the percentage of the population damaged by the frost on mean minimum temperature $\left({ }^{\circ} \mathrm{C}\right)$ for the 15 -day period prior to the frost event. The fit of the regression was improved by taking the natural log of the percentage of the population damaged by frost.

Figure 2.3. The probability that an individual plant will incur frost-damage as a function of leaf area. Closed-circles indicate data points.

Figure 2.4.a. The probability of a plant being absent as a function of leaf area for frostdamaged plants. Closed-circles indicate data points.

Figure 2.4.b. The probability of a plant being absent as a function of leaf area for undamaged plants. Closed-circles indicate data points.

Figure 2.5. Comparison of the relative growth rate of leaf area from 2006 to 2008 for frost-damaged and undamaged plants $(+/-1$ standard error)

Figure 2.6.a. The probability of a plant producing seeds in 2008 as a function of leaf area for frost-damaged plants. Closed-circles indicate data points.

Figure 2.6.b. The probability of a plant producing seeds in 2008 as a function of leaf area for undamaged plants. Closed-circles indicate data points

Figure 3.1. Life-cycle stages used for demographic modeling of ginseng populations...75

Figure 3.2.a. Response of population growth rate $(\lambda)$ to mean maximum growing-season temperature

Figure 3.2.b. Response of population growth rate $(\lambda)$ to mean maximum growing-season temperature expressed in terms of deviation (SD) from site-specific means. Among all temperature models (b), a polynomial fit of $\lambda$ regressed on temperature expressed in SD was the best-supported model $\left(w_{i}=0.90, p<0.01, r^{2}=0.14\right.$

Figure 3.3.a. Response of population growth rate $(\lambda)$ to total growing-season precipitation. The models of best fit for both methods of expressing precipitation data are shown. Among all precipitation models (a), a polynomial fit of $\lambda$ regressed on precipitation $(\mathrm{cm})$, was the best-supported model $\left(w_{\mathrm{i}}=0.64, p<0.05, r^{2}=0.11\right) \ldots \ldots \ldots . .78$ 
Figure 3.3.b. Response of population growth rate $(\lambda)$ to total growing-season precipitation expressed in terms of deviation (SD) from site-specific means .

Figure 3.4.a. Response of population growth rate $(\lambda)$ to annual variation in temperature. Curves were derived from the statistical model that best described the response of $\lambda$ to temperature by population. Several populations were censused just 4 years; hence, the actual temperature variation over the study period was insufficient to define the shape of the temperature response curves for all populations. For clearer visualization of response curves, values corresponding to temperatures $\pm 1.5^{\circ} \mathrm{C}$ from each population's temperature optimum are plotted .80

Figure 3.4.b. Response of population growth rate $(\lambda)$ to annual variation in precipitation by population

Figure 3.5.a. Linear regression of site-specific temperature optima on 30-year mean maximum growing-season temperature. Only the model that included temperature as the independent variable explained a statistically significant proportion of the variation in $y$ $\left(p<0.001, r^{2}=0.91\right)$. For this model, the slope of the line of best fit did not statistically differ from $1(t=0.68, p=0.51)$.

Figure 3.5.b. Linear regression of precipitation optima on 30-year mean total precipitation

Figure 3.6. The relationship between mean temperature during the study period, sitespecific temperature optima, and 30-year (1971-2000) mean temperatures at each site. Mean temperatures over the duration of the study were on average $0.33{ }^{\circ} \mathrm{C}$ higher than the 30-year mean maximum temperature $(F=15.40, p<0.01)$. Temperature optima fell between mean temperatures during the study period and 30-year mean temperatures, but did not statistically differ from either $(F=1.77, p=0.21 ; F=0.24, p=0.63$; respectively)

Figure 4.1. Relationship between population growth rate and mean maximum growing season temperature variation. Temperature variation is expressed as the difference between annual temperature and the 30-year (1971-2000) mean.

Figure 4.2. Probability of extinction as a function of initial population size for four warming scenarios.

Figure 4.3. Relationship between minimum viable population size and temperature increase.

Figure 4.4. Frequency distribution of 2008 population sizes for 30 monitored ginseng populations.

Figure 4.5. Proportion of viable census populations for 4 levels of temperature increase. The highest level of warming corresponds to mean temperature increase projected for 
2069 by the IPCC's SRES A1B scenario, while the remaining 3 temperature levels represent a reduction in projected warming of $100 \%, 67 \%$, and $33 \%$, respectively

Figure 5.1. The effect of temperature on presence in 2009 by population.

Figure 5.2.a. A trend for differential response to temperature of relative growth rate of leaves $\left(\mathrm{RGR}_{\mathrm{LA}}\right)$ between populations.

Figure 5.2.b. Differential response to temperature of peduncle height in 2010 between

populations.

Figure 5.2.c. The effect of temperature on relative growth rate of sympodium height.

Figure 5.3.a. Likelihood of forming a reproductive structure in 2009 among temperature treatments for LowT and MedT populations.

Figure 5.3.b. Differential response to temperature of bud number in 2010 between populations.

Figure 5.3.c. Differential response between populations in terms of change in bud number from 2009 to 2010 to temperature.

Figure 5.4.a. The effect of temperature on seed production in $2010 \ldots \ldots \ldots \ldots \ldots \ldots \ldots \ldots \ldots \ldots . . . .161$

Figure 5.4.b. The effect of temperature on seeds produced per bud in 2010 .

Figure 5.4.c. The effect of temperature on berry weight per seed in 2010 .

Figure 5.5.a. Differential response to temperature of $\mathrm{CO}_{2}$ assimilation rate between populations.

Figure 5.5.b. The effect of temperature on ginseng respiration rate 165

Figure 5.6.a. Differential response to temperature of emergence rate between populations.

Figure 5.6.b. Differential response to temperature of floral development between populations.

Figure 5.6.c. Differential response to temperature of senescence level between populations.

Figure 5.7. Differential response to temperature in terms of root to shoot ratio between populations. 170

Figure 6.1. Proportion of plants absent in 2010 at each transplant site. 193 
Figure 6.2. Mean relative growth rate of ginseng leaf area from 2009 to 2010 across transplant sites.

Figure 6.3. Change in number of buds per plant from 2009 to 2010 across transplant sites.

Figure 6.4. Relative growth rate of ginseng sympodium height from 2009 to 2010 across transplant sites.

Figure 6.5. Percent foliar expansion of ginseng leaves across an elevation gradient....197

Figure 6.6. Proportion of pre-anthesis buds to total bud number in 2010 across transplant sites.

Figure 6.7. Number of buds produced per unit leaf area by plants from either a high or low elevation population.

Figure 6.8. Number of seeds produced per unit leaf area by plants from either a high or low elevation population.

Figure 6.9. Percent of ginseng plants browsed by white-tailed deer in early spring 2010 across transplant sites. 


\section{LIST OF TABLES}

Table 2.1. Summary of two statistical analyses examining among population patterns of frost damage in terms of temperature prior to the frost event.

Table 3.1. Weight of support $\left(w_{i}\right)$ for competing statistical models of ginseng population growth rate $(\lambda)$ regressed on temperature or precipitation expressed in standard units or in terms of SD for linear and second-order polynomial fits.

Table 5.1. Details of statistical analyses by dependent variable

Table 5.2. $\mathrm{P}$-values associated with main, temperature $(\mathrm{T})$ and population $(\mathrm{P})$, and interactive effects $\left(\mathrm{T}^{*} \mathrm{P}\right)$ by dependent variable for all statistical analyses.

Table 5.3. Means (bold) and standard errors of dependent variables by temperature treatment (Low, Medium, High) and population (LowT Population, MidT Population) for ANOVA analyses

Table 6.1. Environmental characteristics of source population sites and transplant sites

Table 6.2. P-values corresponding to G-test and ANOVA results by dependent variable. Statistical trends are marked with a single asterisk, while statistically significant results are labeled with 2 asterisks. 


\section{ChAPTER I}

\section{GENERAL INTRODUCTION}


The burning of fossil fuels and the consequent rise in global temperatures has influenced ecosystems worldwide, affecting a multitude of organisms, which span broad taxonomic and ecological boundaries (Hughes 2000; Parmesan 2006; Parmesan and Yohe 2003; Root et al. 2003; Walther et al. 2002). The impacts of climate change on natural populations have become apparent after a mean global increase in temperature of only $0.7^{\circ} \mathrm{C}$ (IPCC 2007). As climate models forecast further warming, as much as $6^{\circ} \mathrm{C}$ by the end of the century, it is a virtual certainty that current ecosystems face dramatic changes (IPCC 2007). Understanding, predicting, and mitigating these changes is the enormous and pressing task awaiting scientists and policy-makers.

Recent demographic studies of ecological response to climate change have demonstrated that warming is positively related with population decline for several narrow range endemics, as well as several Arctic and Antarctic species. The most publicized of these reports, like those concerning the polar bear (Derocher et al. 2004), have greatly increased public awareness regarding the effects of climate change in natural ecosystems, and may eventually influence high-level policy changes, such as creating caps on $\mathrm{CO}_{2}$ emissions. Notably, these studies have focused on species at high risk of climate change-driven extinction; narrow-range endemics in ecosystems particularly sensitive to climate change effects (Hunter et al. 2010; Jenouvrier et al. 2009; MarreroGomez et al. 2007; Maschinski et al. 2006; Molnar et al. 2010) (e.g., Arctic, Antarctic, alpine regions, and deserts). Such biases are important, because species' response to climate change will likely vary among ecosystems, and depend on the biology of the focal organism. Favoring the study of rare or difficult to monitor species may contribute to the lack of demographic studies of sufficient spatial scale to examine variation in 
population response across a species' range. Such studies are needed to create an accurate understanding of species' response to climate change. In the following suite of studies, I take advantage of 13 years of demographic and ecological research on American ginseng (Panax quinquefolius L.) to examine ginseng response to climate variation across a range of demographic and spatial scales.

American ginseng is the United States' premier wild harvested plant species (Robbins 2000). Sale of ginseng to the Asian market generates millions of dollars annually in supplemental income to households in the Appalachian region (Bailey 1999). Harvest, however, is more than an economic endeavor; it is a practice rooted in Appalachian culture. Often an intergenerational activity, harvest reinforces familial bonds as elders pass down knowledge of ginseng locations and harvest practices. Importantly, the economic value of ginseng promotes the sentiment that forest ecosystems are valuable resources, and the act of harvesting fosters connections between Appalachian families and the eastern deciduous forest (Bailey 1999).

Ginseng is an obligate understory, perennial, herbaceous plant species that occurs from southern Quebec to Georgia (Anderson et al. 1993; Lewis and Zenger 1982). Ginseng plants develop between one and four palmately compound leaves, which arise in a whorl from a single, aerial sympodium. The plant's belowground parts consist of a taproot, the primary storage organ, and a rhizome. During the growing season, a bud develops on the rhizome that will give rise to next season's plant (Anderson et al. 1993; Lewis and Zenger 1982). The autumn detachment of the sympodium from the rhizome leaves a scar, which can be counted to estimate a plant's age (Anderson et al. 1993). Small, 5-merous, hermaphroditic flowers mature centripetally on a solitary umbel. 
Ginseng has a mixed mating system, and does not display vegetative or apomictic reproduction (Mooney and Mcgraw 2007; Schlessman 1985). Ginseng berries are brilliant red and fleshy, containing between one and three seeds; a single reproductive plant typically producing between zero and one hundred seeds. Seeds are primarily dispersed by gravity, though caching by chipmunks has been observed (Van der Voort 2005) and certainly other animals, such as birds, are potential dispersers. Perhaps due to its mating system and seed dispersal mechanism, ginseng populations are spatially genetically structured; plants occur in clumps of closely related individuals (CruseSanders and Hamrick 2004b; Mooney 2007). Studies of naturally occurring genetic variation among ginseng populations find low within population genetic variation, and high among population genetic variation (Cruse-Sanders and Hamrick 2004a; Grubbs and Case 2004). Population modeling of ginseng population dynamics was pioneered by Charron and Gagnon (1991), who used leaf number to delineate stages in four populations of ginseng in southern Quebec. Subsequent researchers built on Charron and Gagnon's basic demographic model, using leaf area in conjunction with leaf number to define stages, and incorporating seed bank dynamics in models of population growth (Furedi 2004; Mooney 2007; Van der Voort 2005). Demographic studies using these models have shown that illegal or irresponsible harvest and browsing by white tail deer negatively impact population growth, and decrease long-term viability of ginseng populations (McGraw and Furedi 2005; Van der Voort and McGraw 2006).

Winter warming and increased climatic variability may increase the frequency of early spring frosts as climate changes over the next century. Spring frosts can cause significant damage to plant tissue (Pearce 2001); extreme frosts resulting in total loss of 
leaves, buds, and shoots (Inouye 2008; Pearce 2001). Frost damage effects can manifest at the population-level by decreasing the likelihood of survival, and reducing growth and reproduction rates (Inouye 2000; Inouye 2008; Inouye et al. 2002). In 2007, we witnessed the effects of a late-spring frost during an annual demographic census of ginseng populations. The objective of Chapter 1 was to take advantage of this event to examine within and among population patterns of frost damage, and to quantify the effect on ginseng population demography. To accomplish this, we measured size-related traits and reproduction of individuals in 30 ginseng populations, in both the year of the frost and the year after. While collecting demographic measurements, we noted whether plants had been damaged by the frost. I analyzed these data to determine whether temperatures preceding the frost event explained variation in among population frost damage, whether size-related traits influenced the probability of individual plants incurring frost damage, and whether the frost affected ginseng survival, growth, and reproduction.

The dominant paradigm of species' response to climate change is largely based on Hutchinsonian niche theory, and was popularized by bioclimatic envelope models. Such approaches operate under the expectation of a species-wide relationship of fitness to temperature (Hampe and Petit 2005). This assumption may hold true for species in which gene flow among populations precludes adaptive differentiation of populations (Kawecki and Ebert 2004; Linhart and Grant 1996), but is at best questionable for species adapted to local climatic conditions (Davis and Shaw 2001; Etterson 2004; Macel et al. 2007). If populations within a species are locally climatically adapted, departure from climatic norms may decrease population growth range-wide. For plants, local adaptation 
is common (Linhart and Grant 1996). Hundreds of experiments have demonstrated adaptive differentiation of populations to a variety of ecological factors, such as light, soil moisture, heavy metals, disease, browsing, temperature, pollinators, and competitors (Linhart and Grant 1996; Savolainen et al. 2007). The objective of Chapter 2 was to determine whether response of ginseng populations suggested a range-wide relationship of population growth rate to climate, or rather, adaptation to local climate. To do this, I used demographic data collected over a 6 - 12 year period from 12 ginseng populations located over a large portion of ginseng's range to parameterize population projection matrices. Matrices were used to estimate annual population growth rates $(\lambda)$, which were then related to climatic variables. Relationships of $\lambda$ to climate were evaluated with various statistical techniques to detect patterns of demographic response to climatic variation.

The ultimate goal of studying species response to climate change is to provide the necessary data that lead to policy-level changes favoring long-term species persistence. Climate-integrated conservation strategies encompass a broad spectrum of initiatives, such as assisted relocation, designing appropriate nature reserves, and preserving dispersal corridors (Araujo et al. 2004; Halpin 1997; Hannah 2008; Hannah et al. 2002a; Hannah et al. 2002b; Hulme 2005; Williams et al. 2005). Actuating such conservation strategies is difficult, because it is necessary to plan for conditions that have yet to occur. Preemptive action anticipating novel conditions is a vast departure from historical management and conservation strategies, which are typically enacted as responses to environmental threats, or to preserve already endangered species. This conceptual change in conservation, which is so critical to the maintenance of biodiversity in the 
context of climate change, must be supported by models rooted in strong empirical data that provide accurate forecasts on which to base conservation decisions. Stochastic population viability analysis (PVA) converts demographic datasets to meaningful projections of long-term viability by incorporating stochasticity inherent in natural systems (Morris 2002). Population viability analyses do this by using transition matrices to describe population structure and vital rates, and iterative Monte Carlo techniques to quantify extinction probability. Output from PVAs often provide a foundation for conservation initiatives; they can be used to set harvest limits, identify critical life stages, and make decisions concerning which and how many populations within a species should be protected to ensure long-term persistence (Morris 2002). Population viability analysis can also be used to establish threats to long-term persistence of a particular focal species (Morris 2002). For ginseng, a PVA was successfully used to quantify the effect of browse by whitetail deer on extinction risk of ginseng populations (McGraw and Furedi 2005). In Chapter 3, I performed a PVA that estimated changes in extinction risk as a function of a suite of climate change scenarios, with the objective of determining whether climate change affects the probability of extinction of ginseng populations.

Reciprocal transplant experiments are commonly used to test for an underlying genetic basis of phenotypic variation (Kawecki and Ebert 2004; Linhart and Grant 1996). Transplant experiments have demonstrated adaptive differentiation of populations to a variety of ecological factors, such as light, soil moisture, heavy metals, disease, browsing, temperature, pollinators, and competitors (Linhart and Grant 1996; Savolainen et al. 2007). In chapter 2 , I examined demographic response of natural ginseng populations to inter-annual temperature variation, to determine whether response patterns suggested 
local climatic adaptation. In Chapters 4 and 5, I used transplant experiments to test for genetic differentiation of ginseng populations with respect to temperature. In both experiments, two populations of ginseng, one from a high elevation site and one from a low elevation site, were transplanted in a fully factorial manner among three temperature treatments. The first two temperature levels represented mean conditions at each population's home site, and the third temperature level represented 'future' temperatures at current projected rates of warming. In Chapter 4, the transplant experiment was performed in a controlled growth chamber environment at the McGill University phytotron over two seasons. The transplant experiment in Chapter 5, however, was performed in a natural setting, and ginseng populations were transplanted along an elevational gradient, in which elevation served as a proxy for temperature. Demographic, phenological, and physiological traits were measured to determine whether ginseng populations were genetically differentiated with respect to temperature, and to investigate the response of populations to climate warming.

The following five chapters address various aspects of the overarching question "How will climate change affect ginseng demography?" Understanding ginseng response to climate change may guide conservation of ginseng, and ecologically similar species, as climate changes. 


\section{References}

Anderson RC, Fralish JS, Armstrong JE, Benjamin PK (1993) The Ecology and Biology of Panax-Quinquefolium-L (Araliaceae) in Illinois. American Midland Naturalist $129: 357-372$

Araujo MB, Cabeza M, Thuiller W, Hannah L, Williams PH (2004) Would climate change drive species out of reserves? An assessment of existing reserve-selection methods. Global Change Biology 10:1618-1626

Bailey B (1999) Social and economic impacts of wild harvested products. In: College of Agriculture, Forestry and Consumer Sciences, vol. Ph.D. West Virginia University, Morgantown, WV, p 111

Charron D, Gagnon D (1991) The Demography of Northern Populations of PanaxQuinquefolium (American Ginseng). Journal of Ecology 79:431-445

Cruse-Sanders JM, Hamrick JL (2004a) Genetic diversity in harvested and protected populations of wild American ginseng, Panax quinquefolius L. (Araliaceae). American Journal of Botany 91:540-548

Cruse-Sanders JM, Hamrick JL (2004b) Spatial and genetic structure within populations of wild American ginseng (Panax quinquefolius L., Araliaceae). Journal of Heredity 95:309-321

Davis MB, Shaw RG (2001) Range shifts and adaptive responses to Quaternary climate change. Science 292:673-679

Derocher AE, Lunn NJ, Stirling I (2004) Polar bears in a warming climate. Integrative and Comparative Biology 44:163-176 
Etterson JR (2004) Evolutionary potential of Chamaecrista fasciculata in relation to climate change. 1. Clinal patterns of selection along an environmental gradient in the great plains. Evolution 58:1446-1458

Furedi M (2004) Effects of herbivory by white-tailed deer (Odocoileus virginianus Zimm.) on the population ecology and conservation biology of American ginseng (Panax quinquefolius L.). In: Department of Biology, vol. Doctorate. West Virginia University, Morgantown, WV, p 206

Grubbs HJ, Case MA (2004) Allozyme variation in American ginseng (Panax quinquefolius L.): Variation, breeding system, and implications for current conservation practice. Conservation Genetics 5:13-23

Halpin PN (1997) Global climate change and natural-area protection: Management responses and research directions. Ecological Applications 7:828-843

Hampe A, Petit RJ (2005) Conserving biodiversity under climate change: the rear edge matters. Ecology Letters 8:461-467

Hannah L (2008) Protected areas and climate change. Year in Ecology and Conservation Biology 2008 1134:201-212

Hannah L et al. (2002a) Conservation of biodiversity in a changing climate. Conservation Biology 16:264-268

Hannah L, Midgley GF, Millar D (2002b) Climate change-integrated conservation strategies. Global Ecology and Biogeography 11:485-495

Hughes L (2000) Biological consequences of global warming: is the signal already apparent? Trends in Ecology \& Evolution 15:56-61 
Hulme PE (2005) Adapting to climate change: is there scope for ecological management in the face of a global threat? Journal of Applied Ecology 42:784-794

Hunter CM, Caswell H, Runge MC, Regehr EV, Amstrup SC, Stirling I (2010) Climate change threatens polar bear populations: a stochastic demographic analysis. Ecology 91:2883-2897

Inouye DW (2000) The ecological and evolutionary significance of frost in the context of climate change. Ecology Letters 3:457-463

Inouye DW (2008) Effects of climate change on phenology, frost damage, and floral abundance of montane wildflowers. Ecology 89:353-362

Inouye DW, Morales MA, Dodge GJ (2002) Variation in timing and abundance of flowering by Delphinium barbeyi Huth (Ranunculaceae): the roles of snowpack, frost, and La Nina, in the context of climate change. Oecologia 130:543-550

IPCC (2007) Fourth Assessment Report of the Intergovernmental Panel on Climate Change. In. Cambridge University Press, Cambridge

Jenouvrier S, Caswell H, Barbraud C, Holland M, Stroeve J, Weimerskirch H (2009) Demographic models and IPCC climate projections predict the decline of an emperor penguin population. Proceedings of the National Academy of Sciences of the United States of America 106:1844-1847

Kawecki TJ, Ebert D (2004) Conceptual issues in local adaptation. Ecology Letters $7: 1225-1241$

Lewis WH, Zenger VE (1982) Population-Dynamics of the American Ginseng PanaxQuinquefolium (Araliaceae). American Journal of Botany 69:1483-1490 
Linhart YB, Grant MC (1996) Evolutionary significance of local genetic differentiation in plants. Annual Review of Ecology and Systematics 27:237-277

Macel M et al. (2007) Climate vs. soil factors in local adaptation of two common plant species. Ecology 88:424-433

Marrero-Gomez MV, Oostermeijer JGB, Carque-Alamo E, Banares-Baudet A (2007) Population viability of the narrow endemic Helianthemum juliae (CISTACEAE) in relation to climate variability. Biological Conservation 136:552-562

Maschinski J, Baggs JE, Quintana-Ascencio PE, Menges ES (2006) Using population viability analysis to predict the effects of climate change on the extinction risk of an endangered limestone endemic shrub, Arizona cliffrose. Conservation Biology $20: 218-228$

McGraw JB, Furedi MA (2005) Deer browsing and population viability of a forest understory plant. Science 307:920-922

Molnar PK, Derocher AE, Thiemann GW, Lewis MA (2010) Predicting survival, reproduction and abundance of polar bears under climate change. Biological Conservation 143:1612-1622

Mooney EH (2007) Genetic and Evolutionary Consequences of Harvest in American ginseng, Panax quinquefolius L. (Araliaceae). In: Department of Biology, vol. Doctorate. West Virginia University, Morgantown, WV, p 192

Mooney EH, Mcgraw JB (2007) Effects of self-pollination and outcrossing with cultivated plants in small natural populations of American ginseng, Panax quinquefolius (Araliaceae). American Journal of Botany 94:1677-1687 
Morris WF, and Daniel F. Doak (2002) Quantitative Conservation Biology. Sinauer Associates Inc., Sunderland, MA

Parmesan C (2006) Ecological and evolutionary responses to recent climate change. Annual Review of Ecology Evolution and Systematics 37:637-669

Parmesan C, Yohe G (2003) A globally coherent fingerprint of climate change impacts across natural systems. Nature 421:37-42

Pearce RS (2001) Plant freezing and damage. Annals of Botany 87:417-424

Robbins CS (2000) Comparative analysis of management regimes and medicinal plant trade monitoring mechanisms for American ginseng and goldenseal. Conservation Biology 14:1422-1434

Root TL, Price JT, Hall KR, Schneider SH, Rosenzweig C, Pounds JA (2003) Fingerprints of global warming on wild animals and plants. Nature 421:57-60

Savolainen O, Pyhajarvi T, Knurr T (2007) Gene flow and local adaptation in trees. Annual Review of Ecology Evolution and Systematics 38:595-619

Schlessman MA (1985) Floral Biology of American Ginseng (Panax-Quinquefolium). Bulletin of the Torrey Botanical Club 112:129-133

Van der Voort M (2005) An ecological study of Panax quinquefolius in central Appalachia: seedling growth, harvest impacts and geographic variation in demography. In: Department of Biology, vol. Doctor of Philosophy in Biology. West Virginia University, Morgantown, WV, p 176

Van der Voort ME, McGraw JB (2006) Effects of harvester behavior on population growth rate affects sustainability of ginseng trade. Biological Conservation $130: 505-516$ 
Walther GR et al. (2002) Ecological responses to recent climate change. Nature 416:389395

Williams P et al. (2005) Planning for climate change: Identifying minimum-dispersal corridors for the Cape proteaceae. Conservation Biology 19:1063-1074 


\section{CHAPTER II:}

\section{VULNERABILITY OF WILD AMERICAN GINSENG TO AN EXTREME}

\section{EARLY SPRING TEMPERATURE FLUCTUATION}




\begin{abstract}
Frost events in natural plant populations can have dramatic demographic consequences. For many plant species, spring emergence occurs when probability of damaging frost is low. Climate change, however, may alter weather patterns such that the environmental cues signaling spring emergence no longer coincide with periods of low frost risk, rendering plant populations susceptible to damaging frost events more frequently than in the past. In 2007, a spring freeze occurred in the eastern United States after a period of unusually warm temperatures. We took advantage of a long-term demographic data set for American ginseng (Panax quinquefolius L.) to examine among and within population patterns of frost damage, as well as the effects of the frost on ginseng demography. Higher temperatures prior to the frost event increased the probability and extent of frost damage at the population level. Within populations, large plants tended to be damaged more frequently than smaller plants. Survival, growth, and reproduction were reduced in frost-damaged plants compared to undamaged plants in the year of the frost event, and negative effects on growth and reproduction persisted the following year. For plants such as ginseng, increases in frost frequency will negatively impact population growth, and likely have serious ramifications for long-term population viability.
\end{abstract}




\section{Introduction}

Historic records of the timing of natural and agricultural events have made it possible to track the effects of increasing temperatures on the phenophases of a diversity of taxa across a broad regional spectrum. While the overall signal shows that phenological events are occurring earlier in response to warming, the magnitude of response varies substantially among species (Bradley et al. 1999; Parmesan and Yohe 2003; Badeck et al. 2004; Schwartz et al. 2006; Parmesan 2007; Miller-Rushing and Primack 2008). There have been ecological surprises as well; a number of species have not responded to warming at all, and a few species have responded in the opposite direction than predicted (Parmesan 2007). Phenological response of species to climate change is important, because the timing of life history events can have drastic effects on fitness (Hall and Willis 2006; Hall et al. 2007; Jentsch et al. 2009). Indeed, adaptive differentiation has been demonstrated with respect to a variety of phenological traits (Ducousso et al. 1990, 1996; Myking and Heide 1995; Leinonen 1996; Aitken and Adams 1997; Li et al. 1997; Leinonen and Hänninen 2002; Savolainen et al. 2004; Ghelardini et al. 2006; Hall and Willis 2006; Kudo and Hirao 2006; Green 2007; Hall et al. 2007; Søgaard et al. 2008; Vitasse et al. 2009a). In the northern hemisphere, timing of the initiation of spring growth is critical for success, especially in the case of plant species. Numerous studies have found that early spring emergence is positively related to biomass accumulation and fecundity (Ross and Harper 1972; Kalisz 1986; Miller 1987; Stratton 1992; Verdú and Traveset 2005). Selection for earlier emergence times increases with plant density, indicating that plants that emerge early gain a competitive advantage over neighbors (Miller et al. 1994) primarily by accessing and usurping light 
resources (van der Toorn and Pons 1988). However, early emergence is risky. In a dynamic climate, frosts are possible in early spring, and can have severe negative repercussions for plant growth and reproduction.

A clear connection has been made between rising global temperatures and increased frost risk in montane, arctic, and boreal ecosystems due to decreased snow accumulation. Decline in winter snow cover, which acts as insulation against harsh climatic conditions for many plant species, may expose plants to low temperature extremes, resulting in winter freeze damage (Ögren 2001; Bélanger et al. 2002; Bannister et al. 2005). Because snow cover also acts as a buffer against exposure to unusually warm temperatures, decreasing snow accumulation, in conjunction with elevated winter temperatures, may cause premature dehardening of cold-tolerant species (Ögren 2001; Bélanger et al. 2002; Bannister et al. 2005). When dehardening is initiated, carbohydrate concentrations within plant material decrease, leaving the plant vulnerable to freeze damage (Ögren 1997). For perennial wildflower species in alpine systems, snowmelt is often the primary cue to break winter dormancy (Inouye 2008). Decreasing winter snow accumulation, and the resultant advancement in spring snowmelt date, has triggered premature emergence of plant populations when the probability of frost remains high (Inouye 2000, 2008; Inouye et al. 2002). In this case, the environmental cue that prompts emergence is no longer meaningful, because snowmelt is no longer correlated with low frost risk.

Novel climatic conditions projected by climate models may interact directly with plant phenology to increase frost risk in the future, even in ecosystems where snow accumulation plays little to no role in plant dynamics. In such cases, rising frost risk as a 
result of elevated temperatures is seemingly counterintuitive. Climate models project a lengthening of the frost-free period and a decrease in the number of freeze events as a result of rising global temperatures (Easterling et al. 1997). However, these studies are specifically referring to the occurrence of below freezing temperatures, and do not distinguish frost events that cause damage to plant or crop species. For most plant species, particularly in temperate environments, spring emergence dates are not immutable, and often depend on temperature cues (Rathcke and Lacey 1985). For this reason, vegetation-damaging spring frost events may, in fact, increase in frequency due to two phenomena predicted by global climate models 1) increased climatic variability and 2) disproportionate warming of winter temperatures relative to summer temperatures. With respect to the first phenomenon, frost risk may increase with greater climatic variability, because of greater frequency of unusually warm, growth-stimulating temperatures in late winter or early spring, or conversely, unusually low temperatures following warm periods (Gu et al. 2008; Rigby and Porporato 2008). In terms of the second factor, milder winters mean that the period of transition from winter to summer, when temperatures may both stimulate growth and also drop below freezing, is longer, leaving populations susceptible to frost damage for a larger portion of the year.

The effect of increasing mean temperatures on frost risk has been extensively examined using phenology-based models. The majority of models find an increase in frost risk associated with climatic warming as a result of 'premature' spring development during periods when frosts are still possible (Cannell and Smith 1984, 1986; Hänninen 1991; Kellomäki 1995; Pepin 1997; Linkosalo et al. 2000; Jönsson 2004). Several models contradict these projections, however, finding no increase in the probability of 
damaging frosts (Eccel et al. 2009), or even a decrease in future frost risk (Kramer 1984; Scheifinger et al. 2003). The disparity in model outcomes is partially explained by species-level differences in phenological response to temperature. Future frost risks are diminished when models use species that require low winter temperatures in order to develop at a maximum rate during spring (Hänninen 1991; Murray et al. 1994). In these cases, winter chilling requirements are not fully met due to increased mean winter temperatures, and therefore these plants do no not develop 'early' in response to elevated spring temperatures. Additionally, models that use environmental cues such as photoperiod to trigger spring bud-burst generally find a decrease in climate-mediated frost risk (Linkosalo et al. 2000). When the date of budburst is constrained, trees develop after the threat of sub-zero temperatures has receded, because the date of the last freezing event advances with increasing mean temperatures (Easterling et al. 1997). Methods of modeling climate change also affect model outcome. One study found that models that simulated climatic warming by uniformly increasing mean temperature across the entire year showed a much greater decline in frost frequency compared to models that incorporated disproportionate warming of winter relative to summer temperatures (Kramer 1994).

There is no clear consensus as to whether mean increases in global temperature will increase frost risk via direct effects on plant phenology, though the majority of models suggest this is the case. Changes in frost risk due to climatic warming are likely to differ among species depending on latitude, responsiveness of spring development to temperature cues, and the mechanisms by which species regulate spring growth and development (e.g., winter-cold requirements, photoperiod response) (Hänninen 1991; 
Linkosalo et al. 2000; Murray et al. 1994). While discrepancies exist among phenologybased models of frost risk, increased climatic variability projected by global climate models will almost certainly contribute to higher occurrence of damaging frosts in future seasonal climates (Rigby and Porporato 2008).

Frosts may cause physical damage to plant tissue as water within or among plant cells freezes and expands (Pearce 2001; Inouye 2008). Freezing also causes cellular dehydration as developing ice crystals draw water from plant cells, the detrimental effects of which are actually more common than the damage caused by ice crystal formation (Pearce 2001). Significant secondary damage due to frost can occur, because cellular lesions act as portals for plant disease (Pearce 2001). The net effect of freezing temperatures on plant tissue is extensive, or total, loss of leaves, buds, and shoots. For example, in a long-term study of Helianthella quinquenervis in the American Rockies, late spring freezes resulted in losses of between 65 and 100 percent of flower buds in 7 of the 8 study years (Inouye 2008). It is clear from such studies that frost events are important in the long-term demography of species in seasonal climates (Inouye 2000; Inouye 2008). The direct effect of a frost event on plant populations is overwhelmingly negative. However, occasionally frosts may play a beneficial role in reducing the abundance of herbivores, seed predators, and other pests and pathogens that negatively impact plant vigor (Inouye 2000).

Plant-damaging frost events are stochastic, and usually infrequent, making patterns and effects of frost in natural ecosystems difficult to study. However, the impacts of warming periods followed by frost damage are disproportionately high compared with their frequency, and deserve greater attention in ecological research. In 
2007, one such extreme warming-freezing cycle caused extensive damage across a large west to east swath in the eastern deciduous forest. This particular event was captured and analyzed using remote sensing, and significant losses to agriculture were also well documented (Gu et al. 2008). Our study took advantage of a long-term demographic data set for American ginseng (Panax quinquefolius L.) to examine patterns and demographic ramifications of the frost for a widespread native forest species with economic and cultural significance. Specifically, we asked 1) Can temperatures preceding and/or during the frost event predict observed patterns of frost damage among populations? 2) Do size characteristics of plants affect the probability of a plant being damaged by frost? 3) What are the effects of the frost on demographically important parameters, including survival, growth, and reproduction? 


\section{Methods}

\section{Study species}

American ginseng is a widespread herbaceous understory perennial found in deciduous forests of the eastern United States and southern Canada (Anderson et al. 1993; McGraw et al. 2003). Ginseng is an important harvested commodity in the Appalachian region, generating millions of dollars in supplemental revenue annually (Robbins 2000). The aboveground portion of the plant consists of an aerial sympodium, between 1 and 5 leaves, and an umbelliferous inflorescence. An inflorescence contains ca. 1 - 100 flowers, and flower number depends greatly on size (Schlessman 1985). In a study by Schlessman (1985), mean flower production across 88 reproductive plants was 12.3, with 2-leaved individuals producing an average of 7.5 flowers per inflorescence and 3-leaved plants producing 17 flowers per inflorescence. Ginseng flowers are hermaphroditic, 5-merous, and contain an inferior ovary with 1 to 2 (rarely 3 ) styles. Flowers are protandrous, and mature centripetally during mid-summer (Schlessman 1985). Ginseng has a mixed mating system. Known pollinators of ginseng include syrphid flies and halictid bees, both generalist pollinators (Lewis and Zenger 1983). Ginseng plants overwinter as a subterranean taproot and rhizome, and the root is the plant's primary storage organ. In the spring, the aboveground plant develops from a bud that forms on the rhizome in the previous growing season. If the aboveground portion of the plant is damaged, it cannot regenerate during that growing season, but may re-emerge the following growing season. While the perennating tissue may survive periodic damage to aboveground parts, repeated damage increases mortality. Ginseng plants are 
long-lived, with old plants attaining ages of 50 years or more (Mooney and McGraw 2009).

Ginseng demography has been modeled using a stage-based population projection approach (Charron and Gagnon 1991; Van der Voort et al. 2003). New seedlings are always 1-leaf plants; though plants may remain 1-leaved for several years, and as such, do not reproduce. Once a plant has attained two leaves it is considered juvenile, and reproduction is generally low and intermittent. Reproduction in 3, 4, and 5- leaf adult plants increases linearly as a function of leaf area. Large adult plants are capable of producing over 100 seeds, but this is unusual and mean seed production per adult plant is typically low. Ginseng plants do not reproduce clonally, except on the rare occasion that physical injury separates a portion of the root or rhizome, which may produce another plant.

\section{Ginseng census and data collection}

Data on ginseng survival, growth, recruitment, and seed production were collected as part of a long-term censusing project. In total, 30 populations distributed across 7 states (IN, KY, NY, PA, MD, VA, WV) were censused, containing a grand total 4,227 of plants. Exact locations of these populations are withheld for conservation

purposes. In order to avoid attracting the attention of harvesters, plants were marked with a subterranean tag. Plants were relocated using a 'phototrail' method, in which photographs and accompanying directions, and/or maps indicate ginseng locations. During the first of two annual censuses, leaf area and sympodium height were measured, and a search was conducted for new seedlings, which were then tagged and measured. 
While collecting these data, we noticed widespread leaf necrosis and deformity in several ginseng populations. Foliar deformities were ascribed to damage caused by a freezing event based on several lines of evidence. Principally, the visual appearance of leaf damage matched confirmed cases of frost damage in agricultural species. In an examination of a 2003 spring frost event on cultivated ginseng root yield and seed production in Ontario, Canada, Schooley and Proctor (2003) described the morphological symptoms of freeze damage on ginseng foliage and sympodia. Symptoms included: deformed, twisted sympodia, shriveled inflorescences, wrinkled, creased, or necrotic leaves, and/or complete loss of foliar material. The visual appearance of plants affected by frost in our census-populations was consistent with descriptions by Schooley and Proctor (2003). Secondly, the damage was widespread geographically, and not speciesspecific; many trees and other plants in the vicinity having also been affected. Temperature data loggers at the sites confirmed freezing temperatures following an extended warm period in April. Notably, the warming, followed by the frost was widely observed across the eastern United States (Gu et al. 2008). Frost damaged plants were simply noted as frost damaged or not during the first census. For plants that survived to the end of the growing season, a second observer confirmed frost damage, typically. During the second census, ginseng seed production was also measured. Temperature data used in the analyses were collected from $\mathrm{HOBO}$ pendant dataloggers (HOBO temperature/light pendant datalogger 64, Onset Computer Corporation) that recorded temperature and light data every hour.

\section{Analyses}


To address our first question regarding predictors of plant-damaging frost on a regional scale, we explored several possibilities. Especially for mild frost events, small differences in freeze severity could greatly affect the probability of a population being frost damaged if temperatures vary around the frost tolerance threshold of the plant. We used the minimum temperature during the frost period as a metric of frost severity. The period of frost was defined by contiguous days in which temperatures fell below $0^{\circ} \mathrm{C}$, which on average was around 7 days for any given population. A population was considered to have sustained frost damage if at least one plant within the population had been recorded as damaged by frost. The independent variable, the minimum temperature during the freezing event, was related to frost damage using logistic regression.

Regional differences in temperature preceding the frost event could also affect the likelihood of a population being damaged. Specifically, warmer temperatures, or longer periods of high temperature, could accelerate development of plants in some populations, leaving them more vulnerable to frost. Mean average, minimum, and maximum temperatures were calculated for 5 time periods corresponding to $1,5,10,15$, and 20 days prior to frost. This 20 day time period was bracketed by below zero temperatures. The same criterion as above was used to label a population as 'frost-damaged'. Logistic regression was used to determine whether the probability of a population incurring frost damage depended on each climatic variable. Among populations that were damaged by frost, we then tested whether these same climatic factors, as well as the minimum temperature during the frost, could explain differences in damage extent, defined as the percentage of plants damaged by frost in a population. For this analysis, we selected all populations that were considered 'frost damaged', again using the criterion that at least 
one plant in the population had sustained frost damage, and calculated the percent of the total population that had incurred damage due to frost. Percentages were logtransformed, and regressed on mean average, minimum, and maximum temperatures for $1,5,10,15$, and 20 -day periods, as well as the minimum temperature during the frost. The residuals of the regression were tested for deviations from normality.

To address our second question regarding differential effects of frost within populations, we selected the largest ginseng population $(n=153)$ that had sustained a high level of frost damage. For that population, we then tested whether physical attributes of the ginseng plant, specifically plant height and leaf area, influenced the likelihood that a plant was damaged by frost using logistic regression. For these two analyses, as well as all subsequent analyses, three outliers suspected of being cultivated genotypes were excluded on the grounds that they likely originated from a different climatic zone and therefore may have differed from native plants in terms of their response to frost. These three plants were considerably larger than the other plants, were located in an area suspected to contain cultivated ginseng, and differed from other plants in terms of morphology and phenology.

To address our third question, we investigated the effect of the frost on demographically important parameters within the previously selected ginseng population. Browsing by white tail deer negatively impacts ginseng population viability (McGraw and Furedi 2005), and loss of leaf material due to deer browsing is in some ways analogous to the loss of leaf material due to frost. To avoid confounding these two factors, all deer-browsed plants were excluded from subsequent analyses. In order to determine whether removal of deer browsed plants biased our analyses, we also tested 
whether the likelihood of being deer browsed differed as a function of being frost damaged or not, using a log-likelihood analysis. We then examined whether being frost damaged affected the probability of survival to 1) the end of the growing season and 2) to the spring of the following year using logistic regression. In plants, survival often increases as a function of size. For this reason, leaf area was used as a covariate in the analyses. Leaf area was calculated from field measurements of leaf length and width using a regression equation, which related these measurements to leaf area $\left(r^{2}=0.9327\right)$. The model was parameterized with leaf areas calculated from digital images of 100 adult ginseng plants. Digital images were processed using the free image processing software, NIH Image J. The effects in the statistical model therefore included: Frost Damage (FD; yes or no), Leaf Area $\left(\mathrm{LA} ; \mathrm{cm}^{2}\right)$, and their interaction (FD x LA).

The effect of frost damage on plant growth was also analyzed. Because the frost caused foliar deformities, leaf area growth rate was calculated for years bracketing the frost event. For this reason, only plants that were present all three seasons were used in the analysis. Relative growth rate (RGR) on a leaf area basis was calculated for the period of 2006 to 2008, using the following equation (McGraw and Garbutt 1990):

$$
\mathrm{RGR}_{\mathrm{A}}=\frac{\ln \mathrm{A}_{2}-\ln \mathrm{A}_{1}}{\mathrm{t}_{2}-\mathrm{t}_{1}}
$$

The data were tested for normality, and analyzed using a one-way analysis of variance, with frost damage as the main effect in the model.

Reproductive responses to frost damage were partitioned into three components. First, logistic regression was used to determine whether the probability of forming a reproductive structure depended on being damaged by frost. Next, among plants that 
formed reproductive buds, logistic regression was used to test whether the probability that a plant would produce seeds differed as a function of being frost damaged or not. Finally, in order to determine whether the frost event affected the number of seeds produced per seed producing plant, an analysis of covariance (ANCOVA) was performed. All analyses were repeated for both 2007, the year of the frost occurrence, and 2008, one year later. Leaf area was used as a covariate, as in prior analyses, using the full factorial model. 


\section{Results}

Of the 30 populations of ginseng that we censused, fourteen were affected by frost. Frost extent, measured as the proportion of damaged plants in the population, differed substantially among populations. In the population most severely affected by frost, 36.8 percent of ginseng plants showed symptoms of frost damage, whereas in the population least affected by frost, less than 1 percent of plants incurred frost damage. The mean percent of the population affected by frost was 10.9 percent.

Temperatures before and during the frost event did explain among-population patterns of frost damage. The minimum temperature during the frost event influenced the likelihood of a population being frost damaged $\left(\chi^{2}=5.71, p=0.0169\right)$, however contrary to expectation, warmer temperatures during the frost increased the likelihood of a population being damaged. All temperature summaries for the time periods prior to the frost, except the 1-day period strongly affected the probability of a population being frost damaged ( $p<0.01$ in all cases; Table 1; Fig.1). Greater pre-frost temperatures increased the probability that a population would incur frost damage (Fig.1 shows one such relationship). The lowest temperature during the frost did not affect the proportion of frost-damaged plants within a population $(\beta=0.0005, p=0.9875)$. However, minimum temperatures $5,10,15$, and 20 days prior to the frost affected the extent of frost damage, with minimum temperatures explaining the largest amount of variation in $y$ (Table 1). Warmer minimum temperatures prior to the freeze increased the percent of the population damaged, and minimum temperatures averaged over a 15-day period explained the most variation in extent of frost damage ( $\beta=0.2735, p=0.0008$; Table 1 ; Fig. 2$)$. In frost- 
damaged populations, maximum temperatures did not predict extent of frost damage (Table $1 ; p>0.05)$

Size-related traits of ginseng plants influenced the likelihood of sustaining frost damage. Plants with larger leaf area were more likely to be damaged by frost $\left(\chi^{2}=4.37\right.$, $p=0.0365$; Fig. 3). However, there was no effect of height on likelihood of incurring frost damage $\left(\chi^{2}=0.79, p=0.3734\right)$.

Overall, the frost event negatively impacted ginseng demography. The effect of leaf area on persistence to the end of the growing season in 2007 depended on the effect of frost damage $\left(\chi^{2}=3.18, p=0.0298 ; \operatorname{Fig}(\mathrm{s}) .4 \mathrm{a}, 4 \mathrm{~b}\right)$. For frost-damaged plants the likelihood of being absent at the end of the growing season increased with greater leaf area. There was also a tendency for frost-damaged plants to be absent the following growing season more frequently than expected $\left(\chi^{2}=2.65, p=0.1037\right)$, but this effect did not depend on leaf area $\left(\chi^{2}=1.13, p=0.2884\right)$.

Frost damage reduced relative leaf area growth rate of ginseng from 2006 to 2008 $\left(F=7.2644, p=0.0089\right.$, Fig.5). In 2007, neither frost $\left(\chi^{2}=1.71, p=0.4656\right)$, nor leaf area $\left(\chi^{2}=2.14, p=0.1437\right)$, nor the interaction between these factors $\left(\chi^{2}=1.13, p=\right.$ 0.5675 ) affected the presence of an inflorescence. In 2008, leaf area alone affected the likelihood of a plant forming a reproductive structure $\left(\chi^{2}=30.56, p<0.0001\right)$, but frost damage, and the interactive term, did not $\left(\chi^{2}=0.09, p=0.7622 ; \chi^{2}=0.21, p=0.6465\right.$ respectively). Of the plants that produced an inflorescence in 2007, only leaf area influenced the probability of a plant producing seeds $\left(\chi^{2}=4.51, p=0.0336\right)$, while frost damage and the interaction of frost damage and leaf area had no effect $\left(\chi^{2}=0.19, p=\right.$ $0.6641 ; \chi^{2}=0.11, p=0.7459$; respectively). As expected, leaf area increased the 
likelihood of producing seeds. Interestingly, in 2008, frost damage and leaf area alone did not affect the probability of producing seeds $\left(\chi^{2}=0.87, p=0.3514 ; \chi^{2}=0.03, p=\right.$ 0.8565 ; respectively), but there was a statistically significant interactive effect between these two factors $\left(\chi^{2}=6.05, p=0.0139 ;\right.$ Fig(s). 6a, 6b). As leaf area increased, those plants that were frost damaged in the prior year showed reduced probability of seed production, while the expected increase in seed production was observed for undamaged plants. Among plants that produced seeds, neither frost damage, nor leaf area, nor the interactive effect influenced the number of seeds produced in $2007(F=2.6703, p=$ $0.1568)$ or in $2008(F=1.5426, p=0.3652)$. 
Table 2.1. Summary of two statistical analyses examining among population patterns of frost damage in terms of temperature prior to the frost event. Mean temperatures have been calculated from daily minimum and maximum temperatures over time periods 1,5 ,

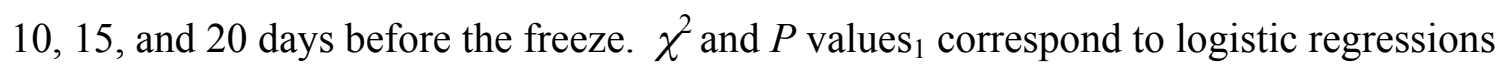
of populations incurring frost damage or not as a function of temperature preceding the frost event. $\beta, r^{2}$, and $P$ values 2 are derived from regressions of the percent of the population damaged by frost on the temperature prior to freeze.

\begin{tabular}{ccccccc}
\hline \hline $\begin{array}{c}\text { Method of } \\
\text { summarizing } \\
\text { temperature } \\
\text { data }\end{array}$ & $\begin{array}{c}\text { Time period } \\
\text { (days) over } \\
\text { which mean } \\
\text { temperatures } \\
\text { were } \\
\text { calculated }\end{array}$ & $\begin{array}{c}\chi^{2} \text { for } \\
\text { logistic } \\
\text { regression }\end{array}$ & $\begin{array}{c}P \text { values } 1 \\
\text { for logistic } \\
\text { regression }\end{array}$ & $\begin{array}{c}\beta \text { values } \\
\text { for linear } \\
\text { regression }\end{array}$ & $\begin{array}{c}r^{2} \text { for } \\
\text { linear } \\
\text { regression }\end{array}$ & $\begin{array}{c}P \text { values }_{2} \\
\text { for linear } \\
\text { regression }\end{array}$ \\
\hline Minimum & 1 & 0.043 & 0.8359 & 0.088 & 0.023 & 0.6175 \\
Maximum & 1 & 0.819 & 0.3655 & -0.098 & 0.113 & 0.2611 \\
Minimum & 5 & 12.566 & 0.0004 & 0.316 & 0.534 & 0.0046 \\
Maximum & 5 & 7.217 & 0.0072 & 0.055 & 0.028 & 0.588 \\
Minimum & 10 & 11.678 & 0.0006 & 0.261 & 0.636 & 0.0011 \\
Maximum & 10 & 7.239 & 0.0071 & 0.078 & 0.041 & 0.5063 \\
Minimum & 15 & 11.182 & 0.0008 & 0.273 & 0.652 & 0.0008 \\
Maximum & 15 & 8.162 & 0.0043 & 0.123 & 0.156 & 0.1819 \\
Minimum & 20 & 11.154 & 0.0008 & 0.283 & 0.631 & 0.0012 \\
Maximum & 20 & 8.604 & 0.0034 & 0.124 & 0.200 & 0.1257 \\
\hline
\end{tabular}




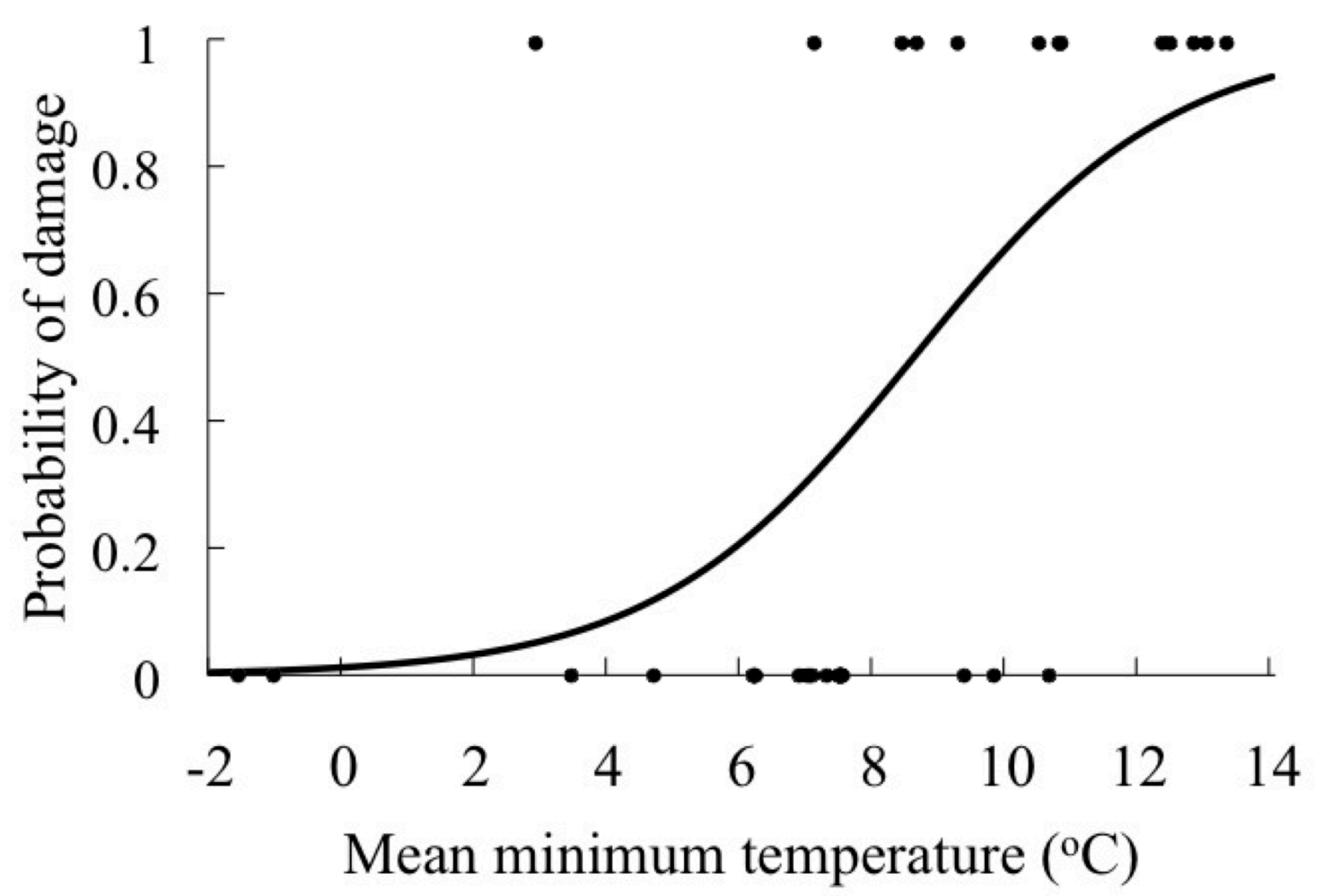

Figure 2.1. The probability of a population being frost-damaged as a function of mean minimum temperature $\left({ }^{\circ} \mathrm{C}\right)$ for the 15 -day period prior to the frost event. Closed-circles indicate data points. 


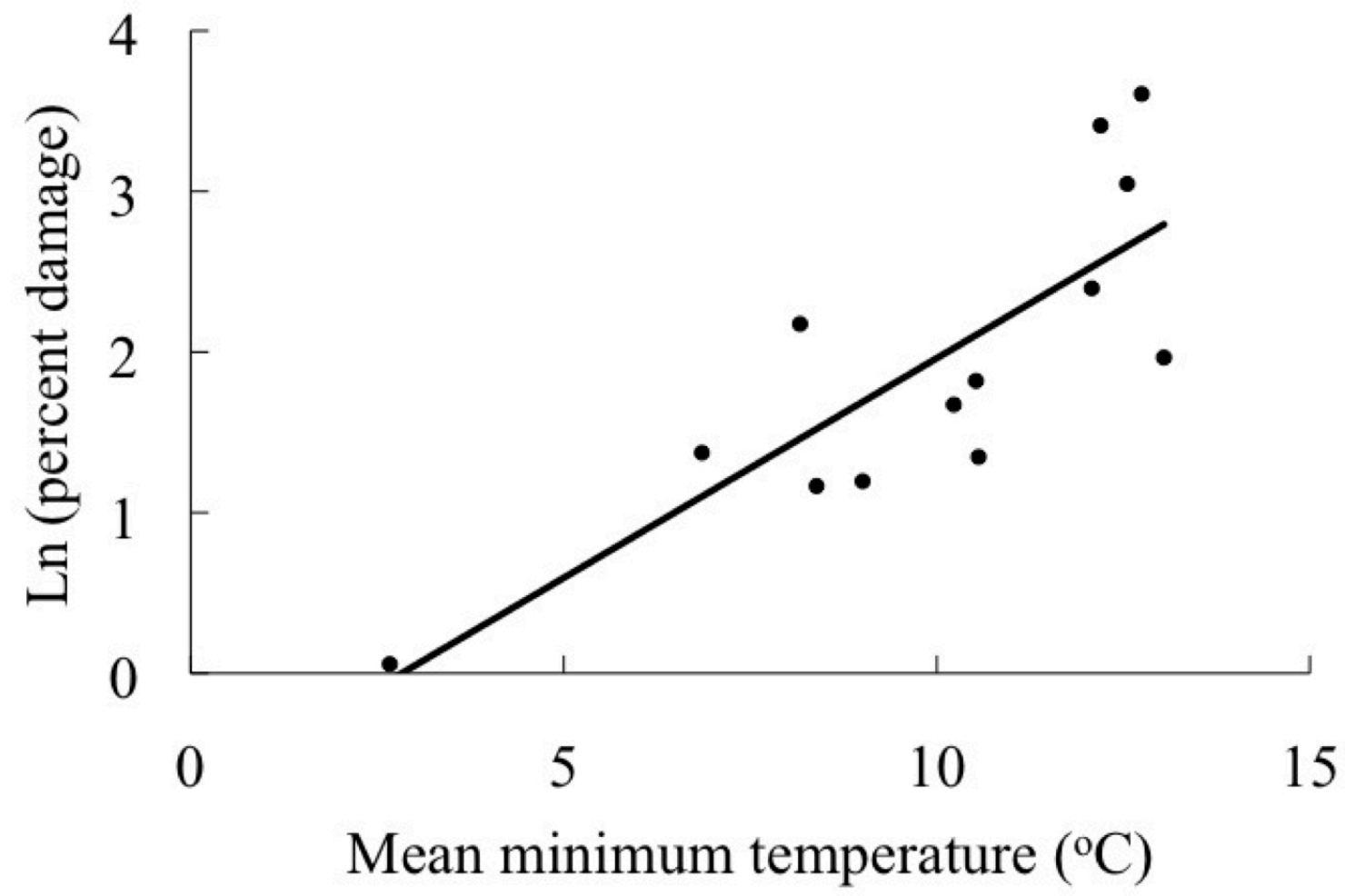

Figure 2.2. Regression of the percentage of the population damaged by the frost on mean minimum temperature $\left({ }^{\circ} \mathrm{C}\right)$ for the 15 -day period prior to the frost event. The fit of the regression was improved by taking the natural log of the percentage of the population damaged by frost. 


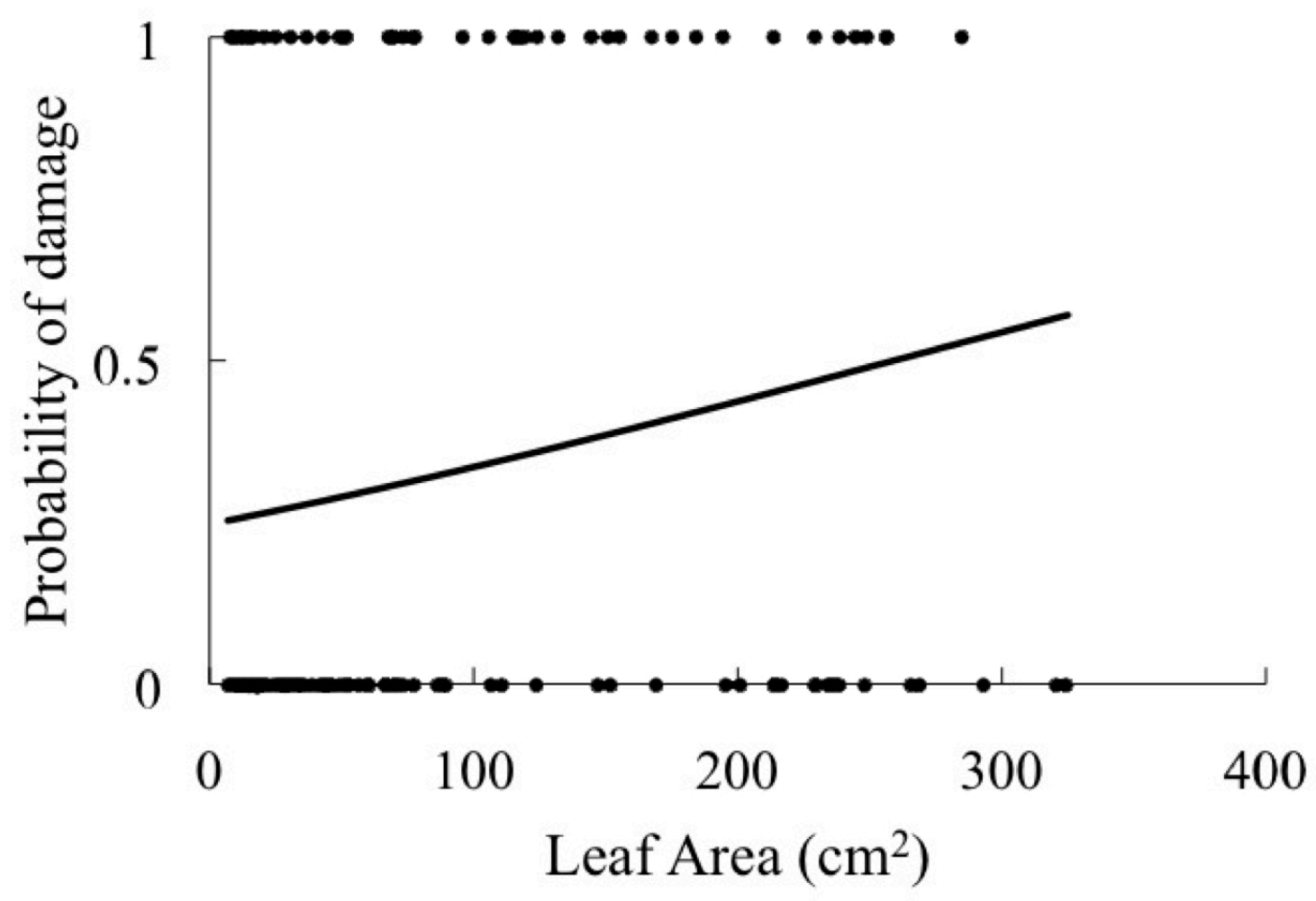

Figure 2.3. The probability that an individual plant will incur frost-damage as a function of leaf area. Closed-circles indicate data points. 


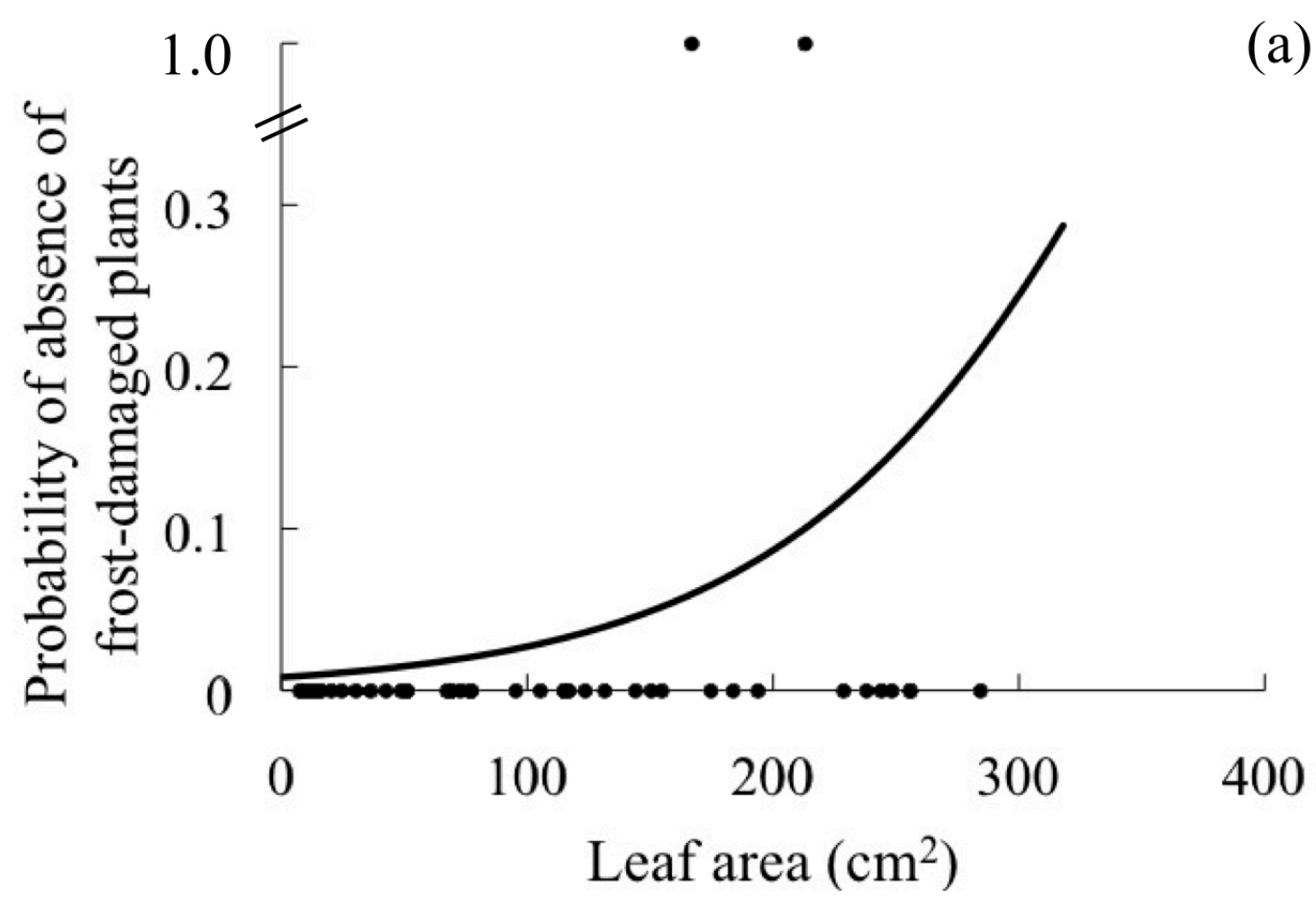

Figure 2.4.a. The probability of a plant being absent as a function of leaf area for frostdamaged plants. Closed-circles indicate data points. 


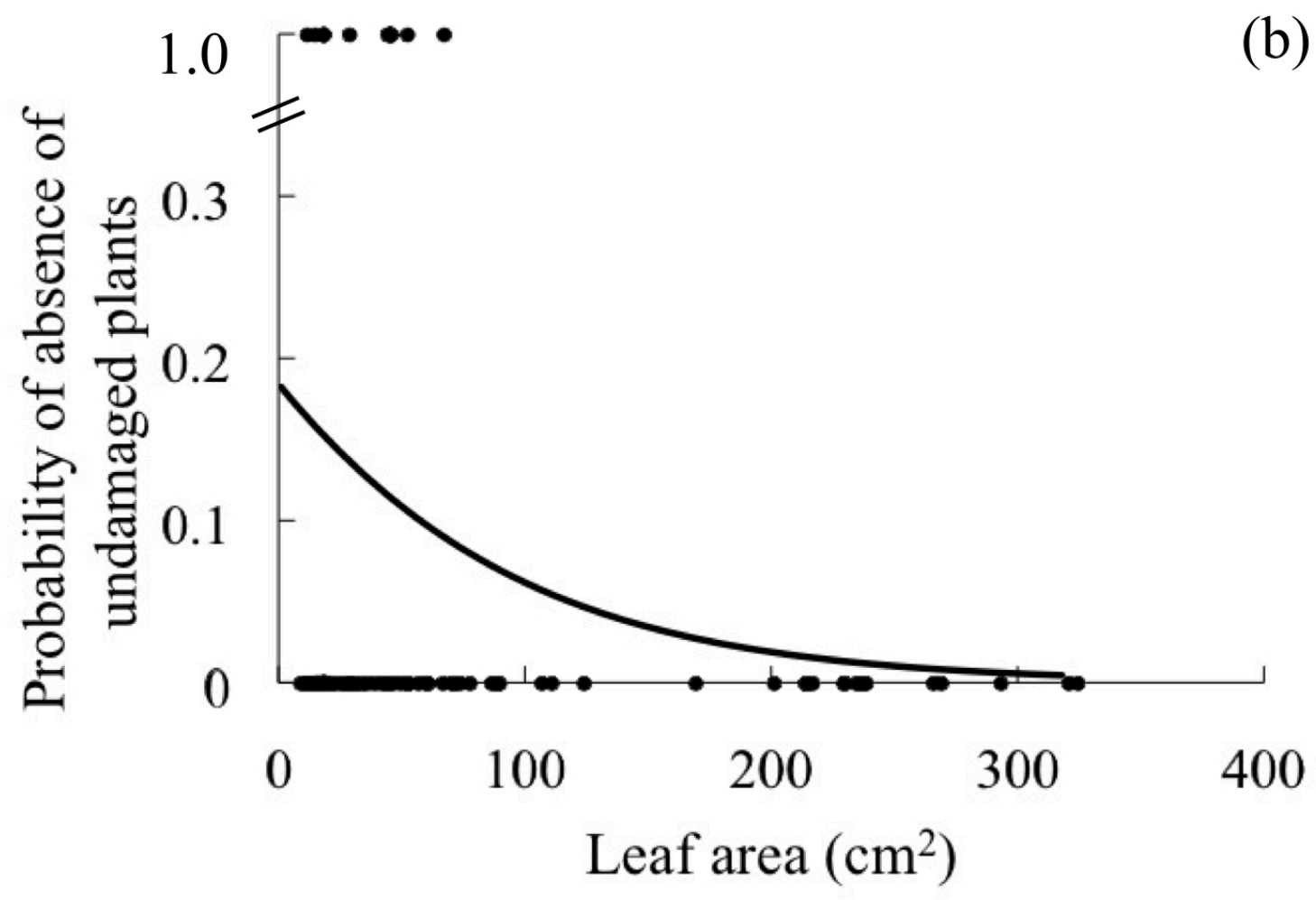

Figure 2.4.b. The probability of a plant being absent as a function of leaf area for undamaged plants. Closed-circles indicate data points. 


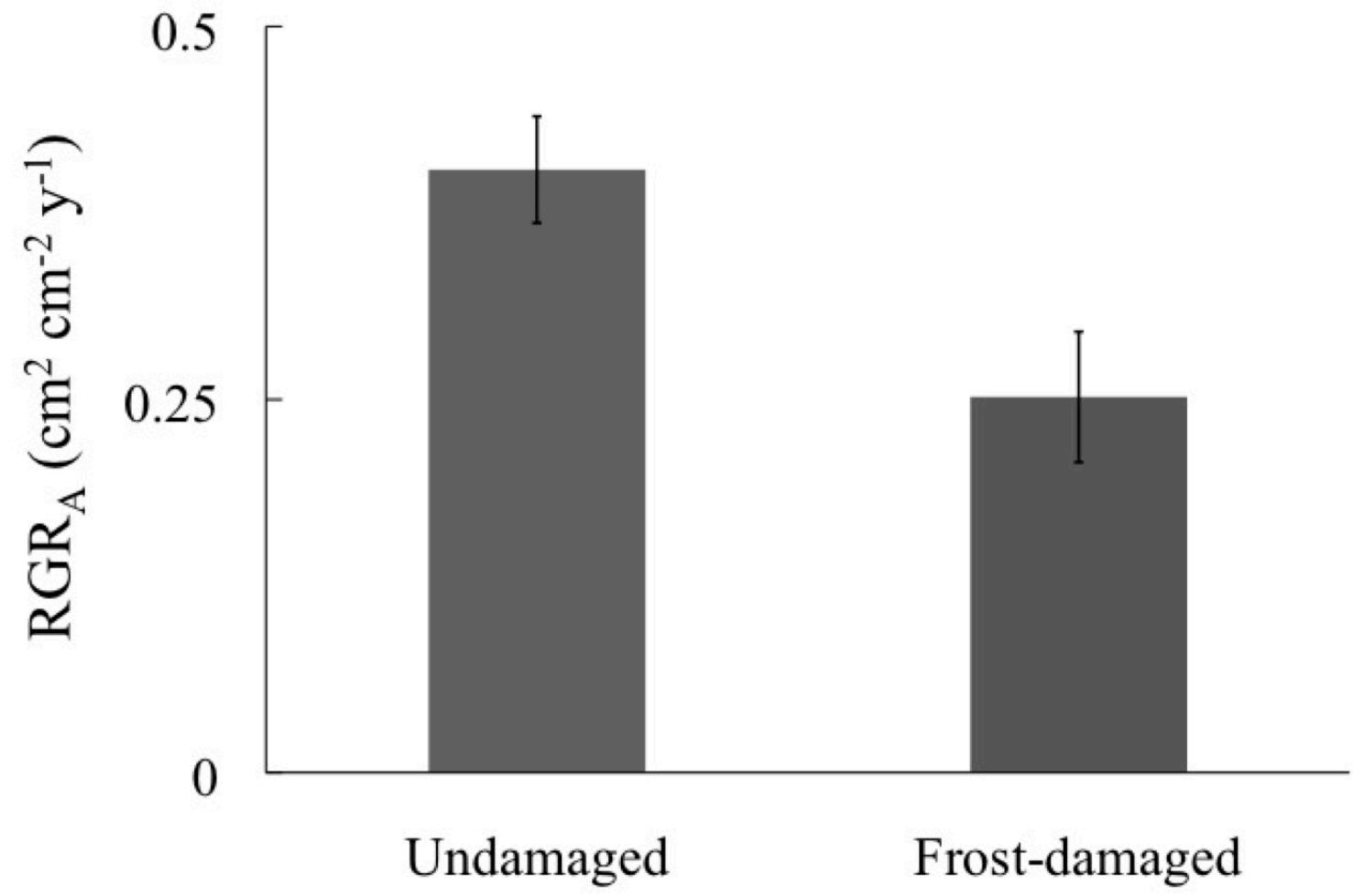

Figure 2.5. Comparison of the relative growth rate of leaf area from 2006 to 2008 for frost-damaged and undamaged plants (+/- 1 standard error). 


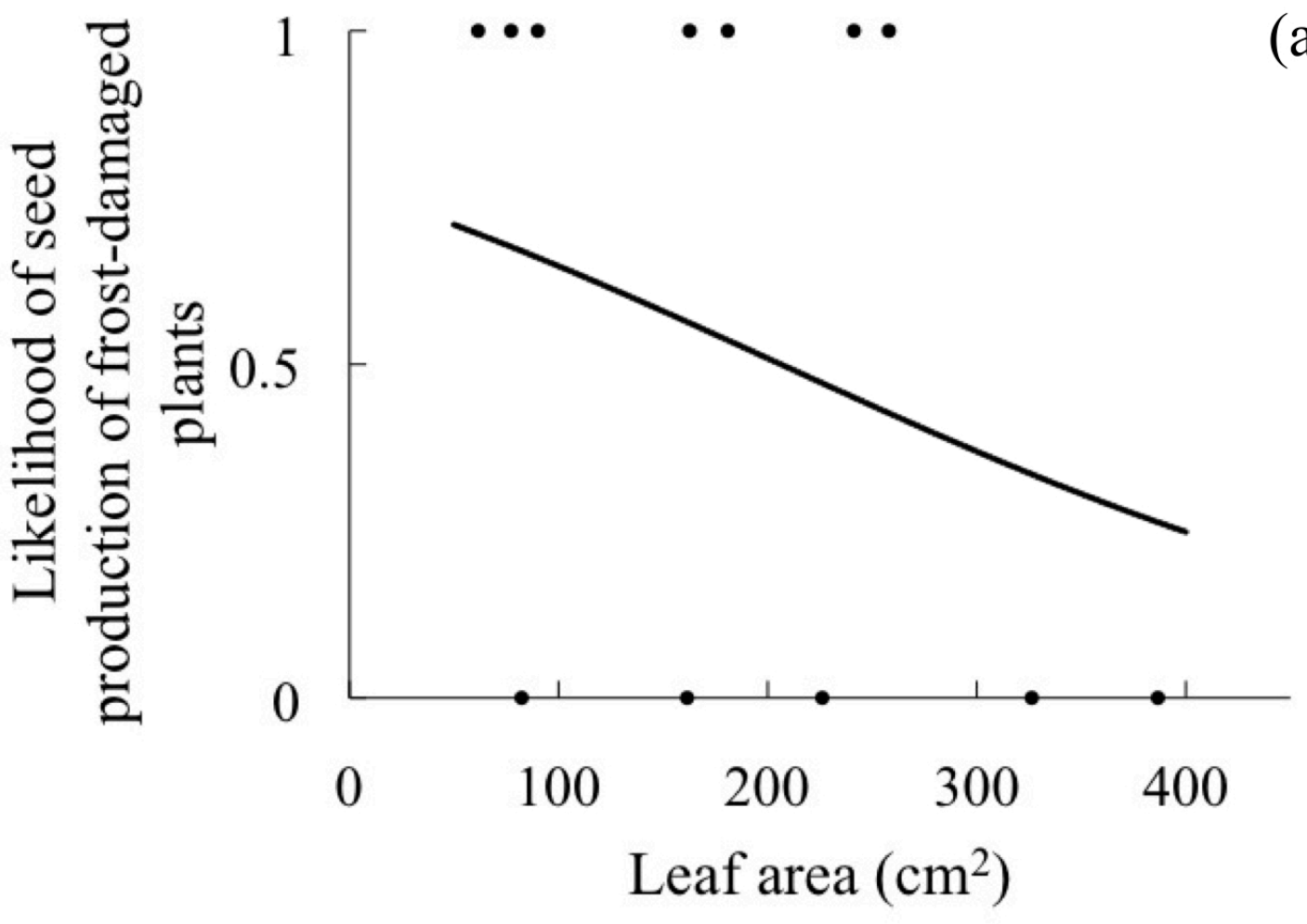

Figure 2.6.a. The probability of a plant producing seeds in 2008 as a function of leaf area for frost-damaged plants. Closed-circles indicate data points. 


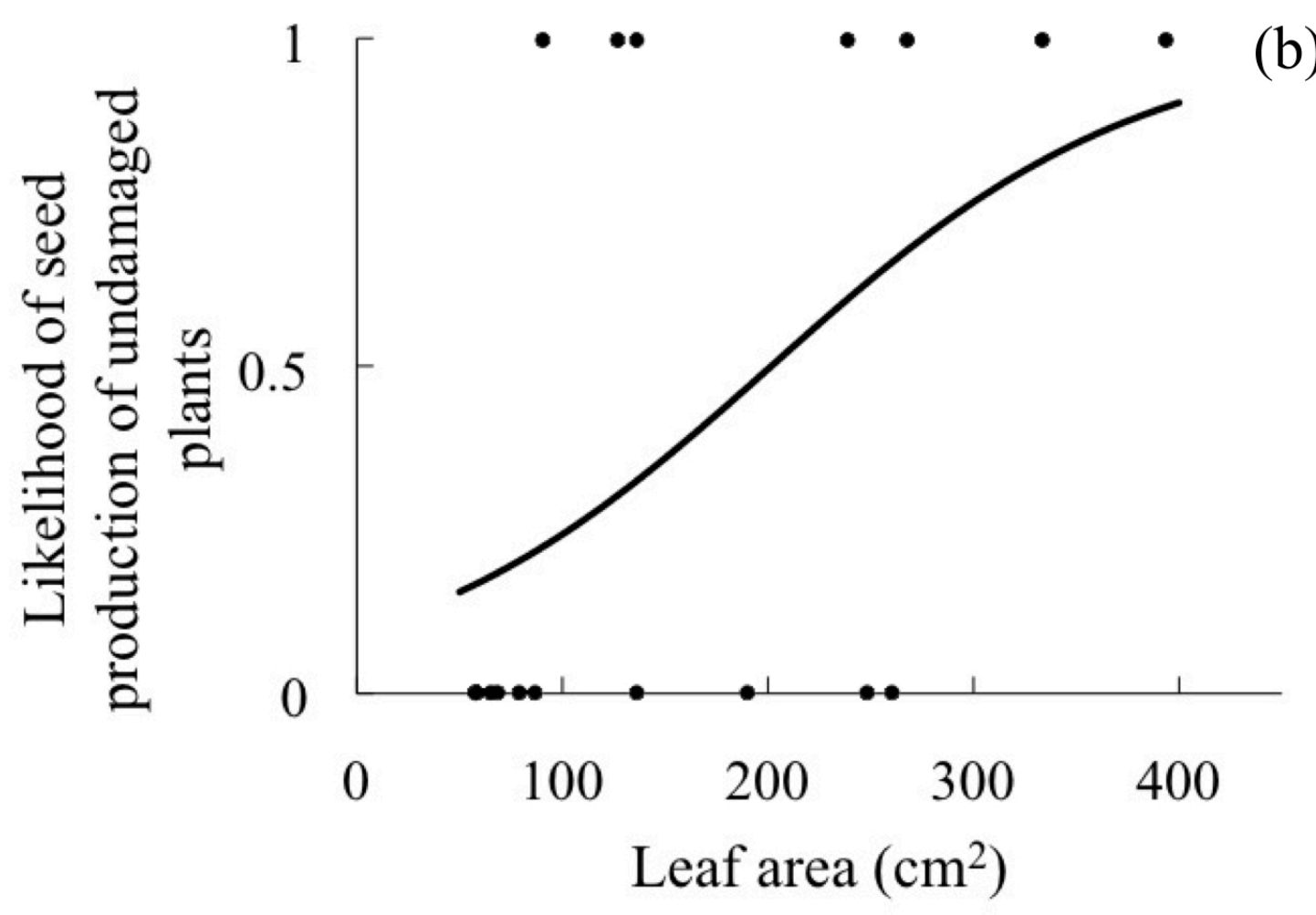

Figure 2.6.b. The probability of a plant producing seeds in 2008 as a function of leaf area for undamaged plants. Closed-circles indicate data points. 


\section{Discussion}

Relatively little is known concerning the role of damaging frosts in the long-term demography of natural populations. Extreme early warming events followed by hard frost, occur seldom and at random, making them hard to study in the absence of longterm censusing projects. In 2007, just such a dramatic temperature fluctuation (Gu et al. 2008) occurred in the concomitant censusing of ginseng populations, providing a rare opportunity to examine among- and within-population patterns of frost damage, and to quantify demographic ramifications of such an infrequent, but important event. We found the likelihood that a population would be damaged by frost, and the percentage of frost-damaged individuals within a population, clearly depended on temperatures prior to the freeze. The most parsimonious explanation is that plant emergence increased as a function of temperature prior to the freeze, thus increasing the likelihood that plants would be exposed when the frost occurred, as well as increasing the number of plants that had emerged at the time of the frost event. Several lines of evidence support this conclusion. In comparison to spring ephemerals, ginseng emerges relatively late in the spring, indicating a frost avoidance, rather than tolerance strategy. Additionally, the ability of temperature preceding the frost to explain differences in frost damage extent was temporally dependent, suggesting an ontogenetic mechanism.

We expected lower minimum temperatures during the frost event to increase the likelihood that a population would be damaged by frost. The fact that the opposite pattern was observed suggests that ginseng was not frost-tolerant at any freezing temperatures, so severity of freezing did not matter. Instead, minimum temperatures 
prior to and during the frost event are likely correlated, and therefore it was those populations with accelerated emergence that experienced the highest amount of damage.

Failure for temperature to explain all of the among-population variation in frost damage extent may be due to genetic differentiation with respect to phenological traits. In tree species, for instance, spring bud burst is highly heritable (reviewed in Howe et al. 2003). Ecotypic variation of bud burst has been observed in many tree species, even when high levels of gene flow oppose local adaptation (Ducousso et al. 1996; Hall et al. 2007; Vitasse et al. 2009a, b). Regional differences in frost-free days explain large amounts of variation among temperature cues that stimulate bud break in these studies (Myking and Heide 1995).

Ginseng populations were censused approximately one month after the frost occurred. Because the most severely damaged plants may have senesced prior to our arrival, it is possible that we are underestimating both the number of plants damaged by the frost, as well as frost effects on demography. In the same vein, the tendency for larger plants to be frost-damaged more frequently than smaller plants may be a result of size-dependent senescence rather than reflecting any real difference in rate of damage. Specifically, smaller plants damaged by frost may have senesced earlier than larger plants due, in part, to differences in carbon stores. An alternative explanation for sizedependent damage is that larger plants emerged earlier than small plants. Rates of emergence and development in perennials have been shown to vary as a function of carbon storage; larger ginseng with greater photosynthate stores may have developed at a faster rate compared to smaller plants (Pillar and Meekings 1997; Bustamante and Búrquez 2008). Whatever the mechanism by which the frost injured larger plants, the 
demographic consequences were enhanced because large adults were negatively impacted.

Indeed, when examining demographic parameters, we found that the frost event had an overall negative impact on ginseng demography. The likelihood of a plant being absent by our second demographic census increased as a function of leaf area in frost damaged plants, representing a complete reversal from the usual positive association of size and survival. Early senescence of frost-damaged plants reduced growing season length, and eliminated their reproductive contribution in 2007. To put ginseng seed production in perspective, reproductive plants from this study population produced an average 1.08 seeds per year during the 8 -year study period. With such low rates of seed production, even seemingly small effects on reproduction may have profound effects on long-term population growth for ginseng. The negative effects of the frost persisted in the subsequent year by both decreasing relative growth rate of frost-damaged ginseng compared to undamaged ginseng, and by decreasing the likelihood of reproduction in frost-damaged plants. For many plant species, there is an apparent trade-off between high reproductive effort and future growth and survival (Galen 1993; Bañuelos and Obeso 2004). The observed reduction in probability of seed production in frost-damaged plants may be an adaptive response to loss of carbon gain resulting from damaged photosynthetic machinery after the frost event, thus ensuring long-term survival and reproductive success of these individuals.

Stochastic events can have dramatic effects on long-term population demography (Menges 1990). These effects are often greater than might be expected based on their low frequency. Indeed, the 2007 spring frost negatively impacted ginseng growth, 
reproduction, and survival. Notably, the effects of the frost on ginseng growth and reproduction were detected even though the physical damage caused by the frost was mild in the population that we examined in detail for this study. In several other populations, frost damage was so severe that the plants were completed denuded by the time we censused them. Because these populations were small, it was not statistically feasible to analyze the effects of the frost on demography. However, for these small populations, such frost events could be one of many such perturbations leading down an extinction vortex (Morris and Doak 2002).

Frosts are clearly a strong selective force in natural populations, levying severe demographic penalties against 'early riser' genotypes of susceptible species. Evidence from provenance and transplant studies suggests that spring emergence within species is aligned with regional frost patterns (Beuker 1994; Myking and Heide 1995; Ducousso et al. 1996; Myking 1999; Savolainen et al. 2004; Ghelardini et al. 2006; Hall et al. 2007). If the climate is altered, such that the historical environmental cues that signal plant emergence no longer coincide with low frost probability, then plant survival, growth, and reproduction may be jeopardized. Outside of arctic, alpine, and boreal ecosystems, however, there is a paucity of ecological research that considers the demographic effects of frost on long-term population growth, nor the potential for climate change to modify frost frequency. Models from forestry and agricultural arenas suggest that climate change may interact with plant phenology, increasing the frequency of damaging frost events in the future (Hänninen 1991, 1996, 2006; Kellomäki et al. 1995; Kramer et al. 1996; Linkosalo et al. 2000; Jönsson et al. 2004). This study provides empirical evidence for the kind of effects that would be expected with increasing frequency if such models 
are correct. Observed patterns of frost damage among populations illustrate how even small increases in temperature greatly increased the probability of being affected by the frost. This study further suggests that species like ginseng, which appear to have low frost tolerance, yet whose emergence is highly sensitive to changes in temperature (Farnsworth et al. 1995), are susceptible to frost damage, with serious negative consequences for population growth. 


\section{Acknowledgments.}

We thank J. Boyzcuk, Z. Bradford, M. Guido, A. Hanna, M. Kaproth, A. Kenyon, C.

Maloy, E. Mooney, and K. Wixted for their work collecting demographic data.

Additionally, we would like to thank the landowners and land-managers that generously

grant access to the ginseng populations that we census. Finally, we are grateful to Editor-

in-Chief, Takashi Saitoh, and two anonymous reviewers for their helpful comments. This

research was funded by NSF LTREB grant DEB-0613611. 


\section{References}

Aitken SN, Adams WT (1997) Spring cold hardiness under strong genetic control in Oregon populations of Pseudotsuga menziesii var. menziesii. Can J of For Res 27:1773-1780

Anderson RC, Fralish JS, Armstrong JE, Benjamin PK (1993) The Ecology and biology of Panax quinquefolium L (Araliaceae) in Illinois. Am Midl Nat 129:357-372

Badeck FW, Bondeau A, Bottcher K, Doktor D, Lucht W, Schaber J, Sitch S (2004) Responses of spring phenology to climate change. New Phytol 162:295-309

Bannister P, Maegli T, Dickinson K, Halloy S, Knight A, Lord J, Mark A, Spencer K (2005) Will loss of snow cover during climatic warming expose New Zealand alpine plants to increased frost damage? Oecologia 144:245-256 DOI 10.1007/s00442-005-0087-3

Bañuelos M-J, Obeso J-R (2004) Resource allocation in the dioecious shrub Rhamnus alpinus: the hidden cost of reproduction. Evol Ecol Res 6:397-413

Bélanger G, Rochette P, Castonguay Y, Bootsma A, Mongrain D, Ryan DAJ (2002) Climate change and winter survival of perennial forage crops in eastern Canada. Agronomy $\mathbf{J}$ $94: 1120-1130$

Beuker E (1994) Adaptation to climatic changes of the timing of bud burst in populations of Pinus sylvestris L and Picea abies (L) Karst. Tree Phys 14:961-970 DOI $10.1093 /$ treephys/23.8.517

Bradley NL, Leopold AC, Ross J, Huffaker W (1999) Phenological changes reflect climate change in Wisconsin. Proc Natl Acad Sci USA 96:9701-9704

Bustamante E, Búrquez A (2008) Effects of plant size and weather on the flowering phenology of the organ pipe cactus (Stenocereus thurberi). Ann Bot 102:1019-1030 DOI $10.1093 / \mathrm{aob} / \mathrm{mcn} 194$ 
Cannell MGR, Smith RI (1984) Spring frost damage on young Picea sitchensis 2. Predicted dates of budburst and probability of frost damage. Forestry 57:177-197

Cannell MGR, Smith RI (1986) Climatic warming, spring budburst and frost damage on trees. J Appl Ecol 23:177-191

Charron D, Gagnon D (1991) The demography of northern populations of Panax quinquefolium (American ginseng). J Ecol 79:431-445

Ducousso A, Petit D, Valero M, Vernet P (1990) Genetic-variation between and within populations of a perennial grass Arrhenatherum elatius. Heredity 65:179-188 DOI 10.1038/hdy.1990.86

Ducousso A, Guyon JP, Kremer A (1996) Latitudinal and altitudinal variation of bud burst in western populations of sessile oak (Quercus petraea (Matt) Liebl). Ann Des Sci For 53:775-782 DOI 10.1051/forest:19960253

Easterling DR, Horton B, Jones PD, Peterson TC, Karl TR, Parker DE, Salinger JM, Razuvayev V, Plummer N, Jamason P, Folland CK (1997) Maximum and minimum temperature trends for the globe. Science 277:364-367 DOI 10.1002/joc.1733

Eccel E, Roberto R, Caffarra A, and Crisci A (2009) Risk of spring frost to apple production under future climate scenarios: the role phenological acclimation. Int J Biometeorology 53:1432-1254 DOI 10.1007/s00484-009-0213-8

Farnsworth EJ, Nunez-Farfan J, Careaga SA, Bazzaz FA (1995) Phenology and growth of three temperate forest life forms in response to artificial soil warming. J Ecol 83:967-977

Galen C (1993) Cost of reproduction in Polemonium viscosum: Phenotypic and genetic approaches. Evolution 47:1073-1079 
Ghelardini L, Falusi M, Santini A (2006) Variation in timing of bud-burst of Ulmus minor clones from different geographical origins. Can J of For Res 36:1982-1991 DOI 10.1139/X06092

Green DS (2007) Controls of growth phenology vary in seedlings of three, co-occurring ecologically distinct northern conifers. Tree Phys 27:1197-1205 DOI 10.1093/treephys/27.8.1197

Gu L, Hanson PJ, Mac Post W, Kaiser DP, Yang B, Nemani R, Pallardy SG, Meyers T (2008) The 2007 eastern US spring freezes: Increased cold damage in a warming world? Bioscience 58:253-262 DOI 10.1111/j.1365-2486.2009.01864.x

Hall MC, Willis JH (2006) Divergent selection on flowering time contributes to local adaptation in Mimulus guttatus populations. Evolution 60:2466-2477 DOI 10.1554/05-688.1

Hall D, Luquez V, Garcia VM, St Onge KR, Jansson S, Ingvarsson PK (2007) Adaptive population differentiation in phenology across a latitudinal gradient in European Aspen (Populus tremula, L.): A comparison of neutral markers, candidate genes and phenotypic traits. Evolution 61:2849-2860 DOI 10.1111/j.1558-5646.2007.00230.x

Hänninen H (1991) Does climatic warming increase the risk of frost damage in northern trees. Plant Cell Environ 14:449-454 DOI 10.1093/treephys/20.17.1175

Hänninen H (1996) Effects of climatic warming on northern trees: Testing the frost damage hypothesis with meteorological data from provenance transfer experiments. Scand J For Res 11:17-25 DOI 10.1080/02827589609382908

Hänninen H (2006) Climate warming and the risk of frost damage to boreal forest trees: identification of critical ecophysiological traits. Tree Phys 26:889-898 DOI 10.1093/treephys/27.2.291 
HOBO temperature/light pendant datalogger 64, Onset Computer Cooperation, Pocasset, MA

Howe GT, Aitken SN, Neale DB, Jermstad D, Wheeler NC, Chen THH (2003) From genotype to phenotype: unraveling the complexities of cold adaptation in forest trees. Can J Bot 81:1247-1266 DOI: 10.1139/b03-141

Inouye DW (2000) The ecological and evolutionary significance of frost in the context of climate change. Ecol Lett 3:457-463 DOI 10.1046/j.1461-0248.2000.00165.x

Inouye DW (2008) Effects of climate change on phenology, frost damage, and floral abundance of montane wildflowers. Ecology 89:353-362 DOI 10.1890/06-2128.1

Inouye DW, Morales MA, Dodge GJ (2002) Variation in timing and abundance of flowering by Delphinium barbeyi Huth (Ranunculaceae): the roles of snowpack, frost, and La Nina, in the context of climate change. Oecologia 130:543-550 DOI 10.1007/s00442-001-0835-y Intergovernmental Panel on Climate Change (2007) Contribution of working group I to the fourth assessment report of the Intergovernmental Panel on Climate Change: the physical science basis of climate change. Solomon S, Quin D, Manning M, Chen Z, Marquis M, Averyt, KB, Tignor M, Miller HL (eds.) Cambridge, United Kingdom and New York, NY, USA

Jentsch A, Kreyling J, Boettcher-Treschkow J, Beierkuhnlein C (2009) Beyond gradual warming: extreme weather events alter flower phenology of European grassland and heath species. Global Change Biol 15:837-849 DOI 10.1111/j.1365-2486.2008.01690.x

Jönsson AM, Linderson ML, Stjernquist I, Schlyter P, Barring L (2004) Climate change and the effect of temperature backlashes causing frost damage in Picea abies. Global Planet Change 44:195-207 DOI 10.1016/j.gloplacha.2004.06.012 
Kalisz S (1986) Variable selection on the timing of germination in Collinsia verna

(Scrophulariacea) Evolution 40:479-491

Kellomäki S, Hänninen H, Kolstrom M (1995) Computations on frost damage to Scots Pine under climatic warming in boreal conditions. Ecol Appl 5:42-52 DOI 10.2307/1942050

Kramer K (1994) A modeling analysis of the effects of climatic warming on the probability of spring frost damage to tree species in the Netherlands and Germany. Plant Cell Environ 17:367-377 DOI 10.1111/j.1365-3040.1994.tb00305.x

Kramer K, Friend A, Leinonen I (1996) Modelling comparison to evaluate the importance of phenology and spring frost damage for the effects of climate change on growth of mixed temperate-zone deciduous forests. Climate Res 7:31-41 DOI 10.1007/s004840000066

Kudo G, Hirao AS (2006) Habitat-specific responses in the flowering phenology and seed set of alpine plants to climate variation: implications for global-change impacts. Popul Ecol 48:49-58 DOI 10.1007/s10144-005-0242-z

Leinonen I (1996) Dependence of dormancy release on temperature in different origins of Pinus sylvestris and Betula pendula seedlings. Scand J For Res 11:122-128 DOI $10.1080 / 02827589609382919$

Leinonen I, Hänninen H (2002) Adaptation of the timing of bud burst of Norway spruce to temperate and boreal climates. Silva Fenn 36:695-701

Lewis WH, Zenger VE (1983) Breeding systems and fecundity in the American ginseng Panax quinquefolium (Araliaceae). Amer J Bot 70:466-468

Li P, Beaulieu J, Bousquet J (1997) Genetic structure and patterns of genetic variation among populations in eastern white spruce (Picea glauca). Can J For Res 27:189-198 
Linkosalo T, Carter TR, Häkkinen R, Hari P (2000) Predicting spring phenology and frost damage risk of Betula spp. under climatic warming: a comparison of two models. Tree Phys 20:1175-1182 DOI 10.1093/treephys/20.17.1175

McGraw JB, Furedi MA (2005) Deer browsing and population viability of a forest understory plant. Science 307:920-922 DOI 10.1126/science.1107036

McGraw JB, Garbutt K (1990) Demographic growth analysis. Ecology 71:1199-1204

McGraw JB, Sanders SM, Van der Voort M (2003) Distribution and abundance of Hydrastis canadensis L. (Ranunculaceae) and Panax quinquefolius L. (Araliaceae) in the central Appalachian region. J Torrey Bot Soc 130:62-69

Menges E (1990) Population viability analysis for an endangered plant. Conserv Biol 4:52-62 Miller TE (1987) Effects of emergence time on survival and growth in an early old-field plant community Oecologia 72:272-278 DOI 10.1007/BF00379278

Miller TE, Winn AA, Schemske DW (1994) The effects of density and spatial distribution on selection for emergence time in Prunella vulgaris (Lamiaceae) Am J Bot 81:1-6

Miller-Rushing AJ, Primack RB (2008) Global warming and flowering times in Thoreau's concord: A community perspective. Ecology 89:332-341 DOI 10.1073/pnas.0806446105

Mooney E, McGraw JB (2009) Relationship between age, size, and reproduction in populations of American ginseng, Panax quinquefolius (Araliaceae), across a range of harvest pressures. Ecoscience 16:84-94 DOI 10.2980/16-1-3168

Morris WF, Doak DF (2002) Quantitative conservation biology: Theory and practice of population viability analysis. $2^{\text {nd }}$ ed. Sinauer Associates Inc., Sunderland, MA 
Murray MB, Smith RI, Leith ID, Fowler D, Lee HSJ, Friend AD, Jarvis PG (1994) Effects of elevated CO2, nutrition and climatic warming on bud phenology in Sitka spruce (Picea sitchensis) and their impact on the risk of frost damage. Tree Phys 14:691-706

Myking T (1999) Winter dormancy release and budburst in Betula pendula Roth and $B$. pubescens Ehrh. ecotypes. Phyton-Ann Rei Bot A 39:139-145

Myking T, Heide OM (1995) Dormancy release and chilling requirement of buds of latitudinal ecotypes of Betula pendula and B. pubescens. Tree Phys 15:697-704 DOI 10.1093/treephys/15.11.697

Ögren E (1997) Relationship between temperature, respiratory loss of sugar and premature dehardening in dormant Scots pine seedlings. Tree Phys 17:47-51 DOI 10.1093/treephys/17.1.47

Ögren E (2001) Effects of climatic warming on cold hardiness of some northern woody plants assessed from simulation experiments. Physiol Plantarum 112:71-77 DOI 10.1034/j.1399-3054.2001.1120110.x

Parmesan C (2007) Influences of species, latitudes and methodologies on estimates of phenological response to global warming. Global Change Biol 13:1860-1872 DOI $10.1111 / \mathrm{j} .1365-2486.2007 .01404 . x$

Parmesan C, Yohe G (2003) A globally coherent fingerprint of climate change impacts across natural systems. Nature 421:37-42

Pearce RS (2001) Plant freezing and damage. Ann Bot 87:417-424

Pepin NC (1997) Scenarios of future climate change: Effects on frost occurrence and severity in the maritime uplands of northern England. Geografis Ann Series A 79A:121-137 
Pillar GJ, Meekings JS (1997) The acquisition and utilization of carbon in early spring by kiwifruit shoots. Ann Bot 79:573-581

Rathcke B, Lacey EP (1985) Phenological patterns of terrestrial plants. Ann Rev Ecol Syst 16:179-214 DOI 10.1146/annurev.es.16.110185.001143

Rigby JR, Porporato A (2008) Spring frost risk in a changing climate. Geophy Res Lett 35. Article Number L12703 DOI 10.1029/2008GL033955

Robbins CS (2000) Comparative analysis of management regimes and medicinal plant trade monitoring mechanisms for American ginseng and goldenseal. Conserv Biol 14:14221434

Ross MA, Harper JL (1972) Occupation of biology space during seedling establishment. J Ecol $60: 77-88$

Savolainen O, Bokma F, Garcia-Gil R, Komulainen P, Repo T (2004) Genetic variation in cessation of growth and frost hardiness and consequences for adaptation of Pinus sylvestris to climatic changes. Forest Ecol Manage 197:79-89 DOI 10.1016/j.foreco.2004.05.006

Scheifinger H, Menzel A, Koch E, Peter C (2003) Trends of spring time frost events and phenological dates in Central Europe. Theor Appl Climatol 74:41-51 DOI $10.1007 / \mathrm{s} 00704-002-0704-6$

Schlessman MA (1985) Floral biology of American ginseng (Panax quinquefolium). Bull of the Torry Bot Club 112:129-133

Schooley J, Proctor JTA (2003) Freeze damage to North American ginseng. Horttechnology 13:697-701 
Schwartz MD, Ahas R, Aasa A (2006) Onset of spring starting earlier across the Northern Hemisphere. Global Change Biol 12:343-351 DOI 10.1111/j.1365-2486.2005.01097.x

Søgaard G, Johnsen Ø, Nilsen J, Junttila O (2008) Climatic control of bud burst in young seedlings of nine provenances of Norway spruce. Tree Phys 28:311-320 DOI 10.1093/treephys/28.2.311

Stratton DA (1992) Life-cycle components of selection in Erigeron annuus: I. Phenotypic selection. Evolution 46:92-106

Van der Toorn J, Pons, TL (1988) Establishment of Plantago lanceolata L. and Plantago major L. among Grass. II. Shade tolerance of seedlings and selection on time of germination. Oecologia 76:341-347

Van der Voort ME, Bailey B, Samuel DE, McGraw JB (2003) Recovery of populations of goldenseal (Hydrastis canadensis L.) and American ginseng (Panax quinquefolius 1.) following harvest. Am Mid Nat 149:282-292

Verdú M, Traveset A (2005) Early emergence enhances plant fitness: A phylogenetically controlled meta-analysis. Ecology 86:1385-1394 DOI 10.1890/04-1647

Vitasse Y, Delzon S, Bresson CC, Michalet R, Kremer A (2009a) Altitudinal differentiation in growth and phenology among populations of temperate-zone tree species growing in a common garden. Can J For Res 39:1259-1269 DOI 10.1139/X09-054

Vitasse Y, Delzon S, Dufrêne E, Pontailler JY, Louvet JM, Kremer A, Michalet R (2009b) Leaf phenology sensitivity to temperature in European trees: Do within-species populations exhibit similar responses? Agric For Meteorol 149:735-744 DOI 10.1016/j.agrformet.2008.10.019 


\section{CHAPTER III:}

EVIDENCE OF LOCAL ADAPTATION IN THE DEMOGRAPHIC RESPONSE OF AMERICAN GINSENG TO INTER-ANNUAL TEMPERATURE VARIATION 


\begin{abstract}
Bioclimatic envelope models are used to predict species' response to climate change. These models are frequently based on the assumption that the northern and southern boundaries of a species' range define its thermal niche. However, this assumption may be violated if populations are adapted to local temperature regimes and have evolved population-specific thermal optima. Considering the prevalence of local adaptation, the assumption of a species-wide thermal optimum may be violated for many species. We used spatially and temporally extensive demographic data for American ginseng (Panax quinquefolius L.) to examine range-wide variation in response of population growth rate $(\lambda)$ to climatic factors. Our results suggest adaptation to local temperature, but not precipitation. For each population, $\lambda$ was maximized when annual temperatures were similar to site-specific, long-term mean temperatures. Populations from disparate climatic zones responded differently to temperature variation, and there was a linear relationship between population-level thermal optima and the 30-year mean temperature at each site. For species that are locally adapted to temperature, bioclimatic envelope models may underestimate the extent to which increasing temperatures will decrease population growth rate. Because any directional change from long-term mean temperatures will decrease population growth rates, all populations throughout a species' range will be adversely affected by temperature increase, not just populations at southern and low-elevation boundaries. Additionally, when a species' local thermal niche is narrower than its range-wide thermal niche, a smaller temperature increase than would be predicted by bioclimatic envelope approaches may be sufficient to decrease population growth.
\end{abstract}




\section{Introduction}

The net effect of climate change on a given species will be a function of its demographic, evolutionary, and spatial responses (Walther et al. 2002; Parmesan 2006; Aitken et al. 2008). Despite the known importance of population-level demographic and evolutionary processes in determining long-term species persistence (Lande 1988, 1998), a popular paradigm of species' response to climate change is rooted in bioclimatic envelope models (Jeltsch et al. 2008), which do not incorporate mechanistic, populationlevel information. Instead, these models use the relation between a species' distribution and climatic factors to define a realized climatic niche and thus are based on the assumption that there is a range-wide relation between fitness and climate. Unless temperatures increase beyond the breadth of the thermal range defined by the current species' distribution, fitness theoretically increases in high-elevation and high-latitude populations within the range as temperatures in these regions shift closer to the specieswide thermal optimum. However, the assumption of a species-wide thermal optimum may be incorrect if past selection has led populations to adapt to current local climate (Davis \& Shaw 2001). If this is the case, the population-level thermal niche may be considerably narrower than the thermal niche as defined by the species' range. Fitness may be optimized to local climate, precluding, in the absence of gene flow, an increase in fitness of northern or high-elevation populations in response to climate change (Holt \& Gaines 1992; Holt 2003, 2009).

Local adaptation refers to the genetic differentiation of populations within a species' range, such that, where a population occurs, local genotypes have greater fitness than other genotypes (Clausen et al. 1947; Kawecki \& Ebert 2004; Hereford 2009). 
Populations may be adapted to diverse environmental factors, including heavy metals, availability of nutrients and light, interactions with other species (Linhart \& Grant 1996), and climate (Turesson 1930; Linhart \& Grant 1996; Etterson 2004). Within a heterogeneous environment, adaptive genetic differentiation of populations occurs when gene flow and genetic drift are too weak to counteract selection and when the effect of alleles on fitness depends on environment, such that no single genotype has the greatest fitness in all environments (Primack \& Kang 1989; Kawecki \& Ebert 2004).

Specialization of populations is adaptive in a stable environment, but may incur a fitness cost in a dynamic environment (Davis \& Shaw 2001). For populations adapted to local climate, rapid increases in air temperature may exceed the limits of a narrow specialized niche, precipitating population decline. Local adaptation has been demonstrated hundreds of times for many species (Taylor 1991; Linhart \& Grant 1996; Kaltz \& Shykoff 1998).

We examined whether American ginseng (Panax quinquefolius) is adapted to local climate by investigating range-wide trends in demographic response to annual climatic variation. We evaluated whether demographic responses to climatic variables suggest a single, range-wide climatic optimum or, as would be expected if populations were adapted to local climate, population-specific, local optima. We also tested whether there was a direct, linear relation between populations' climatic optima and the long-term (30-year) mean climate at each site. 


\section{Methods}

\section{Study species}

American ginseng is a medicinal plant that is harvested in the wild and cultivated with a range of techniques that vary in intensity (Robbins 2000). In the United States, regulation of ginseng harvest from the wild was placed under management of the U.S. Fish and Wildlife Service when ginseng was added to Appendix II of the Convention on International Trade in Endangered Species of Wild Fauna and Flora (CITES) list in 1975. Ginseng is a widespread, herbaceous perennial found in the understory of deciduous forests of the eastern United States and southern Canada (McGraw et al. 2003). Ginseng has hermaphroditic flowers and can reproduce by outcrossing or self-pollination. Pollinators of ginseng include syrphid flies and halictid bees, both generalist pollinators (Lewis \& Zenger 1983). Ginseng plants can live for over 50 years (Mooney \& McGraw 2009). High levels of genetic differentiation have been detected among ginseng populations (Cruse-Sanders \& Hamrick 2004; Grubbs \& Case 2004).

\section{Census}

Over 6 years (1998-2004), we located 12 natural ginseng populations in 6 states (Indiana, Kentucky, New York, Pennsylvania, Virginia, West Virginia). The size of the areas occupied by populations varied from approximately $0.2-4.0$ ha. The closest 2 populations were $0.85 \mathrm{~km}$ apart, a distance sufficient to genetically isolate them (Hackney 1999). Although populations were not randomly selected for census, we considered them representative of the range of aspects, elevations, and land-use types occupied by the species. We withheld exact population locations to prevent harvest of 
the populations. Each population was censused twice per year for $6-12$ years, depending on when censusing was initiated.

All plants within a population were cryptically and uniquely marked with a numbered aluminum tag. To relocate plants, we used a "photo-trail" method in which photographs paired with written directions guided researchers to plants. This method of relocating plants reduced the likelihood of drawing plants to the attention of harvesters and minimized trampling. The first census in each year occurred after the aerial parts of the plants (leaves, sympodia) stopped growing for the season (mid-May to mid-June). At that time, we measured sympodium height and length and width of the longest leaflet per leaf. We used a previously derived multiple-regression equation (Souther \& McGraw 2011) to estimate leaf area from these field measurements of leaflet length and width. During the first yearly census, we searched for new seedlings in a 2-m radius around each plant. This search radius was based on a previous experiment that tracked the movement of approximately 16,000 seeds and showed that $90 \%$ of seeds germinated $<2 \mathrm{~m}$ from where they were deposited (Van der Voort 2006). At the end of the growing season (early to mid-August), we conducted a second census, during which we measured seed production and assessed the status (e.g., senesced, diseased, browsed) of each plant. Ginseng berries have a distinct morphology depending on the number of seeds (between 1 and 3) they contain, which allowed us to directly count seeds.

We conducted a seed-cage experiment for each population to determine seed-bank dynamics and germination rates. In August 2006, we obtained approximately 7200 seeds from a wild-simulated ginseng grower in West Virginia. Wild-simulated refers to a method of ginseng cultivation in which plants are derived from wild stock and grown in 
wooded areas to simulate natural conditions. During the winter, seeds were overwintered in large, sand-filled mesh bags under leaf litter at a forested site that had a natural ginseng population. The following spring we deployed 12 seed cages, one at each site. Cages were formed from $8.5 \mathrm{~cm}$ diameter $\mathrm{x} 8 \mathrm{~cm}$ long segments of polyvinylchloride tubing with plastic screen mesh affixed to the base. We placed 50 stratified seeds into each of 12 seed cages containing soil collected from the site. We topped seed cages with coarse plastic-mesh cloth to allow precipitation but not herbivores to enter the cage. The seed cages were set into the soil in 3 groups of 4 , evenly distributed across each site with an average distance between groups of $15 \mathrm{~m}$. Within the 3 groups, seed cages were placed $25 \mathrm{~cm}$ apart. Each year for 4 years, we counted germinants and tested the viability of the seeds from 3 randomly selected cages ( 1 cage per group) with tetrazolium staining $(\mathrm{n}=3)$ (Roistacher et al. 1953). We used these data to calculate the probability of survival and germination for seeds in each age cohort. For populations in which a prior seed cage experiment had been carried out (McGraw \& Furedi 2005), agerelated seed survival within the seed bank and germination, assessed using the same methods described above, were averaged across the 2 experiments. Although use of the common seed source and resulting seed-cage data to parameterize seed-bank transition probabilities eliminated the influence of local genetic variation in germination rates, we believed it was important to incorporate the age structure of the seed bank and thus capture natural lags in germination caused by site-to-site variation in the soil.

\section{Population projections}


Data from the censuses and seed-cage experiments were used to parameterize population projection matrices with 8 stages (Fig. 1). Within a projection matrix, transition elements $\left(a_{i j}\right)$ represent the number of individuals of size $\mathrm{i}($ at time $\mathrm{t}+1)$ per individual size $\mathrm{j}$ (at time t) (Caswell 2001). The number of individuals in each stage consisted of the individuals present during the first census of each year. Stages 1-4 consisted of seeds within the seed bank that were, respectively, $9,21,33$, and 45 months old. We calculated the age of these seed cohorts as number of months between seed maturation and the census. Probability of seeds surviving and transitioning to the following age from year $t$ to year $t+1$ (transitions $a_{21}, a_{32}, a_{43}$ ) was estimated directly from postgermination viability tests of seeds remaining in the seed cages at each site and was calculated as:

$$
a_{i j}=\frac{S_{i}}{S_{j}},
$$

where $a_{i j}$ is the probability of seed survival from stage $j$ to stage $i$ across 1 year $(i<5, j$ $=i-1)$ and $S$ is the mean number of viable seeds in seed cages.

Stage 5 consisted of one-leaf seedlings. Probabilities of germination (i.e., the transition to stage 5 for stages 1 through $4 ; a_{5 j}$, where $\left.j=1,2,3,4\right)$ were calculated as

$$
a_{5 j}=\frac{G_{i}}{S_{j}}
$$

where $G$ is the mean number of germinants and $S$ is the mean number of viable seeds derived from the seed-cage experiment. Death of seeds was inferred as the proportion that did not either survive or germinate. In this species, germination does not occur in the first spring, so there is no direct adult to seedling transition; all recruits come from the seed class. 
We established the postgermination life-cycle stages to divide the population into groups with similar survival and reproduction rates and to keep parameter-estimation error low. We delineated the first 2 stages on the basis of number of leaves (1-leaf seedlings, stage 5, and 2-leaf juveniles, stage 6). Using analysis of covariance (ANCOVA), we found that after plants reached adult size (3 or 4 leaves), leaf area explained more variance in seed production than number of leaves. Therefore, we created 2 equal-size groups that we based on the median adult leaf area of the population: small adults (stage 7) and large adults (stage 8). Possible transitions among stages 5-8 for aboveground plants included stasis $\left(a_{i j}\right.$ where $\left.i=j\right)$, shrinkage $\left(a_{i j}\right.$ where $\left.i<j\right)$, or growth $\left(a_{i j}\right.$ where $\left.i>j\right)$. We calculated these stage transitions as the proportion of individuals in stage $j$ that transitioned to stage $i$ the following year. In the case of plants that were absent at the spring census (e.g., due to browse, damage, or death), the absent individual was assigned to its stage prior to disappearance. Undetected plants were retroactively assigned to stage 9 (dead) if no above ground parts were observed for 2 consecutive years because long-term vegetative dormancy was rare.

Fertilities, the mean contribution per plant stages 6,7 , and 8 to stage 1 seeds $\left(a_{1 j}\right.$, where $j=6,7,8)$ were calculated as follows:

$$
a_{1 j}=v \frac{\sum S_{j}}{n_{j}}
$$

where $\mathrm{S}$ is the number of seeds produced by each individual in stage $j$ summed over all individuals in the stage, and $n_{j}$ is the total number of individuals in stage $j(j=6,7,8)$. The constant $v$ equals 0.94 and is the proportion of seeds remaining viable from the time of dispersal to the next census ( 9 months). This constant was derived from a replicated 
seed-cage study that showed no statistically significant variation among sites in initial 9month seed survival (McGraw \& Furedi 2005). The finite rate of increase of each population for each transition year was determined by calculating the dominant eigenvalue of the transition matrix (A)(Caswell 2001). Standard errors were calculated with a jackknife procedure.

Over 12 years, 4 extreme, stochastic events dramatically affected ginseng population dynamics: a canopy defoliation due to an outbreak of a tent caterpillar, a major canopy loss following a storm, an outbreak of an unknown herbivore that nearly defoliated one population $(n \approx 400)$, and an outbreak of a seed predator that rendered ginseng seeds uncountable. We excluded the 4 years in which these events occurred a priori from our analyses. In addition, due to the delayed determination of fates of absent plants, the last census transition (2009-2010) was excluded. A total of 60 transition years was used in analyses.

Daily maximum temperature explained more variation in population growth rate $(\lambda)$ for ginseng than minimum or mean temperature; therefore, we used only maximum temperature in our analyses (Hunter-Cevera et al. 2008). We calculated total precipitation at each site over the growing season (15 April- 30 September) in each year by summing daily precipitation measurements from 10 climate stations located within 50 $\mathrm{km}$ of each population (for 2 pairs of populations, 1 of the 10 stations was the same). To measure site-specific temperatures, we deployed a HOBO pendant data logger (Onset Computer Corporation 1996-2010) that recorded hourly temperature at each site in 2007. We created an equation to adjust climate-station temperature data to reflect site-specific temperatures by regressing at least 1 year (in most cases 2 ) of daily maximum growing- 
season temperatures derived from HOBO data loggers on corresponding daily temperature data obtained from the 10 local climate stations. In this regression, Tukey biweight was used to give outliers, principally caused by sunfleck effects on HOBO data, less weight (Motulsky \& Christopolous 2004). Using data adjusted to reflect site-specific temperatures, we calculated the mean maximum growing-season temperature for each population.

\section{Analyses}

To examine range-wide relations between ginseng demography and climatic variables, we calculated $\lambda$ values for each set of transition years for each population $(n=60$ matrices). We then pooled $\lambda$ values across populations and regressed $\lambda$ on mean maximum growing-season temperature $(T)$ and on total growing season precipitation $(P)$. Although multiple $\lambda$ estimates for each population were incorporated into these analyses, we treated each observation of $\lambda$ as independent due to lack of among-population differences in mean $\lambda$ values and absence of temporal covariation of $\lambda$ within populations.

To compare ginseng response to climatic variables among sites with different mean climates, annual growing-season temperature and total growing-season precipitation were expressed in terms of deviation from site-specific means. Annual deviations from the mean for temperature $\left(T_{S D}\right)$ and precipitation $\left(P_{S D}\right)$ were expressed in units of SD as:

$$
T_{S D}=\frac{T_{i}-\bar{T}}{S D}
$$


where $T_{i}$ is the observed mean growing season temperature in a given study year at each site, $\bar{T}$ is the mean temperature across study years at a site, $\mathrm{SD}$ is the standard deviation of annual temperatures from the mean temperature at each site, and

$$
P_{S D}=\frac{P_{i}-\bar{P}}{S D}
$$

where $P_{i}$ is the observed total precipitation in a given growing season at each site, $\bar{P}$ is the mean precipitation across study years at a site, and SD is the standard deviation of annual precipitation from the mean precipitation at each site. We regressed $\lambda$ on $T_{S D}$ and $P_{S D}$

For each climatic variable, we tested 4 competing statistical models. These 4 models included linear and quadratic models of each climatic variable expressed first in standard units and second in terms of SD. To objectively select the model that best fit our data while accounting for disparity in number of parameters for linear versus secondorder polynomial models, we calculated the Akaike information criterion (AIC) (Akaike 1981; Anderson et al. 2000) for each model for each climatic variable separately:

$$
A I C=n \bullet \log _{e}\left(\hat{\sigma}^{2}\right)+2 K
$$

where $n$ is the sample size, $\hat{\sigma}^{2}$ is a value approximated by dividing the residual sum of squares (RSS) given by the regression model by $n$, and $K$ is the number of parameters in the model. Weight of support for each model $\left(w_{\mathrm{i}}\right)$ was calculated as

$$
w_{i}=\frac{\exp \left(-\frac{1}{2} \Delta_{i}\right)}{\sum_{i=1}^{R} \exp \left(-\frac{1}{2} \Delta_{i}\right)}
$$


for $i=1,2, \ldots R$ models, where $\Delta_{\mathrm{i}}=\mathrm{AIC}_{\mathrm{i}}-\mathrm{AIC}_{\min }$.

The mean population-level thermal niche across ginseng populations was defined as the number of SDs from the mean temperature at which $\lambda \geq 1$. We calculated this range with the second-order polynomial fit to the regression of $\lambda$ on $T_{S D}$. We used a mean SD among all populations, weighted by the number of annual temperature observations, to express SD in terms of temperature.

Although the sample of years and populations was limiting for models with a greater number of effects, we explored whether the effects of temperature on $\lambda$ depended on precipitation and whether the results from single climate-variable models were consistent with results of models that considered both temperature and precipitation. To test whether effects were interactive, we created a second-degree polynomial response surface with $T$ and $P$ as explanatory variables (model $=T, P, T^{2}, P^{2}, T^{*} P$ ) for the dependent variable $\lambda$. We repeated this procedure with $T_{S D}$ and $P_{S D}$.

To calculate climatic optima for each population, we determined the relation between $\lambda$ and climate at the population level. We did not want to assume a particular shape of the response of $\lambda$ to model parameters. Therefore, we used 3 ANCOVA models to test for a population* $T$ or population* $T^{2}$ interaction (SAS 2009). Effects in the 3 statistical models were: (1) population, $T$, and population* $T$, (2) population, $T$, population* $T$, and $T^{2}$, and (3) population, $T$, population* $T, T^{2}$, and population* $T^{2}$. The same 3 models were evaluated with precipitation instead of temperature. The model with the highest adjusted $r^{2}$ was selected as the model that best explained variation in $\lambda$ (Gotelli \& Ellison 2004) and was used to calculate population $T$ and $P$ optima. 
When the model fit curves with optima (not minima), we calculated the

temperature or precipitation corresponding to the optima by setting $\frac{\partial y}{\partial x}$ equal to zero and solving for $x$. We then regressed these optimum values on the 30-year (1971-2000) means for each climatic variable obtained from the adjusted climate station data. These 30 years corresponded roughly to the time when adult reproductive plants within the censused populations were established (Mooney \& McGraw 2009). We performed a $t$ test to determine whether the slope of the regression of temperature optima on long-term temperature means differed from a one to one line. To determine whether the population temperature optima differed from 30-year mean temperatures or instead tracked current temperature means, we tested pairwise differences between temperature optima, mean maximum temperature during the study period, and 30-year mean temperature with 2way analysis of variance without replication. 


\section{Results}

Range-wide relation to temperature and precipitation

A range-wide relation of $\lambda$-values across all populations of ginseng to temperature

expressed in degrees Celsius would be consistent with a uniform thermal niche. However, variation in $\lambda$ was not explained by mean maximum growing-season temperature $(T)$ when either a linear model $\left(p=0.65, r^{2}<0.01\right.$; Fig. $2 a$ ) or a second-order polynomial model $\left(p=0.87, r^{2}<0.01\right)$ was fit to the data. When temperature was expressed in terms of SD from mean $T\left(T_{S D}\right)$, there was no linear relation $\left(p=0.35, r^{2}=0.02\right)$. However, consistent with expectations of local climatic adaptation, a second-order polynomial model explained a significant amount of variation in $\lambda\left(p<0.01, r^{2}=0.14\right.$; Fig. $\left.2 b\right)$. The polynomial response was convex, such that temperatures that were either higher or lower than the mean reduced $\lambda$.

The response of $\lambda$ to precipitation contrasted with the response to temperature.

When $\lambda$ was regressed on total growing-season precipitation $(P)$ across all populations, a linear model again did not explain significant variation in $\lambda\left(p=0.12, r^{2}=0.04\right)$; however, a second-order polynomial fit explained significant variation in $\lambda\left(p<0.05, r^{2}=\right.$ 0.11; Fig. $3 a$ ). When $P$ was expressed in terms of SD from the mean $\left(P_{S D}\right)$, neither a linear model $\left(p=0.20, r^{2}=0.03\right.$; Fig. $\left.3 b\right)$ nor a second- order polynomial $\left(p=0.38, r^{2}=\right.$ 0.04) explained a statistically significant amount of the variation in $\lambda$.

Comparing among single climate-variable regression models with temperature ( $T$ and $\left.T_{S D}\right)$ as the explanatory variable, the weight of support $\left(w_{\mathrm{i}}\right)$ for the second-order polynomial model of $T_{S D}$ was 0.90 (Table 1). Weight of support for a polynomial fit of $P$ was 0.64 (Table 1). An estimate of the thermal niche breadth of the average ginseng 
population can be derived from the regression of $\lambda$ on temperature expressed in SD and is defined as range of $T_{S D}$ for which $\lambda \geq 1$. For these populations, the mean, populationlevel thermal niche breadth was approximately $1.62^{\circ} \mathrm{C}$.

For tests that incorporated both climatic variables as explanatory variables, when $T$ and $P$ were not expressed in units of variance, $P$ explained a significant portion of the variation in $\lambda\left(p<0.05, r^{2}=0.07\right)$. However, when climatic variables were expressed in terms of deviation from the mean, $T_{S D}{ }^{2}$ explained significant variation in $\lambda\left(p<0.05, r^{2}=\right.$ 0.06). The effect of $T$ on $\lambda$ did not depend on $P$ in either case $\left(p=0.47, r^{2}<0.01 ; p=\right.$ $0.92, r^{2}<0.01$; respectively)

\section{Climatic optima versus local climate}

We evaluated 3 statistical models per climatic variable to produce the equations to calculate climatic optima. For temperature, the model that best described the data contained all first- and second-order terms, but did not include the population * $T^{2}$ interaction (adjusted $r^{2}=0.29, r^{2}=0.58, F=2.02, p<0.05$ ). This model showed that the effect of temperature on $\lambda$ varied among populations and produced a series of convex polynomial fits (Fig. 4a). For precipitation the complete model, including all first- and second-order terms and the population $* \mathrm{~T}^{2}$ interaction, produced the best fit (adjusted $r^{2}$ $\left.=0.36, r^{2}=0.74, F=1.93, p<0.05\right)$. In this analysis, the effect of precipitation on $\lambda$ also depended on population. However, the polynomial fits were highly variable, and although most were convex, a few were concave (Fig. $4 b$ ). The overall shape of the relations did not conform to one of local adaptation. 
Contrary to expectations of a range-wide temperature optimum, response-curve optima did not converge to a single value when the temperature optima of the populations were regressed on the 30-year mean maximum temperature $\left(T_{30}\right)$. Instead, there was a direct linear relation between temperature optima and $T_{30}$, with $T_{30}$ explaining a large and statistically significant portion of the variation in temperature optima $(F=96.68, p<$ $0.001, r^{2}=0.91$; Fig. $5 a$ ). Temperature optima fell between $T_{30}$ and mean temperatures during the study period, but did not differ significantly from either $(F=0.24, p=0.63 ; F$ $=1.77, p=0.21$; respectively; Fig. 6 ). In contrast to the results for temperature, the 30 year mean total growing season precipitation $\left(P_{30}\right)$ did not explain a statistically significant portion of variation in precipitation optima $\left(F=2.58, p=0.16, r^{2}=0.30\right.$; Fig. $5 b)$. 
Table 3.1. Weight of support $\left(w_{i}\right)$ for competing statistical models of ginseng population growth rate $(\lambda)$ regressed on temperature or precipitation expressed in standard units or in terms of SD for linear and second-order polynomial fits.

\begin{tabular}{cccccc} 
Variable & Model & AIC $^{\mathrm{a}}$ & $D_{\text {AIC }}{ }^{\mathrm{b}}$ & Likelihood & $w_{\mathrm{i}}$ \\
\hline Temperature & linear & -247.46 & 6.49 & 0.04 & 0.04 \\
& polynomial & -245.49 & 8.46 & 0.01 & 0.01 \\
Temperature $\mathrm{SD}^{\mathrm{c}}$ & linear & -248.17 & 5.78 & 0.06 & 0.05 \\
& polynomial & -253.95 & 0.00 & 1.00 & 0.90 \\
\hline \multirow{2}{*}{ Precipitation } & linear & -249.73 & 2.55 & 0.28 & 0.18 \\
& polynomial & -252.28 & 0.00 & 1.00 & 0.64 \\
Precipitation $\mathrm{SD}^{\mathrm{c}}$ & linear & -248.96 & 3.32 & 0.19 & 0.12 \\
& polynomial & -247.79 & 4.49 & 0.11 & 0.07 \\
\hline
\end{tabular}

${ }^{a}$ Akaike information criterion.

${ }^{c}$ Expressed in terms of SD from the mean.

${ }^{c}$ Lowest AIC values corresponds to the model with best fit.

${ }^{\mathrm{b}}$ Difference in AIC value from the best model. 


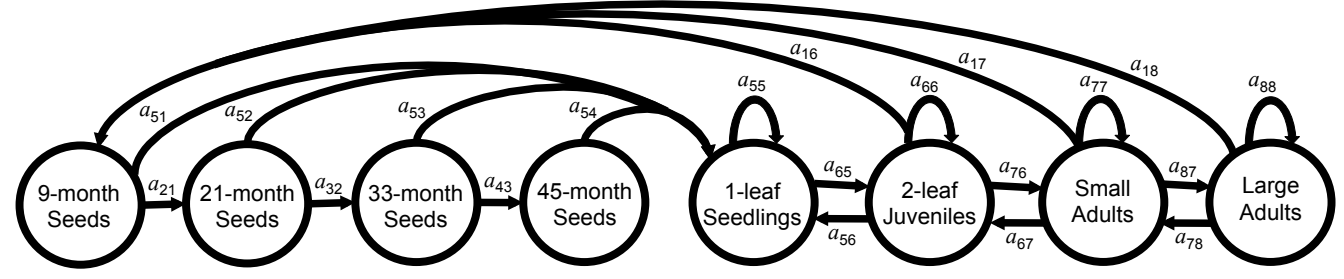

Figure 3.1. Life-cycle stages used for demographic modeling of ginseng populations.

The seed bank is divided into 4 age-based stages (9-, 21-, 33-, and 45-month-old seeds), and the plant population is categorized by size-based metrics (1-leaf, 2-leaf, small adult, and large adult plants). Arrows and $a_{i j}$ elements, which represent the probability of transitioning from class $j$ to class $i$ over the time span of 1 year, indicate possible transitions for individuals within ginseng populations. 
(a)

(a)

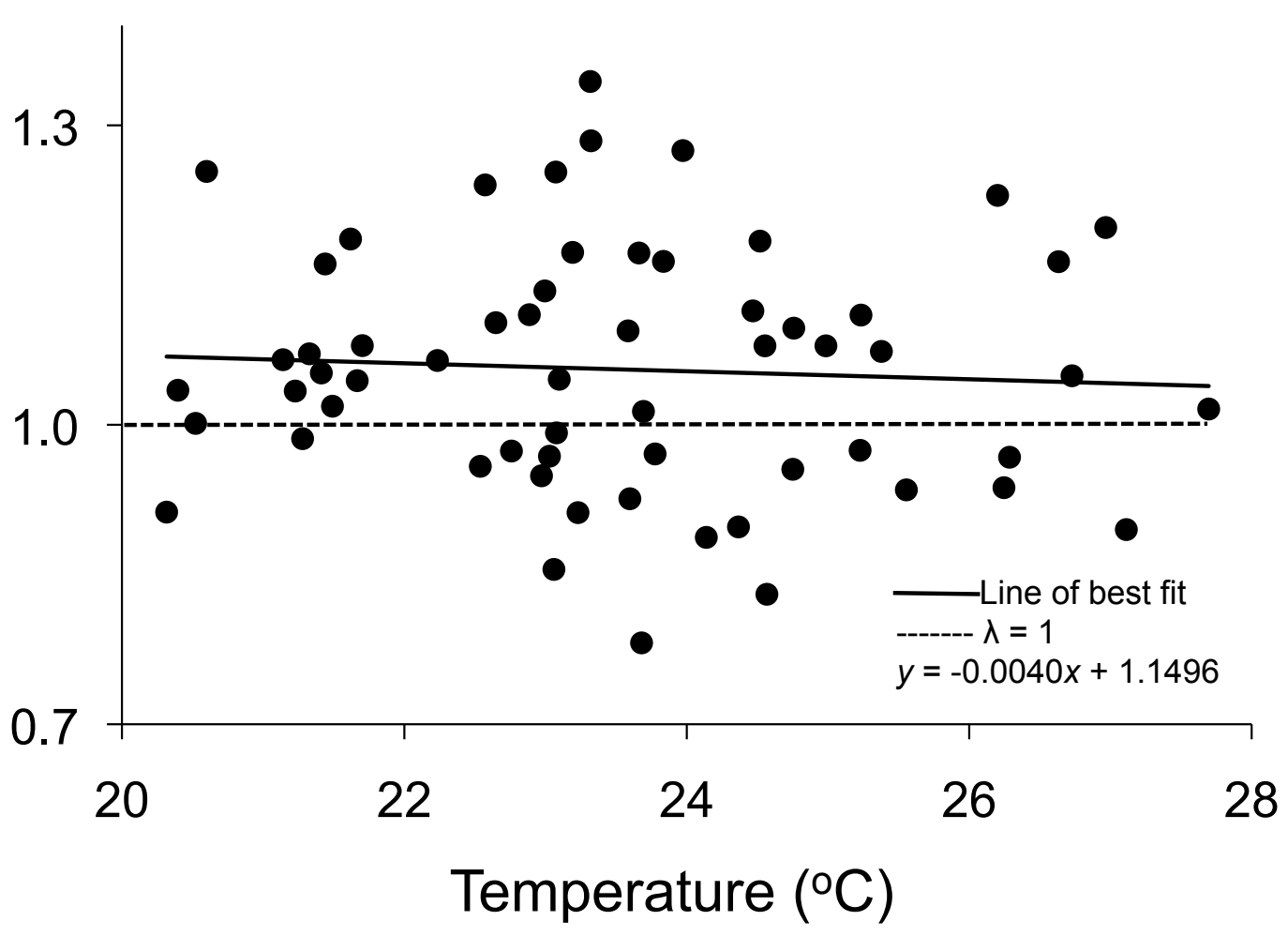

Figure 3.2.a. Response of population growth rate $(\lambda)$ to mean maximum growing-season temperature. 
(b)

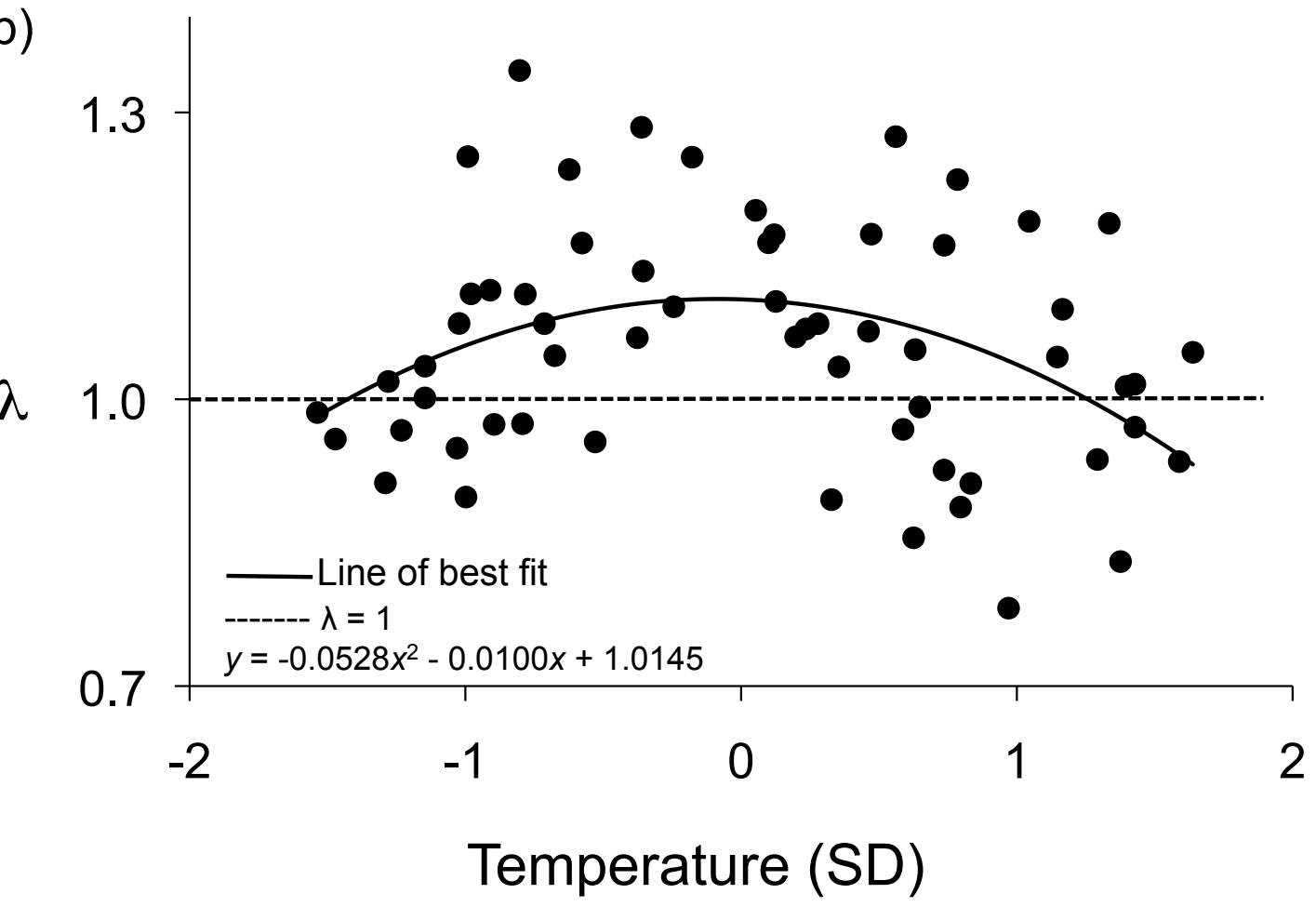

Figure 3.2.b. Response of population growth rate $(\lambda)$ to mean maximum growing-season temperature expressed in terms of deviation (SD) from site-specific means. Among all temperature models (b), a polynomial fit of $\lambda$ regressed on temperature expressed in SD was the best-supported model $\left(w_{i}=0.90, p<0.01, r^{2}=0.14\right)$. 


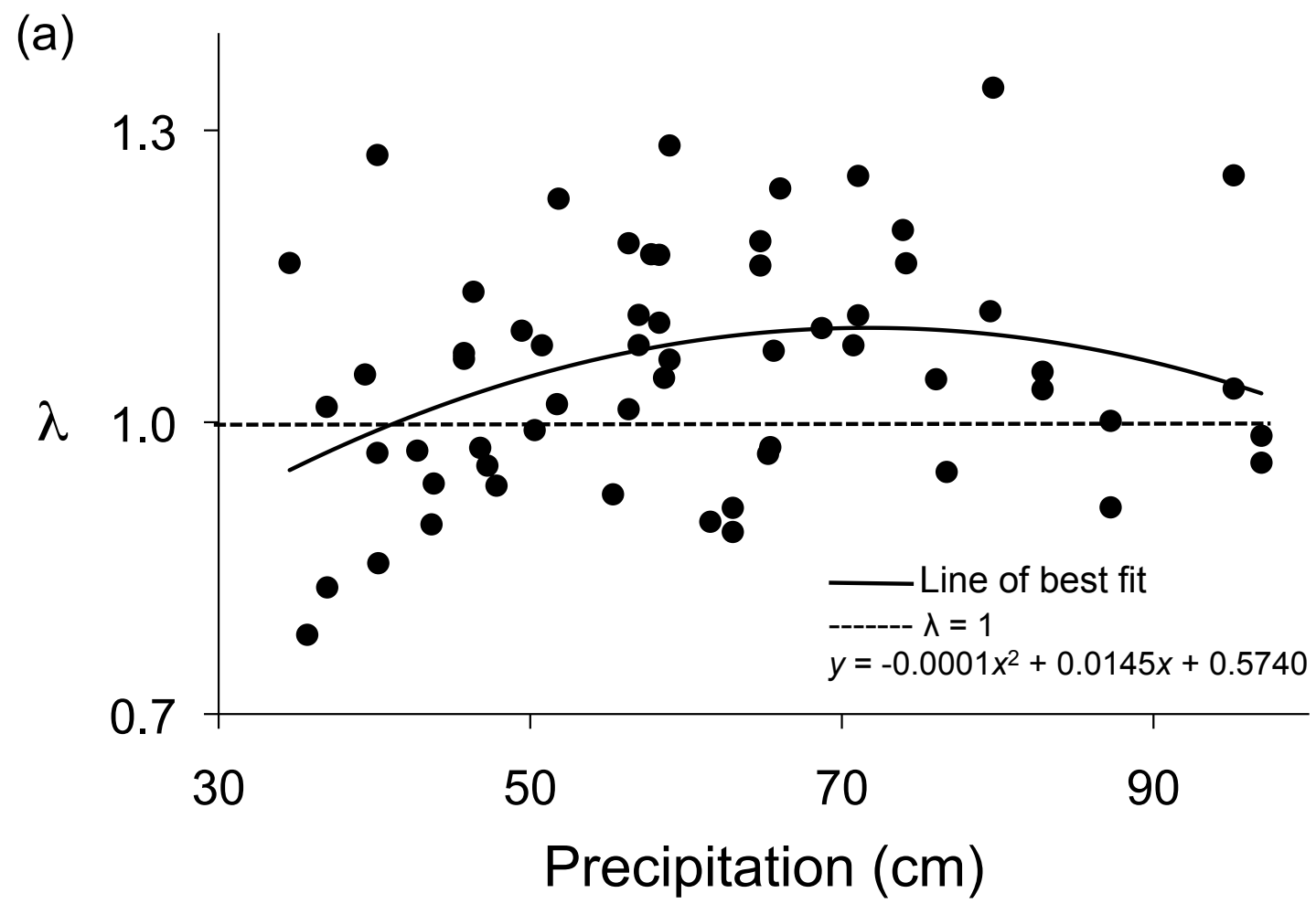

Figure 3.3.a. Response of population growth rate $(\lambda)$ to total growing-season precipitation. The models of best fit for both methods of expressing precipitation data are shown. Among all precipitation models (a), a polynomial fit of $\lambda$ regressed on precipitation $(\mathrm{cm})$, was the best-supported model $\left(w_{\mathrm{i}}=0.64, p<0.05, r^{2}=0.11\right)$. 


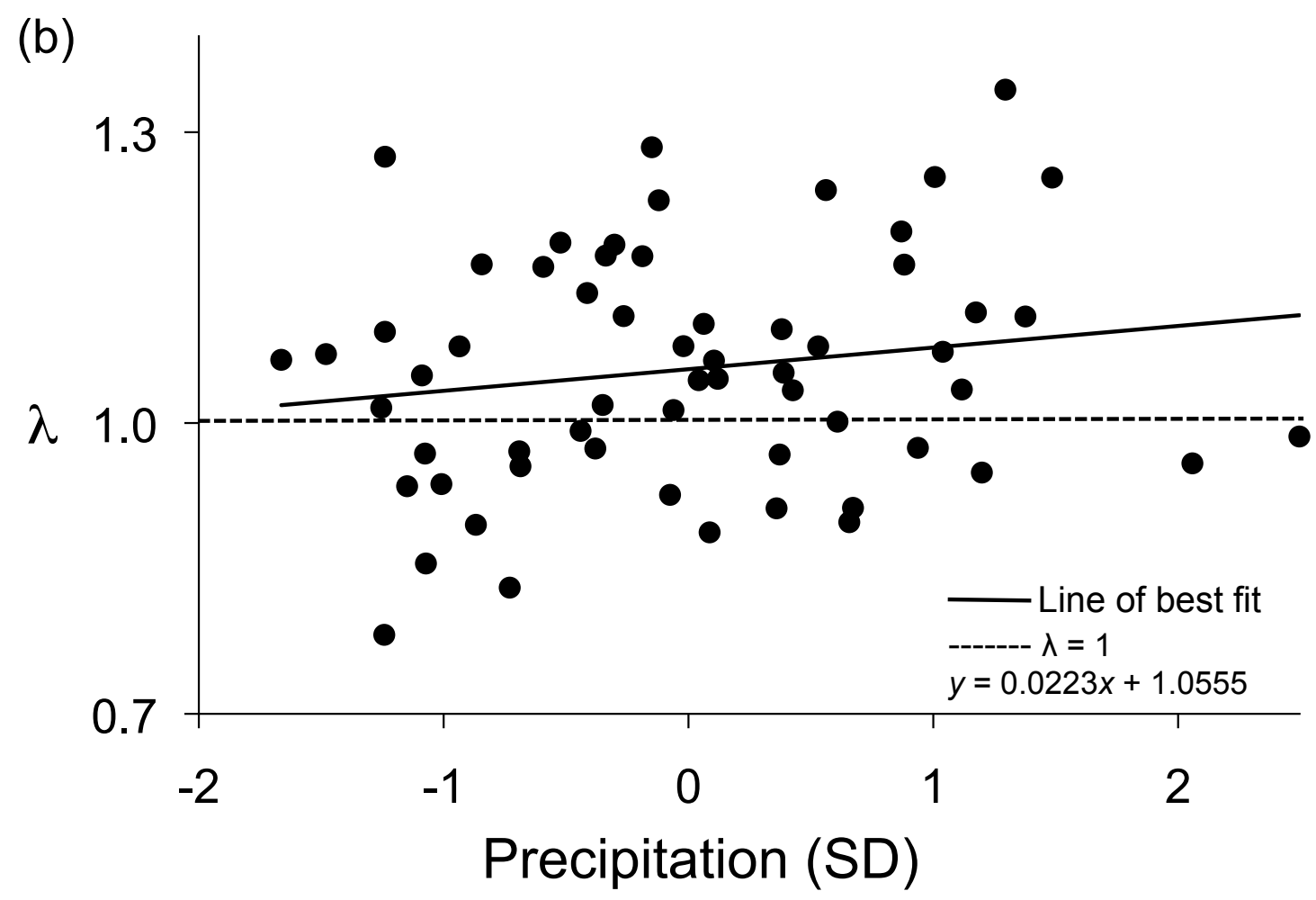

Figure 3.3.b. Response of population growth rate $(\lambda)$ to total growing-season precipitation expressed in terms of deviation (SD) from site-specific means. 


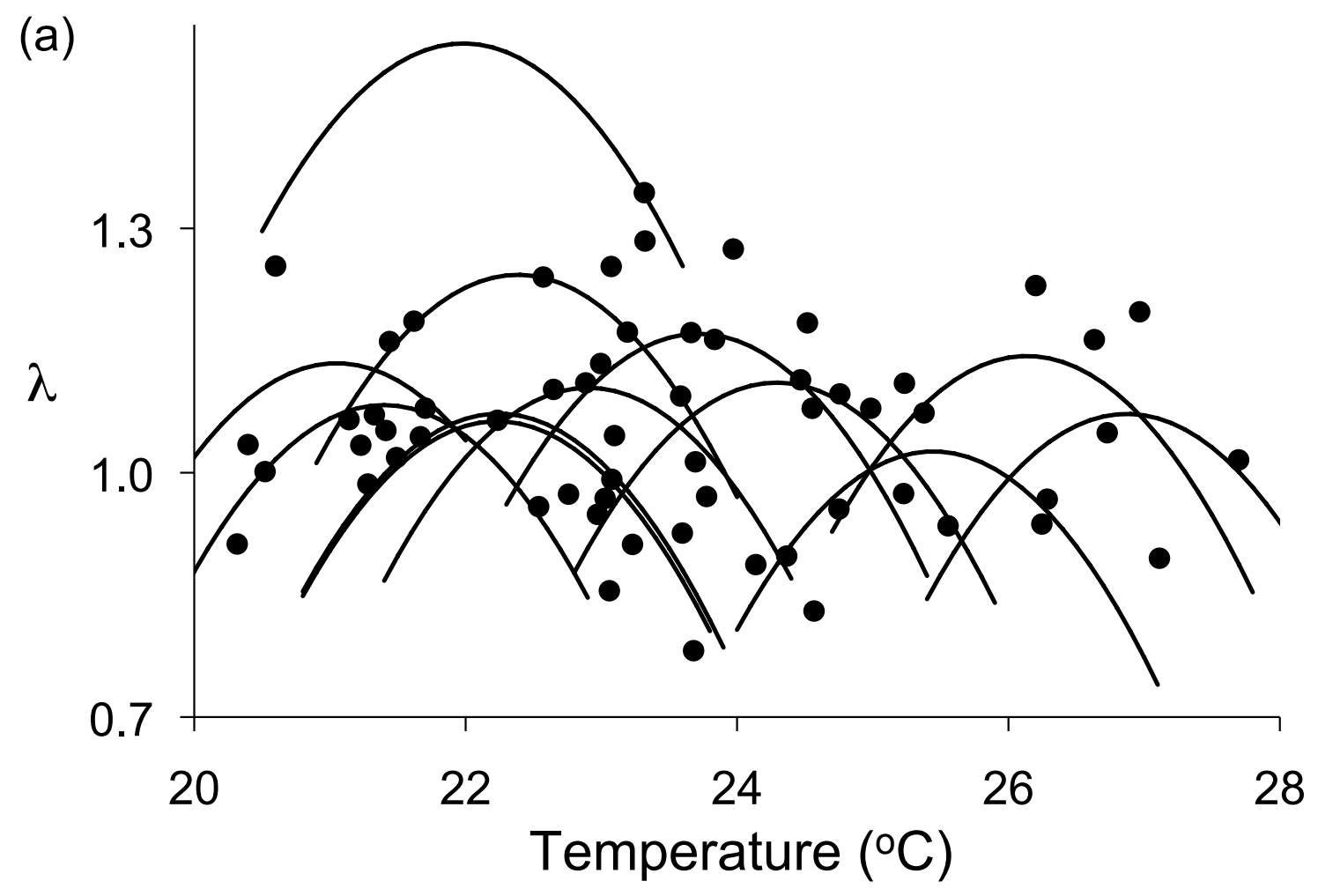

Figure 3.4.a. Response of population growth rate $(\lambda)$ to annual variation in temperature. Curves were derived from the statistical model that best described the response of $\lambda$ to temperature by population. Several populations were censused just 4 years; hence, the actual temperature variation over the study period was insufficient to define the shape of the temperature response curves for all populations. For clearer visualization of response curves, values corresponding to temperatures $\pm 1.5^{\circ} \mathrm{C}$ from each population's temperature optimum are plotted. 


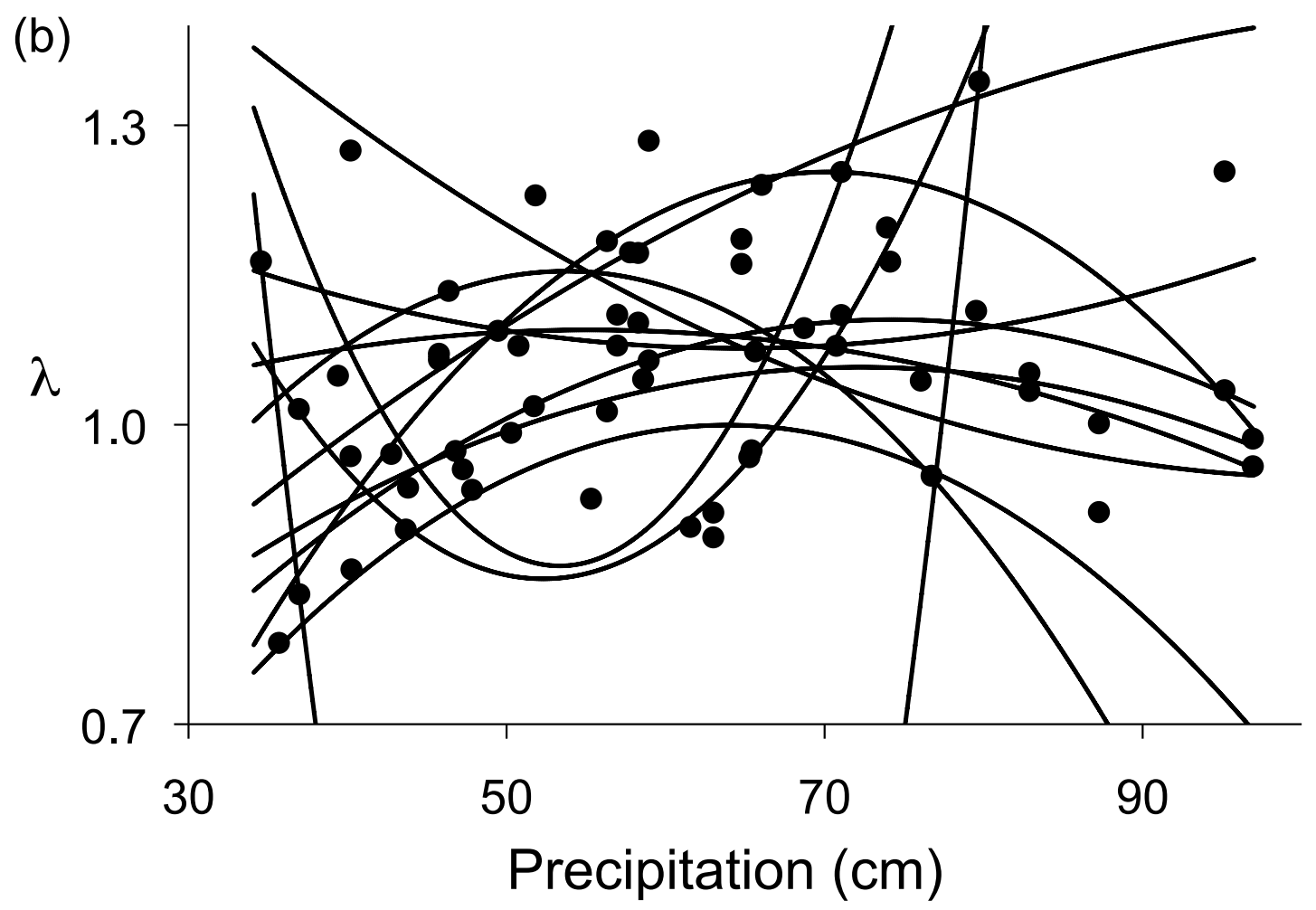

Figure 3.4.b. Response of population growth rate $(\lambda)$ to annual variation in precipitation by population. 


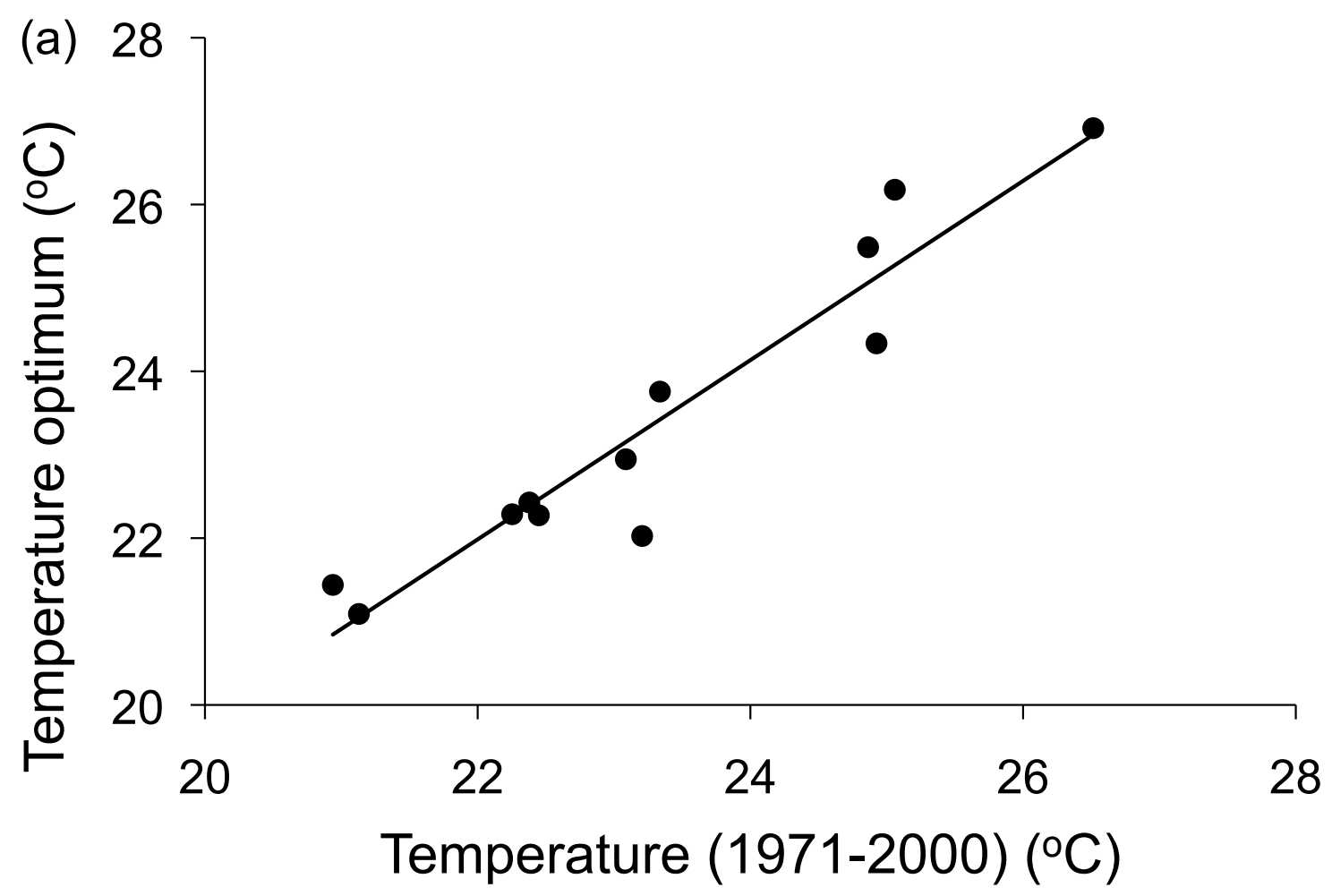

Figure 3.5.a. Linear regression of site-specific temperature optima on 30-year mean maximum growing-season temperature. Only the model that included temperature as the independent variable explained a statistically significant proportion of the variation in $y$ $\left(p<0.001, r^{2}=0.91\right)$. For this model, the slope of the line of best fit did not statistically differ from $1(t=0.68, p=0.51)$. 


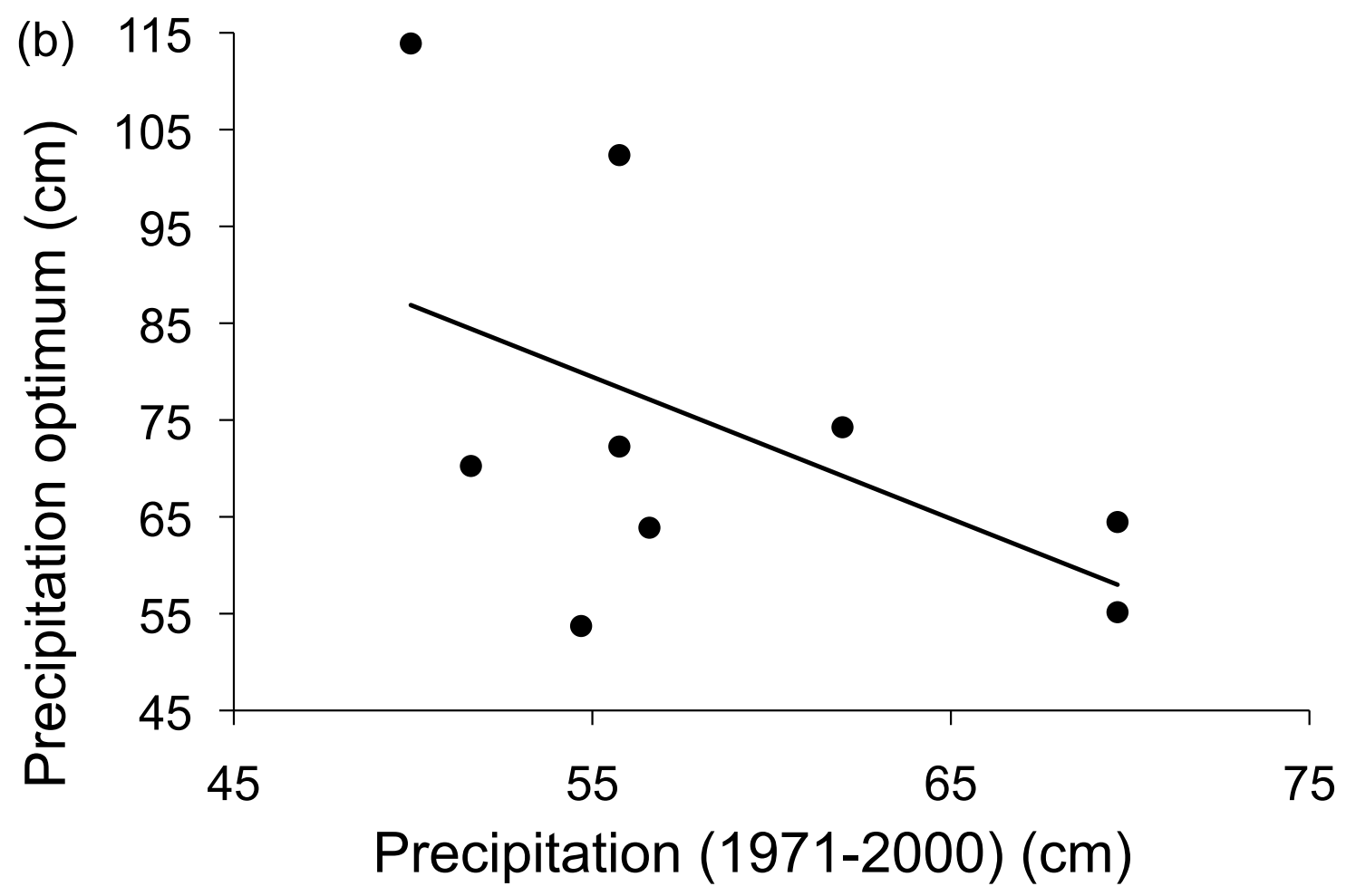

Figure 3.5.b. Linear regression of precipitation optima on 30-year mean total precipitation. 


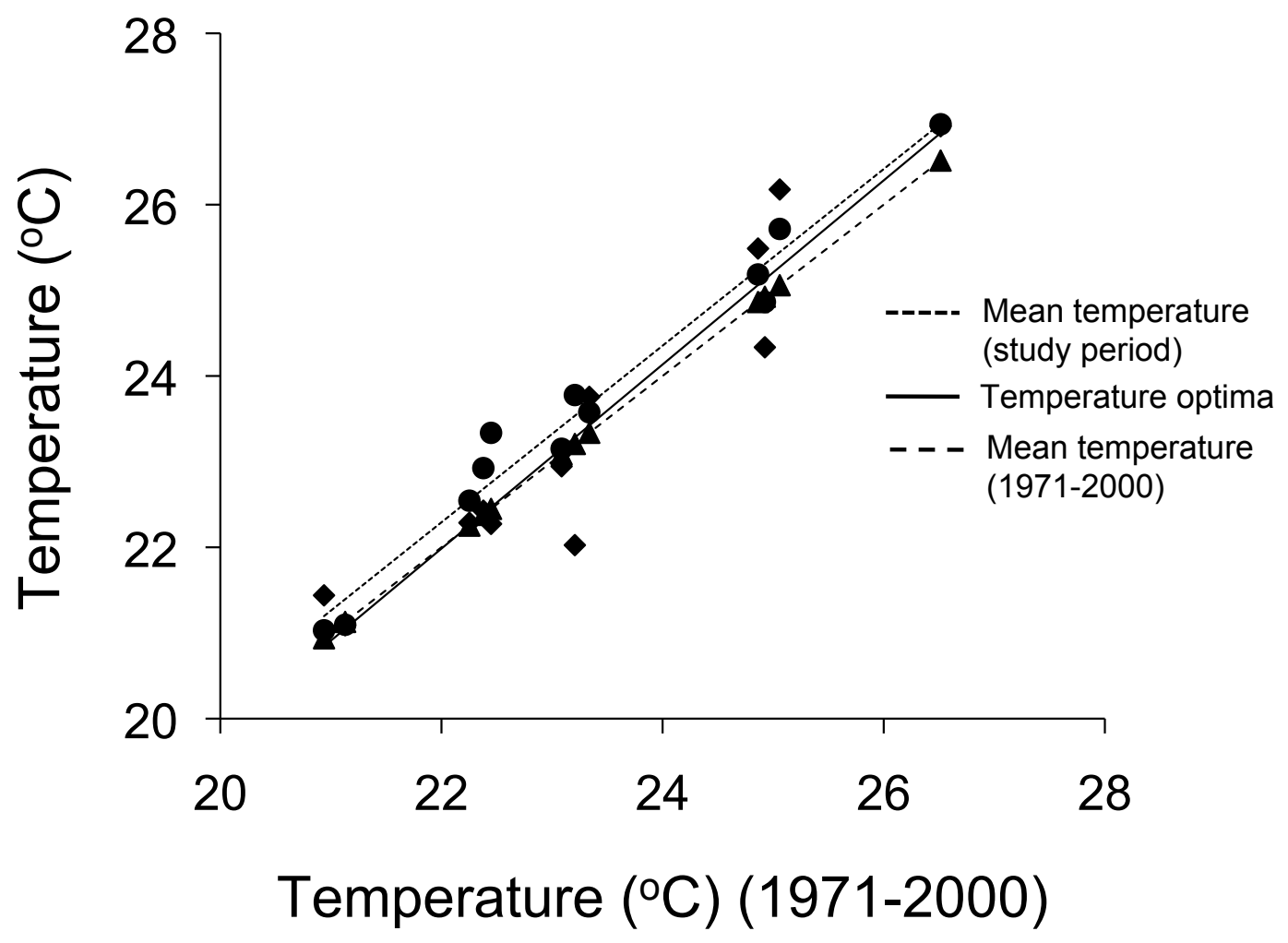

Figure 3.6. The relation between mean temperature during the study period, site-specific temperature optima, and 30-year (1971-2000) mean temperatures at each site. Mean temperatures over the duration of the study were on average $0.33{ }^{\circ} \mathrm{C}$ higher than the 30 year mean maximum temperature $(F=15.40, p<0.01)$. Temperature optima fell between mean temperatures during the study period and 30-year mean temperatures, but did not statistically differ from either $(F=1.77, p=0.21 ; F=0.24, p=0.63$; respectively). 


\section{Discussion}

Results were consistent with expectations of adaptation to local temperature regimes in the form of a convex response curve when $\lambda$ was regressed on temperature expressed in terms of SD from local means. Deviation from site-specific mean temperatures in either direction reduced $\lambda$. These results were observed despite the numerous other biotic and abiotic factors that affect ginseng population growth (McGraw \& Furedi 2005; Van der Voort \& McGraw 2006; Souther \& McGraw 2011). Additionally, there was a direct linear relation between each population's local temperature regime and the temperature at which population growth rate was optimized, indicating specialization of populations to local temperatures. There was little evidence to suggest local adaptation to precipitation. In contrast, a range-wide, parabolic relation of $\lambda$ regressed on precipitation indicates precipitation may constrain the overall distribution of ginseng.

Experimental tests of local climatic adaptation are necessary to definitively establish a genetic basis. However, two lines of evidence strongly suggest the observed response of $\lambda$ to temperature variation has an underlying genetic component. First, ginseng plants are deciduous; thus, multiyear acclimation of the photosynthetically active plant parts is unlikely. A long-term acclimation response would have to be explained by carryover effects from the previous year's temperature on the structure and physiology of the root and rhizome. If such long-term acclimation caused the observed response to temperature, we would expect that $\lambda$ values would be temporally correlated, such that in 2 consecutive warm years, one would anticipate a higher population growth rate in the second year. However, we detected no temporal correlation of $\lambda$ values. Rather, $\lambda$ appears to respond independently to each year's temperature. Although experimental 
manipulations of temperature could provide a stronger empirical test of local climatic adaptation, such studies have confounding variables. For example, growth chambers allow control of temperature but cannot replicate field conditions, and field manipulations of temperature are likely to confound effects such as precipitation alteration and herbivore exclusion.

For species composed of many locally adapted populations, the population-level thermal niche is narrow compared with the thermal niche defined by the spatial distribution of the species. Consequently, the increase in temperature associated with a decrease in probability of persistence of the species may be substantially smaller than would be predicted by models that define a species' thermal niche on the basis of its geographic range. For ginseng we estimated a mean niche breadth of approximately 1.62 ${ }^{\circ} \mathrm{C}$. On average, a further mean temperature increase of approximately $0.73{ }^{\circ} \mathrm{C}$ would be necessary for $\lambda$ values to decrease below replacement across all populations in ginseng's range. Projections of climate models estimate an increase in global temperature of 1.1$6.4{ }^{\circ} \mathrm{C}$ by 2100 (IPCC 2007). Therefore, projected increases in temperature exceed ginseng's population-level thermal niche. The difference in mean temperature across study sites is approximately $5.9^{\circ} \mathrm{C}$. Use of a climatic-envelope approach to model ginseng response to climate change would erroneously predict the persistence or growth of ginseng populations at high latitudes and elevations in most scenarios.

In general, local adaptation of plants is expected (Linhart \& Grant 1996; Kawecki \& Ebert 2004; Savolainen et al. 2007). Climate change may have direct effects on demography of species with local climatic adaptations or indirect effects propagated across trophic levels. Local adaptation is promoted by low gene flow (Kawecki \& Ebert 
2004; Savolainen et al. 2007), which suggests that dispersal may be low within genetically differentiated populations. Habitat fragmentation may further preclude dispersal that enables persistence as climate changes. When spatial response is not possible, the persistence of locally adapted populations will rely on rapid in situ adaptation to novel climatic conditions (Davis \& Shaw 2001; Bradshaw \& Holzapfel 2006) or possibly human-assisted relocation (Richardson et al. 2009). 


\section{Acknowledgments.}

M. Van der Voort, MA. Furedi, E. Mooney, M. Kaproth, A. Hanna, K. Wixted, Z.

Bradford, and many dedicated undergraduate research interns helped collect demographic data. We thank the landowners and land managers for granting us access to census populations. We also thank 2 anonymous reviewers for insightful comments. This research was funded by National Science Foundation-Long Term Research in Environmental Biology grant DEB-0613611, and National Science Foundation Doctoral Dissertation Improvement grant DEB-0909862. 


\section{References}

Aitken, S. N., S. Yeaman, J. A. Holliday, T. L. Wang, and S. Curtis-McLane. 2008. Adaptation, migration or extirpation: climate change outcomes for tree populations. Evolutionary Applications 1:95-111.

Akaike, H. 1974. A new look at the statistical model identification. Engineering Technology \& Applied Sciences 19:22-22.

Anderson, D. R., K. P. Burnham, and W. L. Thompson. 2000. Null hypothesis testing: problems, prevalence, and an alternative. Journal of Wildlife Management 64:912-923.

Bradshaw, W. E., and C. M. Holzapfel. 2006. Climate change. Evolutionary response to rapid climate change. Science 312:1477-1478.

Caswell, H. 2001. Matrix population model: construction, analysis, and interpretation. $2^{\text {nd }}$ edition. Sinauer Associates, Sunderland, Massachusetts.

Clausen, J., D. D. Keck, and W. M. Hiesey. 1947. Heredity of geographically and ecologically isolated races. The American Naturalist 81:114-133.

Cruse-Sanders, J. M., and J. L. Hamrick. 2004. Genetic diversity in harvested and protected populations of wild American ginseng, Panax quinquefolius L. (Araliaceae). American Journal of Botany 91:540-548.

Davis, M. B., and R. G. Shaw. 2001. Range shifts and adaptive responses to Quaternary climate change. Science 292:673-679.

Etterson, J. R. 2004. Evolutionary potential of Chamaecrista fasciculata in relation to climate change. 1. Clinal patterns of selection along an environmental gradient in the great plains. Evolution 58:1446-1458. 
Gotelli, N. J., and A. M. Ellison. 2004. A Primer of Ecological Statistics. Sinauer Associates, Sunderland, Massachusetts.

Grubbs, H. J., and M. A. Case. 2004. Allozyme variation in American ginseng (Panax quinquefolius L.): variation, breeding system, and implications for current conservation practice. Conservation Genetics 5:13-23.

Hereford, J. 2009. A quantitative survey of local adaptation and fitness trade-offs. The American Naturalist 173:579-588.

Holt, R. D. 2003. On the evolutionary ecology of species' ranges. Evolutionary Ecology Research 5:159-178.

Holt, R. D. 2009. Bringing the Hutchinsonian niche into the 21 st century: ecological and evolutionary perspectives. Proceedings of the National Academy of Sciences of the United States of America 106:19659-19665.

Holt, R. D., and M. S. Gaines. 1992. Analysis of adaptation in heterogeneous landscapes - implications for the evolution of fundamental niches. Evolutionary Ecology 6:433-447.

Hunter-Cevera, K. R., S. Souther, and J. B. McGraw. 2008. Demographic response of American ginseng to interannual climate variation. Ecological Society of America (ESA), Washington, D.C.

IPCC (Intergovernmental Panel on Climate Change). 2007. Fourth assessment report of the Intergovernmental Panel on Climate Change. Cambridge University Press, Cambridge, United Kingdom. 
Jeltsch, F., K. A. Moloney, F. M. Schurr, M. Kochy, and M. Schwager. 2008. The state of plant population modelling in light of environmental change. Perspectives in Plant Ecology Evolution and Systematics 9:171-189.

Kaltz, O., and J. A. Shykoff. 1998. Local adaptation in host-parasite systems. Heredity 81:361-370.

Kawecki, T. J., and D. Ebert. 2004. Conceptual issues in local adaptation. Ecology Letters 7:1225-1241.

Lande, R. 1988. Genetics and demography in biological conservation. Science 241:14551460.

Lande, R. 1998. Anthropogenic, ecological and genetic factors in extinction and conservation. Researches on Population Ecology 40:259-269.

Lewis, W. H., and V. E. Zenger. 1983. Breeding systems and fecundity in the American ginseng, Panax quinquefolium (Araliaceae). American Journal of Botany 70:466468.

Linhart, Y. B., and M. C. Grant. 1996. Evolutionary significance of local genetic differentiation in plants. Annual Review of Ecology and Systematics 27:237-277.

McGraw, J. B., and M. A. Furedi. 2005. Deer browsing and population viability of a forest understory plant. Science 307:920-922.

McGraw, J. B., S. M. Sanders, and M. Van der Voort. 2003. Distribution and abundance of Hydrastis canadensis L. (Ranunculaceae) and Panax quinquefolius L. (Araliaceae) in the central Appalachian region. Journal of the Torrey Botanical Society 130:62-69. 
Mooney, E. H., and J. B. McGraw. 2009. Relationship between age, size, and reproduction in populations of American ginseng, Panax quinquefolius (Araliaceae), across a range of harvest pressures. Ecoscience 16:84-94.

Motulsky, H. and A. Christopoulos. 2004. Fitting models to biological data and using linear and nonlinear regression: a practical guide to curve fitting. Oxford University Press, New York.

Parmesan, C. 2006. Ecological and evolutionary responses to recent climate change. Annual Review of Ecology Evolution and Systematics 37:637-669.

Primack, R. B., and H. Kang. 1989. Measuring fitness and natural selection in wild plantpopulations. Annual Review of Ecology and Systematics 20:367-396.

Richardson, D. M., et al. 2009. Multidimensional evaluation of managed relocation. Proceedings of the National Academy of Sciences of the United States of America 106:9721-9724.

Robbins, C. S. 2000. Comparative analysis of management regimes and medicinal plant trade monitoring mechanisms for American ginseng and goldenseal. Conservation Biology 14:1422-1434.

Roistacher, C. N., J. G. Bald, and K. F. Baker. 1953. The tetrazolium test for dormancy and germinability of gladiolus cormels. Science 118:186-187.

SAS. 1989-2010. JMP version 8.0.1.SAS Institute, Cary, North Carolina.

Savolainen, O., T. Pyhajarvi, and T. Knurr. 2007. Gene flow and local adaptation in trees. Annual Review of Ecology Evolution and Systematics 38:595-619.

Souther, S. and J. McGraw. 2011. Vulnerability of wild American ginseng to an extreme early spring temperature fluctuation. Population Ecology 53:119-129. 
Taylor, E. B. 1991. A review of local adaptation in Salmonidae, with particular reference to Pacific and Atlantic salmon. Aquaculture 98:185-207.

Turesson, G. 1930. The selective effect of climate upon the plant species. Hereditas 14:99-152.

Van der Voort, M. E. 2006. An ecological study of Panax quinquefolius in central Appalachia: seedling growth, harvest impacts and geographic variation in demography. PhD thesis. West Virginia University, Morgantown, .

Van der Voort, M. E., and J. B. McGraw. 2006. Effects of harvester behavior on population growth rate affects sustainability of ginseng trade. Biological Conservation 130:505-516.

Walther, G. R., E. Post, P. Convey, A. Menzel, C. Parmesan, T. J. C. Beebee, J. M. Fromentin, O. Hoegh-Guldberg, and F. Bairlein. 2002. Ecological responses to recent climate change. Nature 416:389-395. 


\section{CHAPTER IV:}

CLIMATE CHANGE INCREASES EXTINCTION RISK FOR LOCALLY ADAPTED SPECIES 


\begin{abstract}
Adaptation of populations within a species' range to the local environment is a common feature of a broad spectrum of plant and animal species. While such specialization enhances population performance under constant environmental conditions, local adaptation may be a liability in a directionally changing system. If populations within a species' range are specialized to local climatic conditions, climate change may threaten even widespread species with extinction, as temperatures diverge from mean conditions, causing fitness declines across the entire species' range. Due to difficulty collecting long-term, spatially extensive demographic data, the influence of intraspecific specialization to climate on climate change-driven extinction risk has not been determined. Here we show that climate warming decreases long-term viability of a locally climatically adapted herb, American ginseng (Panax quinquefolius L.). A simulated increase in maximum growing season temperatures of only $1^{\circ} \mathrm{C}$ over the next 70 years sharply increased extinction risk. The minimum viable population size (MVP) under a mid-level climate change scenario was 300 individuals, a population size greater than $87 \%$ of the populations we census. Due to a positive, exponential relationship of MVP to warming, only small increases in projected warming rates would be sufficient to increase MVP to numbers beyond any known natural population sizes. For species adapted to local temperature regimes, climate warming is a threat to long-term persistence. In the absence of rapid migration or rapid evolutionary adaptation, a significant portion of global biodiversity may be at greater risk of extinction due to climatic warming than previously anticipated.
\end{abstract}




\section{Introduction}

Conservation of biodiversity over the next century will depend on our ability to anticipate the response of species to future climatic conditions (Hannah et al. 2002; McLaughlin et al. 2002; Parmesan and Yohe 2003; Root et al. 2003; Walther et al. 2002). To do this, we must accurately model the ecological impacts of warming (Hannah et al. 2002; Thuiller 2007). Stochastic, demographic models provide estimates of extinction risk posed by climate change, and can be used to inform protection strategies for particular populations or species (Hunter et al. 2010; Jenouvrier et al. 2009; Maschinski et al. 2006; McLaughlin et al. 2002; Morris 2002). These population viability analyses (PVAs) have shown that climate change can negatively affect long-term persistence of narrow-range endemics such as Cliff rose (Maschinski et al. 2006) or Checkerspot butterfly (McLaughlin et al. 2002), and Arctic or Antarctic species, such as the Polar bear(Hunter et al. 2010), or Emperor penguins (Jenouvrier et al. 2009). The few species that have been evaluated in this way possess narrow ecological niches, often manifested in a restricted geographic range.

Ecological specialization can occur at different taxonomic levels, ranging from the species to the subpopulation (Linhart and Grant 1996). Local adaptation, specialization at the population level to local environment, is considered the norm, particularly for plant species (Linhart and Grant 1996). Populations may be adapted to any number of site-specific environmental factors, including climate (Linhart and Grant 1996). Specialization allows populations to maximize fitness when conditions are stable, but comes at a fitness cost in a dynamic environment (Davis and Shaw 2001). These fitness costs can manifest themselves demographically. In one study, the finite rate of 
increase $(\lambda)$ of 12 populations of American ginseng decreased below replacement levels when temperatures significantly deviated from site-specific means (Souther and McGraw 2011a). Local climatic adaptation has largely been ignored in models of species response to climate change, due to difficulty collecting demographic data of sufficient spatial and temporal scale to define intra-specific relationships between population growth and temperature. However, adaptation to local climate will likely be an important determinant of species response to climate change(Davis and Shaw 2001; Holt and Gaines 1992). For species in which populations are adapted to local temperature regime, if warming exceeds the population-level thermal niche, all populations across a species' range may decline. In this way, climate change may drive extinctions of species with seemingly broad ecological niches (Davis and Shaw 2001; Holt and Gaines 1992).

Here we use a stochastic, population projection matrix model as the basis of a formal population viability analysis to evaluate the effect of predicted climate change on American ginseng (Panax quinquefolius L.). Ginseng response to inter-annual climate variation suggests that populations are locally adapted to temperature (Souther and McGraw 2011a). Because ginseng populations respond similarly to deviation in annual temperature from site-specific means, we were able to pool demographic data for 12 populations in order to create a robust model of viability response to climate change that included a total of 74 transition matrices (Souther and McGraw 2011a). Using this model, we asked 'Will climate change increase extinction risk for a species adapted to local climate?'. 


\section{Methods}

\section{Study species}

American ginseng (Panax quinquefolius L.) is the United States' premier wild-harvested medicinal plant (Robbins 2000). Particularly in the Appalachian region, harvest of ginseng is a traditional practice, and sale of ginseng in the medicinal plant trade is source of supplemental income to rural, often poor, residents (Robbins 2000). Concerns that ginseng was becoming increasingly scarce prompted ginseng's listing on Appendix II of the Convention on International Trade in Endangered Species of Wild Fauna and Flora (CITES) in 1973 (Robbins 2000). Currently, ginseng harvest is regulated by the U.S. Fish and Wildlife service in collaboration with individual states(Robbins 2000). While considered uncommon, ginseng is widespread, occurring in thousands of small populations from southern Quebec in Canada to northern Georgia in the U.S., and west to the Mississippi River (Anderson et al. 1993). Ginseng is an obligate understory species endemic to eastern deciduous forest. Within this habitat, populations occur on a variety of aspects, and elevations (McGraw et al. 2003).

\section{Census data}

We located at total of 30 populations over a 7-year period (1998-2004). So as not to alter harvester behavior, all known individuals were cryptically tagged, and relocated using a 'phototrail' method, in which photographs, paired with notations of distances and azimuths, guided ginseng relocation. We censused ginseng populations twice annually.

During the first annual census (May $1^{\text {st }}-$ June $15^{\text {th }}$ ), we measured size-related traits, including sympodium height and predictors of leaf area, leaflet length and width (Souther 
and McGraw 2011b). Using a standardized protocol, we also conducted a search for new seedlings in a $2 \mathrm{~m}$ radius around each plant (Van der Voort 2005). Because ginseng seeds are readily counted within the fruit (1-3 seeds per berry), we obtained complete fertility measures during the second annual census (August 1 - August 31).

For this study, we selected 12 populations that had an $\mathrm{N}>100$ for at least 5 consecutive censuses. We chose populations with large $\mathrm{N}$ to assure accurate parameterization of projection matrices used in the viability analysis (Souther and McGraw 2011a). Populations occurred across six states (Indiana, Kentucky, New York, Pennsylvania, Virginia, West Virginia), spanning a range of latitudes $\left(36^{\circ} 54^{\prime} \mathrm{N}-42^{\circ} 38^{\prime} \mathrm{N}\right)$ and longitudes $\left(-74^{\circ} 05^{\prime} \mathrm{E}--84^{\circ} 05^{\prime} \mathrm{E}\right)$ (Souther 2011a). Exact locations of populations are withheld to prevent targeted harvest of ginseng. Study populations were located in a variety of environments, representative of the range of aspects, elevations, and plant community types occupied by ginseng as a species.

\section{Seed cage experiments}

Ginseng seeds may persist in the soil for up to four years. In order to estimate germination and survival rates of seed cohorts of different ages, we conducted a seed cage experiment. We obtained 7,200 seeds from a grower of 'wild-simulated' ginseng in West Virginia. The term 'wild-simulated' refers to a method of ginseng cultivation in which plants are derived from wild stock and grown in 'natural' wooded conditions. Ginseng seeds require an 18-month stratification period before germination. Therefore, prior to seed cage deployment, we bulk stratified ginseng seeds in mesh bags in sand at a 
forested site having a natural ginseng population. We created seed cages by affixing plastic mesh to the base of $8.5 \mathrm{~cm}$ diameter x $8 \mathrm{~cm}$ long segments of black polyvinylchloride pipe. For each population, three groups of four cages (total cages $=12$ ) were placed in three locations evenly distributed across the site. After filling seed cages with native soil, we manually dispersed fifty seeds atop the soil in each cage, then covered cages with a wide-gauge plastic mesh hardware cloth, thus allowing germination, while preventing seed escape and granivory. Annually, after counting germinants, we removed three, randomly selected cages, one from each of the three locations, in order to test seed viability using tetrazolium staining $(\mathrm{N}=3)$ (Roistacher et al. 1953).

\section{Population projection matrices}

Census and seed cage data were used to parameterize 8-stage population projection matrices (A) representing the set of probabilities characterizing rates of survival, growth, and reproduction from one year to the next (Caswell 2001):

$$
A=\left(\begin{array}{cccccccc}
0 & 0 & 0 & 0 & 0 & a_{16} & a_{17} & a_{18} \\
a_{21} & 0 & 0 & 0 & 0 & 0 & 0 & 0 \\
0 & a_{32} & 0 & 0 & 0 & 0 & 0 & 0 \\
0 & 0 & a_{43} & 0 & 0 & 0 & 0 & 0 \\
a_{51} & a_{52} & a_{53} & a_{54} & a_{55} & a_{56} & 0 & 0 \\
0 & 0 & 0 & 0 & a_{65} & a_{66} & a_{67} & a_{68} \\
0 & 0 & 0 & 0 & 0 & a_{76} & a_{77} & a_{78} \\
0 & 0 & 0 & 0 & 0 & a_{86} & a_{87} & a_{88}
\end{array}\right)
$$

The number of plants in each class consisted of all individuals present at the time of the first annual census. The first 4 classes (1-4) were seed cohorts aged 9-months, 21- 
months, 33-months, and 45-months. Seed cohort ages were calculated from the time of seed maturation in August to the time of the first annual census in May. The final four stages (5-8) were size classes of post-germination individuals. These stages consisted of 1-leaf, 2-leaf, small adult, and large adult plants. The number of stages used in this model was a trade-off between accurately characterizing groups of individuals with similar survival and reproduction rates, and allowing adequate parameterization of transition probabilities to and from these classes. One-leaf seedlings exhibited high mortality rates and never produced seeds. After plants attained 2 leaves, survival was much higher, yet seed production was uncommon. Plants with more than 2 leaves (3-5leaf plants) were considered adults, and demonstrated the highest survival and the majority of plants flowered, often resulting in seed production. Once adults, reproduction and survival were better explained by leaf area than leaf number, and consequently we used the median leaf area to divide the adult class into two, roughly equal-sized stages (small and large adults).

Population projection matrix models and their derivatives have become the standard approach to quantifying population growth for plant and animal species with complex life histories and size-dependant vital rates (Caswell 2001). Due to its 'slow' life history, lack of vegetative reproduction, short-lived seed bank, large seed size, and consistent deterministic growth patterns, ginseng is an ideal species for using this methodology. A relatively new approach to population projection studies, the integral projection model, treats size classes as a continuum. For ginseng, because of the existence of discrete seed, seedling, juvenile and adult classes, we chose to use the traditional stage-based approach 
(Caswell 2001). The following sections detail the estimation of matrix elements $\left(\mathrm{a}_{\mathrm{ij}}\right)$ from the field data.

Transition probabilities quantifying seed bank dynamics were calculated from the seed bank experiment. For 7 of the 12 populations two sequential seed cage studies were performed, and for those, results were averaged across experiments. Seed survival $\left(\mathrm{a}_{21}\right.$, $\mathrm{a}_{32}, \mathrm{a}_{43}$ ) from year to $_{t}$ year ${ }_{t+1}$ was estimated directly from seed viability tests, and was calculated as:

$$
a_{i j}=\frac{S_{i}}{S_{j}}
$$

where $\mathrm{i}<5, \mathrm{j}=\mathrm{i}-1$, and $\mathrm{S}$ was mean number of viable seeds remaining in the soil. Germination rates $\left(a_{51}, a_{52}, a_{53}, 54\right)$, quantifying the transition from viable seeds at time $t$ to 1-leaf seedlings (stage 5) at time $\mathrm{t}+1$ were calculated as:

$$
a_{5 j}=\frac{G_{i}}{S_{j}}
$$

where $j=1,2,3,4$, and $\mathrm{G}$ was the number of germinants, and $\mathrm{S}_{\mathrm{j}}$ was the number of viable seeds in stage $\mathrm{j}$. Seed mortality was inferred by subtraction as the proportion of seeds that neither germinated nor survived.

Transition probabilities of post-germination stages included shrinkage $\left(a_{i j}\right.$ where $\left.i<j\right)$, stasis $\left(a_{i j}\right.$ where $\left.i=j\right)$, or growth $\left(a_{i j}\right.$ where $\left.i>j\right)$, and were calculated directly from census data as the proportion of individuals in stage $j$ that transitioned to stage $i$ the following year. Plants missing at the time of the first annual census were assigned a 
stage corresponding to their stage prior to disappearance. Long-term dormancy is uncommon, so death (stage 9) was retroactively assigned after two consecutive years of absence.

Fertility transitions $\left(a_{1 j}\right)$ represent the number of viable seeds in the soil at time $t+1$ that were produced by an individual in stage $j$, per individual of stage $j$ present in the population at time t. Fertilities for juveniles and adults were calculated as:

$$
a_{1 j}=p \frac{\sum S_{j}}{n_{j}}
$$

where $S_{j}$ is the number of seeds produced in stage $\mathrm{j}$ in year $\mathrm{t}$, and $\mathrm{n}_{\mathrm{j}}$ is the total number of individuals in stage $j(j=6,7,8)$ in year t. The multiplier $\mathrm{p}$ is the proportion of seeds produced in August of year $t$ that were present in May of year $t+1$. This multiplier varied among sites due to variation in early seed mortality among sites (e.g., due to seed predation, etc.). Because we directly counted new seedlings and we knew 'expected' rates of survival in the seed pool from seed cage data, we were able to estimate this multiplier, which was unique to each population:

$$
p=\frac{\left(\overline{\frac{G_{o b s}}{0.90}}\right)}{\overline{G_{e}}}
$$

where $\overline{G_{o b s}}$ is the mean number of observed, naturally occurring germinants over a three year period (2008 - 2010), 0.90 is a correction factor to account for the estimated $10 \%$ of seeds that disperse beyond the $2 \mathrm{~m}$ search radius for germinants(McGraw and 
Furedi 2005), and $\overline{G_{e}}$ is the mean number of expected germinants $2008-2010$ given prior seed production and seed bank transition probabilities. We calculated $\mathrm{G}_{\mathrm{e}}$ for each year as:

$G_{e}=\left(\left(S D_{21} \bullet a_{51}\right)+\left(S D_{33} \bullet a_{21} \bullet a_{52}\right)+\left(S D_{45} \bullet a_{32} \bullet a_{53}\right)+\left(S D_{57} \bullet a_{43} \bullet a_{54}\right)\right)$

where SD is the total number of seeds produced $21,33,45$, or 57 months prior to germination, $\mathrm{a}_{21}, \mathrm{a}_{32}, \mathrm{a}_{43}$ are age-related survival rates of seeds in the seed bank, and $\mathrm{a}_{5 \mathrm{j}}$ (where $\mathrm{j}=1,2,3,4$ ) is the germination rate for each cohort of seeds.

Projection matrices (A) were generated for each population over all transition years from 1998-2009, yielding a total of 75 matrices. The finite rate of increase (1) for each matrix was determined from the dominant eigenvalue of the matrix. The 2009-2010 transition was not included, because the fate of missing plants was uncertain. In 2008, we witnessed an illegal harvest event in one ginseng population(McGraw et al. 2010). The harvest was so severe that we could not, with certainty, positively identify a portion of the remaining plants. For this reason, we excluded a priori the 2008-2009 transition for this population. In total, 74 transition matrices were used for the population viability analyses.

\section{Climate data}

In a previous study, we found that daily mean maximum growing season temperature best explained variation in 1 among years for each population. Therefore we used this climate statistic in all subsequent analyses (henceforth, temperature will refer to mean daily maximum growing season temperature) (Souther and McGraw 2011a). We assembled 
temperature data from weather stations located within $50 \mathrm{~km}$ of each population. In 2007 , we placed a HOBO pendant datalogger, suspended from a wooden stake, at a random location at each site, such that the datalogger faced northward and was located a plantlevel (approximately $30 \mathrm{~cm}$ above the soil surface). In order to infer population-specific temperatures, we regressed daily temperatures from $\mathrm{HOBO}$ dataloggers on those derived from climate station data for each population. We then used this regression equation to calculate annual mean growing season temperatures (April 1 - September 30), as well as a 30-year (1971-2000) mean growing season temperatures from climate station records.

\section{Climate change simulations}

We obtained global climate model predictions of mean maximum temperature increase from the Program for Climate Model Diagnosis and Intercomparison's (PCMDI) archive. The PCMDI data portal serves as a repository for data used in the Intergovernmental Panel on Climate Change's (IPCC) fourth assessment report. In this report, climate models project temperature increase for several emissions storylines, described in the IPCC's Special Report on Emissions Scenarios (SRES)(IPCC 2007). These emissions storylines describe different scenarios of fossil fuel use over the next century. For our

analyses, we selected the A1B scenario, a mid-level estimate of greenhouse gas emissions that describes a world of rapid economic growth that relies on both fossil and non-fossil fuels for energy (IPCC 2007). We selected the National Center for Atmospheric Research's (NCAR) CCSM3.0 climate model, which provided climate projection data on a monthly basis in a spatially explicit, gridded format $\left(\right.$ cells $\left.=1.4^{\circ} \times 1.4^{\circ}\right)$. Compared to other modeling groups, the magnitude of temperature increase projected by the NCAR 
CCSM3.0's climate model is average to slightly above average (IPCC 2007). Using these model projections, we estimated mean annual temperature increase by regressing mean annual maximum growing season (April 1 - September 31) temperature on year, the slope of this line giving the mean temperature increase on a per annum basis. We averaged the slope of these regressions across grid cells in which censused populations were present, and across all 4 runs of the NCAR CCSM3.0 climate model, yielding an estimate of mean annual temperature increase for all populations. Variation in annual temperatures from the mean did not vary as a function of climate change, and were normally distributed.

To create stochastic climate projections to drive matrix selection during the population viability analysis, we randomly generated annual temperatures from a normal distribution based on mean temperatures projected by climate models, using the variance of temperatures observed at censused ginseng populations. We generated 1,000, 70-year temperature runs for the A1B warming scenario. In order to examine the sensitivity of population viability to warming, we generated 3 additional climate scenarios: 1) A onethird reduction in warming rate, 2) a two-thirds reduction in warming rate, and 3) a 100 percent reduction in warming rate (no change from the year 2000 temperature mean).

\section{Climate-driven population viability analysis}

The population viability analysis was performed in MATLAB (MATLAB 2009b). Stochastic population projections driven by each of the four climate change scenarios 
formed the basis of our population viability analysis. Starting from an initial population size $\left(\mathrm{N}_{\mathrm{i}}\right)$, each simulation run consisted of a series of annual population projections:

$$
N_{(t+1)}=A_{i} \bullet N_{(t)}
$$

in which the matrix $A_{i}$ corresponding to an annual temperature most similar to the temperature determined by the climate scenario was selected. Thus, as the mean climate warmed over time within any one run, matrices were increasingly selected from the right side of the distribution of temperature-years (Fig. 1). Because temperatures were expressed in terms of deviation from 30-year averages for each population, this did not bias the matrix selection geographically; relatively warm years could be chosen from any population.

Each simulation run proceeded for 70 years, which corresponded with a $1^{\circ} \mathrm{C}$ mean increase in temperature from year 2000 to 2069 . By limiting warming to $1{ }^{\circ} \mathrm{C}$, we prevented oversampling A matrices that corresponded to the 'warmest' temperatures (ca. $+1.5^{\circ} \mathrm{C}$ from current mean temperatures) observed during the demographic census of ginseng populations.

For each simulation run, population response was binary, with the simulation resulting in either population extinction or persistence. The dynamics of small populations are governed by unique demographic and genetic factors (e.g., Allee effects, demographic stochasticity, erosion of genetic variation). Because the net effect of these factors reduces $\mathrm{N}$, most populations are doomed to extinction before $\mathrm{N}=0$ (Morris and Doak 2002). For this reason, in most population viability analyses, a population is considered 
extinct once it drops below a quasi-extinction threshold where $\mathrm{N}>0$. We set the quasiextinction threshold for this PVA at 20 individuals because 1) in an experimental manipulation of ginseng population size, Allee effects were found to decrease $\lambda$ in population sizes $\mathrm{N}<20$ (Hackney and McGraw 2001; McGraw and Furedi 2005), and 2) demographic stochasticity imperils populations when $\mathrm{N}<20$ for many species(Morris 2002). Hence, a population was scored as extinct when $\mathrm{N} \leq 20$.

After 1000 simulation runs were performed, we calculated a probability of persistence (P) as:

$$
P=\frac{N_{v}}{1000}
$$

where $\mathrm{N}_{\mathrm{v}}=$ the number of runs that resulted in persistence $(\mathrm{N}>20)$. A population was designated 'viable' if less than 5\% of runs resulted in extinction (populations persisted in $95 \%$ of runs). A viability threshold of 0.95 is a standard definition of viability (Morris and Doak 2002).

The 1000 runs above were all begun with the same initial population size. In order to identify the minimum viable population size, these 1,000 runs were repeated at 99 different initial Ns. We varied initial $\mathrm{N}$ from the quasi-extinction threshold (20) to $\mathrm{N}=$ 1000 in increments of 10. Minimum viable population (MVP) was defined as that initial $\mathrm{N}$ that resulted in a viable population. 
Finally the entire process described above (99 initial population Ns x 1,000 runs x 70 years/run) was repeated for the 4 climate scenarios. 


\section{Results}

As expected, under any climate scenario, as initial $\mathrm{N}$ was increased, the probability of extinction declined. Warming increased extinction risk at all population sizes compared with a no warming scenario (Fig. 2). The median size of populations that we regularly census was 140 individuals. At this population size, there was a $23 \%$ probability of extinction at the projected rate of warming. By comparison, if no warming occurs, a population of $\mathrm{N}=140$ had almost no chance of extinction $(<0.001)$ (Fig. 2). Under current climatic conditions, the threshold of a viable population after 70 years (i.e., with an extinction risk $\leq 0.05$ ) was reached at $\mathrm{N}=55$ individuals (Fig. 3). By contrast, under SRES A1B predictions, with only a $1^{\circ} \mathrm{C}$ increase in mean maximum growing season temperature, a viable population was 300 individuals (Fig. 3). Minimum viable population size (MVP) increased exponentially with simulated warming (Fig. 3). Of the 30 ginseng populations that we census, all but 4 were smaller than 300 individuals (Fig. 4). The proportion of censused populations that were viable decreased sharply as predicted temperature increase rose (Fig. 5). Under current climatic conditions, $83 \%$ of census populations were considered viable. This number dropped to $13 \%$ in simulations of population response to the highest level of warming (Fig. 5). 


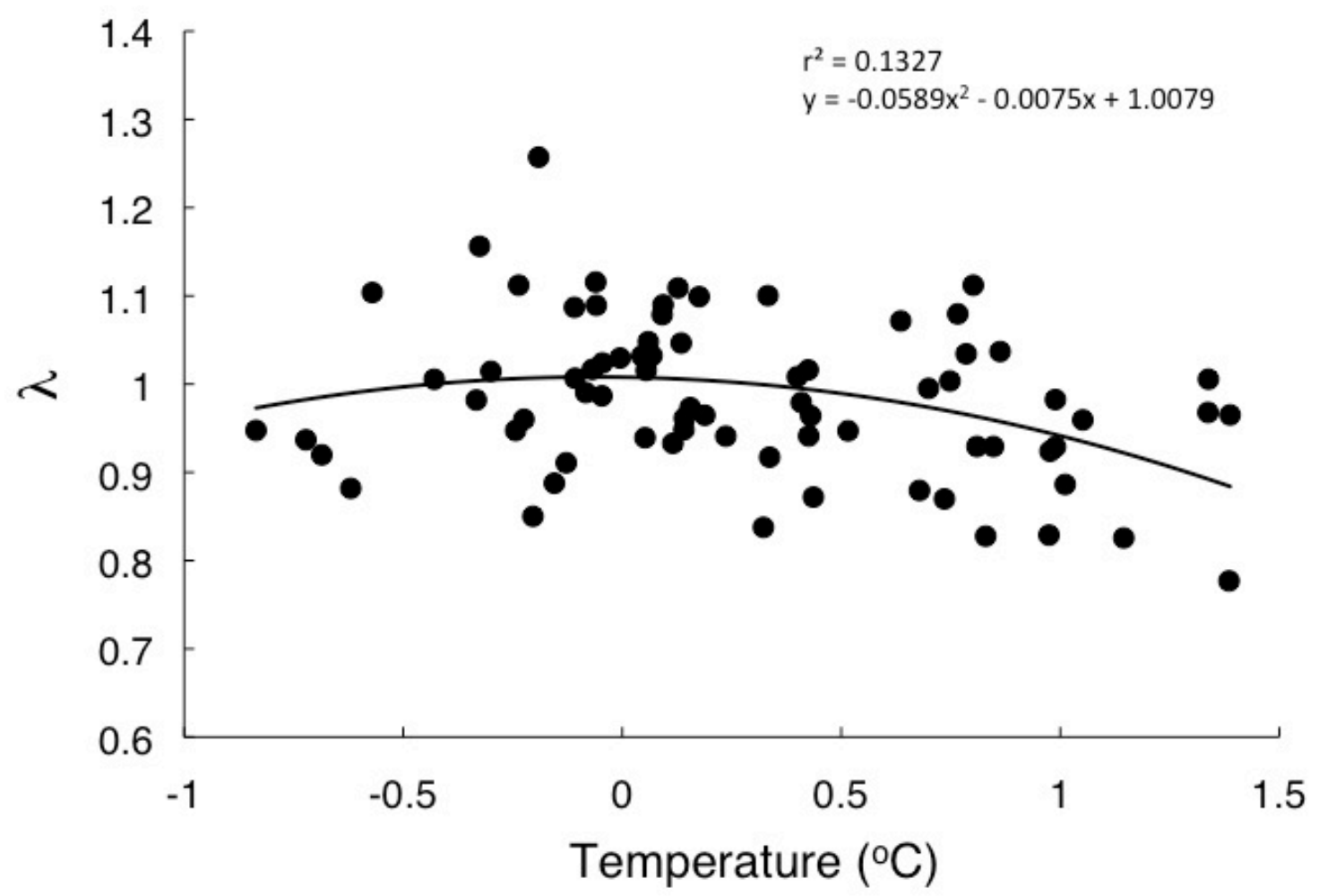

Figure 4.1. Relationship between population growth rate and mean maximum growing season temperature variation. Temperature variation is expressed as the difference between annual temperature and the 30-year (1971-2000) mean. 


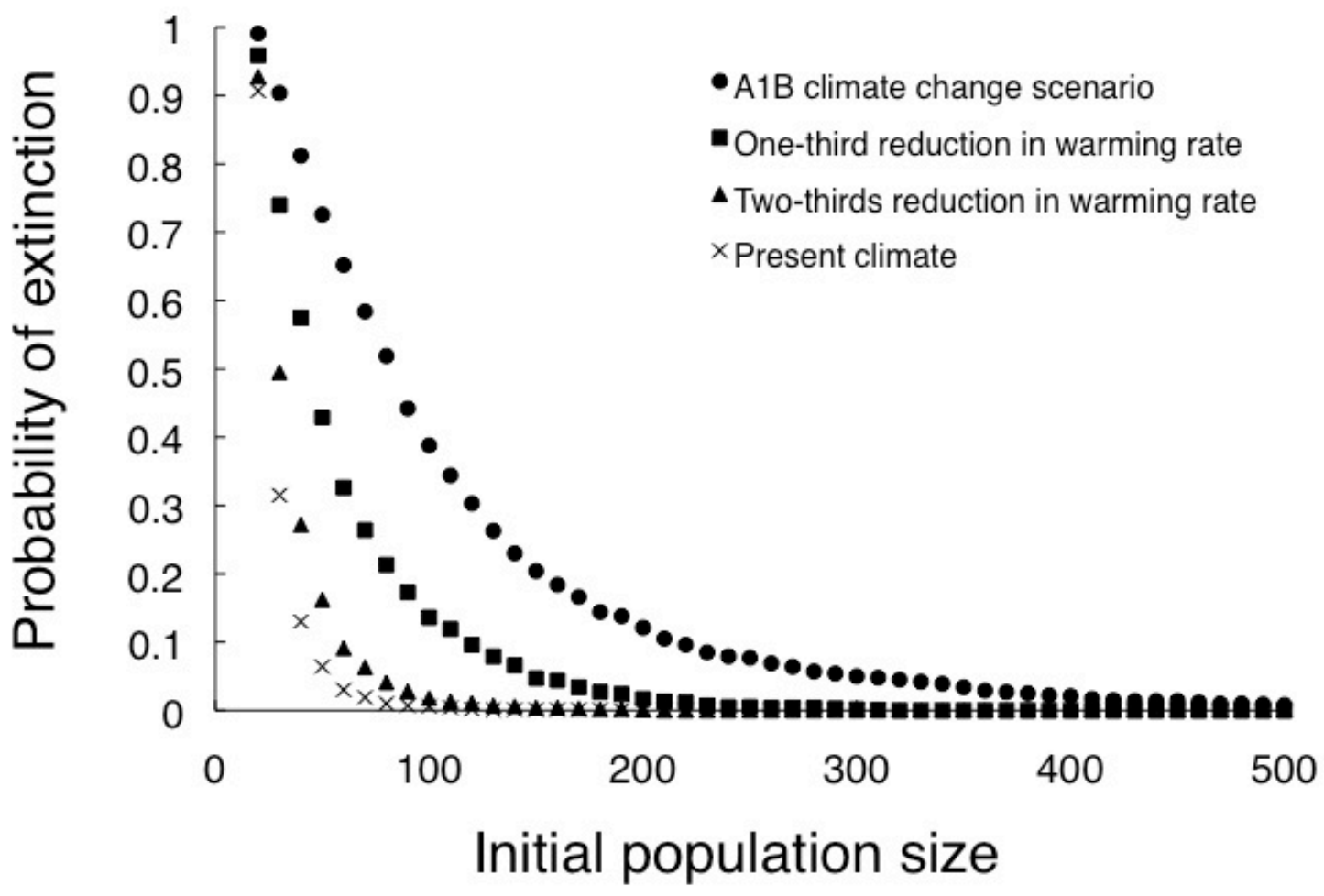

Figure 4.2. Probability of extinction as a function of initial population size for four warming scenarios. 


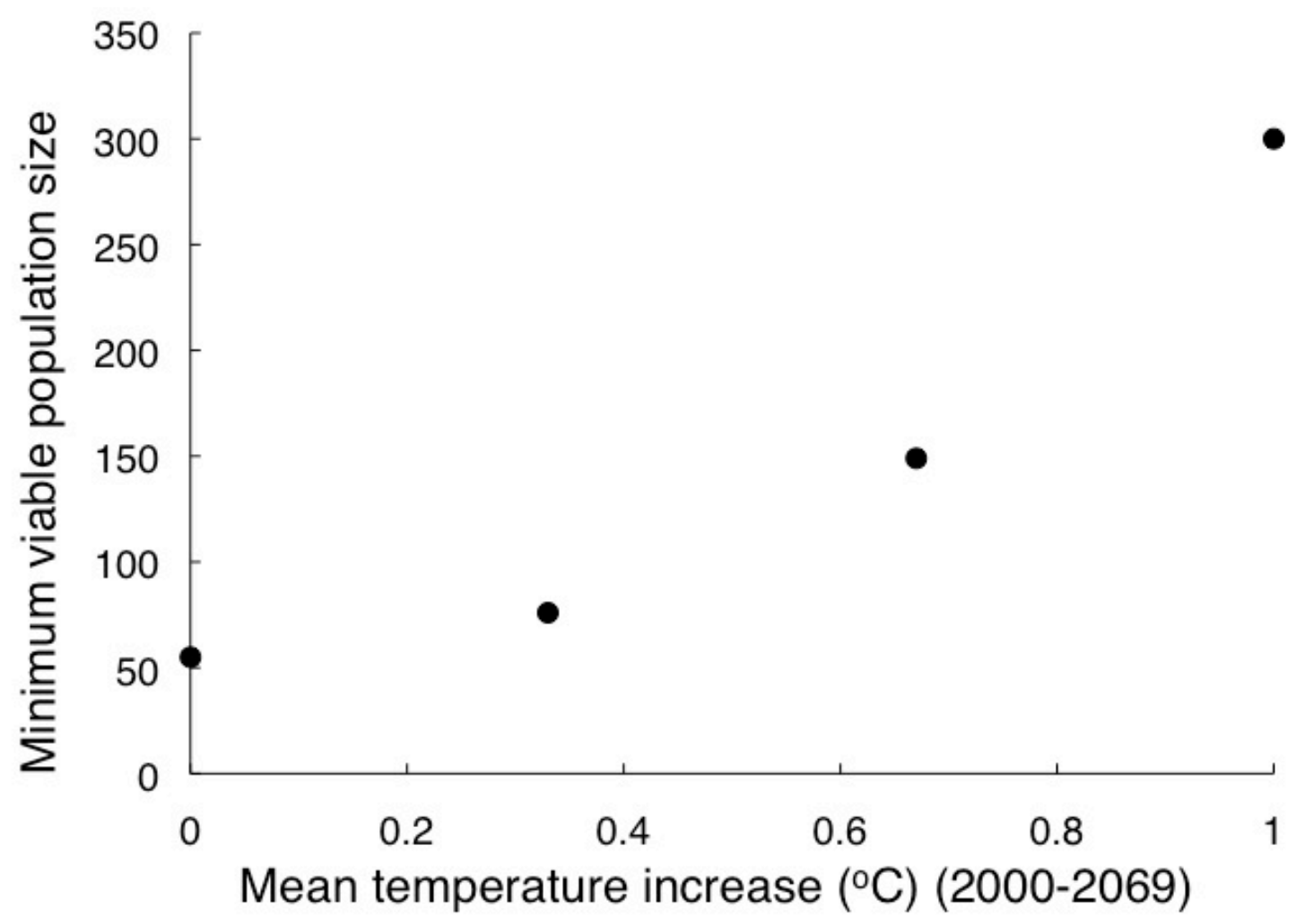

Figure 4.3. Relationship between minimum viable population size and temperature increase. 


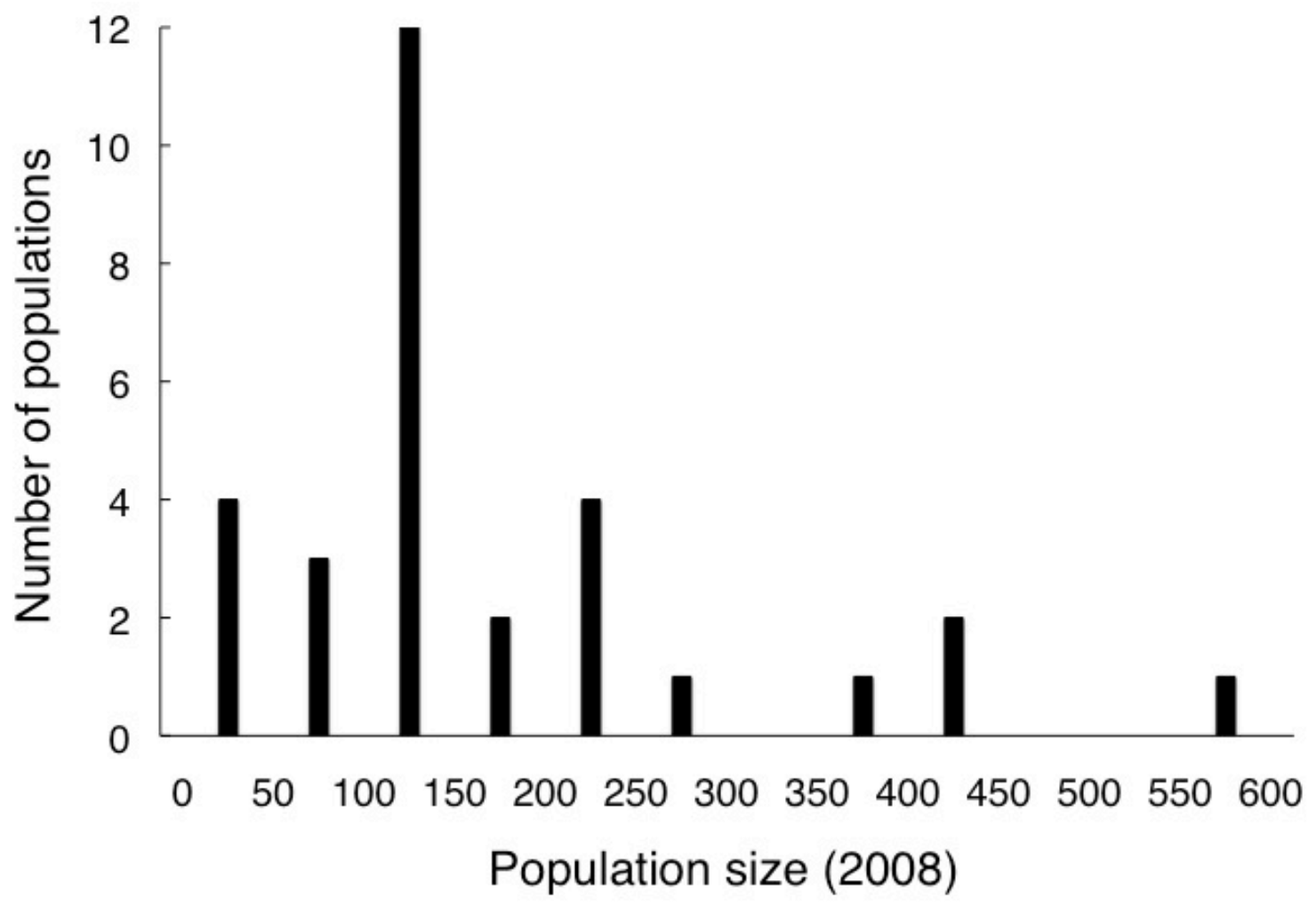

Figure 4.4. Frequency distribution of 2008 population sizes for 30 monitored ginseng populations. 


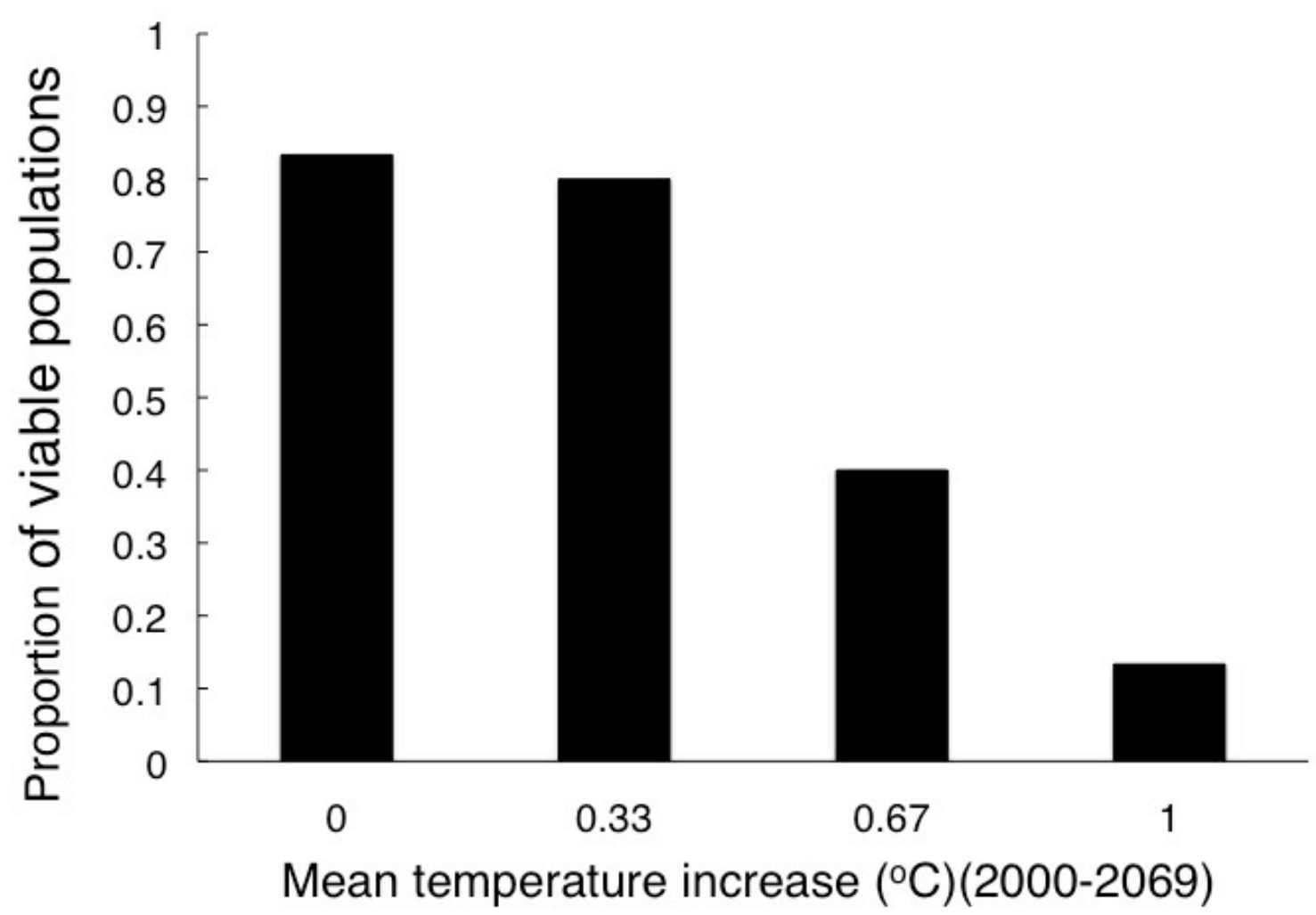

Figure 4.5. Proportion of viable census populations for 4 levels of temperature increase.

The highest level of warming corresponds to mean temperature increase projected for 2069 by the IPCC's SRES A1B scenario, while the remaining 3 temperature levels represent a reduction in projected warming of $100 \%, 67 \%$, and $33 \%$, respectively. 


\section{Discussion}

This population viability analysis suggests that expected rates of climatic warming could sharply decrease ginseng population viability and increase extinction risk. While model projections of ginseng population viability are stark, only $4(\sim 13 \%)$ of the 30 populations that we currently monitor would be considered viable if global temperatures increase at predicted rates, we are likely underestimating extinction risk. In this study, census populations are likely larger on average than natural populations since such populations were both easier to find, and more desirable for the purpose of demographic modeling. For ginseng, small populations are typical, while large populations are rare and tend to occur only in areas protected from harvest and deer browse (McGraw et al. 2003). Alarmingly, minimum viable population size (MVP) increased exponentially with temperature rise. Substantial reduction of the rate of projected warming would be necessary to maintain a majority of viable populations, while small increases in temperature beyond the SRES A1B scenario would quickly increase MVP beyond any known natural population size.

A previous analysis showed that the pattern of ginseng population growth rate response to inter-annual temperature variation suggested adaptation to the local temperature regime (Souther and McGraw 2011a). The current analysis demonstrates that a small degree of warming $\left(1^{\circ} \mathrm{C}\right)$ may increase risk of extinction for even widespread species, if populations have specialized to local temperatures, resulting in a narrow thermal niche breadth. Because ginseng population growth rate is optimized at local climatic conditions, the PVA suggests that directional warming will increase extinction 
risk for all populations throughout ginseng's range. Over the next 70-years, rare, large populations may serve as genetic reservoirs for this species, and are potential conservation targets.

Climate change is not the only threat to ginseng. Factors, such as deer browse (McGraw and Furedi 2005), harvest (Van der Voort and McGraw 2006), and invasive species (Wixted and McGraw 2010) negatively impact ginseng populations. Rarity typically increases market value of wild-harvested products, creating a positive feedback cycle, in which scarcity drives harvest demands, resulting in ever fewer, increasingly sought after individuals. For ginseng, increased rarity mediated by climatic warming could lead to a greater intensity of harvest, precipitating the descent of populations into an extinction vortex. In this way, widespread loss of ginseng due to climatic warming will threaten the sustainability of ginseng harvest, which generates millions of dollars in supplemental income to rural Appalachian families, and is a traditional, cultural practice (Bailey 1999; Robbins 2000).

The current analysis focused on effects of warming, however other environmental factors are changing concomitantly with temperature increase, and may affect the longterm persistence of ginseng. Increased carbon dioxide levels could partially compensate for decreased photosynthetic rates caused by high temperatures, thus ameliorating the negative effects of warming on ginseng population growth. Alterations to precipitation regime will likely affect ginseng demography (Souther and McGraw 2011a), however, changes in precipitation as a function of climate change are difficult to predict (IPCC 2007). Hence, realistically incorporating precipitation effects into models of population response to climate change is difficult, and precipitation changes remain a source of 
uncertainty in these projections. Biotic factors such as disease, deer browse, and insect herbivory may also vary with warming in unpredictable way. Several of these factors, in particular disease and soil moisture, likely co-varied with temperature in this study, and thus are tacitly incorporated into population viability projections of ginseng response to climate change.

Dispersal to northern and upland regions and adaptation to novel climatic conditions may rescue species threatened by climate change (Aitken et al. 2008). However, several lines of evidence indicate that both responses may be limited in ginseng. Studies of within and among population genetic variation suggest short dispersal distances (Cruse-Sanders and Hamrick 2004a; Cruse-Sanders et al. 2005; Grubbs and Case 2004; Mooney 2007), and hence, restricted ability to track rapid climate change spatially. These studies also find low within population genetic variation (CruseSanders and Hamrick 2004a; Cruse-Sanders and Hamrick 2004b; Grubbs and Case 2004), a common attribute of populations with high degree of selfing (Linhart and Grant 1996). Because adaptation to novel climatic conditions requires genetically based phenotypic variation, low within population genetic variation suggests low adaptive potential of ginseng to climate change.

To our knowledge, this is the first study to model the direct effects of warming on extinction risk for a widespread species in which populations are adapted to local temperature regime. Our results are consistent with transplant experiments that show a reduction in fitness when populations are introduced into climatic environments to which populations are not adapted (Linhart and Grant 1996; Turesson 1930). When populations within a widely distributed species adapt to local temperatures, the thermal niche of the 
species is effectively narrower than would be predicted by its distribution. Hence, a less than expected degree of warming given the species' range may be sufficient to threaten long-term persistence. Local adaptation is common across ecosystems, particularly in plants (Linhart and Grant 1996). In a rapidly changing climate, specialization can become transformed to overspecialization. By this mechanism, a significant proportion of global biodiversity may be at greater risk of climate change mediated extinction than previously anticipated. 


\section{Acknowledgments.}

Thank you to M. Van der Voort, MA. Furedi, E. Mooney, M. Kaproth, A. Hanna, K.

Wixted, Z. Bradford and many dedicated undergraduate research interns who helped collect demographic data. We thank the landowners and land managers for granting us access to census populations. This research was funded by National Science FoundationLong Term Research in Environmental Biology grant DEB-0613611, and National Science Foundation Doctoral Dissertation Improvement grant DEB-0909862. We acknowledge the modeling groups, the Program for Climate Model Diagnosis and Intercomparison (PCMDI) and the WCRP's Working Group on Coupled Modelling (WGCM) for their roles in making available the WCRP CMIP3 multi-model dataset. Support of this dataset is provided by the Office of Science, U.S. Department of Energy. 


\section{References}

Aitken SN, Yeaman S, Holliday JA, Wang TL, Curtis-McLane S (2008) Adaptation, migration or extirpation: climate change outcomes for tree populations. Evolutionary Applications 1:95-111

Anderson RC, Fralish JS, Armstrong JE, Benjamin PK (1993) The Ecology and Biology of Panax-Quinquefolium-L (Araliaceae) in Illinois. American Midland Naturalist $129: 357-372$

Bailey B (1999) Social and economic impacts of wild harvested products. In: College of Agriculture, Forestry and Consumer Sciences, vol. Ph.D. West Virginia University, Morgantown, WV, p 111

Caswell H (2001) Matrix Population Model: Construction, Analysis, and Interpretation, Second edn. Sinauer Associates Inc., Sunderland, Massachusetts

Cruse-Sanders JM, Hamrick JL (2004a) Genetic diversity in harvested and protected populations of wild American ginseng, Panax quinquefolius L. (Araliaceae). American Journal of Botany 91:540-548

Cruse-Sanders JM, Hamrick JL (2004b) Spatial and genetic structure within populations of wild American ginseng (Panax quinquefolius L., Araliaceae). Journal of Heredity 95:309-321

Cruse-Sanders JM, Hamrick JL, Ahumada JA (2005) Consequences of harvesting for genetic diversity in American ginseng (Panax quinquefolius L.): a simulation study. Biodiversity and Conservation 14:493-504

Davis MB, Shaw RG (2001) Range shifts and adaptive responses to Quaternary climate change. Science 292:673-679 
Grubbs HJ, Case MA (2004) Allozyme variation in American ginseng (Panax quinquefolius L.): Variation, breeding system, and implications for current conservation practice. Conservation Genetics 5:13-23

Hackney EE, McGraw JB (2001) Experimental demonstration of an Allee effect in American ginseng. Conservation Biology 15:129-136

Hannah L et al. (2002) Conservation of biodiversity in a changing climate. Conservation Biology 16:264-268

Holt RD, Gaines MS (1992) Analysis of Adaptation in Heterogeneous Landscapes Implications for the Evolution of Fundamental Niches. Evolutionary Ecology 6:433-447

Hunter CM, Caswell H, Runge MC, Regehr EV, Amstrup SC, Stirling I (2010) Climate change threatens polar bear populations: a stochastic demographic analysis. Ecology 91:2883-2897

IPCC (2007) Fourth Assessment Report of the Intergovernmental Panel on Climate Change. In. Cambridge University Press, Cambridge

Jenouvrier S, Caswell H, Barbraud C, Holland M, Stroeve J, Weimerskirch H (2009) Demographic models and IPCC climate projections predict the decline of an emperor penguin population. Proceedings of the National Academy of Sciences of the United States of America 106:1844-1847

Linhart YB, Grant MC (1996) Evolutionary significance of local genetic differentiation in plants. Annual Review of Ecology and Systematics 27:237-277

Maschinski J, Baggs JE, Quintana-Ascencio PE, Menges ES (2006) Using population viability analysis to predict the effects of climate change on the extinction risk of 
an endangered limestone endemic shrub, Arizona cliffrose. Conservation Biology $20: 218-228$

MATLAB (2009b). In, 7.9.0.529 edn. The Mathworks Inc.

McGraw JB, Furedi MA (2005) Deer browsing and population viability of a forest understory plant. Science 307:920-922

McGraw JB, Sanders SM, Van der Voort M (2003) Distribution and abundance of Hydrastis canadensis L. (Ranunculaceae) and Panax quinquefolius L. (Araliaceae) in the central Appalachian region. Journal of the Torrey Botanical Society 130:6269

McGraw JB, Souther S, Lubbers AE (2010) Rates of Harvest and Compliance with Regulations in Natural Populations of American Ginseng (Panax quinquefolius L.). Natural Areas Journal 30:202-210

McLaughlin JF, Hellmann JJ, Boggs CL, Ehrlich PR (2002) Climate change hastens population extinctions. Proceedings of the National Academy of Sciences of the United States of America 99:6070-6074

Mooney EH (2007) Genetic and Evolutionary Consequences of Harvest in American ginseng, Panax quinquefolius L. (Araliaceae). In: Department of Biology, vol. Doctorate. West Virginia University, Morgantown, WV, p 192

Morris WF, and Daniel F. Doak (2002) Quantitative Conservation Biology. Sinauer Associates Inc., Sunderland, MA

Parmesan C, Yohe G (2003) A globally coherent fingerprint of climate change impacts across natural systems. Nature 421:37-42 
Robbins CS (2000) Comparative analysis of management regimes and medicinal plant trade monitoring mechanisms for American ginseng and goldenseal. Conservation Biology 14:1422-1434

Roistacher CN, Bald JG, Baker KF (1953) The tetrazolium test for dormancy and germinability of gladiolus cormels. Science 118:186-187

Root TL, Price JT, Hall KR, Schneider SH, Rosenzweig C, Pounds JA (2003) Fingerprints of global warming on wild animals and plants. Nature 421:57-60

Souther S, and James B. McGraw (2011a) Signal of local adaptation in the demographic response of American ginseng to inter-annual temperature variation. Conservation Biology in press

Souther S, McGraw, J. (2011b) Vulnerability of wild American ginseng to an extreme early spring temperature fluctuation. Population Ecology 53:119-129

Thuiller W (2007) Biodiversity - Climate change and the ecologist. Nature 448:550-552

Turesson G (1930) The selective effect of climate upon the plant species. Hereditas 14:99-152

Van der Voort M (2005) An ecological study of Panax quinquefolius in central Appalachia: seedling growth, harvest impacts and geographic variation in demography. In: Department of Biology, vol. Doctor of Philosophy in Biology. West Virginia University, Morgantown, WV, p 176

Van der Voort ME, McGraw JB (2006) Effects of harvester behavior on population growth rate affects sustainability of ginseng trade. Biological Conservation $130: 505-516$ 
Walther GR et al. (2002) Ecological responses to recent climate change. Nature 416:389395

Wixted KL, McGraw JB (2010) Competitive and allelopathic effects of garlic mustard (Alliaria petiolata) on American ginseng (Panax quinquefolius). Plant Ecology $208: 347-357$ 


\section{CHAPTER V:}

\section{EXPERIMENTAL TEST FOR ADAPTIVE DIFFERENTIATION OF GINSENG POPULATIONS TO TEMPERATURE I: A GROWTH}

\section{CHAMBER STUDY.}




\begin{abstract}
Local climatic adaptation may influence species' response to climate change. If populations within a species are adapted to local climate, directional change away from mean climatic conditions will negatively affect fitness of populations throughout the species' range. We tested for adaptive differentiation of populations of American ginseng (Panax quinquefolius L.) with respect to temperature by reciprocally transplanting individuals from two ginseng populations, whose sites of origin differed in elevation, among temperature treatments in a controlled growth chamber environment. The response of populations to temperature treatments differed among populations, suggesting genetic differentiation of populations. However, the pattern of response of fitness-related dependent variables generally did not suggest 'home-site' advantage, as would be expected if populations were locally climatically adapted. Failure to consistently detect a 'home-site' advantage response suggests that the nature of adaptation to temperature is complex, and environmental factors that naturally covary with temperature in the field may be critical to understanding the nature of adaptation to temperature.
\end{abstract}




\section{Introduction}

Local adaptation refers to intra-specific genetic differentiation of populations such that local genotypes have higher fitness in their home-sites relative to foreign genotypes (Antonovics 2006; Bennington and McGraw 1995; Etterson 2004; Futuyma and Moreno 1988; Kaltz and Shykoff 1998; Kawecki and Ebert 2004; Linhart and Grant 1996; McGraw 1987; Savolainen et al. 2007). Heterogeneous selective forces within a species' range promote specialization of populations to local environmental conditions (Futuyma and Moreno 1988; Kawecki and Ebert 2004). Evolution of locally adapted populations (referred to as 'ecotypes') occurs when gene flow and genetic drift are too weak to counteract selection (Futuyma and Moreno 1988; Kawecki and Ebert 2004). If selection is sufficiently strong, adaptive differentiation can occur even when gene flow is high (Antonovics 2006; Bennington and McGraw 1995; Futuyma and Moreno 1988; Kawecki and Ebert 2004; Linhart and Grant 1996). For local adaptation to occur, there is a requisite fitness trade-off, such that morphological or physiological traits that increase fitness in one environment incur a fitness cost in a different environment. Adaptive differentiation of populations would not occur if a single genotype could gain superiority in all environments (Futuyma and Moreno 1988; Kawecki and Ebert 2004).

Reciprocal transplant experiments are the standard test for local adaptation (Futuyma and Moreno 1988; Kawecki and Ebert 2004; Linhart and Grant 1996). In such experiments, populations are reciprocally transplanted among sites in order to compare performance of 'home' versus 'non-local' genotypes in each population's home-site. A population by environment interaction, such that populations demonstrate a 'home-site' advantage, indicates local adaptation (Kawecki and Ebert 2004). Reciprocal transplant 
experiments can be modified to explore adaptive differentiation of populations to specific environmental factors. In such an experiment, gardens comprised of various populations or genotypes are established across an environmental gradient (e.g. elevation) (Linhart and Grant 1996). A clinal response of morphological, physiological, reproductive, or phenological traits along the environmental gradient is indicative of intra-specific adaptive differentiation (Linhart and Grant 1996; Savolainen et al. 2007). Such experiments have demonstrated population-level adaptation to a variety of selective forces, including, but not limited to, heavy metals and other edaphic factors, light regime, and climate (Linhart and Grant 1996).

Specialization to local conditions may be adaptive in a stable environment, but may be a fitness liability in a dynamic environment (Holt 2009; Holt and Barfield 2008; Holt and Gaines 1992). For species adapted to local climate, directional climate change may push populations from fitness peaks, and threaten long-term persistence (Davis and Shaw 2001; Davis et al. 2005). Past transplant studies along elevational or latitudinal gradients, which served as a proxy for climate gradients, have shown that alteration in climate regime can levy large fitness costs (Etterson 2004; Savolainen et al. 2007). For instance, Etterson (2004) demonstrated that non-local genotypes of Chamaecrista fasciculate experienced up to $96 \%$ reduction in seed production compared to local genotypes in a transplant experiment across a latitudinal gradient. Relative to the range of climatic conditions occupied by the species, the population-level climatic niche breadth is reduced if populations are adapted to local climate. This means that the geographic range of a species may not be a good indicator of the species' thermal niche if populations are locally climatically adapted. If future climatic conditions exceed the 
population-level climatic niche, climate change may initiate decline of all populations throughout a species' range, even if the species is widespread (Souther and McGraw 2011a). Similarly, population decline may result following smaller change in climate than would be expected given the spatial distribution of the species. Given the serious implications of local adaptation for species' response to climate change, tests for local climatic adaptation are germane to species conservation, both in terms of predicting species' response to climate change and also in terms of constructing appropriate conservation strategies.

A signal of local adaptation to temperature was detected in the demographic response of American ginseng populations to inter-annual temperature variation (Souther 2011a). As annual temperatures deviated from site-specific means, population growth rate $(\lambda)$ decreased (Souther and McGraw 2011a). In this study, we conducted a growth chamber experiment using two populations of ginseng, one from a high elevation site and one from a mid-elevation site, to investigate two questions: 1) Is there a genetic basis to ginseng response to temperature? 2) What are the effects of temperature on ginseng survival, growth, reproduction, and basic physiology? In a traditional reciprocal transplant approach to study differential population response to temperature, individuals are transplanted to gardens created along an altitudinal or latitudinal gradient (Linhart and Grant 1996). However, environmental factors, such as species composition and precipitation, covary with temperature along these gradients. Using growth chambers to manipulate mean temperature, while maintaining other environmental factors constant, we could better isolate temperature effects on ginseng biology. Based on evidence suggesting that ginseng populations are adapted to local temperature conditions (Souther 
and McGraw 2011a), we anticipated that ginseng response to temperature will be genetically based. We also expected that fitness-related traits would be maximized at temperature conditions approximating each population's home-site. 


\section{Methods}

Study species.

American ginseng (Panax quinquefolius L.) is a wild harvested medicinal herb endemic to the understory of the eastern deciduous forest of North America (Anderson 1996; Anderson et al. 1993; McGraw et al. 2003; Robbins 2000). Annually, the harvest of ginseng generates millions of dollars in supplemental income for Appalachian families (Bailey 1999; Robbins 2000). Concerns that ginseng was becoming increasingly rare due to overharvest prompted the 1975 listing of ginseng on Appendix II of the CITES (Convention on International Trade in Endangered Species of Fauna and Flora) treaty (Robbins 2000). Harvest of ginseng is currently regulated by the U.S. Fish and Wildlife Service (Robbins 2000).

Ginseng has a mixed mating system, and does not reproduce vegetatively or by apomixis (Lewis and Zenger 1983; Schlessman 1985). Ginseng flowers are small, whitish-green, 5-merous, and hermaphroditic (Lewis and Zenger 1983; Schlessman 1985). Known pollinators of ginseng include syrphid flies and halictid bees, both generalist pollinators (Lewis and Zenger 1983; Schlessman 1985). Ginseng berries are red and fleshy, and contain between 1 and 3 seeds. Seeds are believed to be primarily gravity dispersed, though caching by chipmunks has been documented, and certainly other animals, such as birds, are potential dispersers (Van der Voort 2005). Studies of genetic variation in natural populations find low within population genetic variation, and

high among population genetic variation (Cruse-Sanders and Hamrick 2004; Grubbs and Case 2004). 


\section{Source populations.}

In order to test for a genetic basis of ginseng response to temperature, we selected populations of American ginseng from sites differing in mean temperature conditions. Using elevation as a proxy for temperature, two populations, occurring at a high and a mid-elevation site (780m, 340m, respectively) were located, marked, and mapped in northern West Virginia in fall 2008. Precise locations are withheld to prevent targeted harvest of remaining individuals at each site, as well as nearby populations. Herein, we refer to the high elevation population as LowT Population, and the mid elevation population as MedT Population.

\section{Transplant procedure.}

In April 2009, prior to spring emergence, 156 ginseng roots with attached rhizomes $(\mathrm{n}=$ 96, LowT Population, $\mathrm{n}=60$, MedT Population, respectively) were carefully excavated, cleaned of soil, weighed, and aged (Anderson 1993). In order to prevent transport of soilborne pathogens to growth chamber facilities, roots were sterilized using a $10 \%$ bleach solution (Hackney 1999). Cleaned roots were individually wrapped in moist paper towels, placed inside plastic bags, and transported on ice in coolers to growth chamber facilities at the McGill Phytotron in Montreal, Quebec, Canada. Roots were transplanted to 7.5" Fiber Grow nursery pots (MYE Canadian Operations Incorporated) filled with growth medium (see below) within 48 hours of packaging the roots for transport.

\section{Growth medium.}


We collected soil from each population's site and homogenized equal parts of these soils as growth substrate. We combined soil from both sites in order to replicate natural soil conditions, while maintaining uniform conditions among all treatments that did not provide either population with an a priori 'home-site' advantage with respect to edaphic factors. To reduce risk of introduction of soil-borne pathogens into the growth chamber facilities, soil was sterilized by autoclaving for 1 hour on the dry cycle at 60psi. Ginseng typically occurs on well-drained soils, particularly on sloped terrain (Anderson et al. 1993). In order to replicate this in a growth chamber environment, sterile perlite and sand in equal parts were added to the soil mixture, such that the perlite-sand mixture comprised $50 \%$ of the growth medium.

\section{Temperature treatments.}

In order to set growth chamber conditions, daily 30-year (1971-2000) mean maximum and minimum temperature data were obtained from two local weather stations located less than $25 \mathrm{~km}$ from each population's site. In order to account for elevation-related temperature differences between climate stations and source population sites, temperature data were corrected using the moist adiabatic lapse rate. Three temperature treatments were created; the low treatment corresponded to mean temperature conditions at the LowT Population, the medium treatment corresponded roughly to the MedT Population site (LowT Population temperature $+3^{\circ} \mathrm{C}$ ), and the high temperature treatment represented 'future' climatic conditions projected by climate models (LowT Population temperature $+6^{\circ} \mathrm{C}$ ). Climate models project a mean global temperature increase of between $1.1-5.8^{\circ} \mathrm{C}$ by the end of the century (IPCC 2007). The high temperature 
treatment $\left(+3{ }^{\circ} \mathrm{C}\right.$ for the MedT Population; $+6^{\circ} \mathrm{C}$ for the LowT Population) bracketed several warming scenarios that ranged from mid-to-high severity in terms of extent of temperature increase (IPCC 2007).

\section{Growth chamber parameters.}

Temperatures in the growth chambers were changed on a weekly basis to parallel seasonal temperature change experienced by source populations in their natural habitat. Daily maximum and minimum temperatures corresponded to weekly mean maximum and minimum temperatures for each temperature treatment (low, medium, high). Over each 24-hour period, growth chamber temperatures were gradually ramped between temperature minima and maxima over a 6-hour period, and remained at both the daily maximum and minimum temperature for 6 hours. Day length also changed on a weekly basis, and corresponded to the average weekly day length in West Virginia. Light levels were set at $40 \mu \mathrm{mol}^{*} \mathrm{~m}^{-2} * \mathrm{~s}^{-1}$, simulating understory light conditions (Kota 2005). Understory plants $(>0.05 \mathrm{~m})$ experience naturally high carbon dioxide levels that vary substantially during the course of the day and throughout the growing season (Bazzaz and Williams 1991). Carbon dioxide levels for all growth chambers were set at 410 ppm; a level that is $\sim 30 \mathrm{ppm}$ above current ambient atmospheric conditions, and that corresponds to $\mathrm{CO}_{2}$ levels near the forest floor in summer (Bazzaz and Williams 1991). Seventy percent humidity was maintained within the growth chambers. We did not want to confound the effects of temperature with soil moisture, so plants were watered every 1 3 days as necessary to maintain moist soil conditions. Consequently, plants in the warmer temperature treatments were watered more frequently. 


\section{Experimental design.}

An equal number of plants from each population were randomly assigned to 1 of the 3 temperature treatments, and placed into the corresponding growth chamber. To control for growth chamber differences, treatments and corresponding plants were rotated among growth chambers on a monthly basis. To account for environmental gradients within growth chambers, plants within growth chambers were rotated weekly.

Plants received treatments for two consecutive growing seasons $\left(\sim\right.$ April $20^{\text {th }}-$ September $\left.30^{\text {th }}\right)$. After the first growing season, plants were over-wintered in a lath house at Gault Nature Reserve. We submerged plants, within their pots, in sand, flush to pot soil level. To insulate against extreme winter temperatures of Quebec, pots were covered with fiberglass insulation and heavy plastic sheeting after complete foliar dehiscence. At the onset of year 2 of the experiment (April 2010), we fertilized all plants with $200 \mathrm{ml} 50 \%$ Hoagland's 20-20-20 nutrient solution to simulate spring influx of nutrients from litter decomposition. This was the only nutrient application in the course of the two-season experiment.

\section{Dormancy and Survival.}

Ginseng dormancy is regularly observed in ginseng populations, and is believed to result from injury incurred by the bud, root, rhizome, or shoot early in the growing season. We scored ginseng presence and absence both years. At the end of the experiment, the fate of 
death was assigned when the root was completely missing. If a root was present, but there was no shoot, the plant was considered dormant, but not dead.

\section{Growth measurements.}

During the first week of July of 2009 and 2010, after ginseng had terminated leaf expansion, we collected size-related measurements, including leaf area, sympodium height, and peduncle length. Leaf area was estimated from foliar measurements, using a previously derived regression equation that related leaflet length and width to leaf area (Souther and McGraw 2010). At the termination of the experiment, roots were separated from shoots, cleaned, and weighed with the same protocol used prior to transplantation. Fresh weight of aboveground biomass (leaves, sympodium, peduncle) was measured. Aboveground biomass was dried at $65^{\circ} \mathrm{C}$ for 48 hours.

We calculated relative growth rate of leaf area $\left(\mathrm{RGR}_{\mathrm{LA}}\right)$ as:

$$
R G R_{L A}=\frac{\ln \left(L A_{2}\right)-\ln \left(L A_{1}\right)}{t_{2}-t_{1}}
$$

where LA is leaf area and $t$ is time (McGraw and Garbutt 1990). Relative growth rate of the sympodium ( RGR $\left._{\mathrm{SYM}}\right)$, root $\left(\mathrm{RGR}_{\mathrm{ROOT}}\right)$, and peduncle $\left(\mathrm{RGR}_{\mathrm{PED}}\right)$ were calculated using this same formula, with sympodium height, fresh root weight, and peduncle length in place of LA.

Reproductive measurements. 
We conducted floral bud counts during the first week of July $(2009,2010)$. At the end of September, we counted ginseng berries and seeds. The number of seeds per bud was calculated by dividing the total seed number per plant by the total bud number per plant. Change in bud number, seed number, and seeds produced per bud over the study period was calculated by subtraction of measurements in 2009 from those in 2010. In 2010, we measured berry mass per seed producing plant. We calculated mean berry weight per seed by dividing the bulk berry weight by seed number for each plant.

\section{Physiological measurements.}

Photosynthesis and respiration were measured using a Li-Cor 6400 Portable Photosynthesis System over a 5-day period in July 2010. During this time, growth chambers were programmed so that temperatures remained constant at the weekly temperature maximum and minimum, except during a 1-hour period in which temperatures changed between these two states. We randomly selected 10 plants from each population in each temperature treatment $(n=10)$ on which to measure gas exchange. We measured photosynthesis and respiration at the weekly maximum temperature for each temperature treatment.

Photosynthesis was measured between 7:00 am - 12:00 pm and from 1:00 pm-6:00 pm. To avoid systematic error in photosynthetic measures caused by diurnal variation in photosynthetic rate, the order of photosynthetic measurements within and among temperature treatments was randomly assigned. Net photosynthesis $\left(\mathrm{A}_{\max }\right)$ was measured at ambient light levels, $40 \mu \mathrm{mol}^{*} \mathrm{~m}^{-2} \mathrm{~s}^{-1}$, and at light saturation, $500 \mu \mathrm{mol} * \mathrm{~m}^{-2} * \mathrm{~s}^{-1}$ 
(saturating light level determined by creating a photosynthetic light response curve). Carbon dioxide levels were kept constant at 380ppm. Respiration was measured using the same procedures as above, but in the absence of light, between 9:00 pm - 12:00 am.

Phenological measurements, physical appearance, \& allocation.

Emergence was scored on May $8^{\text {th }} 2009$, and April $20^{\text {th }} 2010$. Plants were scored by visually assessing plants against 6 pre-determined phenophases ( 1 being the least developed and 6 being the most developed) that differed in degree of sympodium development, erectness, and foliar expansion. In July 2009 \& 2010 while performing bud counts, we measured flowering phenology by tallying the number of floral buds in each of three flowering states (pre-anthesis, anthesis, and post-anthesis) per plant. During seed counts in September, we examined berry-ripening phenology by counting the number of green (unripe) and red (ripe) berries for each plant. At this time in 2010 we also scored senescence level. Senescence level was assessed visually. Plants that had little to no browning (brown leaf area $<5 \%$ total leaf area) were assigned a senescence level of 1 . Plants with mild foliar browning (5 - 25\% of total leaf area) were assigned a senescence level of 2 , those with severe browning ( $26-75 \%$ of total leaf area) a level of 3 , and those that were nearly totally brown ( $75-100 \%$ of total leaf area) 4 . Root to shoot ratio was calculated by dividing the wet weight of the root and rhizome by the wet weight of the shoot (leaves, sympodium, peduncle). Although dry weights would have been preferable, the valuable roots were conserved for future research. 


\section{Analyses}

For all analyses, model effects included temperature, population, and

temperature*population. As is the case with many plant species, size strongly influences survival and reproduction in ginseng, and there were initial differences in plant size among individuals and between the 2 study populations. For this reason, a metric of size was used as a covariate in most analyses (Table 1). For dormancy, survival, and growthrelated analyses, we used the covariate initial root weight. Because reproduction varies as a function of leaf area (Mooney and McGraw 2009), leaf area corresponding to the year of reproduction (e.g. response variable $=$ bud production year 1 , covariate $=$ leaf area year 1) was used as a covariate in all analyses of reproductive traits. Plants grew to large sizes the $2^{\text {nd }}$ year of the study, and we suspected that taller plants might have competitively suppressed smaller individuals via shading. To account for this, sympodium height was also included as a covariate in year 2 analyses of reproduction variables. If the covariate was non-significant, it was removed from the analysis, and the analysis was rerun.

Several outliers were excluded from analyses (Table 1). In the second year of the study, 3 pots were dropped during the rotation of treatments among growth chambers, resulting in a loss of that season's shoot. These 3 plants were excluded from analyses of $2^{\text {nd }}$ year dormancy and survival. During the transplantation process the vegetative buds of 10 plants were damaged, resulting in foliar deformities in year 1 of the experiment. We excluded individuals for which damage was noted from the analysis of $\mathrm{RGR}_{\mathrm{LA}}$. Root to shoot ratio was calculated using wet weights. Five plants were excluded from the 
analysis of root to shoot ratio because they had senesced and were completely desiccated at the time of harvest, making the comparison with other plants invalid.

For all analyses with a continuous dependent variable, a 2-way analysis of variance (ANOVA) was used to analyze data (Table 1). A G-test was used for analyses in which the dependent variable was nominal (Table 1). Where necessary, data were transformed to improve normality (Table 1). 
Table 5.1. Details of statistical analyses by dependent variable. 


\begin{tabular}{|c|c|c|c|c|}
\hline Dependent variable & Covariate(s) & Excluded & Analysis & Transformation \\
\hline (P/A) 2009 & Initial root weight & None & G-test & None \\
\hline (P/A) 2010 & Initial root weight & 3 dropped plants & G-test & None \\
\hline Overall survival & Initial root weight & 4 dropped plants & G-test & None \\
\hline $\mathrm{RGR}_{\mathrm{LA}}$ & Initial root weight & $\begin{array}{c}10 \text { plants with } \\
\text { damaged leaves \& } \\
\text { MPs }\end{array}$ & 2-way ANOVA & Square-root \\
\hline $\mathrm{RGR}_{\mathrm{SYM}}$ & Initial root weight & MPs & 2-way ANOVA & None \\
\hline $\mathrm{RGR}_{\text {ROOT }}$ & None & 4 dead plants & 2-way ANOVA & Square-root \\
\hline Peduncle length 2009 & Leaf area 2009 & $\begin{array}{l}\text { Non-reproductive } \\
\text { plants \& MPs }\end{array}$ & 2-way ANOVA & None \\
\hline Peduncle length 2010 & $\begin{array}{c}\text { Leaf area } 2010 \& \\
\text { Height } 2010\end{array}$ & $\begin{array}{l}\text { Non-reproductive } \\
\text { plants \& MPs }\end{array}$ & 2-way ANOVA & None \\
\hline $\mathrm{RGR}_{\mathrm{PED}}$ & Leaf area 2010 & $\begin{array}{c}\text { Non-reproductive } \\
\text { plants }(2009,2010) \\
\& \text { MPs }\end{array}$ & 2-way ANOVA & Log transformed \\
\hline $\begin{array}{l}\text { Produced bud }(\mathrm{Y} / \mathrm{N}) \\
2009\end{array}$ & Leaf area 2009 & 1-leaf plants \& MPs & G-test & None \\
\hline $\begin{array}{l}\text { Produced buds }(\mathrm{Y} / \mathrm{N}) \\
2010\end{array}$ & Leaf area 2010 & 1-leaf plants \& MPs & G-test & None \\
\hline Bud number 2009 & Leaf area 2009 & $\begin{array}{l}\text { Non-reproductive } \\
\text { plants \& MPs }\end{array}$ & 2-way ANOVA & None \\
\hline Bud number 2010 & $\begin{array}{c}\text { Leaf area } 2010 \& \\
\text { Height } 2010\end{array}$ & $\begin{array}{l}\text { Non-reproductive } \\
\text { plants \& MPs }\end{array}$ & 2-way ANOVA & Square-root \\
\hline $\begin{array}{c}\text { Produced seeds }(\mathrm{Y} / \mathrm{N}) \\
2009\end{array}$ & Leaf area 2009 & $\begin{array}{l}\text { Non-reproductive } \\
\text { plants \& MPs }\end{array}$ & G-test & None \\
\hline $\begin{array}{c}\text { Produced seeds }(\mathrm{Y} / \mathrm{N}) \\
2010\end{array}$ & Leaf area 2010 & $\begin{array}{l}\text { Non-reproductive } \\
\text { plants \& MPs }\end{array}$ & G-test & None \\
\hline Seed number 2009 & Leaf area 2009 & $\begin{array}{c}\text { Non-seed producers } \\
\& \text { MPs }\end{array}$ & 2-way ANOVA & None \\
\hline Seed number 2010 & Height 2010 & $\begin{array}{c}\text { Non-seed producers } \\
\& \text { MPs }\end{array}$ & 2-way ANOVA & $\begin{array}{l}\text { Cube-root } \\
\text { transformed }\end{array}$ \\
\hline Seeds per bud 2009 & Leaf area 2009 & $\begin{array}{l}\text { Non-reproductive } \\
\text { plants \& MPs }\end{array}$ & 2-way ANOVA & None \\
\hline Seeds per bud 2010 & Height 2010 & $\begin{array}{l}\text { Non-reproductive } \\
\text { plants \& MPs }\end{array}$ & 2-way ANOVA & None \\
\hline $\begin{array}{c}\text { D bud number (2009- } \\
2010)\end{array}$ & $\begin{array}{c}\text { Leaf area } 2010 \& \\
\text { Height } 2010\end{array}$ & $\begin{array}{l}\text { 1-leaf plants \& MPs } \\
(2009,2010)\end{array}$ & 2-way ANOVA & Square-root \\
\hline
\end{tabular}




\begin{tabular}{|c|c|c|c|c|}
\hline Dependent variable & Covariate(s) & Excluded & Analysis & Transformation \\
\hline $\begin{array}{l}\text { D seed number (2009- } \\
2010)\end{array}$ & Height 2010 & $\begin{array}{c}\text { Non-reproductive } \\
\text { plants \& MPs (2009, } \\
2010)\end{array}$ & 2-way ANOVA & None \\
\hline $\begin{array}{l}\text { D seed per buds } \\
(2009-2010)\end{array}$ & None & $\begin{array}{c}\text { Non-reproductive } \\
\text { plants \& MPs (2009, } \\
2010)\end{array}$ & 2-way ANOVA & None \\
\hline Weight per seed 2010 & None & $\begin{array}{l}\text { Non-seed producers } \\
\text { \& MPs }\end{array}$ & 2-way ANOVA & None \\
\hline Bulk berry weight & $\begin{array}{c}\text { Leaf area } 2010 \& \\
\text { Height } 2010\end{array}$ & $\begin{array}{l}\text { Only seed producers } \\
\text { 2nd year \& MPs }\end{array}$ & 2-way ANOVA & Square-root \\
\hline Root: Shoot & None & $\begin{array}{c}\text { Non-seed producers } \\
\& \text { MPs \& } \\
\text { desiccation plants }\end{array}$ & 2-way ANOVA & None \\
\hline Desiccation level & None & MPs & 2-way ANOVA & None \\
\hline Bud phenology 2009 & None & $\begin{array}{c}\text { Non-reproductive } \\
\text { plants \& MPs }\end{array}$ & 2-way ANOVA & None \\
\hline Bud phenology 2010 & None & $\begin{array}{c}\text { Non-reproductive } \\
\text { plants \& MPs }\end{array}$ & 2-way ANOVA & None \\
\hline Emergence 2009 & None & MPs & 2-way ANOVA & None \\
\hline $\begin{array}{c}\text { Photosynthesis (PAR } \\
=500)(2010)\end{array}$ & Plant $\left(\mathrm{T}^{*} \mathrm{P}\right)$ & None & 2-way ANOVA & None \\
\hline $\begin{array}{c}\text { Photosynthesis (PAR } \\
=40)(2010)\end{array}$ & $\operatorname{Plant}\left(\mathrm{T}^{*} \mathrm{P}\right)$ & None & 2-way ANOVA & None \\
\hline Respiration 2010 & $\operatorname{Plant}(\mathrm{T} * \mathrm{P})$ & None & 2-way ANOVA & None \\
\hline
\end{tabular}




\section{Results.}

\section{Dormancy and Survival.}

Given the observed patterns of demographic response of natural ginseng populations to temperature (Souther and McGraw 2011a), we hypothesized that the response of fitnessrelated traits to temperature treatments would suggest that ginseng populations are adapted to local temperature. Specifically, populations would respond differentially to temperature treatments, such that fitness-related traits were maximal when populations were exposed to home-site temperature treatments. Overall mortality was low for the experiment: only 4 plants (3.2\% of all individuals) died during the transplant process and over the course of the study, so there were no significant effects of population, temperature, or their interaction (Table 2). There was a trend for the effect of temperature on dormancy in 2009 to differ by population (Table 2). Supporting our hypothesis that ginseng populations are adapted to local temperature, there was a higher probability of being present when plants were exposed to temperatures similar to those in their home-site (Fig. 1). There was no interactive effect of temperature and population on dormancy in 2010, or on survival (Table 2).

\section{Growth.}

For plants, size is an important predictor of reproduction and survival, two factors likely correlated with fitness. We expected, therefore, that there would be a differential response between populations in terms of relative growth rate (RGR) of leaves, sympodia, roots, and peduncle to temperature treatments. This was true for $\mathrm{RGR}_{\mathrm{LA}}$ and $R_{\text {RRED }}$, but not for $\mathrm{RGR}_{\mathrm{SYM}}$ or $\mathrm{RGR}_{\mathrm{ROOT}}$ (Table 2). There was a tendency for the effect 
of temperature on $\mathrm{RGR}_{\mathrm{LA}}$ to differ between populations (Table 2). Specifically, the two populations responded differently at the medium and high temperature levels. Contrary to expectations that $\mathrm{RGR}_{\mathrm{LA}}$ would be greatest for each population in its home-site temperature treatment, foliar growth rate peaked one temperature treatment above each population's home-site temperature regime, such that $\mathrm{RGR}_{\mathrm{LA}}$ of individuals in the LowT Population was greatest in the medium temperature treatment, and $\mathrm{RGR}_{\mathrm{LA}}$ of individuals from the MedT Population was greatest in the high temperature treatment (Fig. 2a).

While no differential response in peduncle length was detected in 2009 , the effect of temperature on peduncle length differed for the two populations the following year (Table 2). In the low temperature treatment, the mean peduncle length of the MedT Population was greater than that of the LowT Population (Fig. 3b). This effect was reversed at the high temperature level, where LowT Population peduncles grew longer relative to MedT. There was a main effect of temperature on peduncle length in 2010, such that plants in the medium temperature treatment had the longest peduncles, and plants in the high temperature treatment had the shortest (Table 3). When we examined change in peduncle length over the study period, temperature effects were obscured, and only a trend for populations to differ in $\mathrm{RGR}_{\mathrm{PED}}$ was detected (Table 2).

There was no statistically significant differential response to temperature of the two populations for either height growth $\left(\mathrm{RGR}_{\mathrm{SYM}}\right)$ or root growth $\left(\mathrm{RGR}_{\mathrm{ROOT}}\right)$. However, temperature affected RGR $_{\mathrm{SYM}}$ (Table 2). For all plants, sympodium growth was maximized in both the low and medium temperature treatments, but dropped steeply when plants were exposed to high temperatures. Specifically, at the high temperature level, RGR $_{\text {SYM }}$ was reduced $36 \%$ compared to plants in the low temperature treatment, 
and $35 \%$ compared to plants in the medium temperature treatment (Fig. 2c).

Additionally, RGR SYM $_{\text {and }}$ RGR $_{\text {ROOT }}$ differed between populations (Table 2). For both of these dependent variables, individuals from the MedT Population had higher growth rates (Table 3).

\section{Reproduction.}

Consistent with our expectations, the effect of temperature on whether a plant was reproductive differed between populations during 2009 (Table 2). Specifically, populations responded differently at the medium temperature level; individuals from the LowT Population were more likely to produce buds than MedT Population individuals (Fig. 3a). For both populations, the probability of forming a reproductive structure was the highest at a temperature one level above home-site temperature conditions (Fig. 3a). In 2010, this differential reproductive response of the two populations disappeared (Table 2).

There was a tendency for the effect of temperature on bud number to differ between populations in 2009, a pattern that was statistically significant in 2010 (Table 2). While the two populations responded differently to temperature in terms of bud number, they did so in an unexpected manner. Mean bud number was not greatest when populations were exposed to the treatment that approximated home-site conditions, as typically expected if populations are locally adapted. Rather the two populations showed a differential response to the increase from medium to high temperatures, with the LowT population showing greater bud number at high temperature, while the MedT population was unresponsive (Fig. 3b). This general pattern was repeated for change in bud number 
2009-2010 (Table 2; Fig. 3c). Temperature influenced bud production in 2010, with plants in the medium temperature treatment producing $16 \%$ more buds per plant compared to plants in the high temperature treatment, which produced the least number of buds (Table 3). In 2009 only, populations differed in the number of buds produced, such that plants from the MedT Population produced a greater number of buds per plant than the LowT Population (Table 2).

While we expected that the effect of temperature on metrics of seed production would differ between populations, this was not the case (Table 2). In general, temperature alone influenced measures of seed production, and in all cases seed production was lowest in the high temperature treatment (Table 2). Compared to plants in the low temperature treatment, plants exposed to the high temperature treatment were $43 \%$ less likely to produce seeds in 2009 . This general pattern strengthened the following year, with plants in the high temperature treatment being $61 \%$ less likely to produce seeds than those in the low temperature treatment (Table 2, Fig. 4a). While temperature did not affect the mean number of seeds produced per plant in 2009 , there was a tendency for temperature treatments to affect seed production in 2010 (Table 2), such that seed production was maximized in the medium temperature treatment. In both 2009 and 2010, temperature affected the number of seeds per bud (Table 2). In both years, the highest temperature level reduced the seeds produced per bud by $62 \%$ and $65 \%$ respectively compared to the low temperature level (shown for 2010; Fig. 4b). Change in seed production between the two years, both in terms of number of seeds produced and seeds produced per bud, did not depend on temperature treatment (Table 2). Temperature 
also affected mean berry mass per seed (Table 2 ). Berry mass per seed was reduced by $41 \%$ at the highest temperature level compared to the low temperature level (Fig. 4c).

Populations differed in terms of seed production. In 2009, LowT Population plants were almost twice as likely to produce seeds than MedT Population plants. While the number of seeds produced per reproductive plant did not differ between populations in 2009, seed production did differ in 2010, with plants from the LowT Population producing 2.21 times the number of seeds per plant as individuals in the MedT Population (Table 3). In both years of the study, the LowT Population produced a greater number of seeds per bud; LowT Population plants producing on average 2.58 and 1.64 times the number of seeds per bud relative to MedT Populations plants in 2009 and 2010, respectively (Table 3).

\section{Physiological measurements.}

Because photosynthesis and respiration are highly temperature- dependent, the optimization of these processes to mean site-specific temperature conditions could potentially explain differences in survival, growth, and reproduction between populations in the temperature treatments. Hence, we expected that photosynthetic and respiration rates would mirror the response of fitness-related traits to temperature treatments, such that response of these important physiological processes to temperature would differ among populations. While there was no interactive effect of temperature and population on light saturated photosynthetic rate, the effect of temperature on photosynthetic rate at ambient light levels differed between populations (Table 2). Populations responded differentially to the change in temperature between medium and high levels; 
photosynthetic rates decreased for plants from the MedT Population, but not for plants from the LowT Population (Fig. 5a). In general, photosynthetic rates were highest in the low temperature treatment and lowest in the high temperature treatment (Table 2, Table 3). Also, populations differed in terms of photosynthetic rates. Plants from the LowT Population assimilated $\mathrm{CO}_{2}$ at 1.07 times the rate of plants from the MedT Population (Table 3).

Temperature alone affected respiration rate (Table 2). Respiration rates of plants in the high temperature treatment were 1.66 times greater than respiration rates of plants in the low temperature treatment (Fig. 5b).

Phenological measurements, physical appearance, \& allocation.

There was a trend for the effect of temperature on emergence phenology in 2009 to differ between populations (Table 2). Overall, increasing temperature accelerated emergence rate (Fig. 6a). However, plants from the LowT Population and MedT Population responded differently at the low temperature level, such that LowT Population plants were more developed compared to MedT Population plants (Fig. 6a). The effect of temperature on bud phenology did not differ between populations in 2009, but did in 2010 (Table 2). Generally, increasing temperature accelerated onset of flowering, so that the ratio of pre-anthesis buds to total buds was lower in the medium and high temperature treatments relative to the low temperature treatment. Plants from the LowT Population and the MedT Population responded differentially to the transition from the medium and high temperature treatments. In the medium temperature treatment, MedT plants had a greater proportion of pre-anthesis buds relative to LowT plants, while this effect was 
reversed in the high temperature treatment (Fig. 6b). The effect of temperature on senescence level depended on population (Table 2). Plants from the LowT and MedT Populations responded differentially to the low and high temperature treatments. At the low temperature level, leaves of plants from the MedT Population showed greater levels of senescence than those from the LowT Population, while this effect was reversed at the high temperature treatment (Fig. 6c).

Temperature, in general, had a large effect on all phenological measurements, higher temperatures advancing emergence, anthesis, and senescence. This temperature effect was, in some cases, profound. For example, in 2009 the proportion of pre-anthesis buds was reduced by $77 \%$ in the high temperature level compared to plants in the low temperature level (Table 3).

We expected that plant biomass allocation would differ by population depending on temperature treatment. In fact, the effect of temperature on root to shoot ratio did differ between populations (Table 2). Mean root to shoot ratio of MedT Population plants did not vary among temperature treatments, while root to shoot ratio of LowT Population plants did; hence plants, depending on population of origin, responded differentially at the medium and high temperature treatments (Fig. 7). Specifically, at the medium temperature treatment, the MedT Population plants allocated more biomass to the root per unit mass of the shoot than LowT Population plants, whereas the reverse was true at the high temperature treatment (Fig. 7). 
Table 5.2. $\mathrm{P}$-values associated with main, temperature $(\mathrm{T})$ and population $(\mathrm{P})$, and interactive effects $\left(\mathrm{T}^{*} \mathrm{P}\right)$ by dependent variable for all statistical analyses.

\begin{tabular}{|c|c|c|c|c|c|c|c|c|}
\hline & P/A 2009 & P/A 2010 & $\begin{array}{c}\text { Overall } \\
\text { survival }\end{array}$ & $\mathbf{R G R}_{\mathrm{LA}}$ & $\mathbf{R G R}_{\mathrm{SYM}}$ & RGR $_{\text {ROOT }}$ & $\begin{array}{c}\text { Peduncle } \\
\text { length } 2009\end{array}$ & $\begin{array}{c}\text { Peduncle } \\
\text { length } \\
2010\end{array}$ \\
\hline Temperature $(\mathrm{T})$ & 1.0000 & 0.2160 & 1.0000 & 0.7514 & $0.0307 * *$ & 0.8773 & 0.1193 & $0.0395 * *$ \\
\hline Population (P) & 1.0000 & 0.2742 & 1.0000 & 0.3395 & $0.0104 * *$ & $0.0067 * *$ & 0.2331 & 0.6806 \\
\hline \multirow[t]{2}{*}{$\mathrm{T} * \mathrm{P}$} & $0.0545^{*}$ & 0.2617 & 1 & $0.0908^{*}$ & 0.7309 & 0.7833 & 0.3072 & $0.0363 * *$ \\
\hline & RGR $_{\text {PED }}$ & $\begin{array}{c}\text { Produced } \\
\text { buds }(\mathbf{Y} / \mathbf{N}) \\
2009\end{array}$ & $\begin{array}{c}\text { Produced } \\
\text { buds }(\mathbf{Y} / \mathbf{N}) \\
2010\end{array}$ & $\begin{array}{c}\text { Bud number } \\
2009\end{array}$ & $\begin{array}{c}\text { Bud } \\
\text { number } \\
2010\end{array}$ & $\begin{array}{c}\text { Produced } \\
\text { seeds }(\mathbf{Y} / \mathbf{N}) \\
2009\end{array}$ & $\begin{array}{c}\text { Produced } \\
\text { seeds }(\mathbf{Y} / \mathbf{N}) \\
2010\end{array}$ & $\begin{array}{c}\text { Seed } \\
\text { number } \\
2009\end{array}$ \\
\hline Temperature $(\mathrm{T})$ & 0.3261 & 0.2797 & 0.6682 & 0.4173 & $<0.0001 * * *$ & $0.009 * *$ & $<0.0001 * * *$ & 0.2174 \\
\hline Population (P) & $0.0572 *$ & 0.3889 & 0.2714 & $0.0003 * * *$ & 0.2277 & $0.0263 * *$ & 0.4055 & 0.6686 \\
\hline \multirow[t]{2}{*}{$\mathrm{T} * \mathrm{P}$} & 0.2462 & $0.0055^{* *}$ & 0.5226 & $0.0662 *$ & $0.0275^{* *}$ & 0.4699 & 0.6731 & 0.1683 \\
\hline & $\begin{array}{c}\text { Seed } \\
\text { number } \\
2010\end{array}$ & $\begin{array}{l}\text { Seeds per } \\
\text { bud } 2009\end{array}$ & $\begin{array}{l}\text { Seeds per } \\
\text { bud } 2010\end{array}$ & $\begin{array}{c}\Delta \text { bud } \\
\text { number } \\
(2009-2010)\end{array}$ & $\begin{array}{c}\Delta \text { seed } \\
\text { number } \\
(2009-2010)\end{array}$ & $\begin{array}{c}\Delta \text { seeds per } \\
\text { bud } \\
(2009-2010)\end{array}$ & $\begin{array}{c}\text { Berry } \\
\text { weight per } \\
\text { seed }(2010)\end{array}$ & $\begin{array}{c}\text { Photosynt } \\
\text { hesis } \\
\text { (PAR = } \\
\text { 500) } \\
(2010) \\
\end{array}$ \\
\hline Temperature $(\mathrm{T})$ & $0.0805^{*}$ & $0.0210 * *$ & $0.0017 * *$ & $0.0002 * * *$ & 0.2153 & 0.2245 & $0.0208^{* *}$ & 0.2041 \\
\hline Population (P) & $0.0025^{* *}$ & $0.0010 * *$ & $0.0097 * *$ & $0.0042 * *$ & 0.1404 & 0.1244 & 0.8536 & 0.7649 \\
\hline \multirow[t]{2}{*}{$\mathrm{T} * \mathrm{P}$} & 0.2953 & 0.591 & 0.8845 & $0.0177 * *$ & 0.6691 & 0.4232 & 0.5758 & 0.587 \\
\hline & $\begin{array}{c}\text { Photosynthe } \\
\text { sis }(\text { PAR = } \\
\text { 40) }(2010)\end{array}$ & $\begin{array}{c}\text { Respiration } \\
2010\end{array}$ & $\begin{array}{c}\text { Emergence } \\
(2009)\end{array}$ & $\begin{array}{c}\text { Pre- } \\
\text { flowering } \\
\text { buds: total } \\
\text { buds (2009) } \\
\end{array}$ & $\begin{array}{c}\text { Pre- } \\
\text { flowering } \\
\text { buds: total } \\
\text { buds (2010) } \\
\end{array}$ & $\begin{array}{c}\text { Senescence } \\
\text { level }\end{array}$ & Root: Shoot & \\
\hline Temperature $(\mathrm{T})$ & $<0.0001 * * *$ & $<0.0001 * * *$ & $<0.0001 * * *$ & $<0.0001 * * *$ & $<0.0001 * * *$ & $<0.0001 * * *$ & $0.0036^{* *}$ & \\
\hline Population (P) & $0.0132 * *$ & 0.2857 & 0.1677 & $<0.0001^{* * *}$ & 0.6835 & 0.8689 & 0.5022 & \\
\hline $\mathrm{T}^{* \mathrm{P}}$ & $0.0049 * *$ & 0.5775 & $0.0931 *$ & 0.7733 & $0.0221 * *$ & $0.0132 * *$ & $0.0116^{* *}$ & \\
\hline $\begin{array}{l}* \mathrm{P}<0 \\
* * \mathrm{P}< \\
* * * \mathrm{P}\end{array}$ & $\begin{array}{l}10 \\
.05 \\
0.001\end{array}$ & & & & & & & \\
\hline
\end{tabular}


Table 5.3. Means (bold) and standard errors of dependent variables by temperature treatment (Low, Medium, High) and population (LowT Population, MidT Population) for ANOVA analyses. 


\begin{tabular}{|c|c|c|c|c|c|}
\hline Dependent variable & Low & Medium & High & LowT Pop & MedT Pop \\
\hline \multirow[t]{2}{*}{$\overline{\mathrm{RGR}_{\mathrm{LA}}}$} & 0.9870 & 1.0304 & 0.9477 & 0.9958 & 0.9805 \\
\hline & 0.0213 & 0.0197 & 0.0201 & 0.0155 & 0.0182 \\
\hline \multirow[t]{2}{*}{$\mathrm{RGR}_{\mathrm{SYM}}$} & 0.4131 & 0.4056 & 0.2643 & 0.2940 & 0.4281 \\
\hline & 0.0460 & 0.0442 & 0.0439 & 0.0325 & 0.0402 \\
\hline \multirow{2}{*}{$\mathrm{RGR}_{\mathrm{ROOT}}$} & 0.7157 & 0.7422 & 0.7061 & 0.6413 & 0.8059 \\
\hline & 0.0311 & 0.0304 & 0.0299 & 0.0220 & 0.0275 \\
\hline \multirow[t]{2}{*}{ Peduncle length 2009} & 7.9182 & 7.6777 & 6.8470 & 7.7534 & 7.2085 \\
\hline & 0.3772 & 0.3867 & 0.3816 & 0.2512 & 0.3706 \\
\hline \multirow[t]{2}{*}{ Peduncle length 2010} & 15.1639 & 16.9285 & 14.9317 & 15.8169 & 15.5325 \\
\hline & 0.6316 & 0.5940 & 0.6340 & 0.4028 & 0.5481 \\
\hline \multirow[t]{2}{*}{ RGR $_{\text {PED }}$} & 0.7566 & 0.9878 & 0.7548 & 0.7011 & 0.9738 \\
\hline & 0.1477 & 0.1434 & 0.1477 & 0.0951 & 0.1399 \\
\hline \multirow[t]{2}{*}{ Bud number 2009} & 17.9440 & 18.7696 & 16.2263 & 14.5495 & 20.7438 \\
\hline & 1.3849 & 1.4130 & 1.3606 & 0.9178 & 1.3420 \\
\hline \multirow[t]{2}{*}{ Bud number 2010} & 28.6932 & 47.7329 & 49.2341 & 43.0808 & 39.5779 \\
\hline & 0.2058 & 0.1935 & 0.2066 & 0.1312 & 0.1786 \\
\hline \multirow[t]{2}{*}{ Seed number 2009} & 6.5325 & 4.5147 & 4.6057 & $\mathbf{5 . 5 2 9 7}$ & 4.9055 \\
\hline & 0.8232 & 0.8810 & 1.6815 & 0.5090 & 1.3304 \\
\hline \multirow{2}{*}{ Seed number 2010} & 6.5172 & 10.8144 & 8.4797 & 12.2816 & 5.5631 \\
\hline & 0.1093 & 0.1038 & 0.2177 & 0.0801 & 0.1514 \\
\hline \multirow[t]{2}{*}{ Seeds per bud 2009} & 0.1639 & 0.1249 & 0.0632 & 0.1691 & 0.0655 \\
\hline & 0.0256 & 0.0259 & 0.0250 & 0.0170 & 0.0246 \\
\hline \multirow[t]{2}{*}{ Seeds per bud 2010} & 0.2158 & 0.2088 & 0.0762 & 0.2073 & 0.1266 \\
\hline & 0.0279 & 0.0270 & 0.0285 & 0.0182 & 0.0245 \\
\hline \multirow[t]{2}{*}{$\Delta$ bud number (2009-2010) } & 15.3476 & 28.7146 & 30.6484 & 28.9466 & 20.2023 \\
\hline & 0.2901 & 0.2489 & 0.2761 & 0.1792 & 0.2374 \\
\hline \multirow[t]{2}{*}{$\Delta$ seed number (2009-2010) } & 3.9624 & 9.3348 & 7.2490 & 8.6454 & 5.0521 \\
\hline & 2.3129 & 2.0904 & 2.3213 & 1.3807 & 1.9786 \\
\hline \multirow[t]{2}{*}{$\Delta$ seeds per bud (2009-2010) } & 0.0671 & 0.0990 & -0.0033 & 0.0156 & 0.0930 \\
\hline & 0.0445 & 0.0427 & 0.0422 & 0.0285 & 0.0409 \\
\hline \multirow[t]{2}{*}{ Berry weight per seed (2010) } & 0.3823 & 0.3801 & 0.2266 & 0.3269 & 0.3324 \\
\hline & 0.0267 & 0.0260 & 0.0521 & 0.0200 & 0.0378 \\
\hline \multirow[t]{2}{*}{ Photosynthesis $(\mathrm{PAR}=500)(2010)$} & 2.8079 & 3.0214 & 2.8460 & 2.8762 & 2.9073 \\
\hline & 0.0888 & 0.0888 & 0.0912 & 0.0738 & 0.0725 \\
\hline \multirow[t]{2}{*}{ Photosynthesis (PAR = 40) (2010) } & 1.5196 & 1.4272 & 1.2445 & 1.4439 & 1.3503 \\
\hline & 0.0316 & 0.0316 & 0.0316 & 0.0258 & 0.0258 \\
\hline \multirow[t]{2}{*}{ Respiration 2010} & -0.1546 & -0.1714 & -0.2559 & -0.2022 & -0.1857 \\
\hline & 0.0132 & 0.0135 & 0.0132 & 0.0108 & 0.0110 \\
\hline \multirow[t]{2}{*}{ Emergence (2009) } & 4.4871 & 5.7697 & 6.0000 & 5.5081 & 5.3298 \\
\hline & 0.1097 & 0.1122 & 0.1120 & 0.0812 & 0.0997 \\
\hline \multirow[t]{2}{*}{ Pre-flowering buds: total buds (2009) } & 0.7659 & 0.2658 & 0.1786 & 0.1989 & 0.6081 \\
\hline & 0.0445 & 0.0458 & 0.0439 & 0.0293 & 0.0425 \\
\hline \multirow[t]{2}{*}{ Pre-flowering buds: total buds (2010) } & 0.9873 & 0.7290 & 0.7102 & 0.8019 & 0.8158 \\
\hline & 0.0300 & 0.0300 & 0.0290 & 0.0202 & 0.0273 \\
\hline Senescence level & 1.2059 & 1.2254 & 2.3853 & 1.6050 & 1.6061 \\
\hline & 0.1001 & 0.0948 & 0.0958 & 0.0691 & 0.0881 \\
\hline Root: Shoot & 1.4105 & 1.3206 & 1.5960 & 1.4198 & 1.4649 \\
\hline & 0.0586 & 0.0572 & 0.0584 & 0.0419 & 0.0524 \\
\hline
\end{tabular}




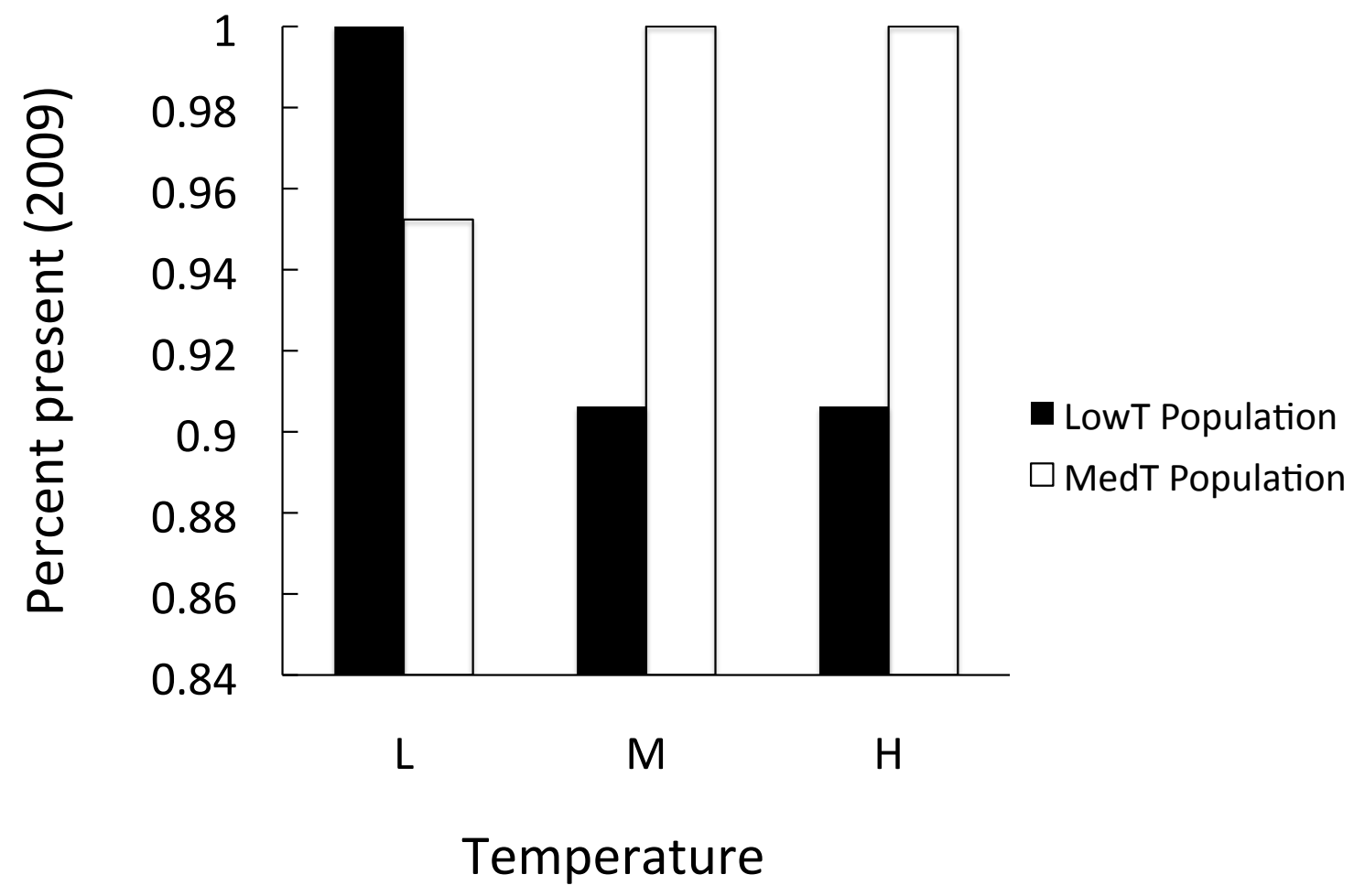

Figure 5.1. The effect of temperature on presence in 2009 by population. 


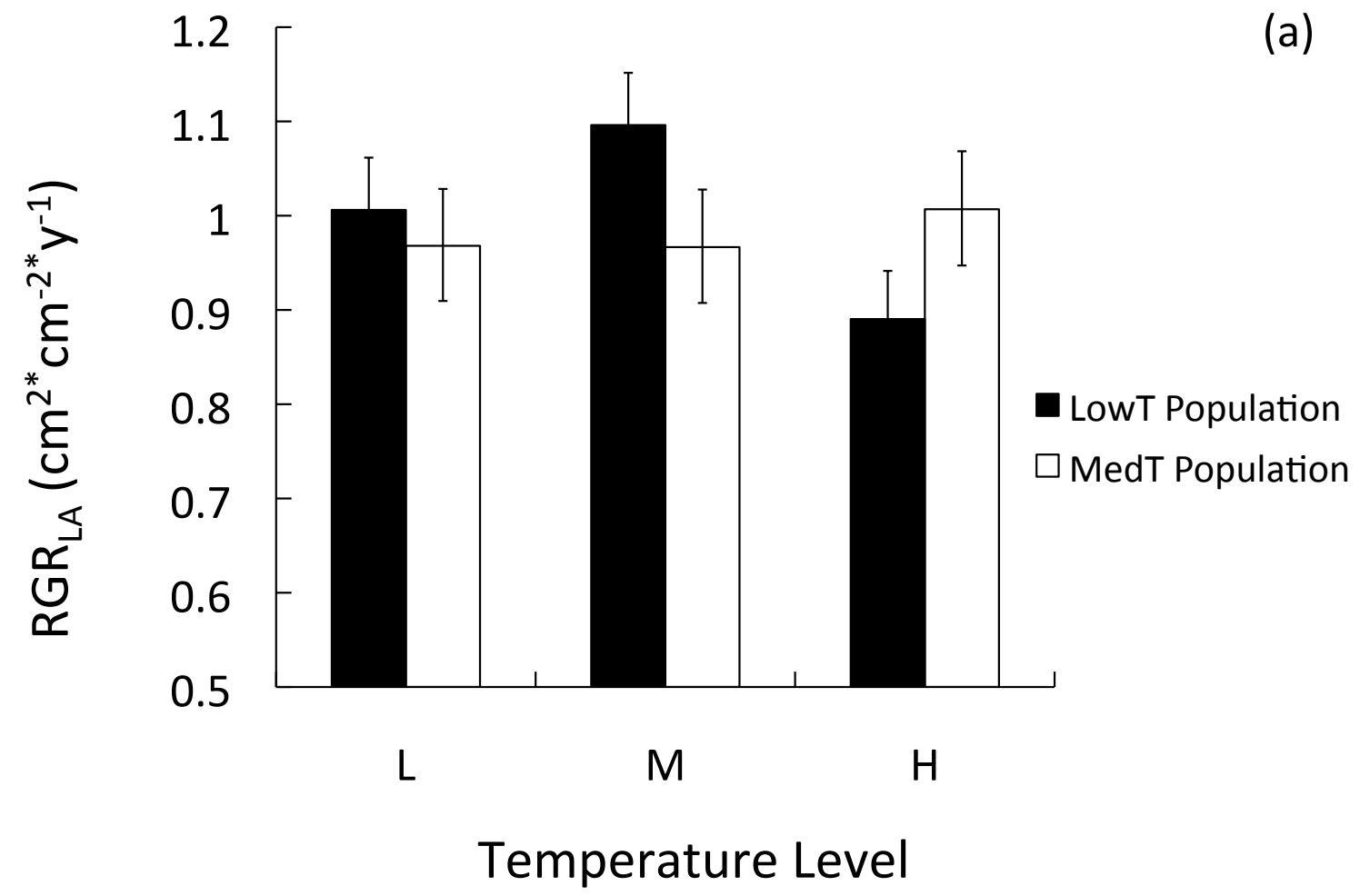

Figure 5.2.a. A trend for differential response to temperature of relative growth rate of leaves $\left(\mathrm{RGR}_{\mathrm{LA}}\right)$ between populations. 


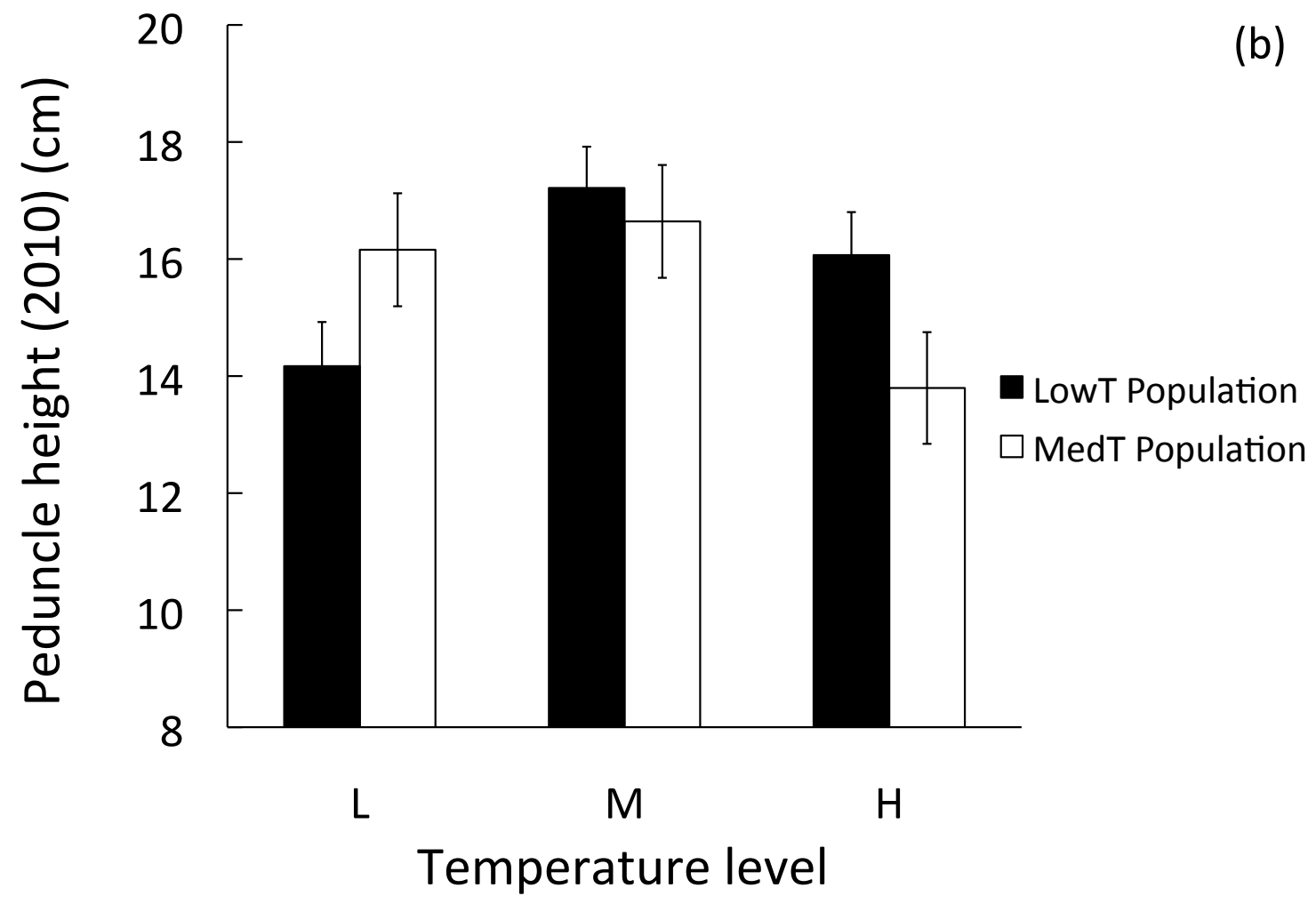

Figure 5.2.b. Differential response to temperature of peduncle height in 2010 between populations. 


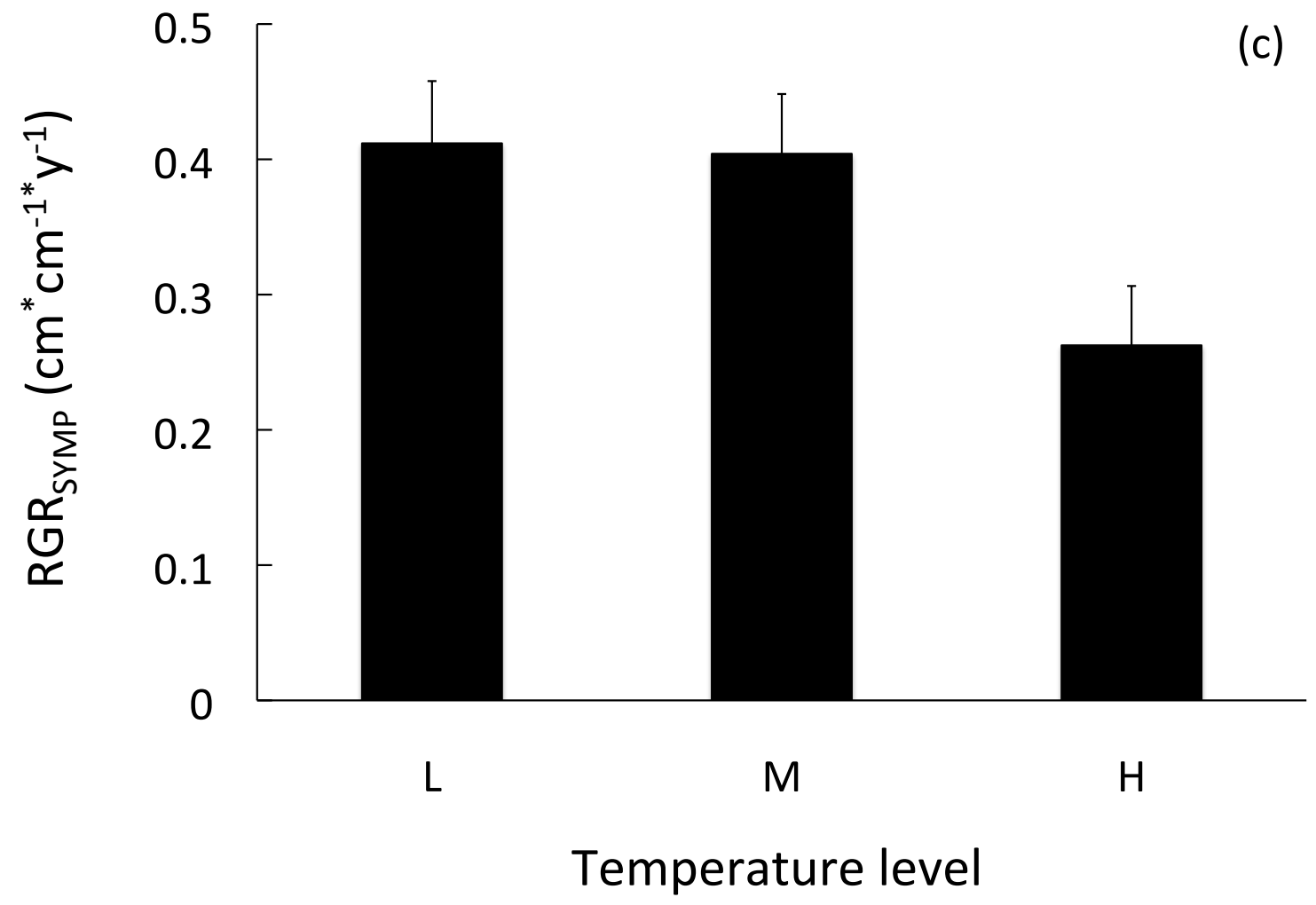

Figure 5.2.c. The effect of temperature on relative growth rate of sympodium height

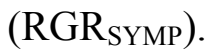




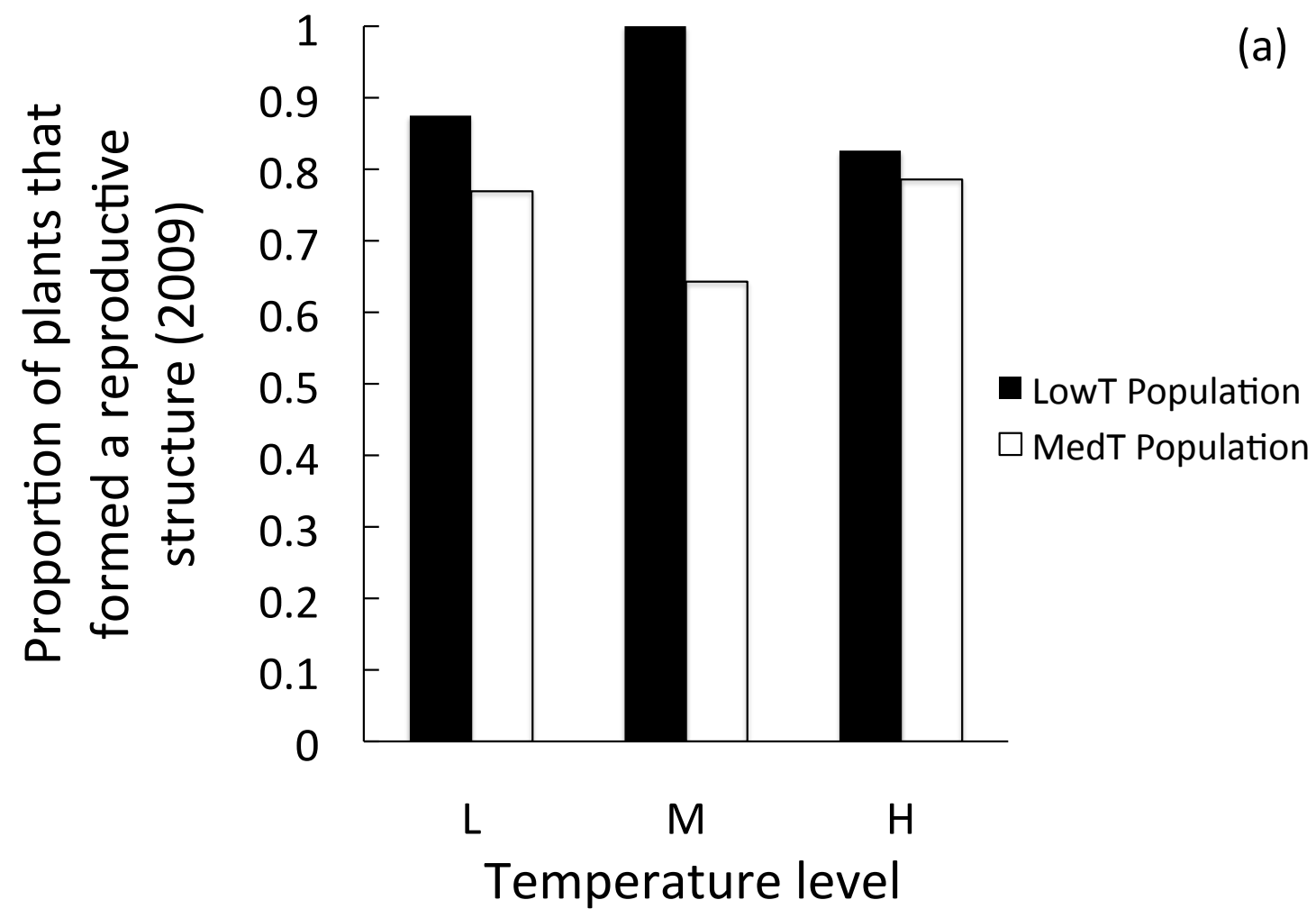

Figure 5.3.a. Likelihood of forming a reproductive structure in 2009 among temperature treatments for LowT and MedT populations. 


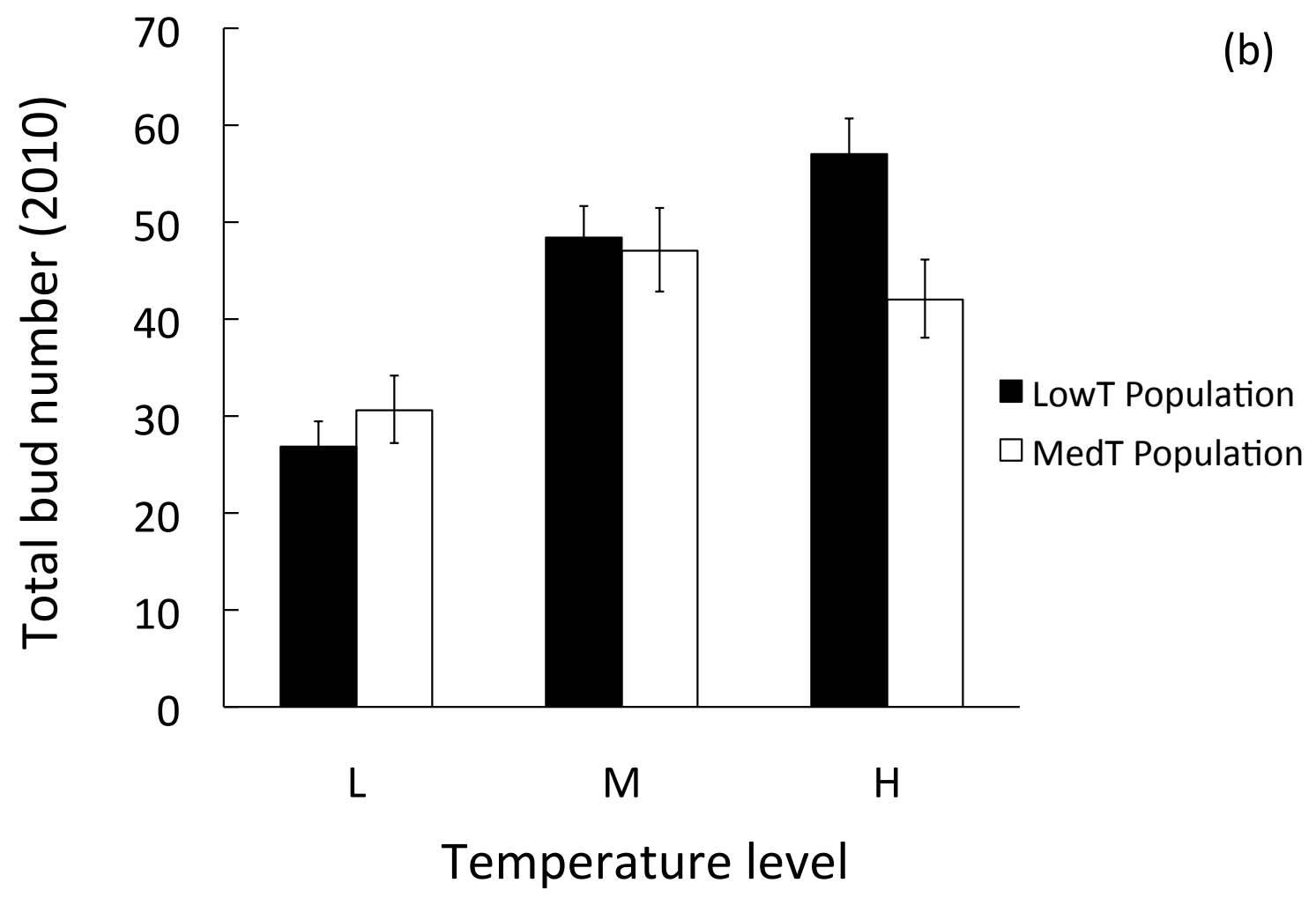

Figure 5.3.b. Differential response to temperature of bud number in 2010 between populations. 


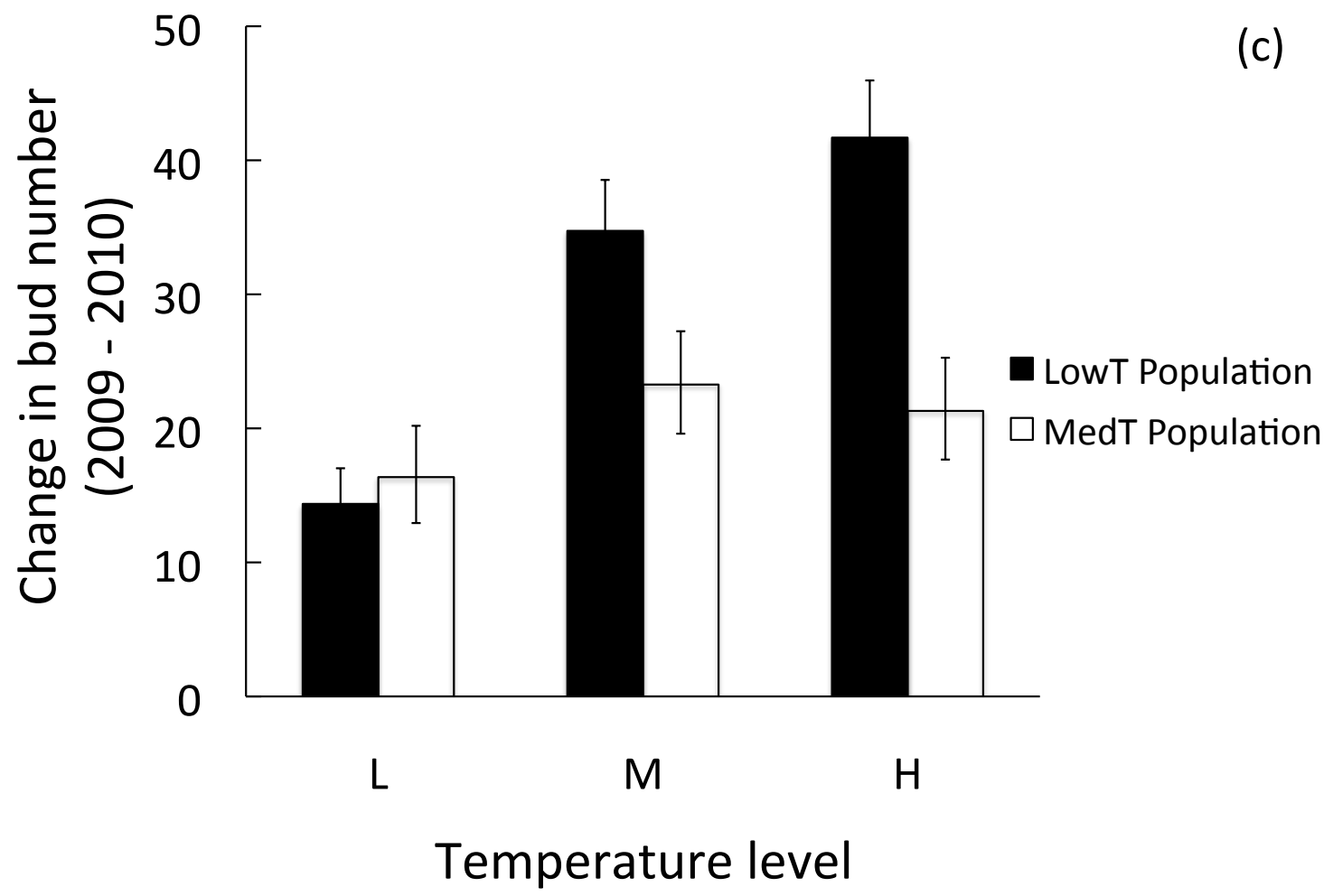

Figure 5.3.c. Differential response between populations in terms of change in bud number from 2009 to 2010 to temperature. 


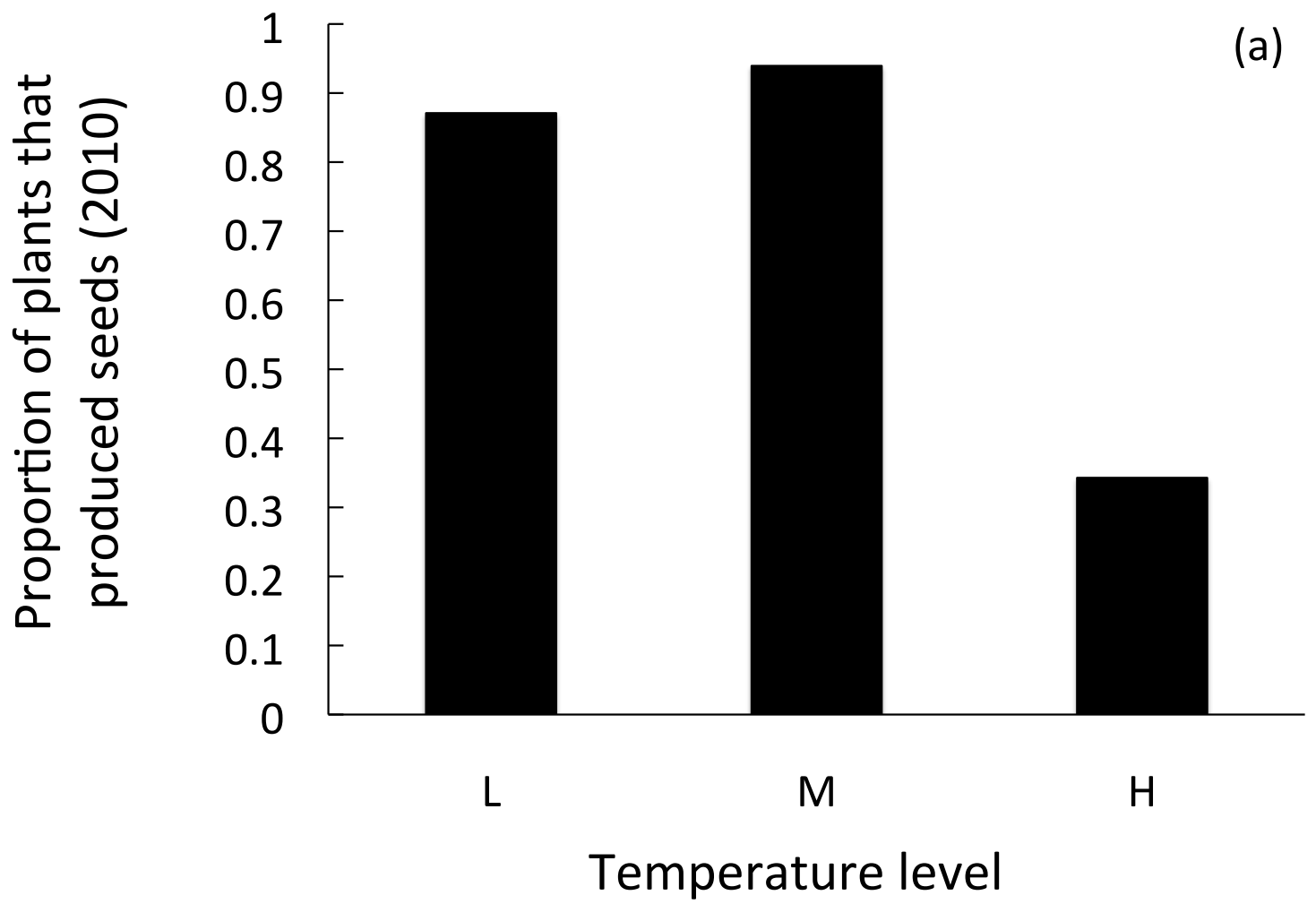

Figure 5.4.a. The effect of temperature on the probability of seed production in 2010 . 


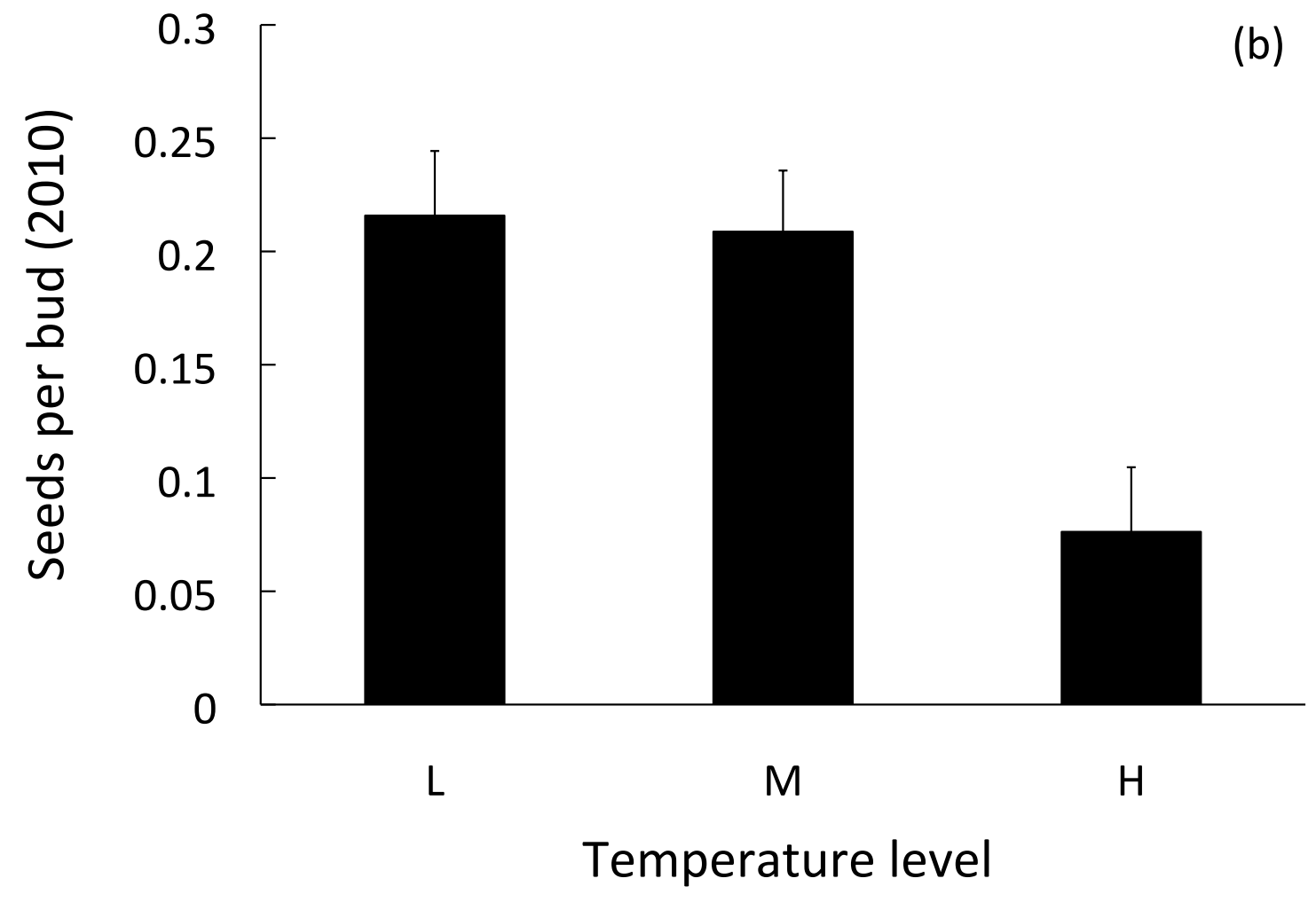

Figure 5.4.b. The effect of temperature on seeds per bud in 2010 . 


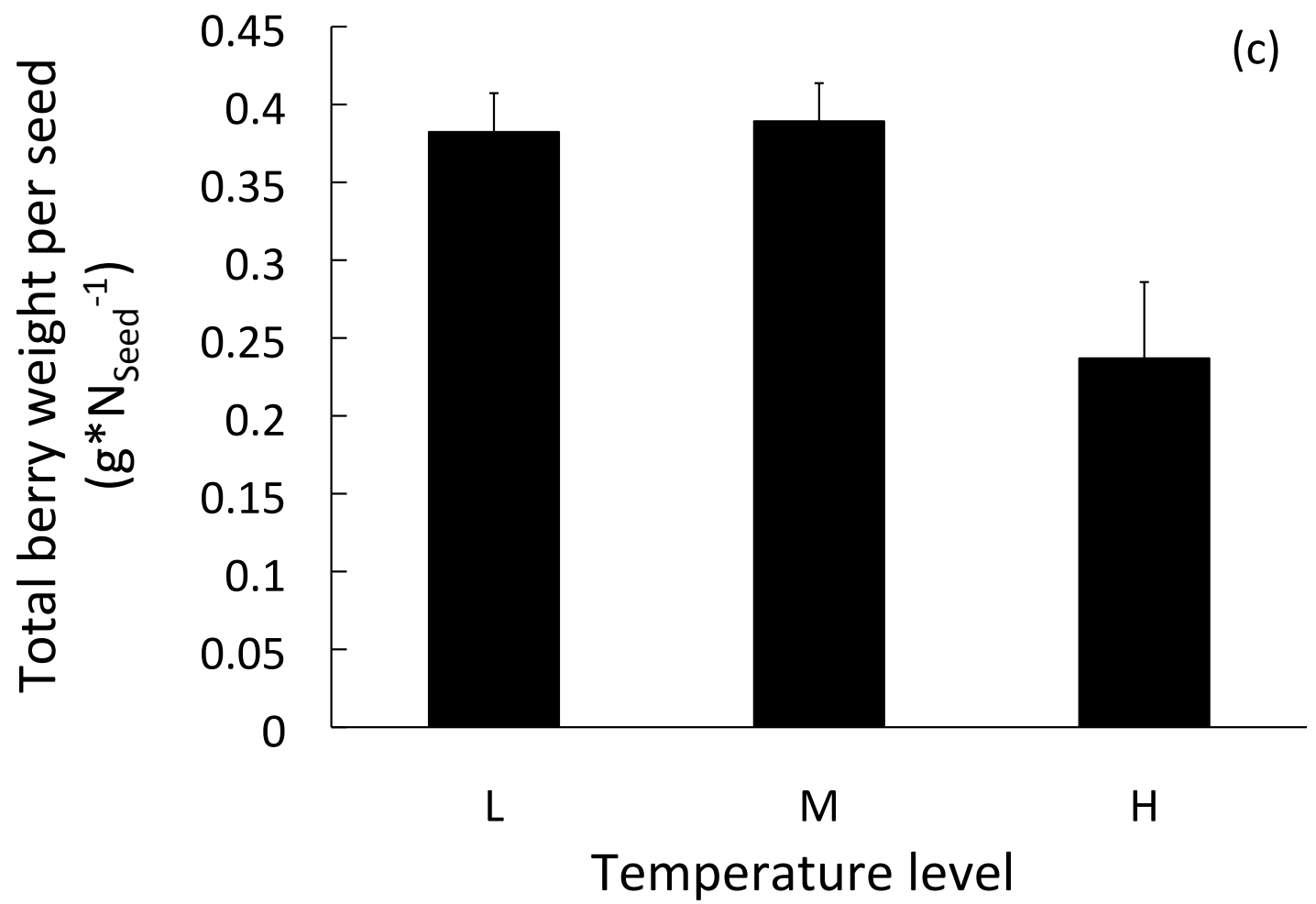

Figure 5.4.c. The effect of temperature on berry weight per seed in 2010 . 


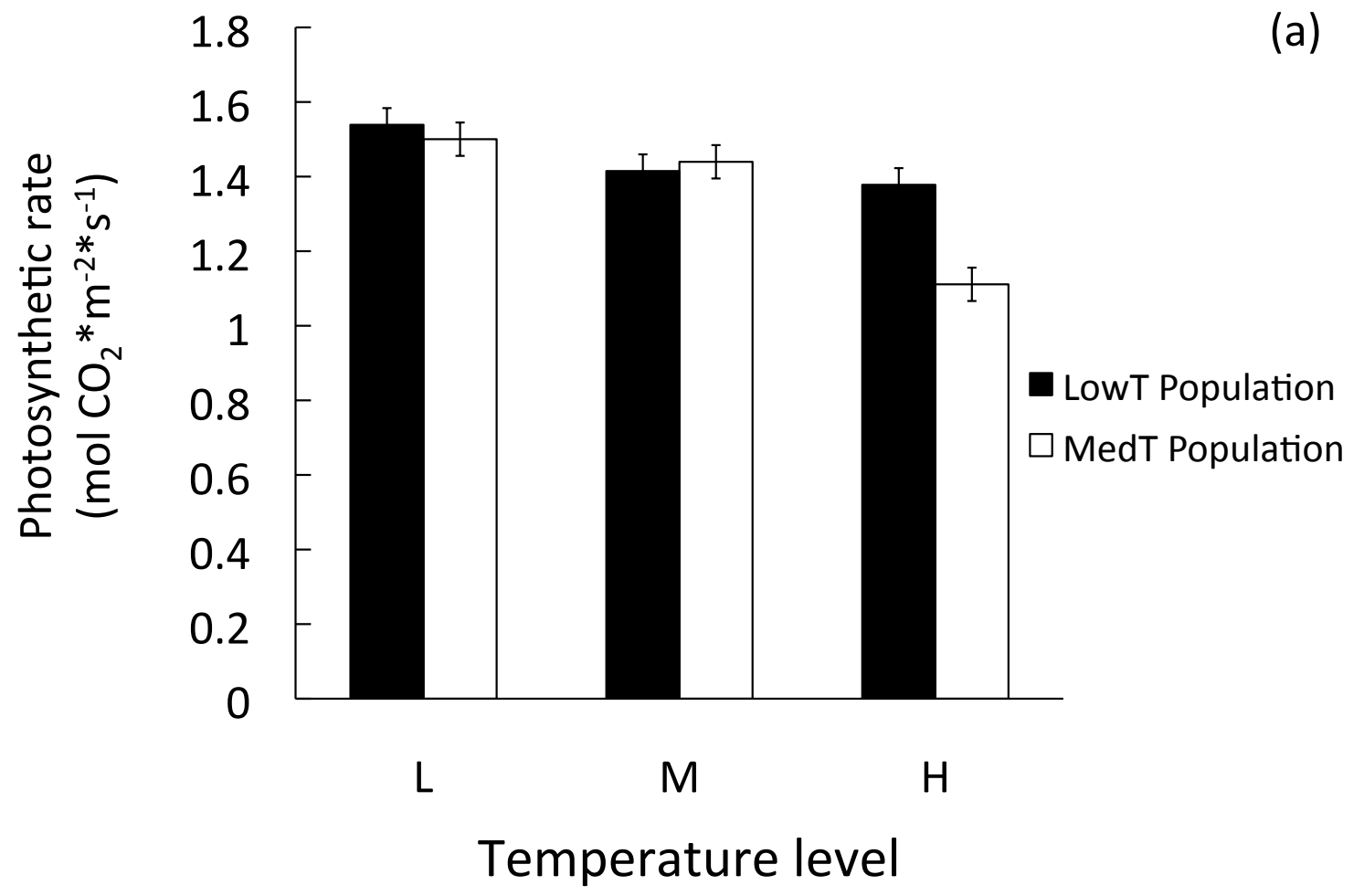

Figure 5.5.a. Differential response to temperature of $\mathrm{CO}_{2}$ assimilation rate between populations. 


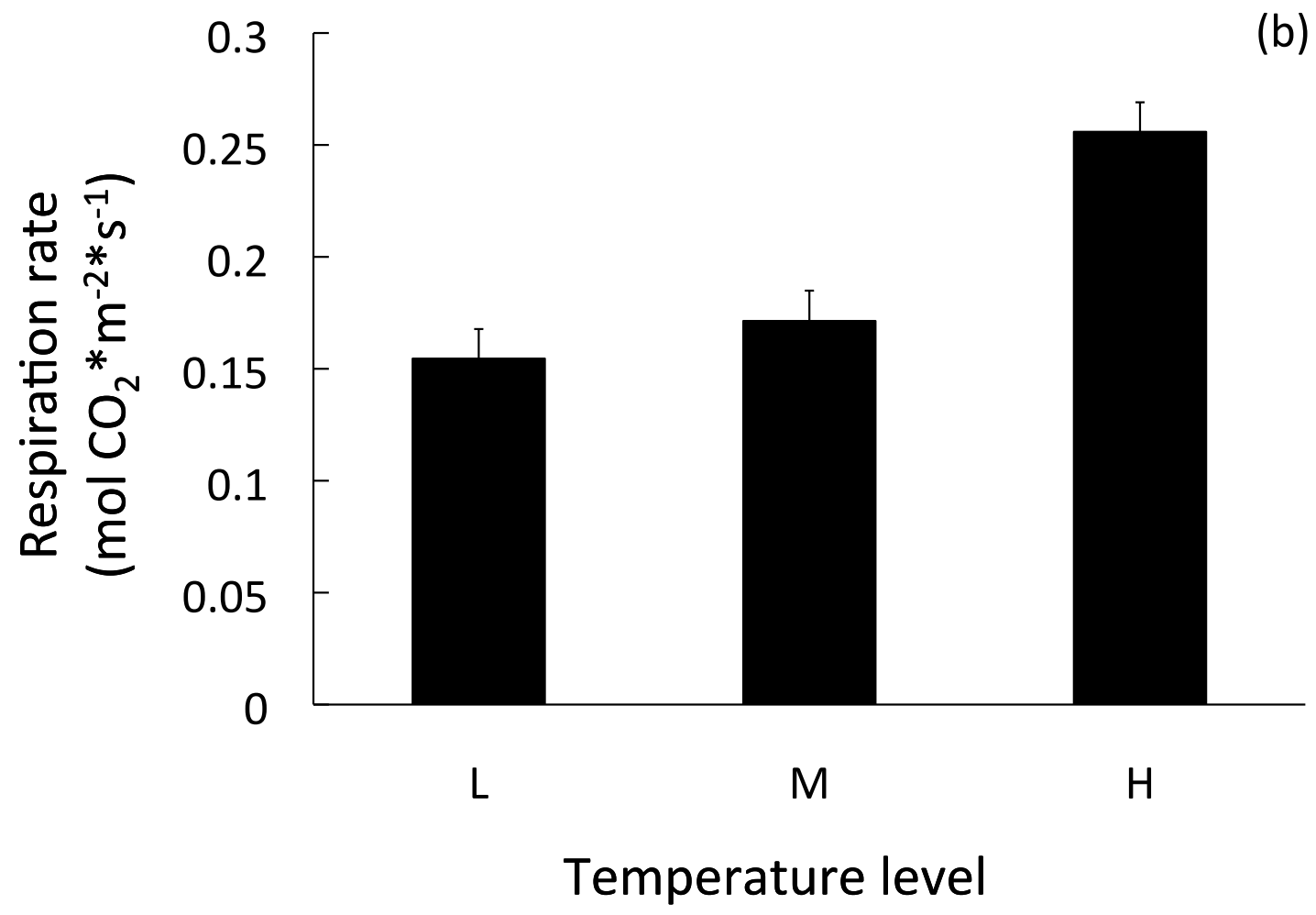

Figure 5.5.b. The effect of temperature on ginseng respiration rate. 


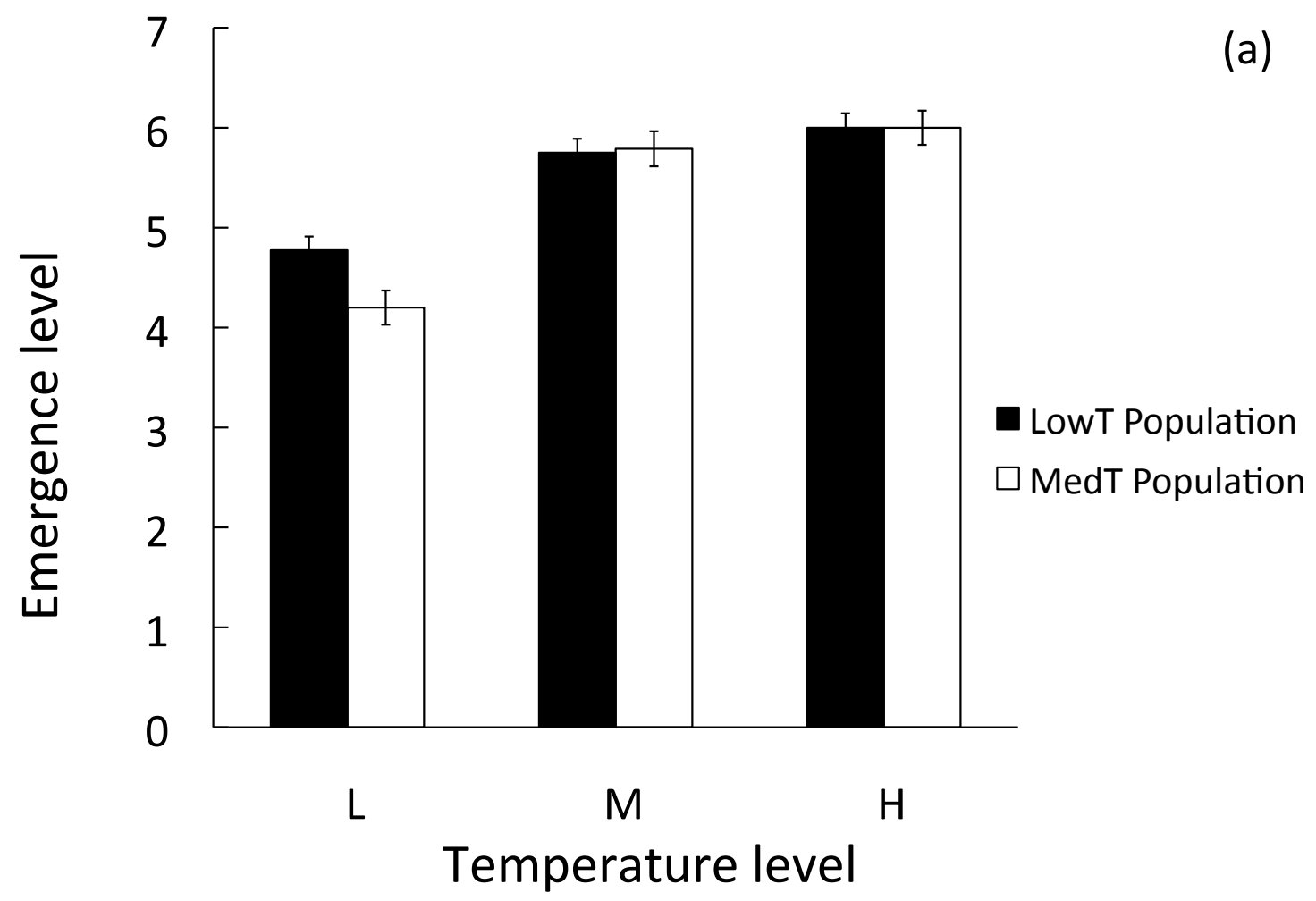

Figure 5.6.a. A trend for differential response to temperature of emergence rate between populations. 


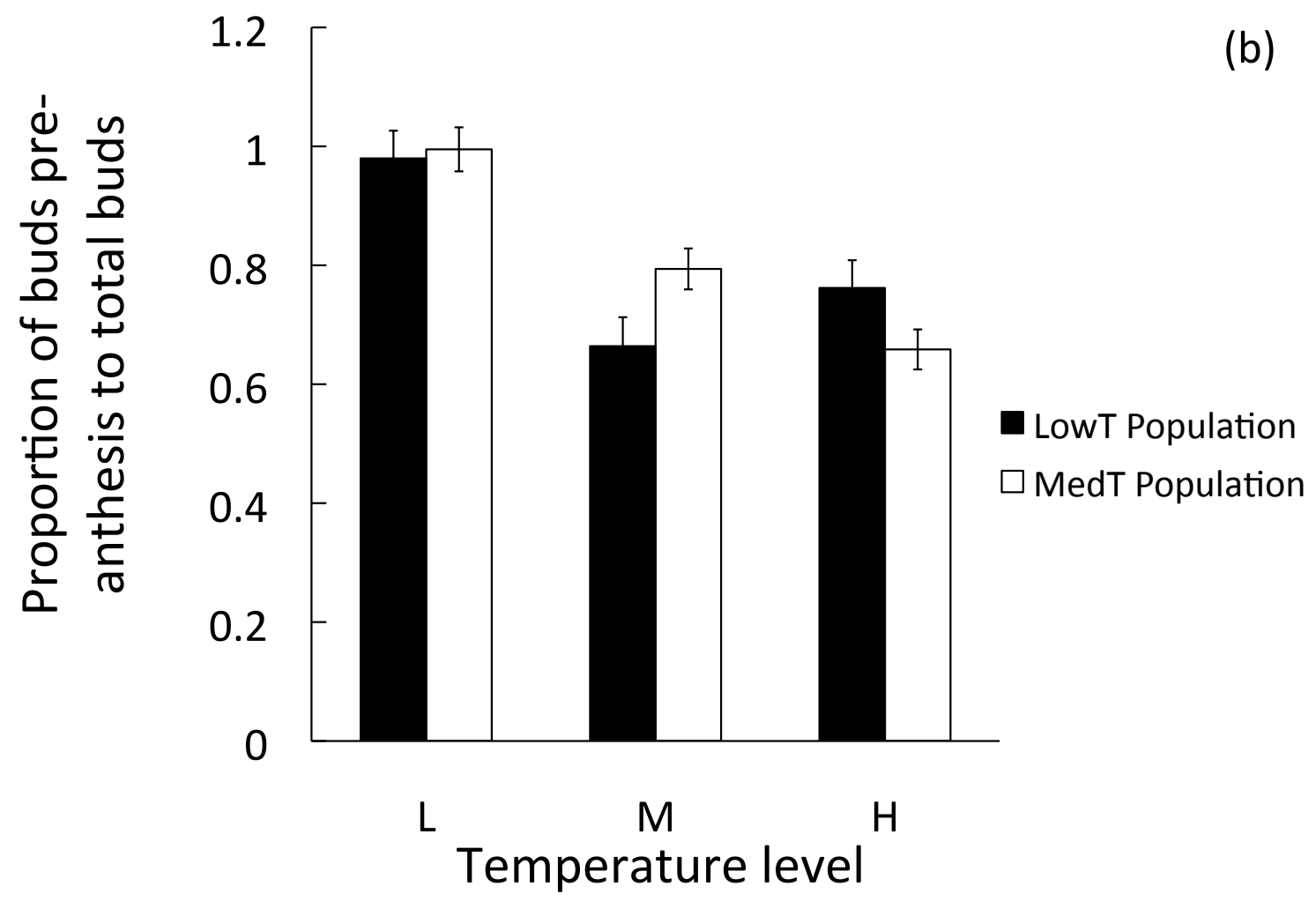

Figure 5.6.b. Differential response to temperature of floral development between populations. 


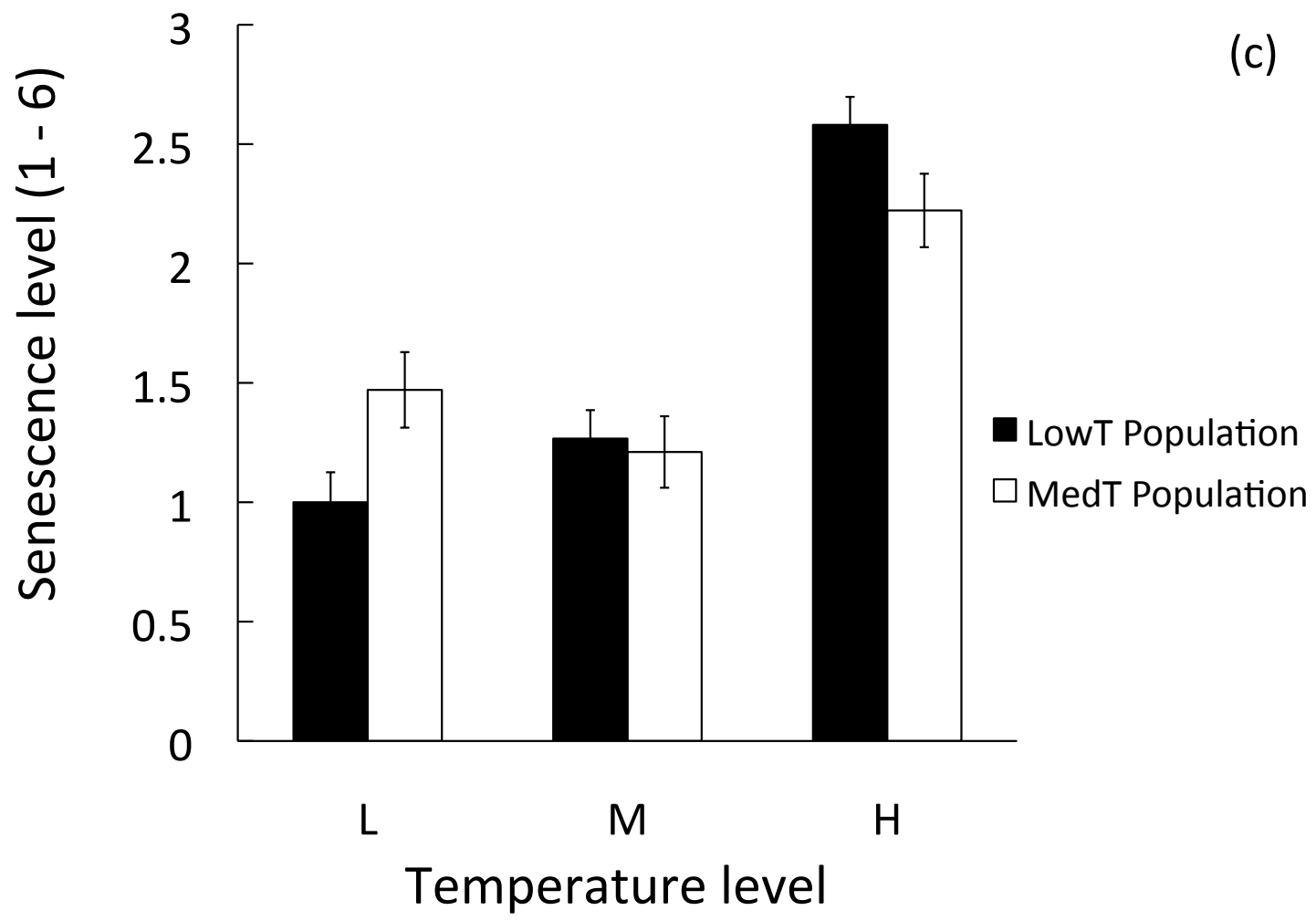

Figure 5.6.c. Differential response to temperature of senescence level between populations. 


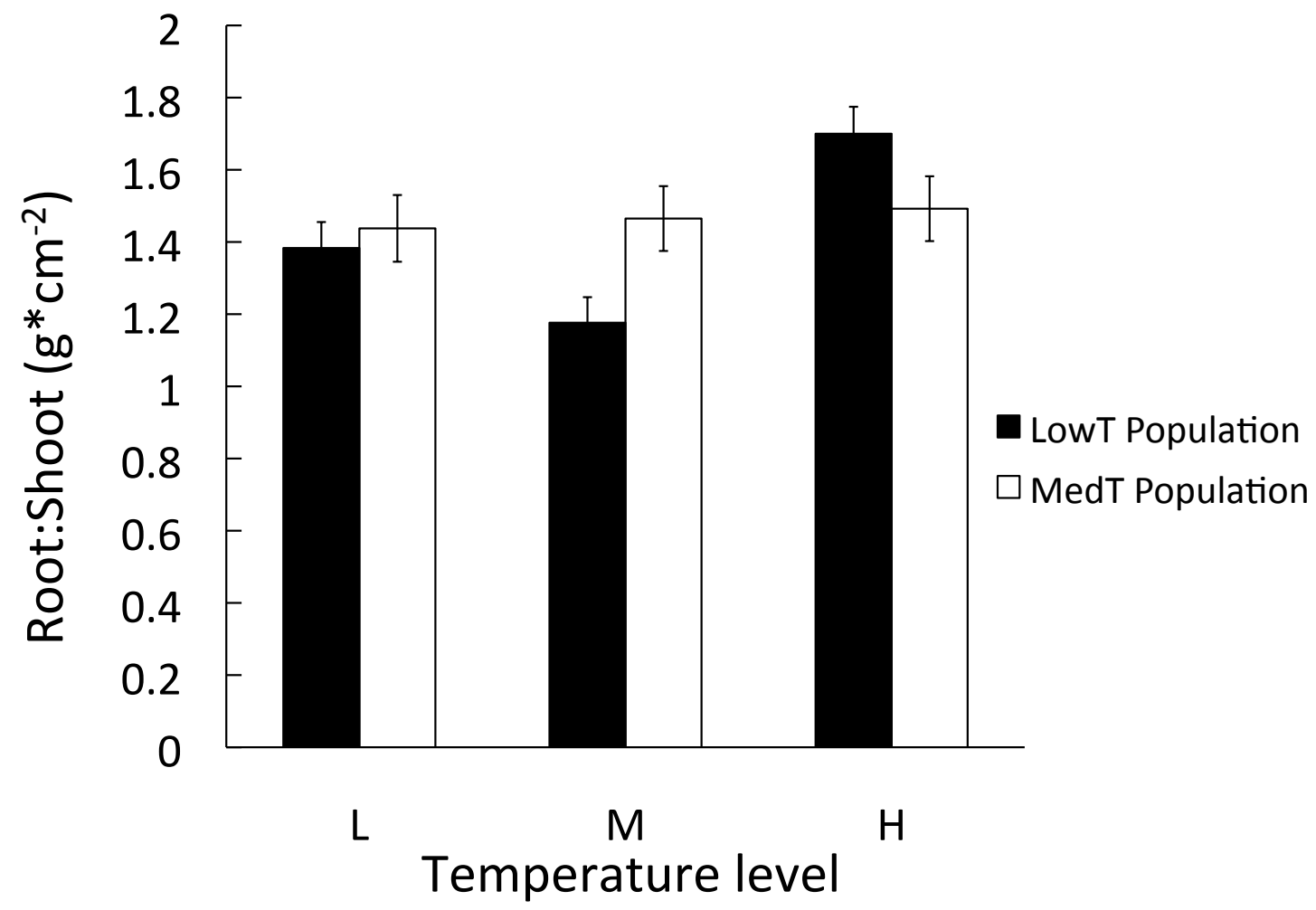

Figure 5.7. Differential response to temperature in terms of root to shoot ratio between populations. 


\section{Discussion}

A previous study examining long-term demographic response of ginseng populations to inter-annual temperature variation found that population growth rates $(\lambda)$ were greatest when growing season temperatures were similar to long-term, site-specific means (Souther and McGraw 2011a). When annual temperatures deviated from longterm mean conditions, $\lambda$ values decreased, suggesting that populations were adapted with respect to local temperature regimes (Souther and McGraw 2011a). Based on these findings, we expected that populations would respond differently to temperature treatments, and that traits likely predictive of long-term fitness, such as survival and seed production, or key physiological traits, like photosynthesis, would be greater for plants exposed to their home-site temperature environment relative to the non-local individuals. Indeed, in terms of presence in $2009, \mathrm{RGR}_{\mathrm{LA}}$, and bud number in 2009 , there was a trend for LowT and MedT Populations to respond differently to temperature. Also, the effect of temperature on peduncle length in 2010, the likelihood of ginseng plants producing buds in 2009, bud number in 2010, change in bud number over the study period, photosynthetic rates, senescence level, and root to shoot ratio differed between populations. However, with the exception of two dependent variables, the likelihood of being absent in 2009 and senescence level, the pattern of response of these variables did not conform to expectations for populations adapted with respect to local temperature.

For both LowT and MedT individuals, relative growth rate of foliar material was greatest in the temperature treatment one level above home-site conditions. Temperature levels representing each population's home-site temperature conditions were based on mean daily maximum and minimum temperature data from 1970 to 2000 . By using mean 
maximum and minimum temperature data, we did not expose plants to extreme temperature conditions. This result may suggest that temperature extremes, which could constitute a strong selective force, drive adaptive differentiation of ginseng populations, and hence, are a more important determinant of growth than mean temperature.

The pattern of the differential response of bud number between populations to temperature levels was unlike that of $\mathrm{RGR}_{\mathrm{LA}}$. Generally, MedT plants developed the greatest number of buds at the medium temperature level, whereas bud production of LowT individuals increased with temperature. For bud number in 2010, populations responded differently in the high temperature treatment, where LowT individuals produced a greater number of buds relative to MedT plants. Rather than indicating that LowT individuals are more successful than MedT individuals under high temperature conditions, these results may suggest that high temperatures triggered a stress response in LowT individuals, causing plants to allocate more energy to reproduction, a phenomenon observed in other plant species (Bradshaw and Hardwick 1989).

Senescence of leaves may be triggered by a number of environmental stressors, including temperature (Buckner et al. 1998; Munne-Bosch and Alegre 2004). In this experiment, the degree of foliar senescence at the high temperature treatment far exceeded senescence levels observed in the field for this time of year (September $30^{\text {th }}$, personal observation), and may be an indicator of plant stress. Mean senescence level was lowest for each population in its home temperature treatment, consistent with expectations of local adaptation. Further suggesting that response of bud number of LowT individuals was a stress response, there was a positive relationship between the degree of senescence of LowT individuals and temperature. 
Significantly, there was a consistent effect of temperature on measures of seed production. Measures of seed production and quality (e.g., seeds per bud, berry weight per seed) did not vary between low and medium temperature treatments, but decreased sharply when plants were exposed to high temperatures. Interestingly, the shape of ginseng respiration rate response to temperature treatments paralleled that of seed production; respiration rates did not respond to low and medium temperature levels, but increased greatly in the high temperature treatment. Loss of carbon due to elevated respiration rates may decrease energy available to allocate to seed and berry development. This overall negative effect of increasing temperature on seed production indicates that warming could negatively impact population growth of native ginseng populations.

Perhaps due to steady availability of nutrients, water and other resources, as well as absence of extreme temperatures, herbivores, pathogens, and competitors, the overall growth chamber environment was more conducive to ginseng growth than its natural habitat. On average, the relative growth rate of ginseng leaves was around $1 \mathrm{~cm}^{2} \mathrm{~cm}^{-2} \mathrm{y}^{-1}$ in the growth chamber environment, compared to an average $\mathrm{RGR}_{\mathrm{LA}}$ of around 0.4 $\mathrm{cm}^{2} \mathrm{~cm}^{-2} \mathrm{y}^{-1}$ in natural populations (Souther and McGraw 2011b). In the growth chamber, final ginseng root mass was on average an incredible 5.5 times the original root mass.

In artificial growth chamber conditions, the pattern of local adaptation to temperature, which was clearly apparent in a field study (Souther and McGraw 2011a), was obscured. Though growth chamber parameters were based on light levels, soil conditions, and humidity levels experienced by ginseng populations in nature, the growth chamber environment is distinct from a natural one. As previously mentioned, plants 
were not exposed to extreme temperatures in the growth chamber. Temperature extremes are potentially strong selective forces, and may drive adaptive differentiation of ginseng populations. Additionally, in the growth chamber environment, temperature variation was artificially decoupled from other environmental factors that naturally covary with temperature in the field, such as soil moisture, herbivory, prevalence of disease, and inter- and intra-specific competition interactions. Inability to discern a signal of local adaptation to temperature in a growth chamber environment may indicate that the nature of adaptive differentiation of populations with respect to temperature conditions is complex, and dependent not only on temperature, but also on environmental factors that covary with temperature. Natural 'experiments' that examine differential response of populations to annual temperature variation, may be a more appropriate method of examining local adaptation with respect to temperature, because temperature and covariates of temperature vary in a realistic way. 


\section{Acknowledgements.}

We thank Zachary Bradford, Zachariah Fowler, Alyssa Hanna, Anne Perez, Christine Picard, John Souther, Scott Spal, and Stephanie Young for help excavating ginseng roots, and Mark Romer and Claire Cooney for providing phytotron support. Thank you to McGill University for its stewardship of the Gault Nature Reserve and for logistic support of this research. This research was supported by National Science Foundation Doctoral Dissertation Improvement grant DEB-0909862. 


\section{References}

Anderson MP (1996) American ginseng (Panax quinquefolium L.) in southwestern Wisconsin: Patterns of demography and habitat associations. In: Landscape Architecture vol. Master of Science. University of Wisconsin, Madison, Wisconsin, p 132

Anderson RC, Fralish JS, Armstrong JE, Benjamin PK (1993) The Ecology and Biology of Panax-Quinquefolium-L (Araliaceae) in Illinois. American Midland Naturalist $129: 357-372$

Antonovics J (2006) Evolution in closely adjacent plant populations X: long-term persistence of prereproductive isolation at a mine boundary. Heredity 97:33-37

Bailey B (1999) Social and economic impacts of wild harvested products. In: College of Agriculture, Forestry and Consumer Sciences, vol. Ph.D. West Virginia University, Morgantown, WV, p 111

Bennington CC, Mcgraw JB (1995) Natural-Selection and Ecotypic Differentiation in Impatiens-Pallida. Ecological Monographs 65:303-323

Bradshaw AD, Hardwick K (1989) Evolution and Stress - Genotypic and Phenotypic Components. Biological Journal of the Linnean Society 37:137-155

Buckner B, Janick-Buckner D, Gray J, Johal GS (1998) Cell-death mechanisms in maize. Trends in Plant Science 3:218-223

Cruse-Sanders JM, Hamrick JL (2004) Genetic diversity in harvested and protected populations of wild American ginseng, Panax quinquefolius L. (Araliaceae). American Journal of Botany 91:540-548 
Davis MB, Shaw RG (2001) Range shifts and adaptive responses to Quaternary climate change. Science 292:673-679

Davis MB, Shaw RG, Etterson JR (2005) Evolutionary responses to changing climate. Ecology 86:1704-1714

Etterson JR (2004) Evolutionary potential of Chamaecrista fasciculata in relation to climate change. 1. Clinal patterns of selection along an environmental gradient in the great plains. Evolution 58:1446-1458

Futuyma DJ, Moreno G (1988) The Evolution of Ecological Specialization. Annual Review of Ecology and Systematics 19:207-233

Grubbs HJ, Case MA (2004) Allozyme variation in American ginseng (Panax quinquefolius L.): Variation, breeding system, and implications for current conservation practice. Conservation Genetics 5:13-23

Holt RD (2009) Bringing the Hutchinsonian niche into the 21st century: Ecological and evolutionary perspectives. Proceedings of the National Academy of Sciences of the United States of America 106:19659-19665

Holt RD, Barfield M (2008) Habitat Selection and Niche Conservatism. Israel Journal of Ecology \& Evolution 54:295-309

Holt RD, Gaines MS (1992) Analysis of Adaptation in Heterogeneous Landscapes Implications for the Evolution of Fundamental Niches. Evolutionary Ecology 6:433-447

Incorporated MCO Kord Fiber Grow 7.5" Nursery Pot. In, Brantford, Ontario, Canada IPCC (2007) Fourth Assessment Report of the Intergovernmental Panel on Climate Change. In. Cambridge University Press, Cambridge 
Kaltz O, Shykoff JA (1998) Local adaptation in host-parasite systems. Heredity 81:361370

Kawecki TJ, Ebert D (2004) Conceptual issues in local adaptation. Ecology Letters $7: 1225-1241$

Lewis WH, Zenger VE (1983) Breeding Systems and Fecundity in the American Ginseng, Panax Quinquefolium (Araliaceae). American Journal of Botany $70: 466-468$

Linhart YB, Grant MC (1996) Evolutionary significance of local genetic differentiation in plants. Annual Review of Ecology and Systematics 27:237-277

Mcgraw JB (1987) Experimental Ecology of Dryas-Octopetala Ecotypes .4. Fitness Response to Reciprocal Transplanting in Ecotypes with Differing Plasticity. Oecologia 73:465-468

McGraw JB, Sanders SM, Van der Voort M (2003) Distribution and abundance of Hydrastis canadensis L. (Ranunculaceae) and Panax quinquefolius L. (Araliaceae) in the central Appalachian region. Journal of the Torrey Botanical Society 130:6269

Mooney EH, McGraw JB (2009) Relationship between age, size, and reproduction in populations of American ginseng, Panax quinquefolius (Araliaceae), across a range of harvest pressures. Ecoscience 16:84-94

Munne-Bosch S, Alegre L (2004) Die and let live: leaf senescence contributes to plant survival under drought stress. Functional Plant Biology 31:203-216 
Robbins CS (2000) Comparative analysis of management regimes and medicinal plant trade monitoring mechanisms for American ginseng and goldenseal. Conservation Biology 14:1422-1434

Savolainen O, Pyhajarvi T, Knurr T (2007) Gene flow and local adaptation in trees. Annual Review of Ecology Evolution and Systematics 38:595-619

Schlessman MA (1985) Floral Biology of American Ginseng (Panax-Quinquefolium). Bulletin of the Torrey Botanical Club 112:129-133

Souther S, and James B. McGraw (2011a) Signal of local adaptation in the demographic response of American ginseng to inter-annual temperature variation. Conservation Biology in press

Souther S, McGraw, J. (2011b) Vulnerability of wild American ginseng to an extreme early spring temperature fluctuation. Population Ecology 53:119-129

Van der Voort M (2005) An ecological study of Panax quinquefolius in central Appalachia: seedling growth, harvest impacts and geographic variation in demography. In: Department of Biology, vol. Doctor of Philosophy in Biology. West Virginia University, Morgantown, WV, p 176 


\section{CHAPTER VI:}

EXPERIMENTAL TEST FOR ADAPTIVE DIFFERENTIATION OF GINSENG POPULATIONS TO CLIMATE II: A FIELD STUDY. 


\begin{abstract}
Within species adaptive differentiation of populations is common for plant species. If populations are adapted with respect to local climatic conditions, directional climate change may decrease fitness of populations across a species' range. Reciprocal transplant experiments are the primary method to test for local adaptation. In this study, I used a reciprocal transplant approach to test for adaptive differentiation of American ginseng (Panax quinquefolius L.) populations to climate. To do this, I selected two populations of ginseng, one from a high elevation site and one from a mid-elevation site, and reciprocally transplanted individuals to common gardens established across an elevation gradient. The effect of elevation on ginseng survival, growth, reproduction, and phenology did not differ between populations. However, variation in these variables was explained by site differences. Due to confounding factors, in particular differential deer browse rates among transplant sites, I was unable to determine whether observed patterns of survival, growth, and reproduction were caused by climate effects, or rather by the effects of non-climatic, site-specific variables. Continued demographic study of transplant populations may be helpful to partition the effects of deer browse from those of climate.
\end{abstract}




\section{Introduction}

The presence of genetically distinct, locally adapted populations within a species is common for many plant species (Linhart and Grant 1996). Numerous experiments have demonstrated adaptive differentiation of populations to a variety of ecological factors, such as light, soil moisture, heavy metals, disease, browsing, temperature, pollinators, and competitors (Linhart and Grant 1996). Natural selection can act on any trait, morphological, physiological, or life history, that affects fitness, thereby promoting specialization of populations to local environmental conditions (Linhart and Grant 1996). In a stable environment, specialization enhances performance, and promotes population persistence. In the context of directional climate change, however, such specialization may be a liability. If future climate exceeds the niche of an adaptively differentiated population, and if directional climate change occurs too quickly to allow adaptation to novel conditions, populations may decline due to overspecialization (Davis and Shaw 2001; Davis et al. 2005; Holt 2009; Holt and Gaines 1992).

Common garden and reciprocal transplant experiments have been used to test for adaptive differentiation of populations with respect to climate (Rehfeldt et al. 1999, Rehfeldt et al. 2002, Etterson and Shaw 2001, St. Claire et al. 2005, Etterson 2007, Hall et al. 2007). These studies (e.g., (Etterson 2004a; Etterson 2004b)) have used elevation and latitude as a proxy for climate, interpreting population by environment interactions to indicate that populations are adapted to local climate conditions. In fact, higher performance in the home site may be the result of adaptation to other environmental characteristics; the negative effect of novel soil, over-story, and biotic community on the out-planted group's fitness is confounded with the effects of changing climate regimes. 
In this study, I used a modified reciprocal transplant approach to test for adaptive differentiation of American ginseng populations to climate. Two populations of ginseng, one from a high elevation site and one from a mid-elevation site, were transplanted out of their home-sites to common gardens arrayed across an elevation gradient in West Virginia. Though response of the population may still reflect interactions of genotype with non-climatic, environmental factors, especially with respect to environmental variables correlated along elevational gradients, no population had an apriori 'home-site' advantage.

American ginseng occurs in the eastern deciduous forest from southern Canada to northern Georgia (Anderson et al. 1993). In the Appalachians, ginseng is encountered on a variety of aspects and elevations (McGraw et al. 2003). Because climate is a known selective force in plant populations (Etterson 2004a; Linhart and Grant 1996; Turesson 1930), and given the variation in climatic conditions throughout ginseng's range, populations of ginseng may be adaptively differentiated with respect to climate, such that populations perform optimally at local mean climatic conditions. Analyses of neutral marker variation among American ginseng populations have shown that populations are genetically differentiated (Cruse-Sanders and Hamrick 2004, Grubbs and Case 2004). However, it is not known whether populations are differentiated with respect to climate, and whether genetic differences among populations are adaptive. In this study, I asked, "Are ginseng populations adaptively differentiated with respect to factors occurring across a climatic-elevation gradient?" Based on knowledge of neutral marker differentiation in ginseng (Case et al. 2007; Cruse-Sanders and Hamrick 2004a; CruseSanders and Hamrick 2004b), and the role of climate as a selective force (Linhart and 
Grant 1996; Turesson 1930), we expected ginseng populations to be genetically differentiated, such that survival, growth, and reproduction was greater for individuals transplanted to their 'home' elevation relative to performance of 'non-local' individuals. 


\section{Methods}

\section{Source populations.}

Two populations of ginseng were located, one population occurred at an elevation of $500 \mathrm{~m}$ (mid-elevation) and one population occurred at an elevation of $800 \mathrm{~m}$ (high elevation).

\section{Reciprocal transplant.}

Transplant gardens were established across an elevation gradient ranging from Morgantown, WV to Parsons, WV. Exact locations of the transplant gardens are withheld to prevent targeted harvest of ginseng. Ginseng and/or other herbaceous indicator species of ginseng were found within $100 \mathrm{~m}$ of all transplant garden sites, suggesting that each transplant site was suitable ginseng habitat. Sites differed with respect to temperature, relative humidity, over-story species, and soil Ph (Table 1).

In April of 2009, ginseng from source populations was excavated, weighed, aged using the procedure described in Anderson et al. (1993) before spring emergence. High elevation and mid-elevation populations were reciprocally transplanted between midelevation and high elevation sites, as well as to a low elevation site, which represented a "future", warmer climate (Figure 3.1). At each transplant garden, individuals were planted in three, randomly located, replicate blocks comprised of plants from a single population. To prevent genetic mixing among populations, blocks were located 50m apart (Hackney 1999). Within blocks, ginseng were planted at densities that simulated average cluster size in natural populations. Cages, made of green plastic covered fencing, were placed over each plant to prevent browse by white-tailed deer. 


\section{Data collection.}

Data on survival, growth, and reproduction were collected from 2009 to 2010 as indicators of fitness, though ultimately recruitment of offspring over the life span of an individual plant would be a better measure of fitness. Leaf area was derived from field measurements of leaf lengths and widths (Souther and McGraw 2011). We calculated relative growth rate of leaf area $\left(\mathrm{RGR}_{\mathrm{LA}}\right)$ as:

$$
R G R_{L A}=\frac{\ln \left(L A_{2}\right)-\ln \left(L A_{1}\right)}{t_{2}-t_{1}}
$$

where LA is leaf area and $t$ is time (McGraw and Garbutt 1990). Relative growth rate of the sympodium $\left(\mathrm{RGR}_{\mathrm{SYM}}\right)$ was calculated using this same formula, with sympodium height in place of LA. Bud and seed counts were performed in July and August, respectively. To control for size-related differences in bud and seed production, total bud/seed number per plant was divided by leaf area, yielding buds/seeds per unit leaf area. Change in bud number over the two-year study period was derived by simple subtraction.

Transplant gardens were visited monthly between $4 / 15-10 / 15$ in 2009 and 2010 to measure leaf expansion, reproductive development, and senescence. Percent leaf expansion was calculated by dividing leaf area prior to full foliar expansion by total leaf area after foliar expansion had occurred. As a measure of reproductive development, the proportion of pre-anthesis buds to total buds was calculated by division. At the end of the growing season, a senescence level of $1-4$ was assigned based on foliar coloration; a 
senescence level of 1 indicating that the plant had not yet senesced (was still green) and 4 indicating full senescence (plant gold to brown).

I documented deer browse throughout the experiment. A plant was declared 'browsed' when foliar material was absent, and the remaining sympodia or leaf petioles showed signs of tearing that occurs concomitant with browse. When foliage and sympodia were completely absent, the plant was recorded as missing, not browsed, though browse may have been the causal agent in plant disappearance. In this way, I likely underestimated browse rates.

\section{Statistical analysis.}

For all analyses, 'elevation' and 'population' were considered fixed effects, while 'block' and 'error' were random. For all continuous variables, a two-way analysis of variance (ANOVA) was used to test for adaptive differentiation of populations with respect to elevation. In these analyses, 'block' was nested within the elevation by population interaction. For presence and absence data, I used a G-test to test for an elevation by population interaction. In order to control for the effect of differential levels of deer browse among sites on survival, growth, reproduction, I excluded plants for which early season browse was documented. Browse incurred early in the growing season has been shown to have greater impact on demographic parameters compared to browse that occurs later in the growing season, closer to autumn senescence of ginseng plants(Furedi 2004).

I suspected that observed patterns in growth, survival, and reproduction among sites could be explained by differential rates of deer browse. I tested whether the effect 
of elevation on browse rates differed between populations using a G-test with the statistical effects elevation, population, and elevation*population. 
Table 6.1. Environmental characteristics of source population sites and transplant sites.

\begin{tabular}{|c|c|c|c|c|c|}
\hline $\begin{array}{c}\text { Source } \\
\text { population } \\
\text { site }\end{array}$ & $\begin{array}{c}\text { Mean } \\
\text { maximum } \\
\text { temperature } \\
(5 / 1 / 10- \\
9 / 30 / 10)\left({ }^{\circ} \mathrm{C}\right)\end{array}$ & $\begin{array}{c}\text { Precipitation } \\
\text { (cm) }\end{array}$ & Elevation (m) & $\begin{array}{l}\text { Dominant } \\
\text { tree species }\end{array}$ & Soil pH \\
\hline $\begin{array}{c}\text { MedT } \\
\text { population }\end{array}$ & 22.7 & 55.3 & 500 & $\begin{array}{c}\text { Tilia } \\
\text { americana, } \\
\text { Acer } \\
\text { saccharum, } \\
\text { Prunus } \\
\text { serotina } \\
\text { Liriodendron } \\
\text { tulipifera, } \\
\text { Acer } \\
\text { saccharum, } \\
\text { Quercus } \\
\text { prinus } \\
\end{array}$ & 4.6 \\
\hline $\begin{array}{c}\text { Transplant } \\
\text { Sites }\end{array}$ & $\begin{array}{c}\text { Mean } \\
\text { maximum } \\
\text { temperature } \\
(5 / 1 / 10- \\
\text { 9/30/10) }\left({ }^{\circ} \mathrm{C}\right) \\
\end{array}$ & $\begin{array}{c}\text { Mean } \\
\text { Relative } \\
\text { Humidity } \\
(\%)\end{array}$ & Elevation (m) & $\begin{array}{l}\text { Dominant } \\
\text { tree species }\end{array}$ & Soil pH \\
\hline $\begin{array}{l}\text { Low } \\
\text { temperature }\end{array}$ & 22.5 & 83.1 & 800 & $\begin{array}{c}\text { Acer } \\
\text { saccharum, } \\
\text { Prunus } \\
\text { serotina, } \\
\text { Fagus } \\
\text { grandifolia }\end{array}$ & 4.8 \\
\hline $\begin{array}{l}\text { Medium } \\
\text { temperature }\end{array}$ & 23.8 & 89.6 & 500 & $\begin{array}{l}\text { Liriodendron } \\
\text { tulipifera, } \\
\text { Fagus } \\
\text { grandifolia, } \\
\text { Quercus alba }\end{array}$ & 5.5 \\
\hline $\begin{array}{l}\text { High } \\
\text { temperature }\end{array}$ & 24.7 & 87.5 & 300 & $\begin{array}{l}\text { Liriodendron } \\
\text { tulipifera, } \\
\text { Acer } \\
\text { saccharum, } \\
\text { Carya ovata }\end{array}$ & 5.1 \\
\hline
\end{tabular}




\section{Results}

Contrary to our expectations, the effect of elevation on ginseng survival, growth, reproduction, and phenology did not differ between populations (Table 2). However, elevation did explain variation in ginseng response variables. Ginseng was more likely to be absent at the high elevation site than at medium and low elevation sites (Fig. 1). The response of RGR $\mathrm{LA}_{\text {A }}$ paralleled presence/absence results (Table 2). Plants, on average, decreased in terms of leaf area in the high elevation site, while plants transplanted to medium and high elevations gardens grew; the greatest increases in leaf area occurring at the mid-elevation garden (Fig. 2). Similarly, mean bud number per plant decreased from 2009 to 2010 at the high elevation garden, while no statistically significant change in bud number was detected at the mid- and low elevation gardens (Table 2, Fig. 3). Diverging from this pattern, sympodium growth decreased sharply at the low elevation site relative to RGR $_{\text {SYM }}$ of individuals in the high and mid-elevation sites (Table 2, Fig. 4). Generally, phenology varied in a clinal pattern across the elevation gradient, with plants at the low elevation garden being phenologically advanced relative to mid and low elevation gardens (Table 2, Fig 5, Fig. 6). No site-related differences were detected for bud or seed production per unit leaf area (Table 2). However, populations did differ with respect to these reproductive measures (Table 2). Plants from the high elevation population produced a greater number of buds and seeds per unit leaf area compared to mid-elevation population individuals (Fig. 7, Fig. 8).

Notably, there were differences in browse rates among sites in both 2009 and in $2010\left(\chi^{2}=25.1325, p<0.0001 ; \chi^{2}=8.2997, p=0.0158\right)$. The effect of elevation on browse rates did not differ between populations $\left(\chi^{2}=0.7055, p=0.7028 ; \chi^{2}=0.8404, p\right.$ 
$=0.6569)$, but there was a trend for deer to preferentially browse plants from the high elevation garden in $2010\left(\chi^{2}=2.8001, p=0.0943\right)$. 
Table 6.2. P-values corresponding to G-test and ANOVA results by dependent variable. Statistical trends are marked with a single asterisk, while statistically significant results are labeled with 2 asterisks.

\begin{tabular}{|c|c|c|c|c|c|c|c|c|}
\hline $\begin{array}{c}\text { Dependent } \\
\text { variable }\end{array}$ & $\begin{array}{c}\text { Presence } \\
\text { / Absence } \\
2010\end{array}$ & RGR $_{\text {LEAF }}$ & $\mathbf{R G R}_{\text {SYMP }}$ & $\begin{array}{c}\text { Buds per } \\
\text { unit leaf } \\
\text { area } \\
\left(\mathbf{n} / \mathbf{c m}^{2}\right)\end{array}$ & $\begin{array}{c}\text { Seeds } \\
\text { per unit } \\
\text { leaf area } \\
(\mathrm{n} / \mathrm{cm} 2)\end{array}$ & $\begin{array}{c}\text { Change } \\
\text { in bud } \\
\text { number } \\
(2009- \\
2010)\end{array}$ & $\begin{array}{c}\text { Leaf } \\
\text { expansion } \\
(\% \text { of } \\
\text { total } \\
\text { area) } \\
(2010) \\
\end{array}$ & $\begin{array}{c}\text { Proportion } \\
\text { of buds } \\
\text { pre- } \\
\text { anthesis to } \\
\text { total buds }\end{array}$ \\
\hline $\begin{array}{l}\text { Elevation } \\
\text { (E) }\end{array}$ & $0.0107 * *$ & $0.0015^{* *}$ & $0.0856^{*}$ & 0.3618 & 0.1114 & $0.0288 * *$ & $0.0277 * *$ & $0.0444 * *$ \\
\hline $\begin{array}{l}\text { Population } \\
\text { (P) }\end{array}$ & 0.4998 & 0.1194 & 0.1871 & $0.0400^{*}$ & 0.1008 & 0.3090 & 0.1610 & $0.0874 *$ \\
\hline $\mathrm{E}^{*} \mathrm{P}$ & 0.3104 & 0.2898 & 0.7147 & 0.5340 & 0.2951 & 0.1439 & 0.7344 & 0.1147 \\
\hline
\end{tabular}




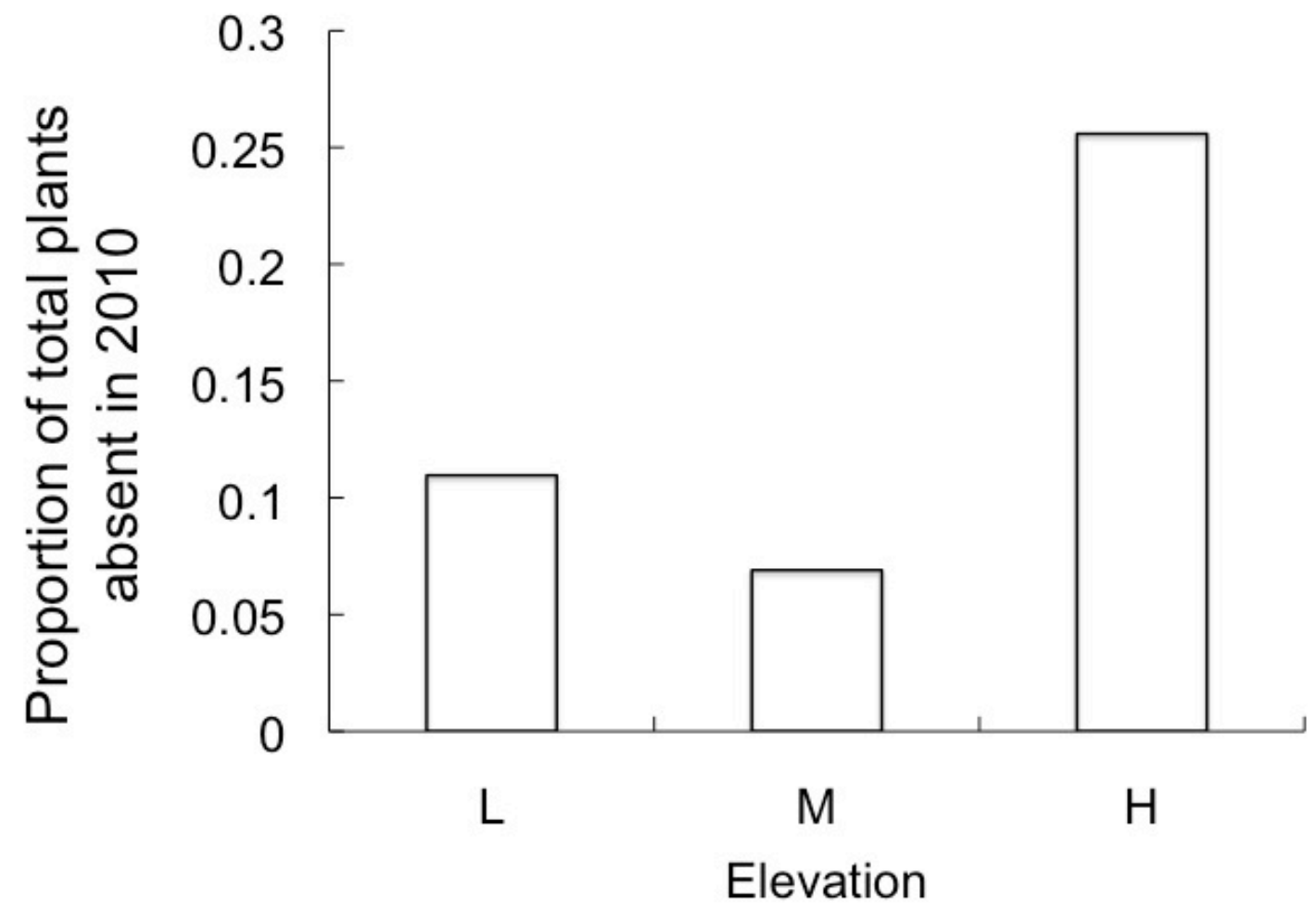

Figure 6.1. Proportion of plants absent in 2010 at each transplant site. 


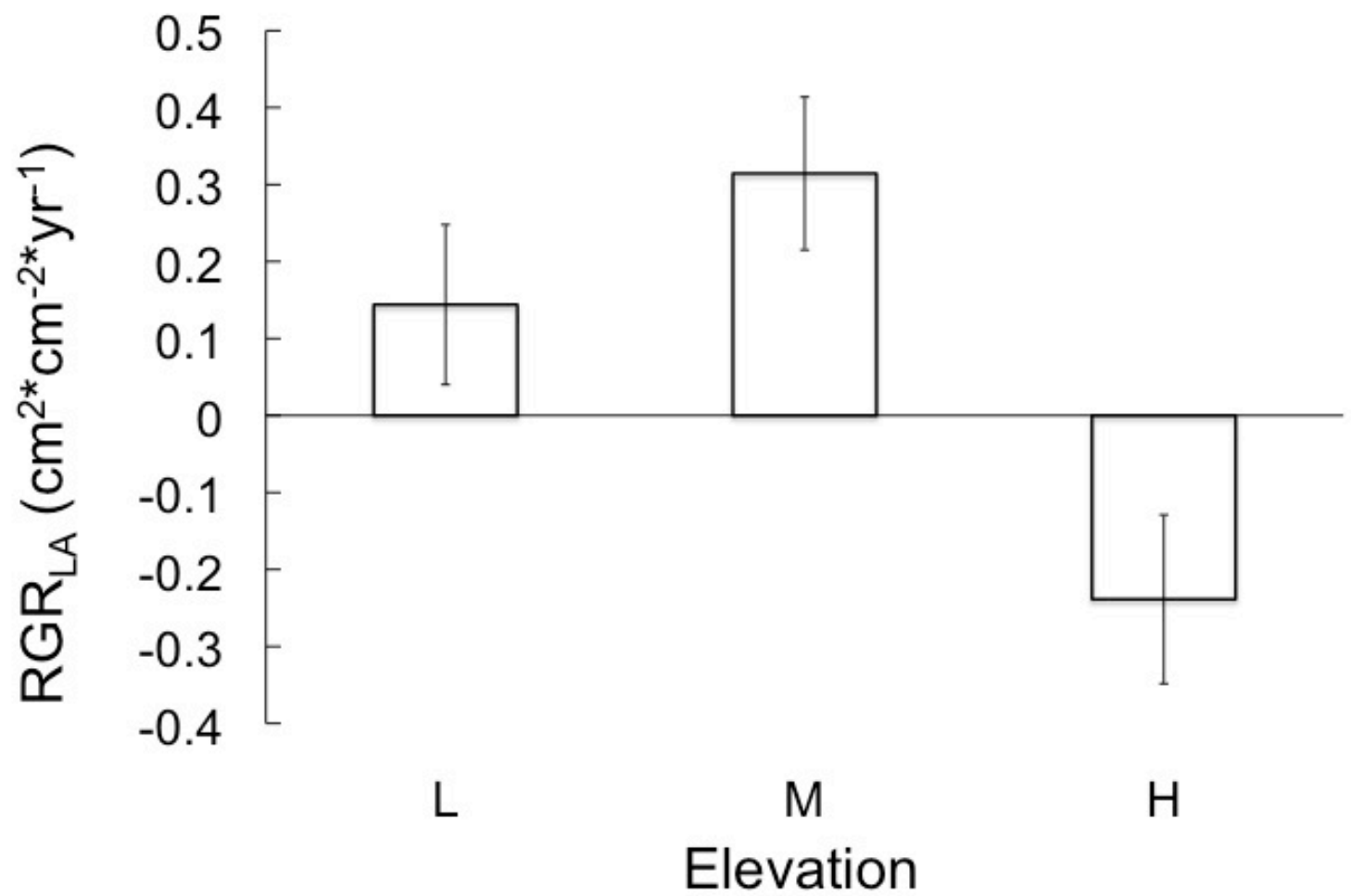

Figure 6.2. Mean relative growth rate of ginseng leaf area from 2009 to 2010 across transplant sites. 


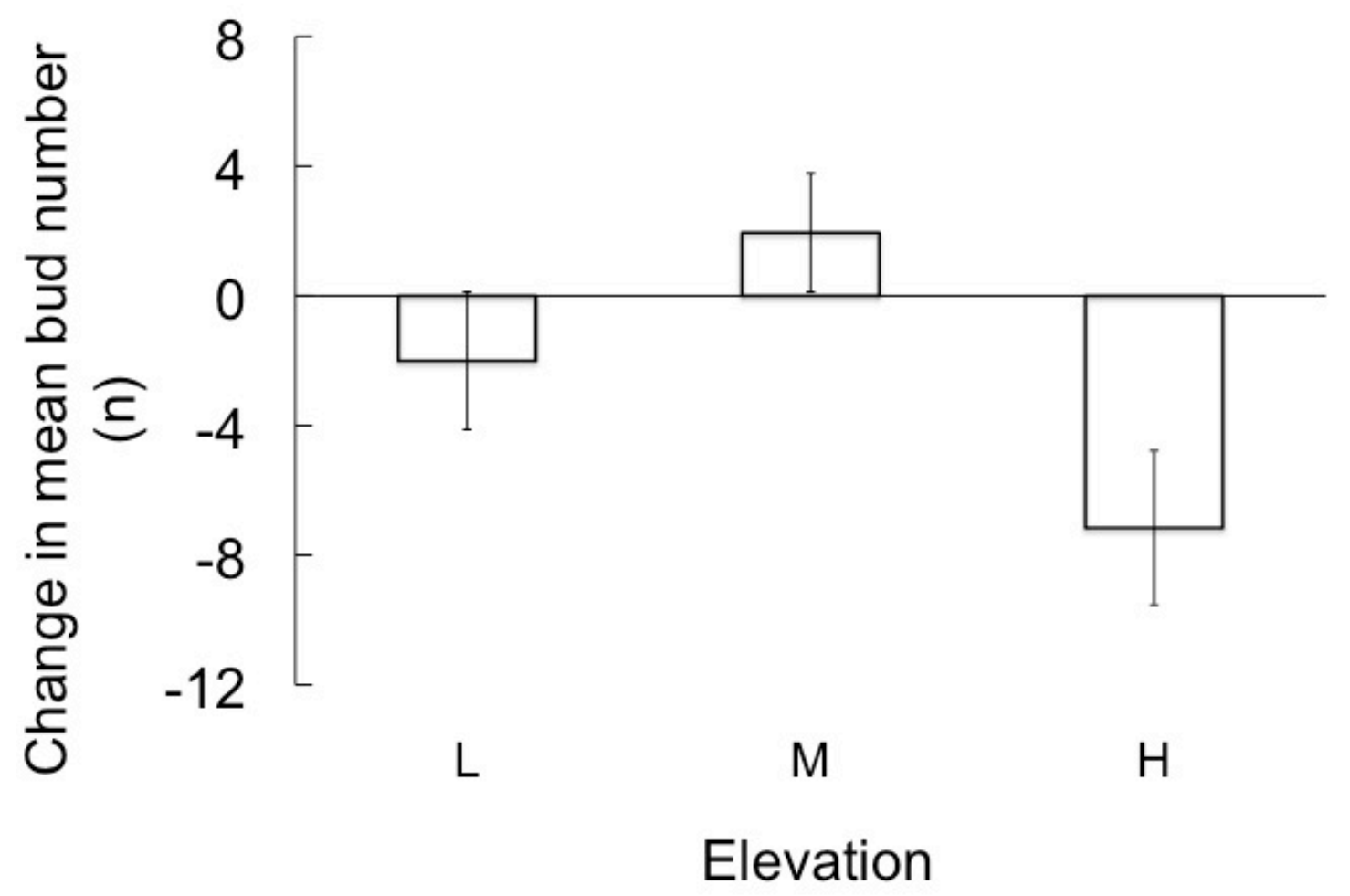

Figure 6.3. Change in number of buds per plant from 2009 to 2010 across transplant sites. 


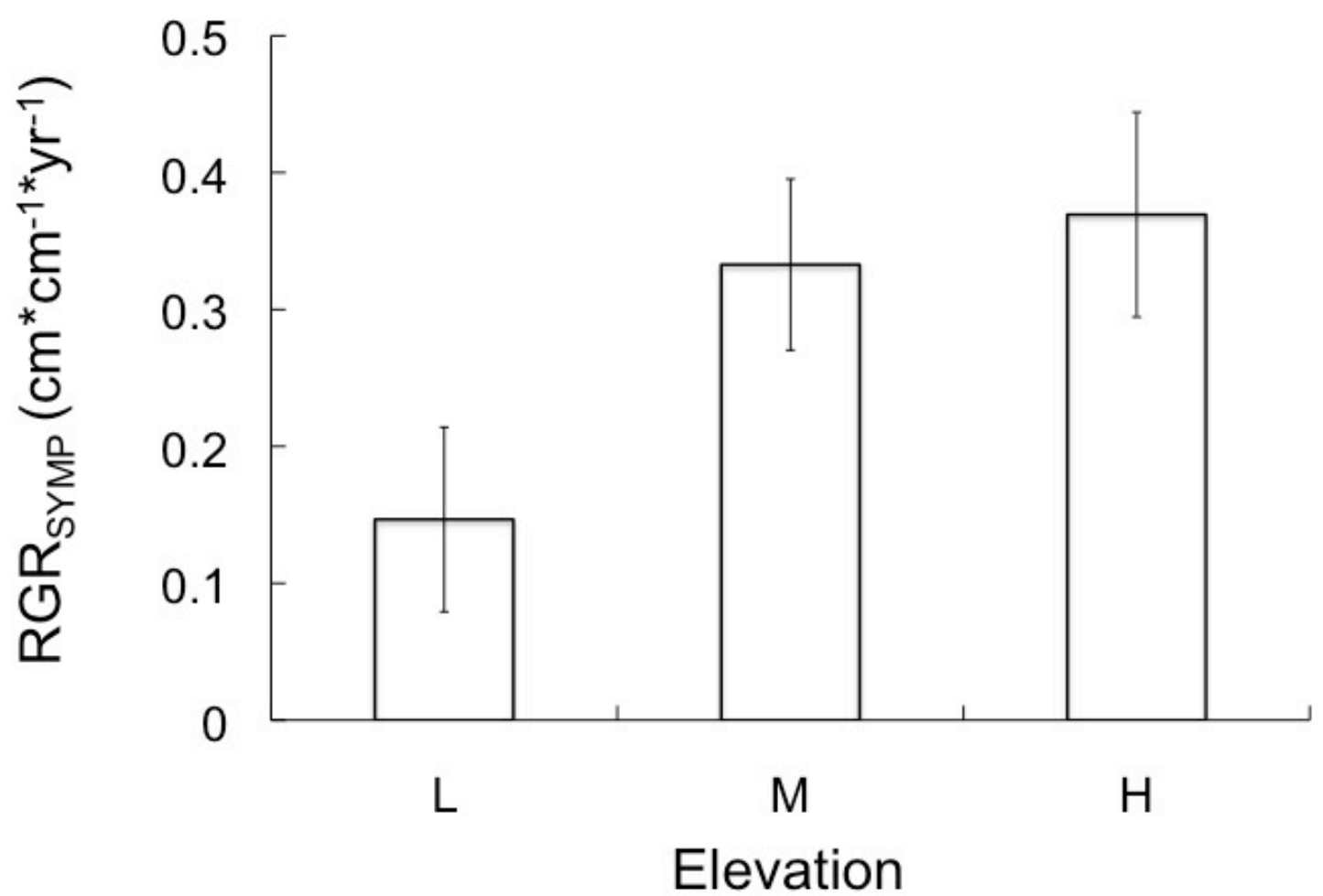

Figure 6.4. Relative growth rate of ginseng sympodium height from 2009 to 2010 across transplant sites. 


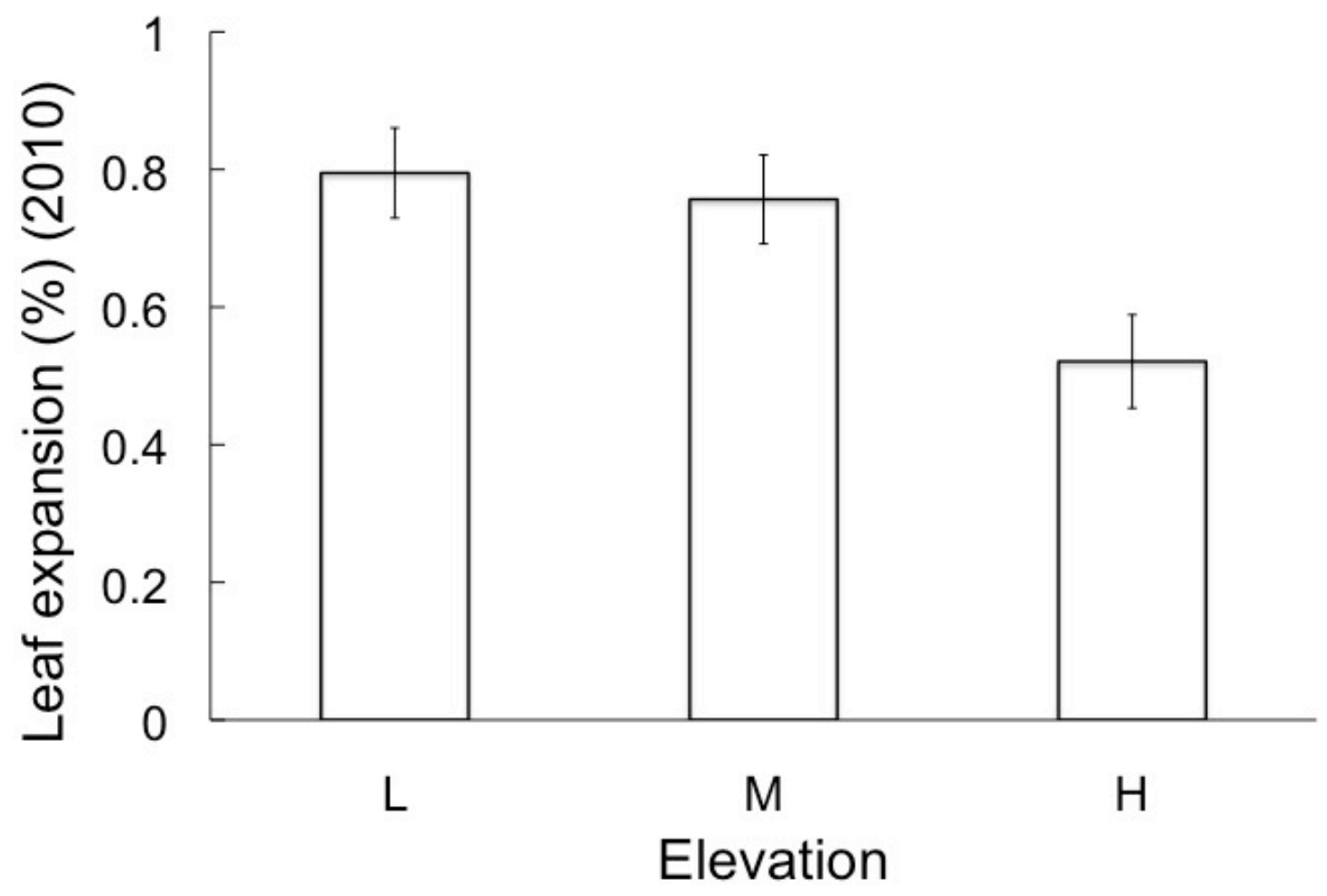

Figure 6.5. Percent foliar expansion of ginseng leaves across an elevation gradient. 


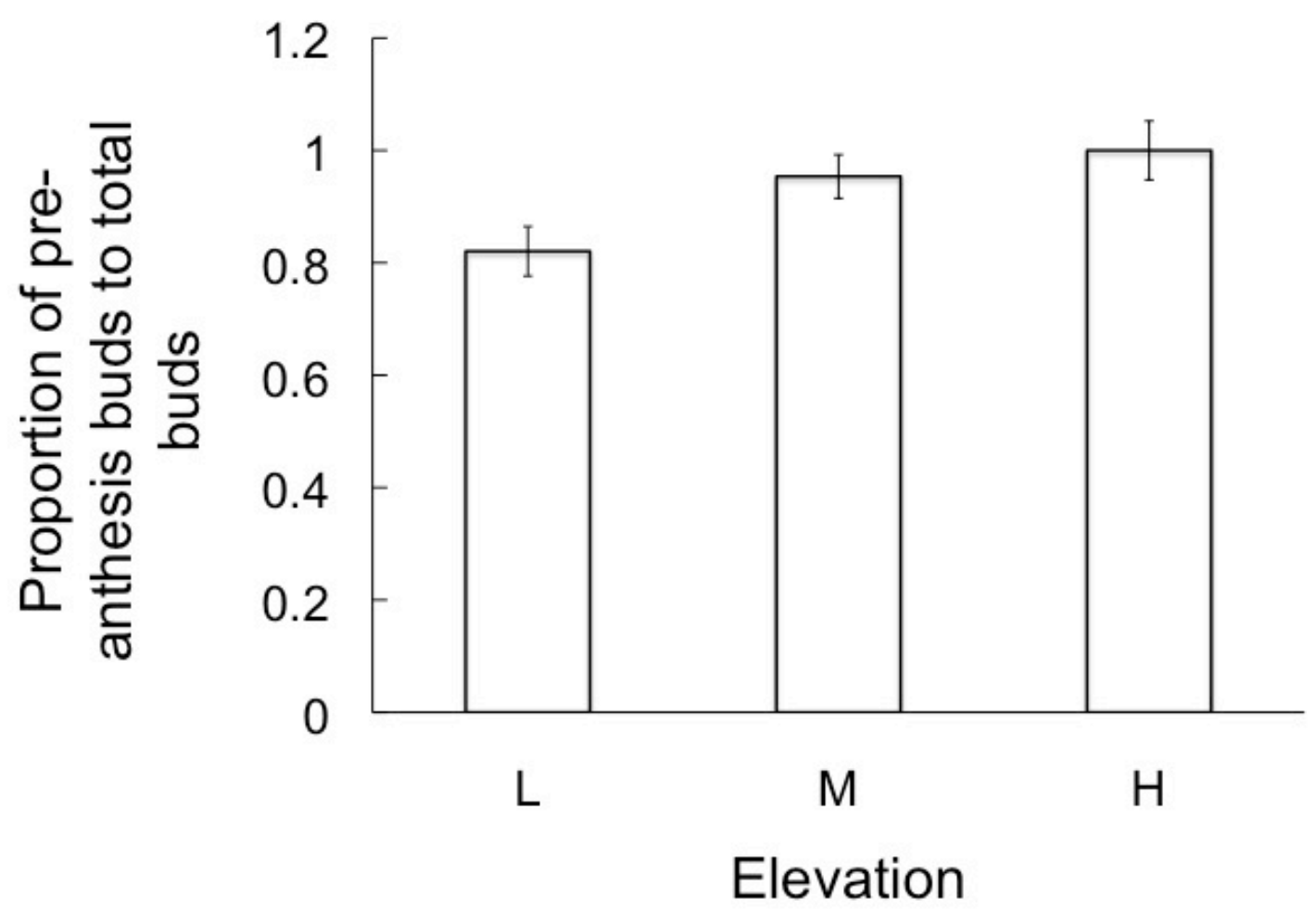

Figure 6.6. Proportion of pre-anthesis buds to total bud number in 2010 across transplant sites. 


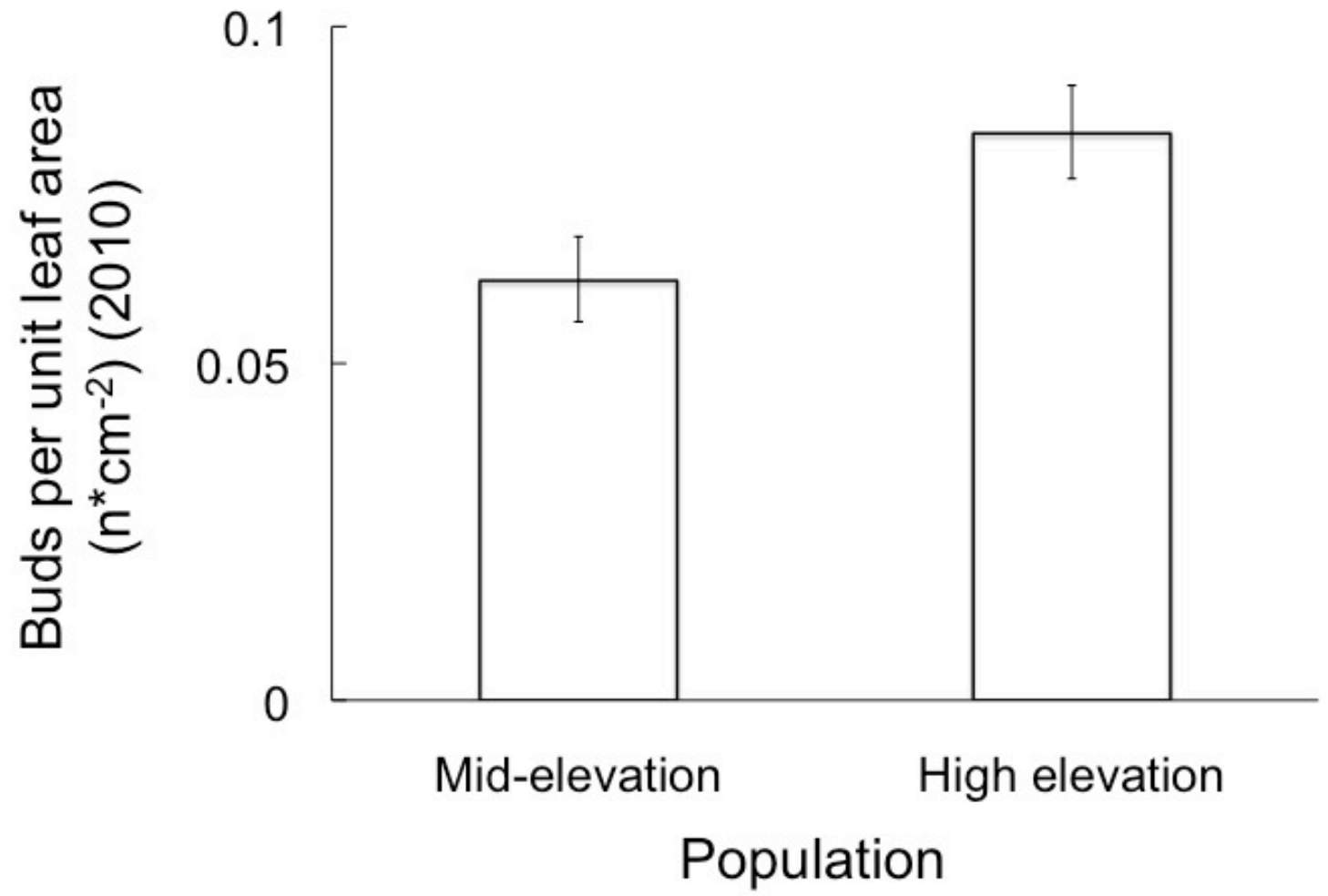

Figure 6.7. Number of buds produced per unit leaf area by plants from either a high or low elevation population. 


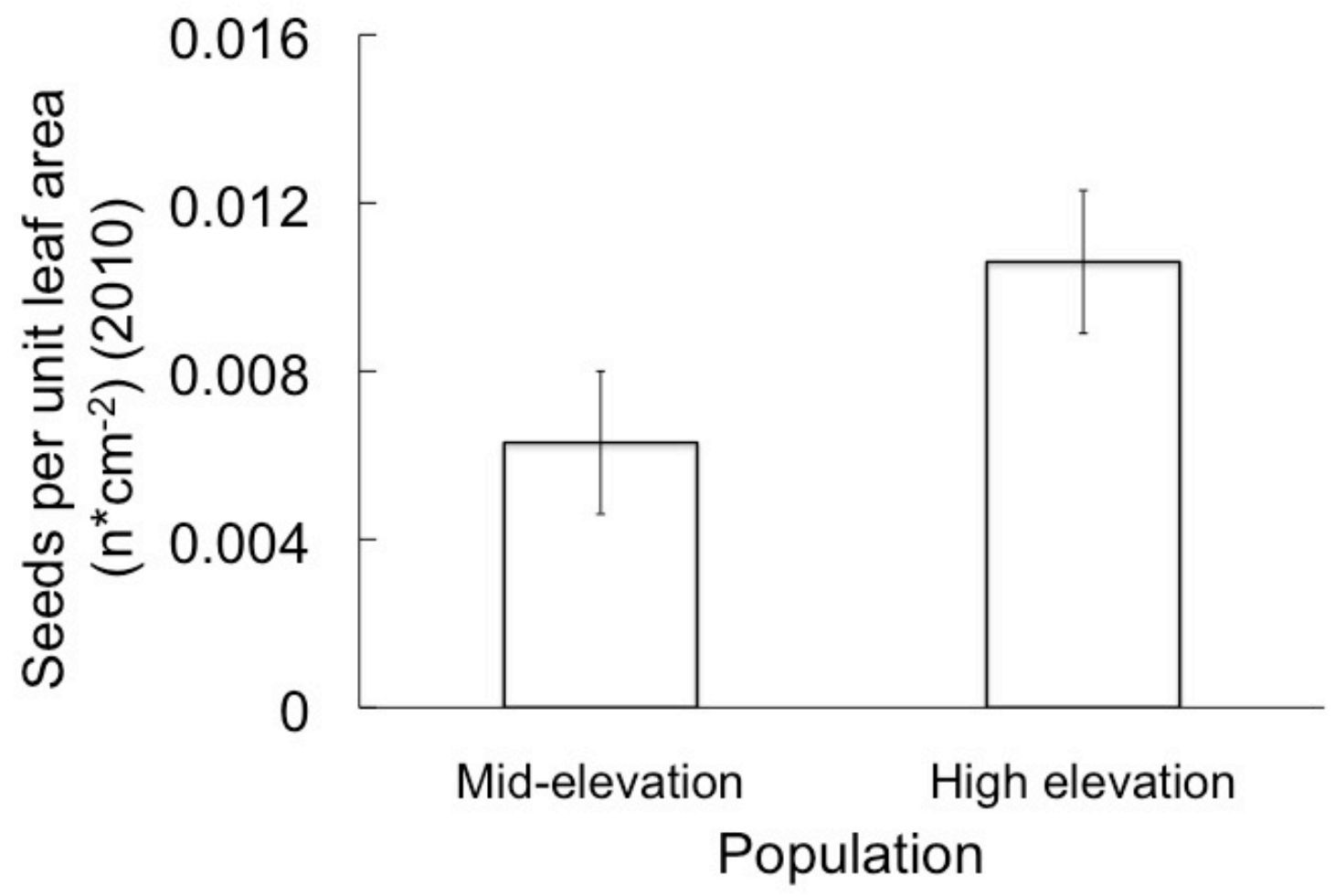

Figure 6.8. Number of seeds produced per unit leaf area by plants from either a high or low elevation population. 


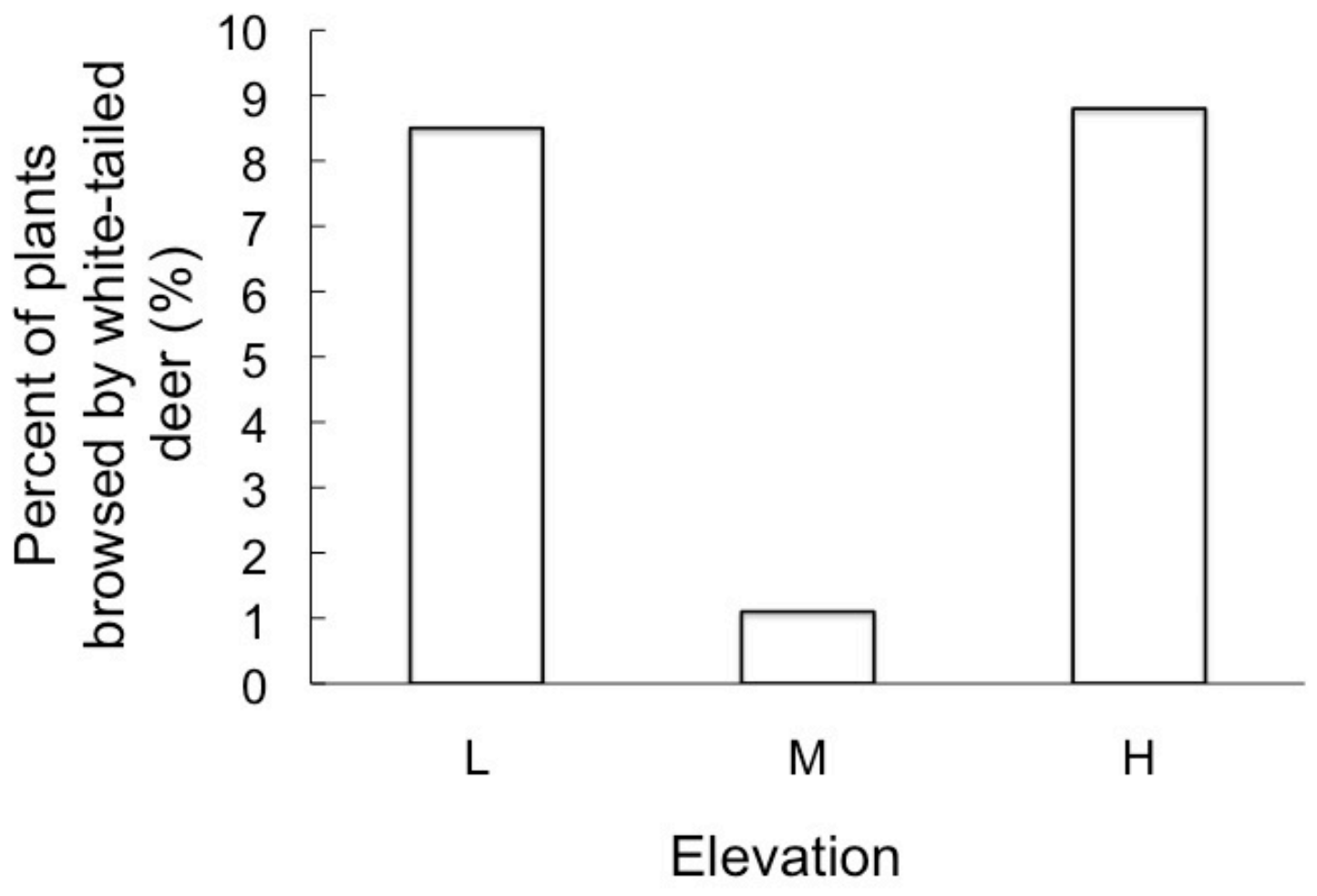

Figure 6.9. Percent of ginseng plants browsed by white-tailed deer in early spring 2010 across transplant sites. 


\section{Discussion}

Overall, ginseng survival, growth, reproduction, and phenology differed among sites. Consistently, plants transplanted to the mid-elevation garden out-performed plants transplanted to low and high elevation sites in terms of survival, growth, and reproduction. Complicating interpretation of these results, rates of deer browse differed among transplant sites in a pattern that could explain these differences. Specifically, deer browse was highest at low and high elevation sites, where plants displayed on average low rates of survival, growth, and reproduction compared to plants at the mid-elevation garden. Deer browse has been shown to negatively affect ginseng demography, and increase extinction risk for ginseng populations(Furedi 2004; McGraw and Furedi 2005), suggesting that deer browse could explain decrease in fitness-related traits observed at low and high elevation sites. Hence, it is difficult to attribute among site differences in ginseng performance to climate effects. I attempted to control for browse-related effects by excluding plants from analyses for which early season browse had been documented. However, I suspect that many plant absences were caused by cryptic browse. For this reason, it is difficult to partition browse effects from climate- and elevation-related effects.

Contrary to expectations, no population by elevation interaction was detected for measurements of ginseng survival, growth, and reproduction. However, I do not believe this result is sufficient to reject the hypothesis that ginseng is adaptively differentiated with respect to climate. Absence of plants particularly at the high elevation population, whether due to browse or other factors, reduced $n$ and consequently decreased statistical power to detect interactive effects on growth and reproduction. Additionally, site effects 
unrelated to climate, specifically deer browse, may mask differential response of populations to climate. Further study of transplant populations, with increased protection against deer browse, is necessary to separate the effects of deer browse on ginseng from the effects of climate. 


\section{Acknowledgments.}

We thank Zachary Bradford, Zachariah Fowler, Alyssa Hanna, Anne Perez, Christine

Picard, John Souther, and Stephanie Young for help excavating ginseng roots. Thank you to Dr. Mary Beth Adams for providing logistical support for this experiment. This research was supported by National Science Foundation Doctoral Dissertation Improvement grant DEB-0909862. 


\section{References}

Anderson RC, Fralish JS, Armstrong JE, Benjamin PK (1993) The Ecology and Biology of Panax-Quinquefolium-L (Araliaceae) in Illinois. American Midland Naturalist $129: 357-372$

Case MA, Flinn KM, Jancaitis J, Alley A, Paxton A (2007) Declining abundance of American ginseng (Panax quinquefolius L.) documented by herbarium specimens. Biological Conservation 134:22-30

Cruse-Sanders JM, Hamrick JL (2004a) Genetic diversity in harvested and protected populations of wild American ginseng, Panax quinquefolius L. (Araliaceae). American Journal of Botany 91:540-548

Cruse-Sanders JM, Hamrick JL (2004b) Spatial and genetic structure within populations of wild American ginseng (Panax quinquefolius L., Araliaceae). Journal of Heredity 95:309-321

Davis MB, Shaw RG (2001) Range shifts and adaptive responses to Quaternary climate change. Science 292:673-679

Davis MB, Shaw RG, Etterson JR (2005) Evolutionary responses to changing climate. Ecology 86:1704-1714

Etterson JR (2004a) Evolutionary potential of Chamaecrista fasciculata in relation to climate change. 1. Clinal patterns of selection along an environmental gradient in the great plains. Evolution 58:1446-1458

Etterson JR (2004b) Evolutionary potential of Chamaecrista fasciculata in relation to climate change. II. Genetic architecture of three populations reciprocally planted along an environmental gradient in the great plains. Evolution 58:1459-1471 
Furedi M (2004) Effects of herbivory by white-tailed deer (Odocoileus virginianus Zimm.) on the population ecology and conservation biology of American ginseng (Panax quinquefolius L.). In: Department of Biology, vol. Doctorate. West Virginia University, Morgantown, WV, p 206

Holt RD (2009) Bringing the Hutchinsonian niche into the 21st century: Ecological and evolutionary perspectives. Proceedings of the National Academy of Sciences of the United States of America 106:19659-19665

Holt RD, Gaines MS (1992) Analysis of Adaptation in Heterogeneous Landscapes Implications for the Evolution of Fundamental Niches. Evolutionary Ecology 6:433-447

Linhart YB, Grant MC (1996) Evolutionary significance of local genetic differentiation in plants. Annual Review of Ecology and Systematics 27:237-277

McGraw JB, Furedi MA (2005) Deer browsing and population viability of a forest understory plant. Science 307:920-922

McGraw JB, Sanders SM, Van der Voort M (2003) Distribution and abundance of Hydrastis canadensis L. (Ranunculaceae) and Panax quinquefolius L. (Araliaceae) in the central Appalachian region. Journal of the Torrey Botanical Society 130:6269

Souther S, McGraw, J. (2011) Vulnerability of wild American ginseng to an extreme early spring temperature fluctuation. Population Ecology 53:119-129

Turesson G (1930) The selective effect of climate upon the plant species. Hereditas 14:99-152 


\section{CHAPTER VII:}

\section{GENERAL CONCLUSIONS}


After less than $1^{\circ} \mathrm{C}$ warming, climate change effects on biota have been detected worldwide (Hughes 2000; Parmesan 2006; Parmesan and Yohe 2003; Root et al. 2003; Walther et al. 2002). Species' response to warming has been complex and multivariate. Climate warming driven changes in species' phenology, distribution, demographic rates, and genetic make-up have been documented for a diversity of species in various ecosystems (Hughes 2000; Parmesan 2006; Parmesan and Yohe 2003; Root et al. 2003; Walther et al. 2002). In the most extreme scenarios, climate models project temperature increases of ca. $6.4^{\circ} \mathrm{C}$ by the end of the century; this amount of warming is roughly 8 times the increase that has already occurred (IPCC 2007). Given observations of species response to contemporary climate change and the unprecedented degree of warming expected over the next century, climate change will no doubt determine future ecosystem composition and affect global species diversity. In order to prevent loss of biodiversity, it is necessary to understand and accurately project species' response to climate, and to identify, early on, species that are vulnerable to climate change driven extinctions.

Climate models predict an increase in frequency of anomalous weather events (IPCC 2007). Late spring frost, which may have profound negative consequences for species in deciduous ecosystems, is one such weather-related event anticipated to increase as a function of climate change (Inouye 2000; Inouye 2008; Inouye et al. 2002; Pearce 2001). For ginseng, I found that spring frosts may decrease growth and reproduction, and that these effects carry-over to the subsequent growing season (Chapter 2). Furthermore, patterns of frost damage among and within populations were variable. The extent of frost damage incurred by a population was influenced by spatial location; populations located in warmer regions were disproportionately affected by the frost. 
Within populations, frost adversely affected 'early-riser' genotypes compared to 'cautious' individuals with delayed emergence. In terms of overall species response to climate change, stochastic events like spring frost, while infrequent can have profound effects on demography. For ginseng, increase in spring frost frequency could hasten extinction of small populations (Morris and Doak 2002).

In addition to altered frequency of acute perturbations like frost events, drought, or heat waves, mean global temperature is gradually increasing. While the effects of discrete events on natural ecosystems are readily observed and easily quantifiable, detecting the effects of gradual change is difficult, and requires long-term data and detailed monitoring of species responsive to small incremental changes in environment. As a proximal step towards understanding ginseng response to directional climate change, I conducted an analysis of demographic response of ginseng populations to interannual climate variation (Chapter 3). Results from this study suggested that populations of ginseng are adapted to local temperature and the set of factors that covary with temperature at a particular site. Deviation of annual temperature from local means caused population growth rate $(\lambda)$ to decrease for all populations across the central portion of ginseng's range. For ginseng, long-term temperature acclimation is not likely. Ginseng is deciduous, and, as such, multi-year acclimation of photosynthetically active plant parts is improbable. This indicates that long-term acclimation would manifest by carry-over temperature effects on root and rhizome structure and physiology. If such long-term acclimation occurred, $\lambda$-values should be temporally correlated, such that after two consecutive warm years, $\lambda$-values of the second year would be higher than anticipated. However, tests for autocorrelation of $\lambda$-values did not detect autocorrelation, 
but rather suggested that $\lambda$ responds independently to each year's temperature. These lines of evidence suggest that differential response of ginseng populations to temperature is not due to acclimation, but rather is genetically based. If ginseng populations are adapted to local temperature conditions, directional change away from mean conditions could decrease population growth rates across ginseng's range, and potentially threaten long-term persistence of this species.

To determine whether climate change effects on demography would translate to increased extinction risk for ginseng, I created a stochastic demographic model to examine the effects of warming on population viability (Chapter 4). Climate change increased extinction risk and decreased viability of ginseng populations. If global temperatures increase at mean projected rates, current ginseng populations would need to consist of at least 300 individuals to be considered viable (less than $5 \%$ chance of extinction) in 70-years. To put this number in perspective, only four of the 30 populations that we currently monitor are comprised of over 300 individuals. Additionally, this minimum viable population size has a positive, exponential relationship with temperature, indicating that small increases in temperature beyond expected levels of warming may have severe negative repercussions for ginseng persistence.

In Chapters 5 and 6, I wanted to experimentally confirm results of the observational study of local climatic adaptation of ginseng populations (Chapter 3), as well as confirm modeling results that suggested that extinction risk for ginseng would increase as the climate changes (Chapter 4). In order to experimentally examine the effects of climate change on ginseng populations, I conducted two parallel reciprocal transplant experiments, one in a growth chamber environment (Chapter 5) and one in a 
natural setting (Chapter 6). Experiments were established to simultaneously test for genetic differentiation of populations to temperature, as well as to determine overall effects of warming on demographic parameters. In the growth chamber experiment (Chapter 5), ginseng response to temperature treatments differed between populations, suggesting genetic differentiation of populations. However, the nature of the differential response between ginseng populations to temperature treatments did not conform to expectations of a species adapted to local temperature. Specifically, fitness-related traits were not consistently greatest for ginseng when exposed to temperature treatments similar to home-site conditions. In Chapter 3, the response of ginseng populations to inter-annual temperature variation was an aggregate response to both temperature as well as all environmental factors, such as herbivory, disease, and soil moisture, that covary with temperature in the field. The results of Chapter 5 indicate that indirect temperature effects, those effects mediated by natural covariates of temperature, are important determinants of population response to temperature increase.

Findings for both Chapter 5 and 6 support model results (Chapter 4) that suggest climatic warming will increase extinction risk for ginseng populations. In Chapter 5, the effect of the 'future' temperature treatment on seed production was overwhelmingly negative across study populations. The results of Chapter 6 , though difficult to interpret due to the confounding non-climatic site effects on study populations, also suggest a negative impact of warmer conditions on ginseng reproduction.

In a recent paper, Parmesan et al. (2011) asserted that linking an individual species' response to climate change is rarely possible, because 1) climate change effects occur at large spatial scales whereas populations experience local climate conditions, and 
2) climate change is occurring in tandem with other forms of global change, thus detecting climate effects on species' performance above the noise of other dynamic environmental factors is difficult. In this dissertation research, I have shown that it is possible to link a single species' response to climate change, and that local climatic conditions are germane to understanding a species' response to climate change. In Chapter 3, climate-effects on population growth rate $(\lambda)$ are apparent despite amongpopulation variation in environmental factors, such as precipitation, deer-browse rates, presence of invasive species, and disease levels. Inter-annual temperature variation only explained around $13 \%$ of the variation in $\lambda$, however, the inherent negative relationship between $\lambda$ and temperature increase detected across ginseng populations in Chapter 3 converted to range-wide increase in extinction risk for ginseng under a climate change scenario (Chapter 4). Finally, in Chapters 5 and 6, exposure to 'future' temperature treatments negatively impacted ginseng reproductive rates. While climate change itself may be a global phenomenon, the net response of a species to climate change may be dictated by population response, which can vary at small spatial scales. Moreover, ginseng's life history and mating system are not unique, but rather similar to many herbaceous species, which comprise a significant proportion of the biodiversity in the eastern deciduous forest (Whigham 2004).

This research provides compelling evidence that climate change will negatively impact long-term persistence of ginseng and other ecologically similar species. In particular, species that are adapted to local climate may be especially threatened by climate-change driven extinctions, even if these species are geographically widespread. To avoid extinction, species may track the climate to which they are adapted via spatial 
changes in distribution or they may adapt to novel climatic conditions (Aitken et al. 2008; Parmesan 2006; Thomas et al. 2004). However, there is growing concern that the pace of climate change, combined with highly fragmented landscapes, will preclude rapid dispersal or in situ evolution (Davis and Shaw 2001; Davis et al. 2005; Jump and Penuelas 2005). If this is the case, conservation of biodiversity may depend on radical reduction of climatic warming rates or human assisted relocation of species unable to track climatic conditions. 


\section{References}

Aitken SN, Yeaman S, Holliday JA, Wang TL, Curtis-McLane S (2008) Adaptation, migration or extirpation: climate change outcomes for tree populations. Evolutionary Applications 1:95-111

Davis MB, Shaw RG (2001) Range shifts and adaptive responses to Quaternary climate change. Science 292:673-679

Davis MB, Shaw RG, Etterson JR (2005) Evolutionary responses to changing climate. Ecology 86:1704-1714

Hughes L (2000) Biological consequences of global warming: is the signal already apparent? Trends in Ecology \& Evolution 15:56-61

Inouye DW (2000) The ecological and evolutionary significance of frost in the context of climate change. Ecology Letters 3:457-463

Inouye DW (2008) Effects of climate change on phenology, frost damage, and floral abundance of montane wildflowers. Ecology 89:353-362

Inouye DW, Morales MA, Dodge GJ (2002) Variation in timing and abundance of flowering by Delphinium barbeyi Huth (Ranunculaceae): the roles of snowpack, frost, and La Nina, in the context of climate change. Oecologia 130:543-550

IPCC (2007) Fourth Assessment Report of the Intergovernmental Panel on Climate Change. In. Cambridge University Press, Cambridge

Jump AS, Penuelas J (2005) Running to stand still: adaptation and the response of plants to rapid climate change. Ecology Letters 8:1010-1020 
Morris WF, and Daniel F. Doak (2002) Quantitative Conservation Biology. Sinauer Associates Inc., Sunderland, MA

Parmesan C (2006) Ecological and evolutionary responses to recent climate change. Annual Review of Ecology Evolution and Systematics 37:637-669

Parmesan C, Yohe G (2003) A globally coherent fingerprint of climate change impacts across natural systems. Nature 421:37-42

Pearce RS (2001) Plant freezing and damage. Annals of Botany 87:417-424

Root TL, Price JT, Hall KR, Schneider SH, Rosenzweig C, Pounds JA (2003) Fingerprints of global warming on wild animals and plants. Nature 421:57-60

Thomas CD et al. (2004) Extinction risk from climate change. Nature 427:145-148

Walther GR et al. (2002) Ecological responses to recent climate change. Nature 416:389395

Whigham DE (2004) Ecology of woodland herbs in temperate deciduous forests. Annual Review of Ecology Evolution and Systematics 35:583-621 


\title{
CURRICULUM VITAE
}

\section{SARA SOUTHER}

\author{
Department of Biology \\ West Virginia University \\ 53 Campus Drive LSB \\ Morgantown WV 26506-6057 \\ Phone: 304-293-5201 x31455 \\ Fax: 304-293-6363 \\ sklsouther@gmail.com
}

\section{RESEARCH INTERESTS}

I am interested in how the genetic background of native plant populations affects demographic response to anthropogenic change, with the ultimate goal of using this information to inform conservation strategies that successfully preserve biodiversity in a changing world.

\section{PROFESSIONAL EXPERIENCE}

\section{David H. Smith Post-doctoral Conservation Research Fellow}

Starting August $15^{\text {th }} 2011$

Post-doctoral research advisor: Dr. Don Waller, University of Wisconsin-Madison

Practitioner mentor: Patricia Ford, U.S. Fish and Wildlife Service

Project title: Disrupting environmental and genetic associations: Can managed

relocation rescue species threatened by climate change?

\section{Graduate Conservation Research Fellow, Arctic Climate Change Graduate} Research Fellow, Department of Biology, West Virginia University

September 2006 - present

Dissertation Advisor: Dr. James McGraw

Dissertation title: Conserving species in a warming climate: Quantifying and projecting changes in American ginseng (Panax quinquefolius L.) abundance and distribution.

\section{Graduate Teaching Assistant, Department of Biology, West Virginia University} January 2008 - May 2008, January 2007 - May 2007

Taught the biology department's capstone course. Instructed students in experimental design, basic statistics, and proposal and manuscript composition.

\section{Agriculture Extension Worker, Peace Corps, Paraguay}

September 2003 - December 2006

Promoted sustainable agricultural practices and soil conservation.

\section{EDUCATION}


Ph.D. expected completion date May 2011, West Virginia University, GPA, 4.0

B.S. 2003 West Virginia University, Biology, overall GPA, 3.94

B.A. 2003 West Virginia University, Sociology and Anthropology, overall GPA, 3.94

\section{PEER-REVIEWED PUBLICATIONS}

Souther, S. and J. B. McGraw. 2011. Experimental test for adaptive differentiation of ginseng populations to temperature. In preparation for Botany.

Souther, S. and J. B. McGraw. 2011. Climate change increases extinction risk for locally adapted species. In preparation for Nature.

Souther, S. and J. B. McGraw. 2011. Range-wide signals of local adaptation to temperature in American ginseng suggest widespread negative consequences of climate change. Accepted for publication in Conservation Biology.

Souther, S and J. B. McGraw. 2010. Vulnerability of American ginseng to an extreme early spring temperature fluctuation. Population Ecology 53(1): 119-129. DOI:

10.1007/s10144-010-0218-5.

McGraw, J. B., Souther, S., and A. E. Lubbers. 2010. Rates of harvest and compliance with regulations in natural populations of American ginseng (Panax quinquefolius L.) Natural Areas Journal 30: $202-210$.

\section{OTHER PUBLICATIONS}

Souther, S. 2/2011. American ginseng: A canary in the coalmine for climate change effects in the Appalachians. In preparation for Goldenseal.

\section{GRANTS FUNDED}

National Science Foundation Doctoral Dissertation Improvement Grant. 5/1/20094/30/2011. \$15,000.00. Examination of range-wide variation in American ginseng (Panax quinquefolius L.) demography and population viability in the context of climate change. Souther, S. and James B. McGraw.

Eberly Office of the Dean Research Grant, 5/1/2010 - 8/30/2010, \$700.00, Souther, S.

Eberly Office of the Dean Research Grant, 5/1/2009 - 8/30/2009, \$500.00, Souther, S.

Eberly Office of the Dean Research Grant, 5/1/2008 - 8/30/2008, \$600.00, Souther, S.

Eberly Office of the Dean Research Grant, 5/1/2007 - 8/30/2007, \$700.00, Souther, S.

\section{ORAL PRESENTATIONS}

Patterns of demographic response of American ginseng (Panax quinquefolius L.) populations to climatic variation. Ecological Society of America (ESA) Conference, Pittsburgh, PA. 8/4/2010. 
Response of American ginseng to inter-annual temperature variation: Implications for ginseng conservation in a changing climate. Appalachian Center for Ethnobotanical Studies (ACES) Annual Conference, Tai Sophia Institute, Columbia, MD. 6/26/2010.

Overview of a wild ginseng conservation web site. U.S. Fish and Wildlife Service American Ginseng Workshop, Bristol, VA. 2/24/09.

\section{POSTER PRESENTATIONS}

Detection of frugivory using game cameras. McGraw, J. B., and S. Souther. Ecological Society of America (ESA) Conference, Pittsburgh, PA. 8/5/2010.

Variable demographic responses to inter-annual temperature variable suggest enhanced risk from global warming for American ginseng. Souther, S. and J. B. McGraw. International Conference in Ecology (INTECOL), Brisbane, Australia. 8/18/2009

Extreme weather: Examination of a late season frost event in populations of American ginseng (Panax quinquefolius). Souther, S. and J. B. McGraw. Ecological Society of America, Milwaukee, WI. 8/4/2008

Demographic response of American ginseng to inter-annual climate variation. HunterSevera, Kristen R., Souther, S., and J. B. McGraw. Ecological Society of America, Milwaukee, WI. 8/4/2008.

\section{TEACHING EXPERIENCE}

Student Mentor for National Science Foundation Conservation Internship. West Virginia University, Morgantown, WV. May - August, 2007, 2008, 2009, 2010.

Student Mentor for Summer Undergraduate Research Experience (SURE). West Virginia University, Morgantown, WV. May - August 2007, May - August 2008.

Graduate Teaching Assistant for Biology 321, The Total Science Experience. West Virginia University, Morgantown, WV. January 2008 - May 2008, January 2007 - May 2007.

\section{HONORS AND AWARDS}

National Science Foundation Conservation Fellowship, 9/2006 - present (selected competitively from graduate applicants)

David Fairchild Blaydes Biology Doctoral Dissertation Scholarship, 1/2011

Earl Core Memorial Scholarship, 5/2010.

Arctic Climate Change Graduate Research Fellowship, 7/2009, 7/2010 (selected competitively from graduate applicants)

Eberly Office of the Dean Travel Award, 8/2010. 
HERF Supplement Fellowship, 9/2008 - 5/2009.

Earl Core Memorial Scholarship, 5/2009.

Eberly Office of the Dean Travel Award, 8/2009.

Eberly Office of the Dean Travel Award, 8/2008.

\section{RELEVANT COURSEWORK}

Biology 361, Plant Ecology (A)

Biology 793, Molecular Ecology (A)

Geography 550, Geographic Information Science (A)

Geography 694, GIS-Ecological Modeling (A)

Biology 761, Ecosystem Dynamics (A)

Biology 762, Plant Population Biology (A)

Biology 752, Physiological Plant Ecology (A)

Genetics 521, Basic Concepts in Modern Genetics (A)

Genetics 535, Population Genetics (A)

\section{PROFESSIONAL ACTIVITIES}

Biology Graduate Student Association (BGSA) President, West Virginia University, 4/2009-4/2010. Initiated educational, social, and service events for the biology graduate student body.

Biology Department Speaker Seminar Coordinator, West Virginia University, 9/2008 5/2009. Organized the Department of Biology guest lecture series.

\section{PROFESSIONAL AFFILIATIONS}

Member of the Society for Conservation Biology (SCB)

Member of the Ecological Society of America (ESA)

\section{FOREIGN LANGUAGE}

Fluent in Spanish and Guarani 